


\section{LA ECONOMÍA DEL \\ CAMBIO CLIMÁTICO \\ EN EL PERÚ}

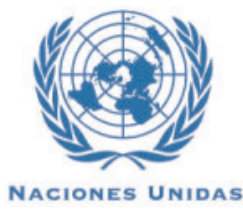

CEPA L
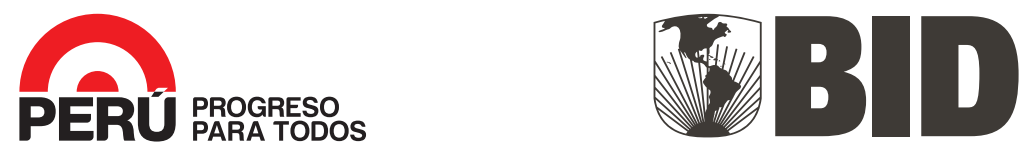
Catalogación en la fuente proporcionada por la

Biblioteca Felipe Herrera del

Banco Interamericano de Desarrollo

La economía del cambio climático en el Perú / Banco Interamericano de Desarrollo, Comisión Económica para América Latina y el Caribe

p. cm. - (Monografía del BID ; 222)

Incluye referencias bibliográficas.

1. Climatic changes—Economic aspects—Peru. 2. Climate change mitigation-Peru. 3. Climatic changes—Adaptation—Peru. I. Banco Interamericano de Desarrollo. División de Cambio Climático y Sostenibilidad. II. Título. III. Serie.

IDB-MG-222

NDB-MG-de referencia de la CEPAL, Naciones Unidas: LC/W.640

Palabras claves: cambio climático, adaptación, impactos económicos, Perú.

Clasificación JEL: C51, Q54, O54, Q58

Hecho el Depósito Legal en la Biblioteca Nacional del Perú № 2014-17710

Primera edición: 2014

Impreso en:

Forma e Imagen de Billy Víctor Odiaga Franco

Dirección: Av. Arequipa 4558-4550 Miraflores, Lima, Perú

300 ejemplares

Producido en Perú: 2014 
Este documento fue realizado por el Banco Interamericano de Desarrollo (BID) y la Comisión Económica para América Latina y el Caribe (CEPAL), en el marco del Estudio Regional de la Economía del Cambio Climático (ERECC) en América Latina y el Caribe, coordinado por la CEPAL, con el apoyo del Gobierno de Perú y el financiamiento del BID.

La redacción final y coordinación del documento estuvo a cargo de Carlos Ludeña y Leonardo Sánchez (BID) y Joseluis Samaniego, Carlos de Miguel, Mauricio Pereira, Karina Martínez y Constanza Pantaleón (CEPAL), con los aportes y sugerencias de Gabriel Quijandría, Eduardo Durand, Roger Loyola, Rosa Morales, Yveth Villanueva y Elizabeth Merino del Ministerio del Ambiente (MINAM); Javier Roca, Rocío García y Natalia Alayza del Ministerio de Economía y Finanzas (MEF) y; Eduardo Calvo y Hernán Alejandro del Ministerio de Relaciones Exteriores (MRE) del Perú.

La investigación base para este documento fue desarrollada por el consorcio de investigación conformado por Practical Action (Soluciones Prácticas), la Facultad de Economía y Planificación y el Centro de Datos para la Conservación de la Universidad Nacional Agraria La Molina, y el Global Climate Adaptation Partnership, y coordinada por Vladimir Gil.

Los insumos para el análisis fueron producidos por Carlos Alberto Arnillas, Waldo Lavado, Grinia Ávalos, Wouter Buytaert, Laura Alvarado, Analía Aramburú, Francisco Galarza, Jaime Mendo, William Cheung, Enrique Flores, Homero Miranda, Carlos Orihuela, Waldemar Mercado, César Cárcamo, Julio Kuroiwa, Juan Torres, Alicia Quezada y Paul Watkiss.

Colaboraron además en la producción de los insumos Rocío Vásquez, Sofía Gonzales, José Luis Nolazco, Elena Emiko Miyashiro, Millie Cabezas, Miguel Bernuy, Enrique Gushiken, Víctor García, Javier Ñaupari, Raúl Tácuna e Yrene Pantoja del consorcio consultor; Dimitri Gutiérrez y Jorge Tam (Instituto del Mar de Perú, IMARPE), Sara Yalle e Iván Maita (Ministerio de Agricultura y Riego, MINAGRI) y Graciela Milla (Ministerio de la Producción, PRODUCE).

El estudio contó con los comentarios de Sebastián Miller, Ana Ríos, Jaime Fernández-Baca y Susana Cárdenas (BID), Lincoln Muniz (INPES) y José Salas (Colorado State University).

Las comunicaciones y difusión estuvieron a cargo de Practical Action (Soluciones Prácticas), en particular de Alicia Quezada y Doris Mejía con la colaboración de Mario Cossío, Francis Salas, Ximena Vidal, Gabriel Reaño y Paul Forsyth.

Se agradece además el apoyo de UKAID del gobierno británico a la iniciativa de los Estudios de la Economía del Cambio Climático en América Latina y el Caribe.

Las opiniones expresadas en esta publicación son de exclusiva responsabilidad de los autores y no necesariamente reflejan el punto de vista del Gobierno del Perú, de la CEPAL y del BID, de su Directorio Ejecutivo ni de los países que representa.

Los límites y los nombres que figuran en los mapas no implican su apoyo o aceptación oficial por las Naciones Unidas.

Se prohíbe el uso comercial no autorizado de los documentos del BID, y tal podría castigarse de conformidad con las políticas del BID y/o las legislaciones aplicables.

Copyright @2014 Banco Interamericano de Desarrollo, Naciones Unidas y Ministerio del Ambiente de Perú.

Todos los derechos reservados; este documento puede reproducirse libremente para fines no comerciales. 
Las siguientes investigaciones son base para la elaboración de esta síntesis:

La economía del cambio climático en el Perú: la climatología del cambio climático

Autores: Waldo Lavado, Grinia Ávalos, Wouter Buytaert

La economía del cambio climático en el Perú: dotación de recursos naturales renovables

Autores: Carlos Alberto Arnillas, Wouter Buytaert, Rocío Vásquez y Sofía Gonzales

La economía del cambio climático en el Perú: agricultura

Autores: Laura Alvarado y Analía Aramburú

La economía del cambio climático en el Perú: ganadería altoandina

Autores: Enrique Flores, Javier Ñaupari y Raúl Tacuna

La economía del cambio climático en el Perú: pesca

Autores: Jaime Mendo y William Cheung
La economía del cambio climático en el Perú: hidroenergía Autores: Homero Miranda Coll-Cárdenas y Carlos Alberto Arnillas

La economía del cambio climático en el Perú: minería Autor: Carlos Orihuela

La economía del cambio climático en el Perú: infraestructura vial Autor: Julio Kuroiwa

La economía del cambio climático en el Perú: turismo

Autores: Waldemar Mercado e Yrene Pantoja

La economía del cambio climático en el Perú: salud Autor: César Cárcamo

Con el apoyo de:

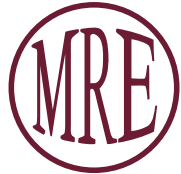

Ministerio de Relaciones Exteriores 


\section{Índice}

Prólogo

Introducción

Capítulo I. El cambio climático en el Perú

A. Climatología actual y tendencias

B. Proyecciones climáticas futuras

\section{Capítulo II. Escenarios macroeconómicos} y demográficos

A. Evolución histórica de la economía del Perú

1. Análisis de la evolución sectorial

2. La producción departamental

3. Demografía

B. Construcción de escenarios macroeconómicos

1. Variables de la función de producción

2. Proyección de crecimiento del PBI

Capítulo III. Metodología y supuestos

A. El modelo conceptual: aspectos generales

1. Supuestos generales

2. Análisis de los recursos naturales 
B. Metodologías específicas para los sectores

seleccionados 46

1. Agricultura 50

2. Ganadería altoandina 52

3. Pesca 54

4. Minería 55

5. Hidroenergía 58

6. Infraestructura 60

7. Turismo 61

8. Salud 63

C. Agregación de impactos sectoriales en el PBI nacional 64

D. Propuestas de adaptación 65

E. Limitaciones de la metodología utilizada 65

Capítulo IV. Impactos sobre los recursos naturales: ecosistemas, uso de la tierra y disponibilidad hídrica $\quad 67$

A. Cambios proyectados en los biomas 68

B. Cambios en el uso de la tierra 70

C. Cambios sobre el balance hídrico 74

Capítulo V. Valoración del impacto del cambio climático en sectores productivos seleccionados $\quad 77$

A. Agricultura 77

1. Relación del sector con las variables climáticas 78

2. Impactos del cambio climático en el sector agrícola 80

B. Ganadería altoandina 83

1. Relación del sector con las variables climáticas 84

2. Impactos del cambio climático en el sector de ganadería altoandina 84

C. Pesca 88

1. Relación del sector con las variables climáticas 90

2. Impactos del cambio climático en el sector pesquero 90 
D. Minería 94

1. Relación del sector con las variables climáticas 96

2. Impactos del cambio climático en el sector minero 96

E. Hidroenergía 99

1. Relación del sector con las variables climáticas 101

2. Impactos del cambio climático en el sector hidroenergético 101

$\begin{array}{ll}\text { F. Infraestructura } & 105\end{array}$

1. Relación del sector con las variables climáticas 106

2. Impactos del cambio climático en el sector de infraestructura 106

$\begin{array}{ll}\text { G. Turismo } & 111\end{array}$

1. Relación del sector las variables climáticas 112

2. Impactos del cambio climático en el sector de turismo $\quad 112$

H. Salud 116

1. Relación del sector las variables climáticas 117

2. Impactos del cambio climático en el sector de la salud

1. Agregación de impactos sectoriales del cambio climático en el PBI nacional

1. Análisis de resultados agregados

2. Consideraciones para la interpretación de resultados

\section{Capítulo VI. Recomendaciones para las medidas} de adaptación

A. Esfuerzos de adaptación al cambio climático en el Perú

1. Esfuerzos en el ámbito regional 130

2. Esfuerzos en el sector privado 132

B. Propuestas de medidas para sectores seleccionados 133

Capítulo VII. Conclusiones y recomendaciones $\quad 139$

$\begin{array}{ll}\text { Bibliografía } & 143\end{array}$ 
Índice de cuadros

Cuadro I.1 Resumen de tendencias climáticas observadas en el Perú, 1963-2010 21

Cuadro I.2 Resumen de tendencias de retroceso glaciar en los Andes peruanos 22

Cuadro I.3 Modelos climáticos globales seleccionados para el análisis del estudio 27

Cuadro I.4 Modelos climáticos globales seleccionados a partir del diagrama de Taylor para cada región del Perú $\quad 28$

Cuadro II.1 Proyección del PBI y PBI per cápita del Perú al 210038

Cuadro III.1 Metodología de análisis de recursos naturales 45

$\begin{array}{lll}\text { Cuadro III.2 } & \text { Resumen de supuestos sectoriales } & 47\end{array}$

Cuadro III.3 Participación de los principales cultivos en el valor bruto de la producción agrícola y en la superficie sembrada, 2009

Cuadro III.4 Supuestos econométricos por cultivo $\quad 51$

Cuadro III.5 Cuencas mineras priorizadas por metal y ubicación geográfica 55

Cuadro III.6 Principales centrales hidroeléctricas del Sistema Interconectado Nacional del Perú 59

Cuadro III.7 Estructura de costos promedio de rehabilitación y mejoramiento de carreteras en el Perú

Cuadro III.8 Perfil del turista extranjero que viaja al Perú, 201062

Cuadro III.9 Gasto y permanencia promedio de turistas extranjeros en el Perú, 201062

Cuadro III.10 Casos registrados de enfermedades transmitidas por vectores en el Perú, 2000-2011 63

Cuadro V.1 Impacto económico del cambio climático en agricultura 82

Cuadro V.2 Impacto del cambio climático en agricultura con respecto al PBI sectorial del año 201082

Cuadro V.3 Impacto del cambio climático en agricultura con respecto al PBI nacional del año 201082

Cuadro V.4 Impacto económico del cambio climático en ganadería altoandina 87

Cuadro V.5 Impacto del cambio climático en ganadería altoandina con respecto al PBI sectorial del año 2010

Cuadro V.6 Impacto del cambio climático en ganadería altoandina con respecto al PBI nacional del año 2010

Cuadro V.7 Impacto económico del cambio climático en el sector pesca 93

Cuadro V.8 Impacto del cambio climático en pesca con respecto al PBI sectorial del año $2010 \quad 93$

Cuadro V.9 Impacto del cambio climático en pesca con respecto al PBI nacional del año $2010 \quad 94$

Cuadro V.10 Impacto económico del cambio climático en minería 98

Cuadro V.11 Impacto del cambio climático en minería con respecto al PBI sectorial del año $2010 \quad 98$ 
Cuadro V.12 Impacto del cambio climático en minería con respecto al PBI nacional del año 2010

Cuadro V.13 Impacto promedio del cambio climático por central hidroeléctrica, 2010-2100 102

Cuadro V.14 Impacto económico del cambio climático en hidroenergía 104

Cuadro V.15 Impacto del cambio climático en hidroenergía con respecto al

PBI sectorial del año 2010

Cuadro V.16 Impacto del cambio climático en hidroenergía con respecto al

PBI nacional del año 2010

Cuadro V.17 Longitud de la red vial según sistema de carretera en el Perú, 2005-2012 106

Cuadro V.18 Cambios en los caudales del río Rímac ante los escenarios climáticos, 2005-2100 107

Cuadro V.19 Cambios en los caudales del río Urubamba ante los escenarios climáticos, 2005-2100 107

Cuadro V.20 Impacto económico del cambio climático en infraestructura vial 110

Cuadro V.21 Impacto del cambio climático en infraestructura vial con respecto al PBI

de transporte del año 2010

Cuadro V.22 Impacto del cambio climático en infraestructura vial con respecto al PBI nacional del año $2010 \quad 110$

Cuadro V.23 Impacto económico del cambio climático en turismo 115

Cuadro V.24 Impacto del cambio climático en turismo con respecto al PBI sectorial del año 2010115

Cuadro V.25 Impacto del cambio climático en turismo con respecto al PBI nacional del año 2010116

Cuadro V.26 Impacto económico del cambio climático en salud 121

Cuadro V.27 Impacto del cambio climático en salud con respecto al PBI nacional del año $2010 \quad 122$

Cuadro V.28 Impacto acumulado del cambio climático, 2010-2040 124

Cuadro V.29 Impacto acumulado del cambio climático, 2010-2100 125

Cuadro V.30 Impacto acumulado del cambio climático para distintos períodos 126

Cuadro V.31 Impacto acumulado del cambio climático sobre el PBI nacional para distintos períodos 126

Cuadro VI.1 Medidas de adaptación para recursos naturales 133

Cuadro VI.2 Medidas de adaptación para el sector de agricultura 134

Cuadro VI.3 Medidas de adaptación para el sector de ganadería altoandina 134

Cuadro VI.4 Medidas de adaptación para el sector pesquero 135

Cuadro VI.5 Medidas de adaptación para el sector minero 135

Cuadro VI.6 Medidas de adaptación para el sector de hidroenergía 136

Cuadro VI.7 Medidas de adaptación para el sector de turismo 136

Cuadro VI.8 Medidas de adaptación para el sector de infraestructura 137 
Índice de gráficos

Gráfico I.1 Cambios en la precipitación mensual por región bajo el escenario A1B, 2010-2100

Gráfico I.2 Cambios en la temperatura media mensual por región bajo el escenario A1B, 2010-2100

Gráfico II.1 Variación interanual del PBI real, 1901-2008 34

Gráfico II.2 Estructura productiva de la economía del Perú 34

Gráfico II.3 PBI por departamento, 2001-2009 35

Gráfico Il.4 Población estimada del Perú, 2010-2100 36

Gráfico II.5 Proyección del PBI sectorial al 2100

Gráfico II.6 Participación sectorial en el PBI al 2100

Gráfico III.1 Modelación del impacto del cambio climático sobre el sector minero 57

Gráfico IV.1 Cambio en la extensión de los biomas bajo el efecto combinado del cambio climático y la agricultura

Gráfico V.1 PBI agropecuario y participación porcentual del sector en el PBI nacional 78

Grafico V.2 Función de producción de cultivos en relación con la temperatura 79

Gráfico V.3 Impacto del cambio climático en el valor de la producción de los cultivos seleccionados bajo los escenarios A1B, A2 y B1, 2010-2100 80

Gráfico V.4 Impacto económico del cambio climático en agricultura 81

Gráfico V.5 Impacto del cambio climático en la carga animal total para la puna 86

Gráfico V.6 Impacto del cambio climático en el ingreso de la ganadería altoandina 86

Gráfico V.7 PBI pesquero y participación porcentual del sector en el PBI nacional 88

Gráfico V.8 Desembarque total de recursos hidrobiológicos según tipo de consumo, 1994-2013 89

Gráfico V.9 Desembarque total de recursos hidrobiológicos según tipo de especie, 1994-2013 89

Gráfico V.10 Impacto del cambio climático en la captura de anchoveta 92

Gráfico V.11 Impacto del cambio climático en el ingreso por harina de pescado 92

Gráfico V.12 PBI minero y participación porcentual del sector en el PBI nacional 95

Gráfico V.13 Evolución de precios de los principales productos mineros peruanos, 1995-2012 95

Gráfico V.14 Déficit hídrico estimado para las cuencas mineras de cobre y zinc, 2010-2100 97

Gráfico V.15 PBI nacional y generación de energía eléctrica, 1976-2011 99

Gráfico V.16 PBI de electricidad y participación porcentual del sector en el PBI nacional 100

Gráfico V.17 Generación de energía eléctrica por tipo de fuente, 1976-2011 100 
Gráfico V.18 Impacto del cambio climático en la produccion hidroenergética

Gráfico V.19 Impacto del cambio climático en el valor de la producción

hidroenergética, 2010-2100

Gráfico V.20 PBI de transporte y participación porcentual del sector en el PBI

nacional, 2004-2013

Gráfico V.21 Probabilidad de ruptura de carreteras para modelos y escenarios A1B, A2 y B1

con respecto al escenario base

Gráfico V.22 Impacto del cambio climático en la reposicion de vías nacionales

Gráfico V.23 PBI nominal del sector Turismo y como porcentaje del PBI Nacional, 1991-2013

Gráfico V.24 Precipitación mensual e interrupciones en la vía férrea hacia la ciudadela de Machu Picchu, por causas ambientales, 2004-2011

Gráfico V.25 Proyección de turistas de vacaciones y capacidad de carga a Machu Picchu al año 2100, escenario base

Gráfico V.26 Turistas que visitan Machu Picchu con probabilidad de eventos extremos de precipitación y capacidades de carga 1 y 2

Gráfico V.27 Gasto en salud total y como porcentaje del PBI nacional

Gráfico V.28 Incidencia de malaria a partir de la temperatura mínima

Gráfico V.29 Proyecciones de casos de malaria para los escenarios A1B, A2 y B1, 2010-2100

Gráfico V.30 Impacto del cambio climático en el costo promedio del tratamiento de la malaria, 2010-2100

Gráfico V.31 Participación sectorial en los impactos acumulados al año 2100, descontados al 0,5\%

Índice de mapas

Mapa I.1 Línea de base climática (temperatura y precipitación) en el Perú, 1970-1999

Mapa I.2 Estaciones de monitoreo de precipitación y temperatura en las cinco zonas seleccionadas del Perú

Mapa I.3 Subregiones seleccionadas para analizar la tendencia temporal del clima en el Perú

Mapa IV.1 Cambios proyectados en biomas para el escenario A2 y el modelo MIMR

Mapa IV.2 Cambios proyectados en el uso de suelo bajo un escenario sin cambio climático

Mapa IV.3 Cambios en el uso del suelo bajo los escenarios A1B, A2 y B1, modelo CSMK3.5

Mapa IV.4 Cambios en la disponibilidad promedio de agua bajo los escenarios A2, A1B y 
Mapa V.1 Impactos del cambio climático en las áreas de pastoreo, 2010-2100

Mapa V.2 Abundancia promedio anual estimada de la anchoveta en la costa peruana, 1983-2006

Mapa V.3 Incidencia anual de la malaria por distrito, periodo 2000-2011

Índice de diagramas

Diagrama I.1 Diagrama de Taylor para la región Norte del Pacífico (NP)

Diagrama III.1 Esquema metodológico general del estudio de impactos económicos para Perú

Índice de recuadros

Recuadro I.1 Escenarios de emisión de gases de efecto invernadero

Recuadro III.1 Análisis de eventos extremos

Recuadro VI.1 Políticas y estrategias para enfrentar el cambio climático 


\section{Prólogo}

Uno de los grandes retos que enfrentará la humanidad en los próximos años será poner freno al cambio climático y adaptarse a los efectos de este fenómeno. La evidencia muestra que los orígenes del cambio climático son atribuibles a la actividad humana y que sus impactos afectan al conjunto de actividades sociales y económicas, así como a los ecosistemas. Tomar medidas requiere de decisiones políticas. En este sentido, entender en detalle cómo el cambio climático afectaría a cada región permitirá articular una respuesta global efectiva que haga frente a los riesgos que este fenómeno genera para el desarrollo sostenible y la reducción de la pobreza. Asimismo, el análisis del impacto económico del cambio climático a nivel nacional resulta fundamental para comprender sus causas e interrelaciones, anticipar efectos y diseñar alternativas de adaptación, así como para contribuir a la caracterización de mejores opciones futuras de desarrollo sostenible.

El Gobierno del Perú ha mostrado su liderazgo y compromiso con la disminución del fenómeno del calentamiento global y con la protección de la naturaleza, no solo facilitando procesos complejos de negociación internacional, como queda de manifiesto en la organización de la Conferencia de las Partes en la Convención Marco de las Naciones Unidas sobre el Cambio Climático (COP 20) en Lima, sino también promoviendo investigaciones como la que se presenta en este documento, que contribuyen a desarrollar mejores políticas públicas y profundizar el conocimiento científico sobre el problema.

El estudio La economía del cambio climático en el Perú refleja ese compromiso que tanto el Gobierno peruano como el Banco Interamericano de Desa- rrollo (BID) y la Comisión Económica para América Latina y el Caribe (CEPAL) tienen respecto de este tema. El trabajo se enmarca en la investigación a escala latinoamericana y caribeña denominada Estudios regionales de economía del Cambio Climático (ERECC), liderada por la CEPAL. Además de contar con el apoyo técnico del Ministerio del Ambiente, el Ministerio de Economía y Finanzas, y el Ministerio de Relaciones Exteriores del Perú, la investigación se ha desarrollado en el marco de los mismos lineamientos técnicos y organizativos que las de los demás países y subregiones que integran esta iniciativa.

En el trabajo se identifica cómo el cambio climático afectará el bienestar y la producción, a partir del impacto en algunos sectores de la actividad económica. Para ello, se hace uso de modelos climáticos mundiales propuestos por el Grupo Intergubernamental de Expertos sobre el Cambio Climático (IPCC), que permiten describir la evolución futura del clima sobre la base de posibles escenarios de emisiones de gases de efecto invernadero. Estos escenarios se construyen a partir de supuestos sobre la evolución de la población, la tecnología, la economía, el uso del suelo, la agricultura y la energía, tanto a nivel mundial como regional. En este estudio se usaron tres escenarios de emisión (A1B, A2 y B1) y siete modelos climáticos para construir escenarios sobre la evolución de la economía del Perú hasta el año 2100 en presencia de calentamiento global, teniendo en cuenta la heterogeneidad topográfica y climática del país.

También es importante resaltar que, en el marco de la metodología del estudio, se han establecido diversos supuestos generales. Para estimar el producto interno bruto en presencia del cambio climático 
no se han considerado procesos de adaptación a este fenómeno, los que se espera caracterizar en el futuro, como resultado del desarrollo de nuevos marcos metodológicos que lo permitan; se considera, además, que los precios reales y los costos económicos son constantes en el tiempo, con el objeto de facilitar las estimaciones; la construcción de la senda base o proyección económica a 2100 representa una situación en la que el país mantiene su senda de desarrollo y se asume que el clima conserva durante todo el período los valores de referencia (1970-2000). Finalmente, se utilizan tres tasas de descuento $(0,5 \%, 2 \%$ y $4 \%)$ para actualizar los costos futuros del cambio climático y realizar las comparaciones económicas.

Los resultados muestran que es muy probable que haya impactos económicos significativos y crecientes en el tiempo en ausencia de políticas globales para frenar el fenómeno o estrategias nacionales de adaptación que reduzcan sus impactos. Los análisis por sectores y actividades económicas revelan costos o pérdidas heterogéneas, y se destaca que el impacto del cambio climático afectaría más a algunos sectores y actividades que a otros. Según los datos analizados, los sectores de pesca, hidroenergía y agricultura serían los más afectados, aunque la ganadería altoandina, la minería, el turismo, la salud y la infraestructura también podrían sufrir impactos adversos.

Entre los principales cambios en los ecosistemas terrestres destacan la reducción de los glaciares y la expansión de sistemas arbustivos hacia las zonas altas de la región andina. Aunque los resultados no presentan evidencias de sabanización en la región amazónica, este proceso no es descartable, dado que las unidades ecosistémicas modeladas son aún muy amplias. El análisis también revela algunas tendencias importantes para el manejo de los recursos hídricos, observándose una ligera reducción del agua disponible en la mayor parte del país, especialmente en las regiones de la costa y la selva. En la costa, la disminución del agua disponible sería más fuerte, debido a que en estas zonas una disminución de la precipitación agravaría el aumento de la evapotranspiración. Por su parte, la reducción de glaciares y los cambios en bofedales y bosques de neblina, tanto por efecto del cambio climático como por la expansión de la agricultura, reducirían los reservorios naturales superficiales que favorecen la regulación estacional del agua.

Aunque los resultados deben considerarse con cautela, teniendo presentes las incertidumbres asociadas a la proyección futura del clima y de la evolución económica, se desprende de la amplitud de las pérdidas la necesidad de actuar lo antes posible para reducir la vulnerabilidad a lo largo de todo el territorio nacional. La representación georreferenciada de los impactos constituye una herramienta valiosa para entender los procesos de un país tan biodiverso y heterogéneo como es el Perú. Un territorio tan complejo como el andino-amazónico debe apreciarse de forma integral, reconociendo las presiones a las que se ve sometido y su heterogeneidad inherente. La información producida y sistematizada para el estudio, así como la estrategia de modelamiento propuesta, constituyen aportes para la formulación de políticas públicas informadas, a través de una mejor descripción espacio-temporal del Perú.

Esta información también permite entender con más claridad las dinámicas socioeconómicas y ambientales, mejora la comprensión de la capacidad productiva y de los enfoques compatibles con un marco de sostenibilidad socioambiental, y contribuye a crear conciencia y movilizar a una ciudadanía que debe ser parte de la solución. La participación del sector privado, el sector público, la academia y la comunidad científica, es decir, la sociedad en su conjunto, es fundamental para lograr un mejor futuro para el país y el planeta.

El Gobierno del Perú, el BID y la CEPAL renuevan su compromiso por seguir profundizando este tipo de investigaciones y el conocimiento para que todos los actores puedan tomar decisiones informadas, de manera de contribuir a la prevención de los efectos del cambio climático y a reducir sus consecuencias adversas sobre todos los ciudadanos.

\section{Santiago Levy}

Vicepresidente de Sectores y Conocimiento

BID
Manuel Pulgar Vidal

Ministro del Ambiente MINAM
Alicia Bárcena

Secretaria Ejecutiva

CEPAL 


\section{Introducción}

La evidencia científica internacional corrobora que el cambio climático se relaciona con el aumento de las emisiones de gases de efecto invernadero (GEI) generadas principalmente por actividades humanas. Este fenómeno se manifiesta en el progresivo aumento de las temperaturas, modificaciones en los patrones de precipitación, cambios en la frecuencia e intensidad de los eventos climáticos extremos y el aumento del nivel del mar. Estas alteraciones afectan el desarrollo socioeconómico y el bienestar de las personas a través de transformaciones en las capacidades de los ecosistemas, lo que a su vez genera cambios en el uso potencial de la tierra, biodiversidad y provisión de agua, entre otros.

Como resalta Stern (2007), aunque el cambio climático es un fenómeno de origen global, sus impactos y las alternativas de respuestas de adaptación se manifiestan a nivel local. Si no es adecuadamente evaluado e internalizado, el cambio climático constituye una limitación al desarrollo sostenible de los países, pues genera mayores costos en los procesos de crecimiento económico y de desarrollo social. Por ello, para actuar frente a los posibles riesgos que podría generar este fenómeno, resulta fundamental entender sus causas, canales de transmisión y efectos de sus impactos futuros a nivel nacional y subnacional.

El estudio "La economía del cambio climático en el Perú" aborda cómo el cambio climático afectaría la actividad económica nacional, evaluando las potenciales modificaciones en la disponibilidad de los recursos naturales y las actividades productivas más sensibles a cambios en el clima (agricultura, ganadería altoandina, minería, energía hidroeléctrica, turismo y pesca), tanto en términos físicos como sociales. También se analizan dos sectores transversales, la infraestructura y la salud, que son condicionantes para el desempeño productivo.

El citado documento es resultado de una investigación a nivel de país basada en la metodología establecida en el Informe Stern (2007) y en diversos estudios realizados en distintos países de América Latina y el Caribe en el marco del proyecto de la Economía del Cambio Climático en América Latina y el Caribe, coordinado por la Comisión Económica para América Latina y el Caribe (CEPAL). Así, mediante el uso de escenarios y modelos climáticos globales, los impactos económicos del calentamiento global en la economía nacional se calculan como la diferencia entre el PBI con ausencia y presencia del cambio climático, en un periodo de análisis que se extiende hasta el año 2100. Además de caracterizar los principales impactos sectoriales, se identifican opciones de adaptación y mitigación que contribuyan al desarrollo sostenible del país.

Debido al horizonte temporal proyectado, las múltiples variables integradas en este análisis y las limitaciones de información, es necesario consignar que los resultados deben interpretarse teniendo en cuenta la incertidumbre asociada. En ese sentido, las cifras obtenidas representan tendencias y órdenes de magnitud, pero no deben considerarse pronósticos exactos. En todo caso, los resultados muestran que ante la ausencia de acciones preventivas -supuesto del estudio-, el cambio climático 
podría generar importantes costos económicos en el futuro para el país.

Por ello, este estudio representa un avance en la discusión de la problemática del impacto del cambio climático en un país altamente vulnerable como el Perú. El análisis climático, territorial y productivo realizado, además de generar información para apoyar las estrategias nacionales de adaptación, constituye una importante herramienta de gestión del territorio a escala nacional. El trabajo también contribuye a la comprensión integrada de las dinámicas socioeconómicas y ambientales de un territorio tan heterogéneo como el peruano, buscando mejorar el entendimiento de su capacidad productiva y priorizando enfoques de sostenibilidad para la toma de decisiones informadas. Los resultados y las metodologías utilizadas pueden contribuir a la discusión de políticas públicas y permiten profundizar en el conocimiento de las relaciones causales y las variables explicativas del impacto del cambio climático. También se resaltan las líneas de investi- gación que deberían profundizarse para mejorar el conocimiento sobre el fenómeno y sus impactos, con el fin de identificar riesgos y disminuir los costos futuros de la inacción.

Es por lo anterior que este documento busca ser un insumo de apoyo a la agenda existente en el Perú e implementar políticas públicas informadas para reducir los impactos económicos del cambio climático y adaptar la economía a dicho fenómeno.

El presente documento sintetiza el enfoque y hallazgos del estudio en siete capítulos: 1) el cambio climático en el Perú, 2) escenarios macroeconómicos y demográficos, 3) metodología y supuestos, 4) impactos sobre los recursos naturales renovables, con énfasis en el cambio del uso y cobertura de la tierra y disponibilidad hídrica, 5) valoración de los impactos del cambio climático en los sectores productivos seleccionados y agregación nacional, 6) recomendaciones para medidas de adaptación y 7) conclusiones y recomendaciones del estudio. 


\section{Capítulo I}

\section{El cambio climático en el Perú}

El Cuarto Informe del IPCC(2007) del Panel Intergubernamental sobre el Cambio Climático (IPCC), indica que las emisiones mundiales de GEl causadas por las actividades humanas han aumentado en $70 \%$ desde la era preindustrial. Coincidiendo con este incremento en la concentración de GEl, se ha registrado un aumento de la temperatura global. El nivel de conocimiento actual permite señalar que la explicación más probable sobre la aceleración del calentamiento global es el incremento en la concentración de los GEl de origen humano.

En este contexto, es vital entender cómo los cambios en las emisiones de GEl impactarán el clima del Perú para poder evaluar cómo modificarán la capacidad productiva nacional. Para ello se necesita 1) entender las principales variaciones observadas en los últimos años en el clima nacional, 2) saber qué indican los modelos globales sobre lo que podría ocurrir con el clima en el Perú, 3) comprender qué información se puede obtener de los modelos y 4) construir una representación del clima presente y futuro del territorio nacional. Este perfil climático del país debe reflejar simultáneamente la heterogeneidad del clima nacional y la incertidumbre existente sobre el futuro.

\section{A. Climatología actual y tendencias}

El Perú es el tercer país en extensión en América del Sur y contiene a la cordillera de los Andes, fenómeno geológico que divide al país en tres regiones geográficas: costa, sierra y selva. La presencia de la cordillera de los Andes y de la corriente costera peruana, determina y modifica las condiciones ecológicas y climáticas del país. En virtud de estos dos factores, el Perú posee casi todas las variantes climáticas que se presentan en el mundo, con un régimen pluviométrico que varía tanto en el tiempo como en el espacio (SENAMHI, 2007; Ávalos, 2005). Esta diversidad de climas incluye el costero árido, el semiseco frío en el altiplano, el templado de los valles interandinos, el cálido con precipitaciones abundantes en la selva y en el norte del país, y el clima frío y seco característico de las alturas andinas (SENAMHI, 2008). La diversidad climática imperante en el Perú se visualiza en el mapa I.1, donde se presenta la precipitación promedio y la temperatura media anual para el escenario climático de referencia para el período 1970 a 1999. 
MAPA I. 1

Línea de base climática (temperatura y precipitación) en el Perú, 1970-1999
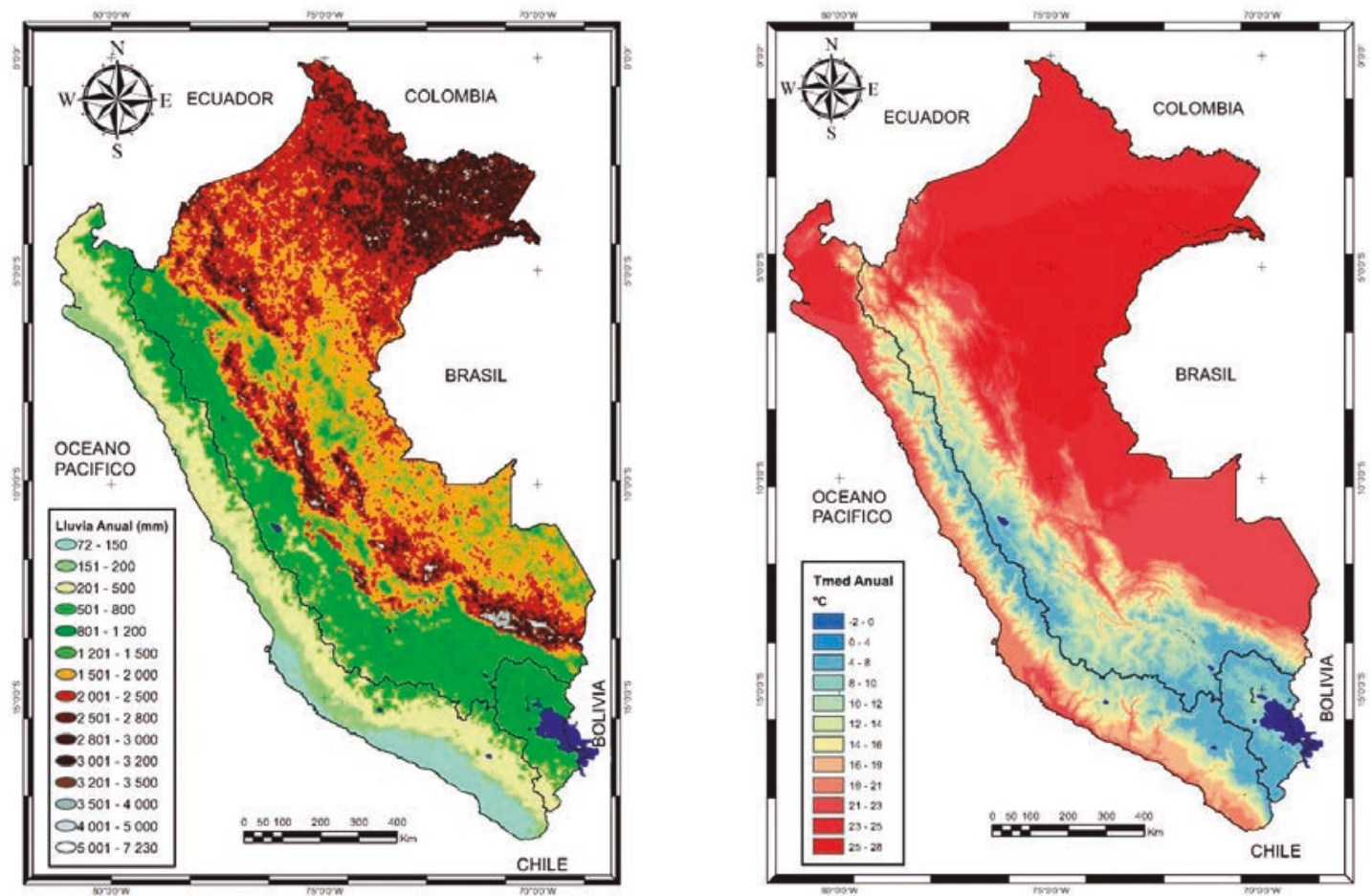

Fuente: Elaboración propia.

Las características del clima nacional han cambiado lenta pero sostenidamente durante los últimos años, como lo atestiguan diversas evidencias científicas recogidas a lo largo del país y que se señalan en cuadro I.1. El cambio del clima se manifiesta mayormente como un aumento de temperatura, pero también se observan incrementos y disminuciones en la precipitación en distintas localidades del país. 


\begin{tabular}{|c|c|c|c|}
\hline Región & Período & Variable & Tendencia \\
\hline \multirow{5}{*}{$\begin{array}{l}\text { Cuenca del río Piura } \\
\text { (Andes noroccidentales) }^{\mathrm{a}}\end{array}$} & $1963-2003$ & Temperatura mínima & $+0,2$ a $0,3^{\circ} \mathrm{C} /$ década \\
\hline & $1963-2003$ & Temperatura máxima & $+0,3$ a $0,45^{\circ} \mathrm{C} /$ década \\
\hline & & & Verano, otoño: +9 a 14 mm/año \\
\hline & $1963-2003$ & Precipitación & Invierno: $-0,5 \mathrm{~mm} / \mathrm{año}$ \\
\hline & & & Primavera: $+0,2$ a 0,5 mm/año \\
\hline \multirow{3}{*}{$\begin{array}{l}\text { Cuenca del río Santa } \\
\text { (Andes occidentales centrales) }^{b}\end{array}$} & $1965-2006$ & Temperatura mínima & 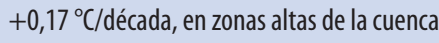 \\
\hline & $1965-2006$ & Temperatura máxima & 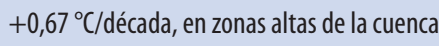 \\
\hline & $1965-2006$ & Precipitación & Anual: $+20-30 \%$ en los últimos 40 años \\
\hline \multirow{9}{*}{$\begin{array}{l}\text { Cuenca del río Mantaro } \\
\text { (Andes centrales orientales)c }^{c}\end{array}$} & $1965-2010$ & & Anual: $-0,3$ a $+0,7^{\circ} \mathrm{C} /$ década \\
\hline & & Temperatura mínima & Verano: $-0,2 \mathrm{a}+0,7^{\circ} \mathrm{C} /$ década \\
\hline & & & Invierno: $-0,7 \mathrm{a}+0,3^{\circ} \mathrm{C} /$ año \\
\hline & $1965-2010$ & & Anual: - $0,1 \mathrm{a}+0,4^{\circ} \mathrm{C} /$ década \\
\hline & & Temperatura máxima & Verano: $-0,3 \mathrm{a}+0,6^{\circ} \mathrm{C} /$ década \\
\hline & & & Invierno: $+0,1$ a +0, ${ }^{\circ} \mathrm{C} /$ década \\
\hline & $1965-2010$ & & Anual:-3 a -51 mm/década \\
\hline & & Precipitación & Verano: -3 a -29 mm/década \\
\hline & & & Invierno: - 1 a - 6 mm/década \\
\hline \multirow{8}{*}{$\begin{array}{l}\text { Arequipa } \\
\text { (Andes del sur) }^{d}\end{array}$} & & & Anual: $+0,12 \mathrm{a}+0,57^{\circ} \mathrm{C} /$ década \\
\hline & $1964-2006$ & Temperatura mínima & Verano: $-0,07 \mathrm{a}+0,56^{\circ} \mathrm{C} /$ década \\
\hline & & & Invierno: $+0,26 \mathrm{a}+0,5^{\circ} \mathrm{C} /$ década \\
\hline & & & Anual: $+0,06$ a $+0,42^{\circ} \mathrm{C} /$ década \\
\hline & $1964-2006$ & Temperatura máxima & Verano: $-0,07$ a $+0,42^{\circ} \mathrm{C} /$ década \\
\hline & & & Invierno: $+0,02 \mathrm{a}+0,44^{\circ} \mathrm{C} /$ década \\
\hline & $1964-2006$ & Precipitación & -2 a $+1,5 \mathrm{~mm} /$ década \\
\hline & & & Anual: $+-0,1$ a $+0,2^{\circ} \mathrm{C} /$ década \\
\hline \multirow{8}{*}{$\begin{array}{l}\text { Parte media-alta de la cuenca del río } \\
\text { Urubamba } \\
\text { (Andes sudorientales) }^{e}\end{array}$} & $1965-2010$ & Temperatura mínima & Verano: $+0,1 \mathrm{a}+0,2^{\circ} \mathrm{C} /$ década \\
\hline & & & Invierno: $-0,4$ a +0,2 ${ }^{\circ} \mathrm{C} /$ década \\
\hline & & & Anual: $+0,07 \mathrm{a}+0,5^{\circ} \mathrm{C} /$ década \\
\hline & $1965-2010$ & Temperatura máxima & Verano: $+0,1 \mathrm{a}+0,6^{\circ} \mathrm{C} /$ década \\
\hline & & & Invierno: $+0,05 \mathrm{a}+0,6^{\circ} \mathrm{C} /$ década \\
\hline & & & Anual: +2 a $+20 \mathrm{~mm} /$ década \\
\hline & $1965-2010$ & Precipitación & Verano: $+9 \mathrm{a}+18 \mathrm{~mm} /$ década \\
\hline & & & Invierno: +1 a +2 mm/década \\
\hline \multirow{7}{*}{$\begin{array}{l}\text { Cuenca del río Mayo } \\
\text { (Andes nororientales) }^{f}\end{array}$} & $1965-2006$ & Temperatura mínima & Alto Mayo: $+0,48^{\circ} \mathrm{C} /$ década \\
\hline & & & Bajo Mayo: +0,22 ${ }^{\circ}$ /década \\
\hline & $1965-2006$ & Temperatura máxima & Alto Mayo: $-0,25^{\circ} \mathrm{C} /$ década \\
\hline & & & Bajo mayo: $+0,43^{\circ} \mathrm{C} /$ década \\
\hline & & & Anual: $-20 a+20 \%$ \\
\hline & $1965-2006$ & Precipitación & Verano: - 10 a $40 \%$ \\
\hline & & & Invierno: -10 a $-40 \%$ \\
\hline
\end{tabular}




\begin{tabular}{|c|c|c|c|}
\hline Región & Período & Variable & Tendencia \\
\hline \multirow{9}{*}{$\begin{array}{l}\text { Parte norte de la región Apurímac } \\
\text { (Andes centrales occidentales) }^{9}\end{array}$} & \multirow{4}{*}{$1965-2009$} & \multirow{3}{*}{ Temperatura mínima } & Anual: $-0,5 \mathrm{a}+0,1^{\circ} \mathrm{C} /$ década \\
\hline & & & Verano: $-0,5 \mathrm{a}+0,1^{\circ} \mathrm{C} /$ década \\
\hline & & & Invierno: $-0,6 \mathrm{a}+0,1^{\circ} \mathrm{C} /$ década \\
\hline & & \multirow{3}{*}{ Temperatura máxima } & Anual: $-0,7 \mathrm{a}+0,3^{\circ} \mathrm{C} /$ década \\
\hline & \multirow[t]{2}{*}{$1965-2009$} & & Verano: $-0,6 \mathrm{a}+0,3^{\circ} \mathrm{C} /$ década \\
\hline & & & Invierno: $-0,6 \mathrm{a}+0,3^{\circ} \mathrm{C} /$ década \\
\hline & \multirow{3}{*}{$1965-2009$} & \multirow{3}{*}{ Precipitación } & Anual: $+36,3$ a $+63,2 \mathrm{~mm} /$ década \\
\hline & & & Verano: $+32,7 \mathrm{a}+44,7 \mathrm{~mm} /$ década \\
\hline & & & Invierno: +1,0 a +1,5 mm/década \\
\hline
\end{tabular}

Fuente: Elaboración propia sobre la base de Marengo et al. (2009 y 2011) y SENAMHI (2005, 2009a, 2009b, 2011a, 2011b y 2011c).

Notas: a)SENAMHI (2005a), b)SENAMHI (2009b), c)SENAMHI (2011a), d)Marengo et al. (2009), e)SENAMHI (2011b), f)SENAMHI (2009a), g)SENAMHI (2011c).

Además de los cambios registrados en temperatura y precipitación, se observa una reducción significativa de las áreas cubiertas por los glaciares del Perú (véase el cuadro I.2). Los glaciares regulan el flujo hídrico de las cuencas abastecidas por los deshielos (como las de los ríos Santa y Rímac), así como sistemas de irrigación (río Majes). El impacto en las cuencas no alimentadas por glaciares, correspondiente a una parte significativa del país, ha sido poco estudiado.

\section{CUADRO I.2}

Resumen de tendencias de retroceso glaciar en los Andes peruanos

\begin{tabular}{|c|c|}
\hline Referencia/Período & Tendencias e Impactos \\
\hline $\begin{array}{l}\text { Mark y Seltzer (2003) } \\
\text { (1965-2002) }\end{array}$ & $\begin{array}{l}22 \% \text { de reducción en el área total de los glaciares; reducción de } 12 \% \text { en el suministro de agua potable para la región costera (donde } \\
\text { vive el } 70 \% \text { de la población). El estimado del volumen de agua perdido es de aproximadamente siete billones de metros cúbicos. }\end{array}$ \\
\hline $\begin{array}{l}\text { Consejo Nacional del Ambiente (CONAM, } \\
2001) \\
(1970-2002)\end{array}$ & $\begin{array}{l}\text { Reducción de hasta } 80 \% \text { en la extensión de glaciares de pequeño porte (menos de } 5200 \text { msnm) y pérdida de } 188 \text { millones de metros } \\
\text { cúbicos en reservas de agua durante los últimos } 50 \text { años. }\end{array}$ \\
\hline $\begin{array}{l}\text { Mark etal. (2005) } \\
(1998-2004)\end{array}$ & $\begin{array}{l}\text { En la cordillera Blanca, el retroceso del glaciar Yanamarey entre } 2001 \text { y } 2004 \text { fue 23\% mayor que entre } 1998 \text { y 1999, y fue responsa- } \\
\text { ble de aumentos de 58\% de la media anual de descarga del río Santa. }\end{array}$ \\
\hline $\begin{array}{l}\text { Mark et al. (2005) } \\
(1977-2004)\end{array}$ & $\begin{array}{l}\text { Retroceso del glaciar Yanamarey, replegándose a una velocidad de } 20 \text { m/año (promedio 1977-2003), cuatro veces más rápido que los } \\
5 \text { m/año observados entre } 1948 \text { y } 1977 .\end{array}$ \\
\hline Pouyaud et al. (2005) (1953-1997) & Aumento de $13 \%$ en la descarga de la laguna LLanganuco, en la cordillera Blanca. \\
\hline $\begin{array}{l}\text { Pouyaud et al. (2005) } \\
\text { (1985-1996) }\end{array}$ & En los últimos diez años la capa de hielo del glaciar Pastoruri se ha reducido en casi $40 \%$. \\
\hline $\begin{array}{l}\text { Silverio (2004) } \\
(1950-2006)\end{array}$ & Reducción de hasta 50\% en la extensión del glaciar Coropuna, generando problemas en la irrigación de la pampa Majes. \\
\hline
\end{tabular}

Fuente: Elaboración propia sobre la base de Marengo et al. (2011).

Junto con la información anterior, también se han registrado cambios en los eventos climáticos extremos como sequías, inundaciones o heladas. Además, con base en el análisis de diez índices de eventos extremos para el período 1965 a 2006, realizado por el SENAMHI (2009a) en todo el país, calculados a partir de cien estaciones de monitoreo de precipitación y 29 de temperaturas extremas, se observa lo siguiente:

- Las lluvias presentan incrementos en la costa y sierra norte, así como disminución en la selva norte, sin cambios sistemáticos en el resto del país. La intensidad de las precipitaciones también presenta incrementos en la costa y sierra norte, aunque disminuye en la sierra central. La sierra sur muestra variaciones moderadas en ambos sentidos. 
- La frecuencia de lluvias moderadas e intensas se ha incrementado en la costa y en la sierra norte, pero ha disminuido en la sierra central.

- Las temperaturas máximas y mínimas se han incrementado hasta en $0,2{ }^{\circ} \mathrm{C}$ por decenio en casi todo el país.

- Hay una mayor recurrencia de los periodos secos respecto a los periodos húmedos en todo el país, particularmente en la sierra central.

- La región de la selva, así como la sierra sur, ha presentado la mayor frecuencia de sequías moderadas y severas en los últimos decenios.

- En general, el número de días fríos tiene una marcada tendencia a disminuir, mientras que los días cálidos se han incrementado.

- El número de noches frías está disminuyendo conjuntamente con el incremento de noches más cálidas.

Las variaciones anuales del clima del Perú están en gran medida determinadas por la presencia del fenómeno climático El Niño-Oscilación Sur (ENSO, por sus siglas en inglés). El ciclo ENSO presenta dos fases: una cálida o positiva (El Niño) y otra fase fría o negativa (La Niña).

El Niño y La Niña son ejemplos climáticos importantes que, aunque no únicos, demuestran la gran vulnerabilidad de las poblaciones ante variaciones climáticas drásticas, como eventos extremos de lluvia y de temperaturas, que han causado grandes pérdidas económicas por sus impactos directos e indirectos, como lo fueron El Niño 1982-1983 (que sumaron un total de 3.283 millones de dólares) y El Niño 1997-1998 (con daños estimados en 3.500 millones de dólares). Estas pérdidas fueron equivalentes al 11,6\% y 6,2\% del PBI anual de 1983 y 1998, respectivamente (SENAMHI, 2014).

Otros dos ejemplos de eventos extremos que tienen impactos significativos en el territorio nacional son las heladas y las sequías. Ambos fenómenos impactan periódicamente el territorio nacional, generando también importantes pérdidas económicas. En la selva, como en la sierra sur, se ha presentado la mayor frecuencia de sequías moderadas y severas de modo mensual y trimestral, mientras que las sequías extremas anuales se han desplegado en la sierra norte (Piura y Tumbes) y en Arequipa.

Con estas condiciones, es comprensible que Perú sea considerado un país altamente vulnerable al cambio climático, por contar con siete de las nueve características de vulnerabilidad reconocidas por la Convención Marco de las Naciones Unidas sobre el Cambio Climático, relacionadas con 1) poseer zonas costeras bajas, 2) zonas áridas y semiáridas, 3) áreas susceptibles a la deforestación o erosión, 4) a los desastres naturales, 5) a la sequía y la desertificación, 6) áreas urbanas altamente contaminadas, y 7) ecosistemas frágiles.

\section{B. Proyecciones climáticas futuras}

Para estimar los potenciales impactos del cambio climático en el Perú es necesario contar con representaciones de los cambios en las condiciones futuras de las variables climáticas como temperatura, precipitación, cambios en la estacionalidad y en la probabilidad de ocurrencia de eventos extremos. Siguiendo la metodología aplicada en estudios similares, se propone utilizar modelos globales climáticos (GCM, por sus siglas en inglés) que representan gran parte de los procesos climáticos, en ocasiones compuestos por dinámicas no lineales. Al ser representaciones abstractas, consiguen acercarse relativamente bien a la realidad y permiten conducir experimentos y simular lo que ocurriría con el clima global cuando cambia la concentración de GEl.

De esta manera, los modelos climáticos permiten construir escenarios mediante cambios controlados en algunas de las variables del modelo o en sus condiciones de entorno. El IPCC ha definido un conjunto de escenarios para estudiar y eva- 
luar cómo el cambio en las concentraciones de GEl podría afectar al clima global (véase recuadro l.1). El Cuarto Informe del IPCC (2007a) presenta varios escenarios climáticos globales. En este estudio se han empleado los escenarios A1B, A2 y B1.

Estos escenarios de emisiones de GEl se dividen en dos grandes familias: los escenarios A, que describen un futuro con alto crecimiento económico; y los escenarios B, en los que el crecimiento es más moderado. Los escenarios parten de supuestos sobre la evolución de los forzantes (población, tecnología, economía, uso del suelo, agricultura y energía) en los ámbitos global, y regional global y regional (Galindo y Caballero, 2011). El IPCC trabaja en base al análisis de varios centros donde se modela el clima global. Existen más de treinta modelos climáticos globales en la base de datos del IPCC'. Cada uno de ellos representa una forma de describir el clima global actual, con su propia lógica y supuestos físicos validados con el clima presente, y todos son igualmente válidos para el futuro.

La información provista por los GCM es presentada a una escala espacial de entre $100 \mathrm{~km}$ y $400 \mathrm{~km}$. Esta resolución no permite considerar adecuadamente algunas variables claves para entender el clima local, relacionadas con topografía, uso del suelo, cuerpos de agua, entre otros. Para mejorar la resolución espacial de los GCM se han empleado algoritmos de regionalización (downscaling) en unidades de 1 km cuadrado.

Al representar el país con una matriz de cuadrados relativamente pequeños (rasters), se logró simbolizar cuencas, departamentos y pisos ecológicos para los distintos análisis. Finalmente, y dado que existen cuencas binacionales y condiciones ecosistémicas consideradas, el territorio modelado se extendió algunos kilómetros más allá de las fronteras peruanas para capturar procesos claves y entender la dinámica territorial.

\section{RECUADRO I.1}

\section{Escenarios de emisión de gases de efecto invernadero}

Para realizar las proyecciones de largo plazo sobre cambio climático se han construido diversos escenarios basados en una serie de supuestos de emisiones y desarrollo socioeconómicos de los países.

El Reporte especial sobre escenarios de emisiones (SRES, por sus siglas en inglés) desarrolló cuatro líneas evolutivas (storylines) (A1, A2, B1 y B2), cada una de ellas con diferentes supuestos de emisiones de GEl, contaminación, uso del suelo y otras variables. El Cuarto Informe del IPCC incluyó tres escenarios, pues el escenario B2 se descartó por la baja probabilidad de ocurrencia. Los siguientes son los principales supuestos asociados a los escenarios:

A1B: Emisión media alta. Rápido crecimiento económico regional con la introducción de tecnologías nuevas y eficientes. Existe un balance entre el uso de fuentes de energía fósil y no fósil.

A2: Emisión alta. Existe crecimiento constante de la población y el desarrollo económico está orientado regionalmente en un mundo heterogéneo. El escenario A2 se refiere a una economía internacional dinámica con un uso intensivo de combustibles fósiles, que genera un crecimiento de concentraciones de GEl en la atmósfera con valores mucho mayores a los presentes, lo que incide en elevar los niveles de temperatura, cambios en los patrones de precipitación, aumento en el nivel medio del mar y mayor frecuencia e intensidad de los fenómenos climáticos extremos. El cambio tecnológico es muy fragmentado y más lento que en otras líneas evolutivas.

Recuadro continúa en la siguiente página.

1 Los modelos climáticos globales o modelos de circulación general son abstracciones matemáticas que simulan e incorporan en sus ecuaciones los procesos físicos de las interacciones fundamentales entre los componentes más importantes del sistema climático: la atmósfera, hidrósfera y biósfera. 
B1: Emisión media baja. Asume la misma población global que en A2 y un cambio en las estructuras económicas, así como un uso de fuentes de energía eficientes y soluciones globales hacia economía, sociedad y ambiente sustentable. El escenario B1 representa un panorama optimista.

B2: Emisión baja. En el escenario B2 habría una menor concentración de GEl y un menor nivel de impacto asociado al calentamiento global.

El IPCC desarrolló para su quinto y más reciente reporte nuevos escenarios de emisiones y concentraciones denominado Representative Concentration Pathway (RCP). Estos escenarios incorporan las simulaciones de atmósfera y océano, y capturan los cambios de uso de suelo, así como las emisiones de gases de corta vida. A diferencia de los SRES, estos no se basan directamente en las líneas evolutivas y cuentan con proyecciones hasta el año 2300 (denominadas, Extended Concentration Pathways).

\section{Concentraciones de $\mathrm{CO}_{2}$ equivalentes}

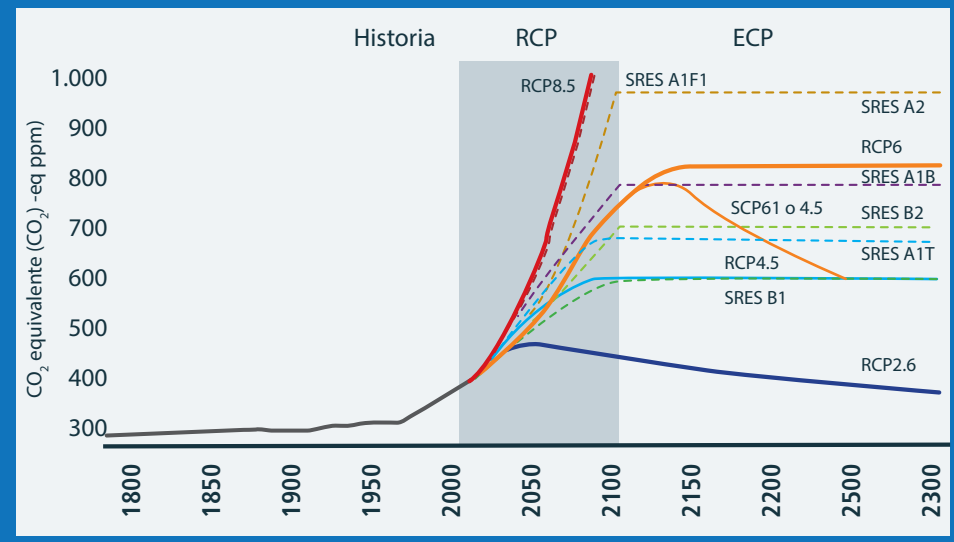

Fuente: Tomado a partir de Cubasch et al. (2013).

Como se aprecia en la figura anterior, en general, los cuatro modelos RCP representan un rango de concentraciones de GEI mayor a los SRES. El escenario RCP 4.5 considera concentraciones equivalentes cenario B1, el RCP 6 rebasa ligeramente los niveles de A1B (principalmente después del 2100) y el RCP 8. es un poco mayor al A2 hasta 2100 y cercano al escenario A1F1. El escenario RCP 2.6 es el menor de todos los escenarios considerados.

Fuente: Elaboración propia a partir de IPCC (2007 y 2014).

Para abordar la incertidumbre de los GCM y validar su aplicación en el Perú, se han seleccionado cinco zonas con características geográficas particulares y diferenciadas climáticamente. Tomando en cuenta la disponibilidad de información de las tres grandes vertientes (costa, sierra y selva), las cinco áreas seleccionadas son 1) norte del Pacífico (NP), caracterizada por la influencia del fenómeno de El Niño; 2) nororiente (NO), región amazónica caracterizada por fuertes precipitaciones; 3 ) centro (C), región central del territorio peruano con características climáticas homogéneas; 4) sur del Pacífico (SP), región signada por su aridez; y 5) altiplano (AL), caracterizada por tener una elevación y características climáticas homogéneas. En el mapa l.2 se presentan las estaciones de monitoreo de precipitación y temperatura asociadas a las cinco zonas mencionadas y que permitirán validar los GCM. 


\section{MAPA I.2}

Estaciones de monitoreo de precipitación y temperatura en las cinco zonas seleccionadas del Perú

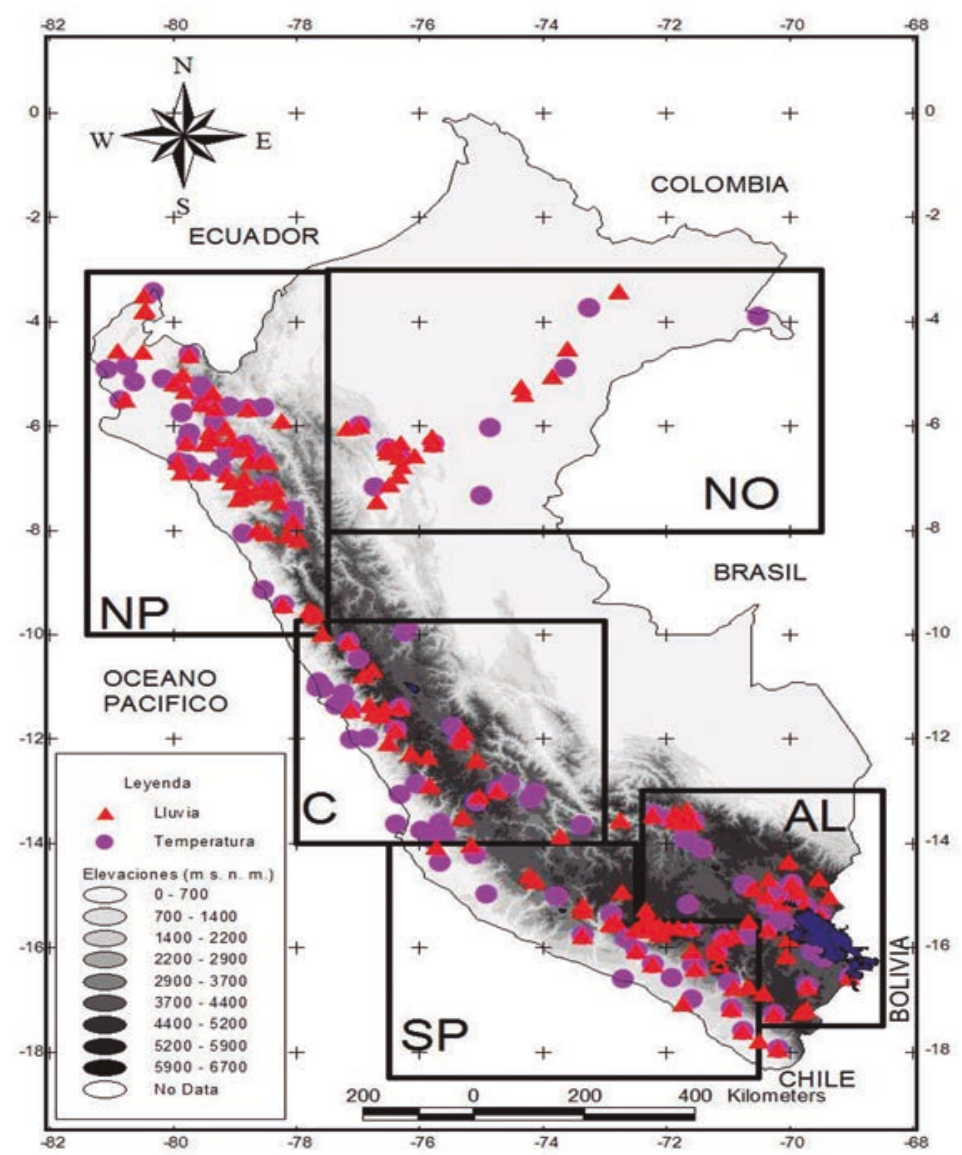

Fuente: Elaboración propia.

Nota: NP (norte del Pacífico), NO (nororiental), C (centro), SP (sur del Pacífico) y AL (altiplano).

El proceso de validación consistió en comparar los datos mensuales de estaciones para el período de 19701999 con los datos obtenidos de diez GCM, siete de los cuales presentan todas las variables seleccionadas para la validación, con las resoluciones espaciales que varían desde $1,1^{\circ} \times 1,1^{\circ}(\mathrm{MIHR})$ hasta $4^{\circ} \times 5^{\circ}(\mathrm{INCM} 3)$, (véase el cuadro l.3). 
CUADRO I.3

Modelos climáticos globales seleccionados para el análisis del estudio

\begin{tabular}{|c|c|c|}
\hline Acrónimo & Instituciones & Modelo \\
\hline BCM2.0 & BCCR (Bjerknes Centre for Climate Research) & BCM2.0 (Bergen Climate Model Version 2.0) \\
\hline CSMK3.0 & CSIRO (Commonwealth Scientific and Industrial Research Organisation) & Mk3.0 (Mark 3.0 Model) \\
\hline CSMK3.5 & CSIRO (Commonwealth Scientific and Industrial Research Organisation) & Mk3.5 (Mark 3.5 Model) \\
\hline GIAOM & $\begin{array}{l}\text { NASA (National Aeronautics and Space Administration) } \\
\text { GISS (Goddard Institute for Space Studies) }\end{array}$ & A0M 4x3(Atmosphere 0cean Model $4 \times 3$ ) \\
\hline INCM3 & INM (Institute of Numerical Mathematics) & CM3.0 (Climate Model 3.0) \\
\hline MIHR & $\begin{array}{l}\text { CCSR (Center for Climate System Research) } \\
\text { FRCGC (Frontier Research Center for Global Change) } \\
\text { NIES (National Institute for Environmental Studies) }\end{array}$ & $\begin{array}{l}\text { MIROC3.2-HI(Model for Interdisciplinary Research on } \\
\text { Climate 3.2 High Resolution) }\end{array}$ \\
\hline MIMR & $\begin{array}{l}\text { CCSR (Center for Climate System Research) } \\
\text { FRCGC (Frontier Research Center for Global Change) } \\
\text { NIES (National Institute for Environmental Studies) }\end{array}$ & $\begin{array}{l}\text { MIROC3.2-MED(Model for Interdisciplinary Research } \\
\text { on Climate 3.2 Medium Resolution) }\end{array}$ \\
\hline NCCCSM & $\begin{array}{l}\text { NASA (National Aeronautics and Space Administration) } \\
\text { NCAR (National Center for Atmospheric Research) } \\
\text { NOAA (National Oceanic and Atmospheric Administration) }\end{array}$ & CCSM3 (Community Climate System Model Version 3.0) \\
\hline GFCM2.0 & GFDL-NOAA (Geophysical Fluid Dynamic Laboratory-National Oceanic and Atmospheric Administration ) & CM2 (Coupled Climate Model 2.0) \\
\hline GFCM2.1 & GFDL-NOAA (Geophysical Fluid Dynamic Laboratory-National Oceanic and Atmospheric Administration ) & CM2.1 (Coupled Climate Model 2.1) \\
\hline
\end{tabular}

Fuente: Elaboración propia.

Para poder identificar qué modelo se desempeñaría mejor, se analizaron las respuestas estacionales de cada GCM empleando el diagrama de Taylor (Taylor, 2001) (véase el diagrama I.1). El esquema permite evaluar cuán bien los resultados de un modelo representan los valores observados a través de análisis estadísticos de correlación y de variabilidad.

\section{DIAGRAMA I.1}

Diagrama de Taylor para la región Norte del Pacífico (NP)

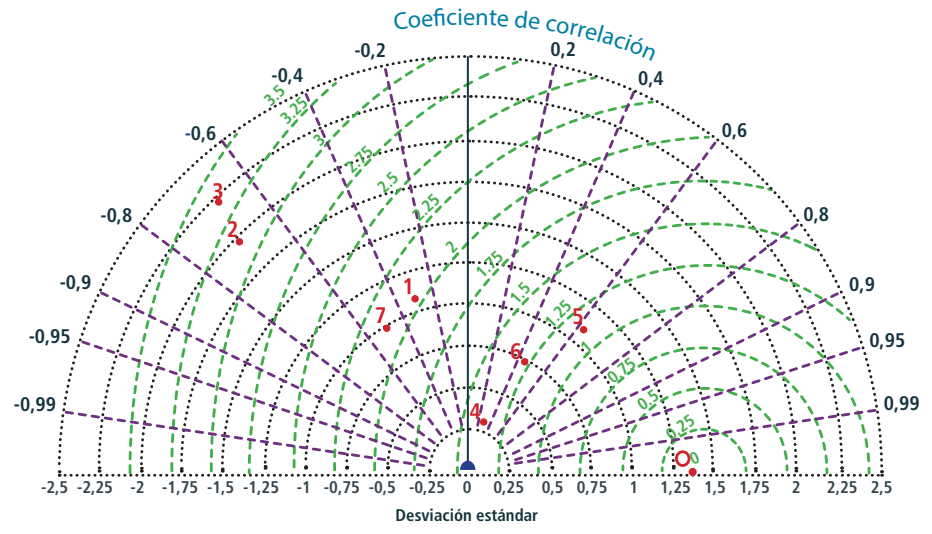

Fuente: Elaboración propia.

Notas: a) Los números en rojo más cercanos al punto 0 corresponden a los modelos que mejor se ajustan a los valores observados en la región Norte del Pacífico: 1. BCM2.0, 2. CSMK3.0, 3. CSMK3.5, 4. GIAOM, 5. INCM3, 6. MIHR, 7. MIMR, 8. NCCCSM, 9. GFCM2.0 y 10. GFCM2.1; b) La región Norte del Pacífico abarca las zonas de Tumbes, Piura, Cajamarca, Lambayeque y parte de San Martín. 
La comparación se realizó para cada GCM en cada región mencionada previamente. El cuadro l.4 resume los tres mejores modelos en cada una de las regiones. Se consideran la región de análisis y la variable de interés. Los mejores modelos para validar los datos mensuales de 1970 a 1999 varían y no se identificó un determinado modelo en el ámbito nacional.

CUADRO I.4

Modelos climáticos globales seleccionados a partir del diagrama de Taylor para cada región del Perú

\begin{tabular}{|c|c|c|c|c|c|c|}
\hline \multirow[b]{2}{*}{ Región/ranking } & \multicolumn{3}{|c|}{ Precipitación } & \multicolumn{3}{|c|}{ Temperatura media } \\
\hline & $10^{\circ}$ & $20^{\circ}$ & $3 .^{\circ}$ & $10^{\circ}$ & $2 .{ }^{\circ}$ & $30^{\circ}$ \\
\hline NP (Norte del Pacífico) & MIHR & GIAOM & INCM3 & MIHR & INCM3 & GIAOM \\
\hline NO (Nor-Oriente) & INCM3 & BCM2.0 & GIAOM & MIHR & BCM2.0 & GIAOM \\
\hline C (Centro) & INCM3 & MIHR & GFCM2.0 & MIHR & GIAOM & BCM2.0 \\
\hline SP (Sur del Pacífico) & GFCM2.0 & CSMK3.0 & CSMK3.5 & INCM3 & GFCM2.0 & CSMK3.5 \\
\hline \multirow[t]{2}{*}{ AL (Altiplano) } & GFCM2.1 & INCM3 & NCCCSM & GIAOM & MIHR & BCM2.0 \\
\hline & \multicolumn{3}{|c|}{ Temperatura máxima } & \multicolumn{3}{|c|}{ Temperatura mínima } \\
\hline Región/ranking & $10^{\circ}$ & $20^{\circ}$ & $3 .^{\circ}$ & $10^{\circ}$ & $2.0^{\circ}$ & $3 .^{\circ}$ \\
\hline NP (Norte del Pacífico) & INCM3 & MIHR & GIAOM & MIHR & INCM3 & CSMK3.5 \\
\hline NO (Nor-Oriente) & BCM2.0 & MIHR & GIAOM & MIHR & GIAOM & BCM2.0 \\
\hline C (Centro) & MIHR & GIAOM & CSMK3.0 & MIHR & GIAOM & CSMK3.0 \\
\hline SP (Sur del Pacífico) & INCM3 & CSMK3.0 & CSMK3.5 & CSMK3.0 & CSMK3.5 & INCM3 \\
\hline AL (Altiplano) & GIAOM & MIHR & BCM2.0 & MIMR & CSMK3.0 & BCM2.0 \\
\hline
\end{tabular}

Fuente: Elaboración propia.

La diversidad de modelos que explican el clima en el territorio peruano ejemplifica la dificultad de utilizar un único modelo climático global. Los modelos regionales buscan enfrentar este problema incorporando información y dinámicas de menor escala. Dada la compleja topografía del país, el desarrollo de modelos locales para el contexto nacional es una necesidad, tal como sugiere el trabajo de Vera et al. (2006)². Sin embargo, se requiere considerable tiempo y recursos para su implementación y ejecución, por lo que en el marco del presente estudio se sugiere seleccionar un método alternativo para generar las proyecciones climáticas futuras.

Luego del análisis de los resultados obtenidos con los GCM, se seleccionó el método Delta (Delta Change en inglés) para construir las proyecciones de temperaturas y precipitación. Este método se basa en la constatación de que los GCM representan mejor los cambios en los parámetros del clima que los datos absolutos (Arnell, 1998; Gellens y Roulin, 1998; Middelkoop et al., 2001; entre otros). Por tanto, las variables analizadas corresponden al aumento o la disminución de la temperatura (en grados Celsius) y al cambio porcentual en la precipitación. El cambio relativo o absoluto generado por el modelo climático global se aplica luego a un mapa de mayor resolución espacial construido con información de la situación presente.

Para construir ese escenario presente del clima (promedio de variables climáticas de los años 1970-1999) se emplearon datos de las mismas estaciones meteorológicas usadas para validar los modelos climáticos globales (véase el cuadro I.4). La información de temperatura fue interpolada empleando la altitud como variable explicativa,

2 Se destacan dos aproximaciones para el desarrollo de estos modelos regionales. En primer lugar están los modelos dinámicos que buscan representar los cambios en las condiciones del clima validando los supuestos físicos del funcionamiento de la atmósfera con datos de estaciones reales. En segundo lugar se encuentran los modelos estadísticos, que correlacionan el clima simulado con el clima observado sin hacer explícitos los procesos físicos de la atmósfera. 
dado que existe una estrecha relación entre temperatura y altitud. Para la información de precipitación se incorporaron como variable explicativa los datos del satélite TRMM, que produce información de probabilidades de ocurrencia de lluvia a una escala de $5 \mathrm{~km}$. De esta forma, para el estudio se construyó un mapa completo del territorio nacional a una resolución que permite rescatar la heterogeneidad causada por los Andes 3 .

Con base en los tres escenarios de cambio climático analizados (A1B, B1 y A2), y en cada uno de los modelos climáticos globales trabajados, se construyeron mapas cada cinco años a 1 km de resolución de las variables Iluvia y temperatura media, máxima y mínima. Para precisar aún más el análisis, la información se agrupó en nueve subregiones a partir del mapa de regiones hidroclimáticas del SENAMHI (véase el mapa I.3).

La información climatológica futura se proyectó en intervalos de 5 años y en base a una media móvil de \pm 15 años en torno al punto medio. Lo anterior buscó representar condiciones promedio, ya que los modelos globales no representan condiciones específicas para un año en particular.

En función del escenario escogido y del horizonte temporal utilizado, las proyecciones de temperatura y precipitación varían. En el caso de la precipitación, los valores anuales en promedio presentarían aumentos para todo el territorio nacional. Para el escenario B1 se esperarían incrementos de 5\%,6\% y 8\% para los períodos 2010-2039, 2040-2069 y 2070-2099, respectivamente. Para el escenario A1B, el incremento sería de 2\%, 3\% y 6\% para los mismos períodos, y de 3\%, 4\% y $7 \%$ para el escenario A2.

A modo de ejemplo, el gráfico I.1 presenta para el escenario A1B los valores mensuales en promedio para las lluvias para el escenario A1B. Se aprecia que se presentarían descensos en los meses de setiembre, octubre y noviembre (primavera) y aumentos en las demás estaciones del año, siendo la sierra norte donde se observarían los mayores aumentos (hasta en un 98\% en junio para el período 2070 a 2099). En el altiplano se presentarían los mayores descensos (hasta una disminución de 32\% en el mes de agosto para el período 2070 a 2099).

MAPA I.3

\section{Subregiones seleccionadas para analizar la tendencia temporal del clima en el Perú}
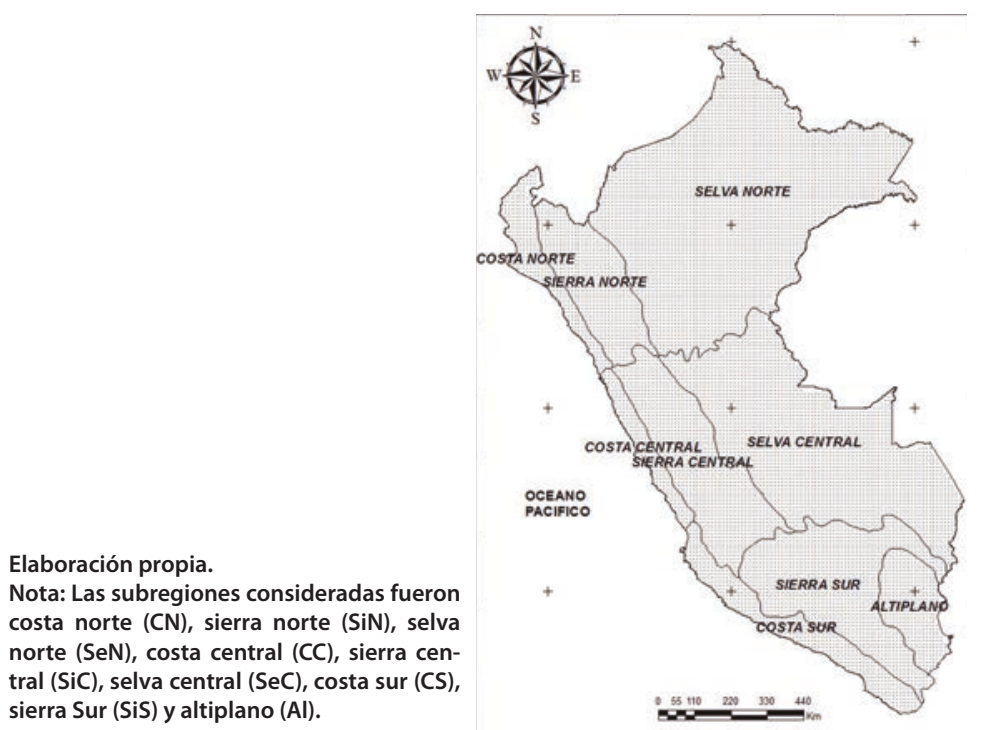

3 Un supuesto clave para este método es que las variables explicativas se mantendrán relativamente estables en el tiempo, lo cual tiene sentido para la altitud, y por tanto, para la temperatura. Para la precipitación se asume que los principales sistemas de circulación del aire en el ámbito global y la forma en la que afectan al Perú, se mantendrán relativamente constantes.

4 Los intervalos quinquenales implican valores, por ejemplo, para 2010, 2015, 2020. Cuando se habla de media móvil de +/-15 años, significa que se emplearon valores de 15 años antes y después. Por ejemplo, para estimar el clima de 2010 se promediaron los valores de precipitación, temperatura mínima media y máxima entre los años 1995 y 2025. 
GRÁFICO I.1

Cambios en la precipitación mensual por región bajo el escenario A1B, 2010-2100

(En porcentaje)

a) Cambio de la lluvia - CN-A1B

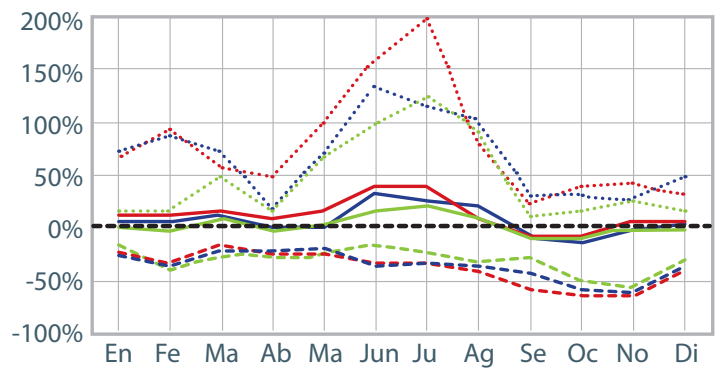

c) Cambio de la lluvia - SeN-A1B

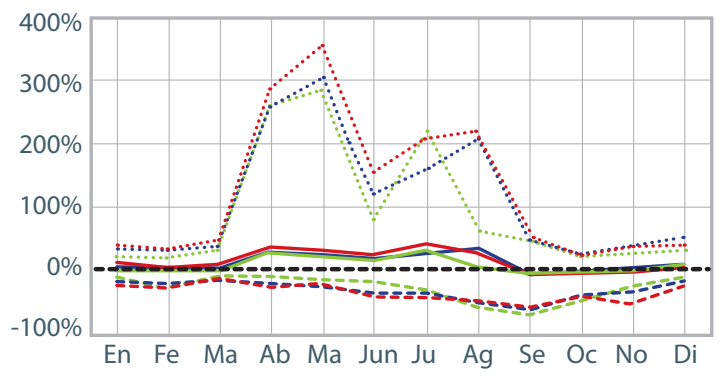

e) Cambio de la lluvia - SiC-A1B

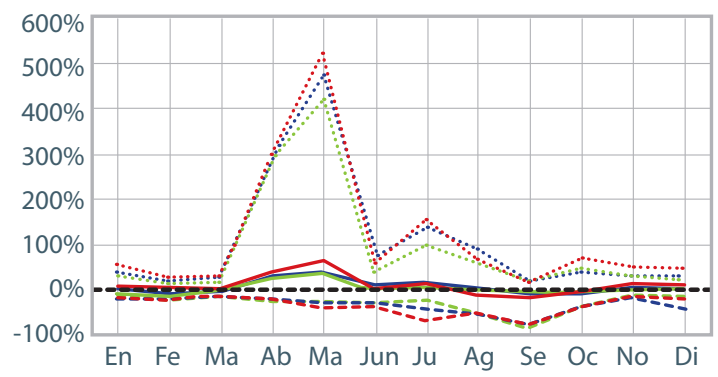

g) Cambio de la lluvia - CS-A1B

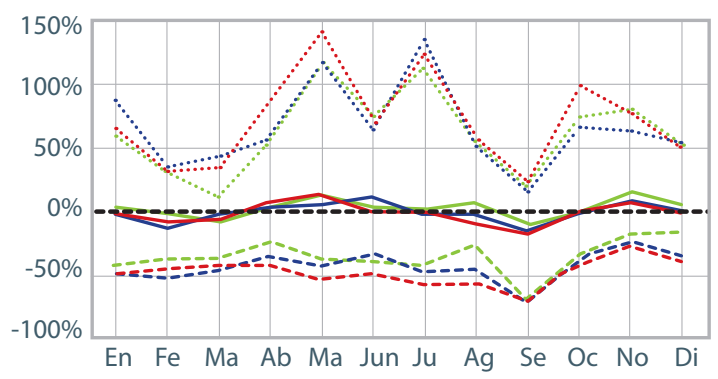

b) Cambio de la Lluvia - SiN-A1B

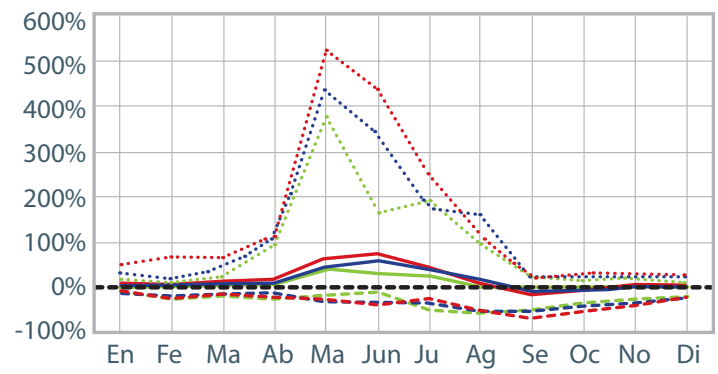

d) Cambio de la lluvia - CC-A1B

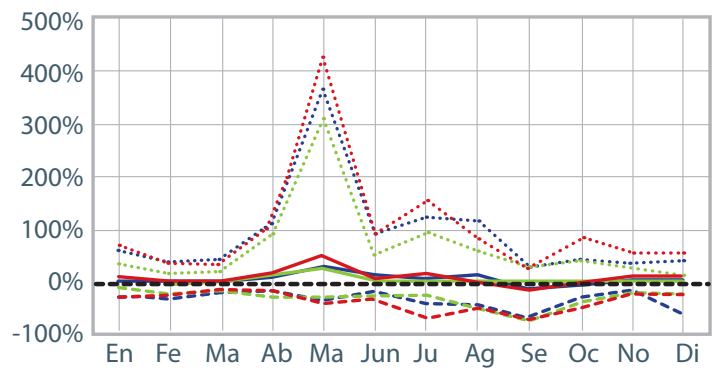

f) Cambio de la lluvia - SeC-A1B

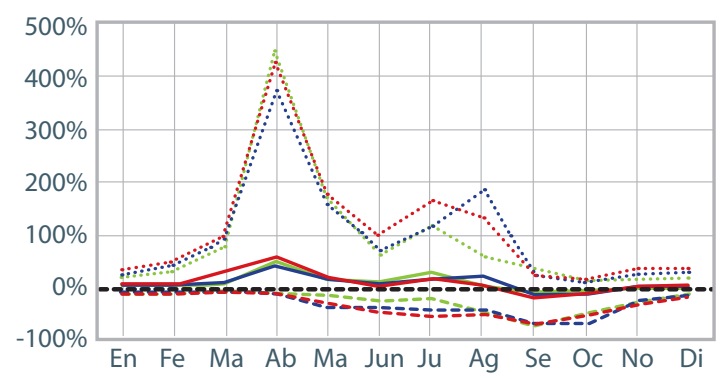

h) Cambio de la lluvia - SiS-A1B

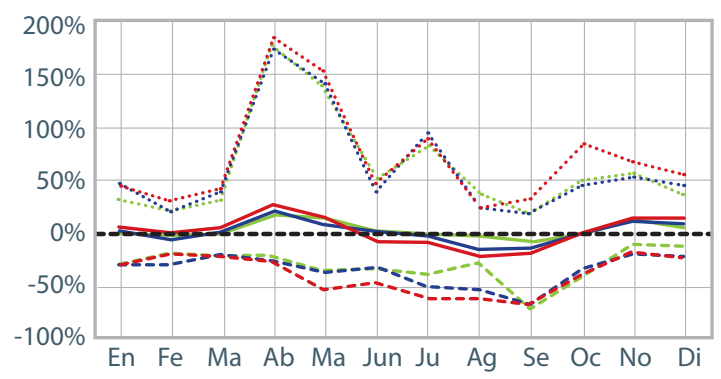


i) Cambio de la Lluvia - Al-A1B

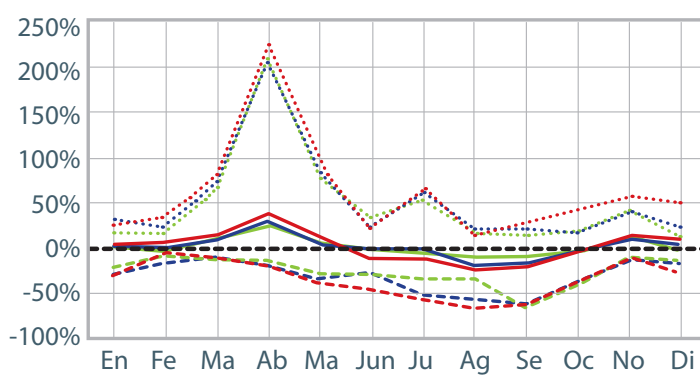

\section{Fuente: Elaboración propia.}

Notas: a) Las líneas punteadas representan los valores máximos, las líneas continuas simbolizan los valores promedios, y las líneas con punto y raya señalan los valores mínimos; b) Las subregiones corresponden a costa norte (CN), sierra norte ( $\mathrm{SiN})$, selva norte (SeN), costa central (CC), sierra central (SiC), selva central (SeC), costa sur (CS), sierra sur (SiS) y altiplano (Al).

Por otro lado, las temperaturas anuales tienen una tendencia más homogénea en todas las regiones y solo varían en función del tipo de escenarios. De acuerdo con lo modelado, se observarían aumentos de $1{ }^{\circ} \mathrm{C}, 2^{\circ} \mathrm{C}$ y $3{ }^{\circ} \mathrm{C}$ para el $\mathrm{A} 1 \mathrm{~B} ; 0,8{ }^{\circ} \mathrm{C}, 1,5^{\circ} \mathrm{C}$ y $2,2{ }^{\circ} \mathrm{C}$ para el $\mathrm{B} 1$; y $1{ }^{\circ} \mathrm{C}, 2{ }^{\circ} \mathrm{C}$ y $3,2{ }^{\circ} \mathrm{C}$ para el $\mathrm{A} 2$, considerando los períodos 2010-2039, 2040-2069 y 2070-2099, respectivamente. Las variaciones de temperatura promedio mensuales se encontrarían en el mismo orden de magnitud, en función del escenario considerado. Los mayores aumentos se observarían en zonas andinas amazónicas del centro del sur (sierra central, selva central, sierra sur y altiplano) durante los meses de mayo a diciembre, en promedio, considerando tanto la temperatura media como la mínima y la máxima. A modo de ejemplo, en el gráfico 1.2 se presentan las variaciones de temperatura promedio mensual para el escenario A1B.

\section{GRÁFICO I.2}

\section{Cambios en la temperatura media mensual por región bajo el escenario A1B, 2010-2100}

\section{(En grados centígrados)}

a) Cambio de la Tmed $\left({ }^{\circ} \mathrm{C}\right)-\mathrm{CN}-\mathrm{A} 1 \mathrm{~B}$

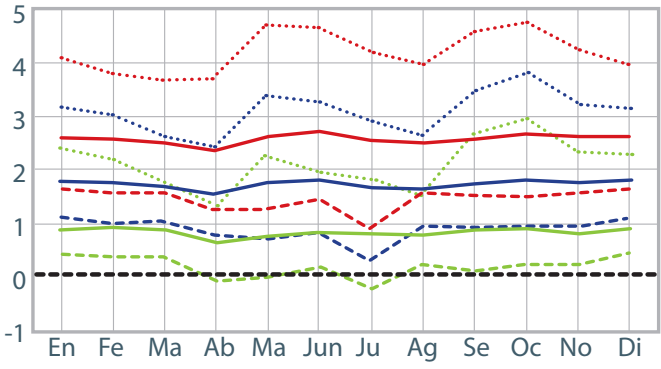

c) Cambio de la Tmed $\left({ }^{\circ} \mathrm{C}\right)-\mathrm{SeN}-\mathrm{A} 1 \mathrm{~B}$

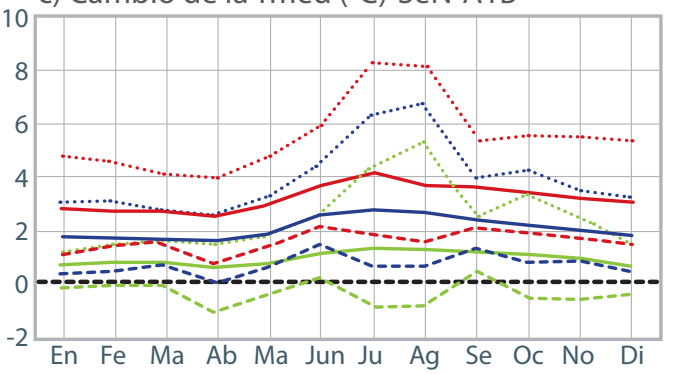

Gráfico continúa en la siguiente página. b) Cambio de la Tmed ( $\left.{ }^{\circ} \mathrm{C}\right)-\mathrm{SiN}-\mathrm{A} 1 \mathrm{~B}$

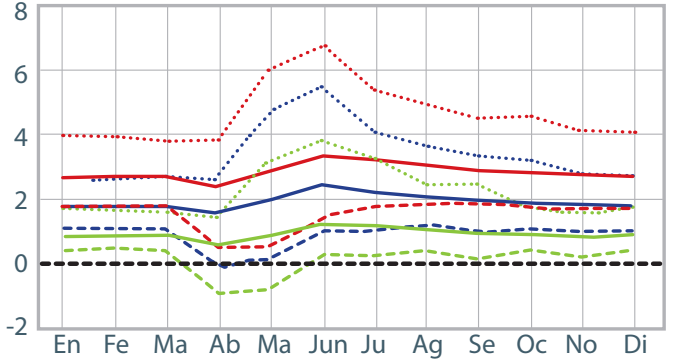

d) Cambio de la Tmed ( $\left.{ }^{\circ} \mathrm{C}\right)-\mathrm{CC}-\mathrm{A} 1 \mathrm{~B}$

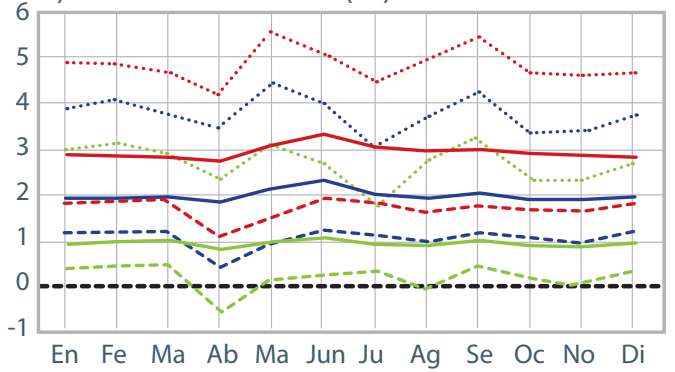


e) Cambio de la Tmed $\left({ }^{\circ} \mathrm{C}\right)-\mathrm{SiC}-\mathrm{A} 1 \mathrm{~B}$

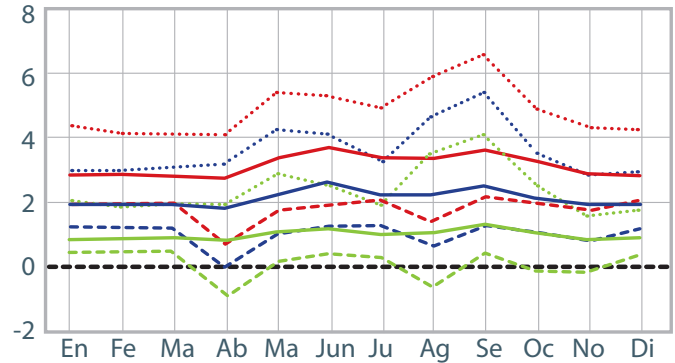

g) Cambio de la Tmed $\left({ }^{\circ} \mathrm{C}\right)-\mathrm{SiN}-\mathrm{A} 1 \mathrm{~B}$

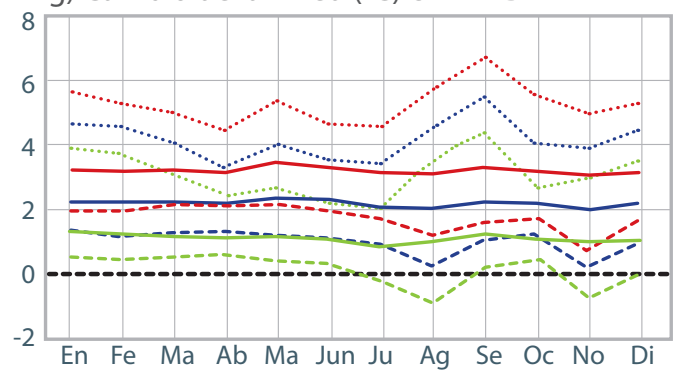

f) Cambio de la Tmed $\left({ }^{\circ} \mathrm{C}\right)-\mathrm{SiN}-\mathrm{A} 1 \mathrm{~B}$

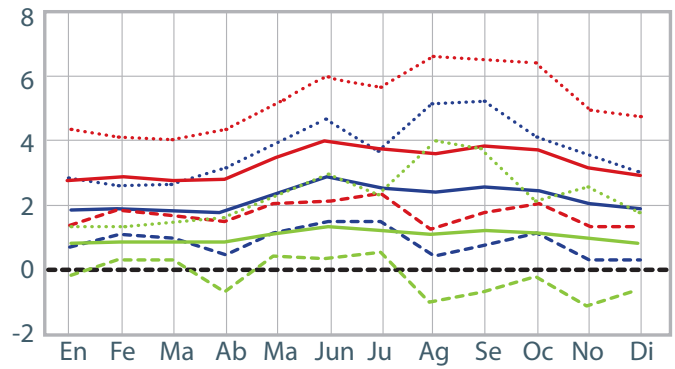

h) Cambio de la Tmed $\left({ }^{\circ} \mathrm{C}\right)-\mathrm{SiS}-\mathrm{A} 1 \mathrm{~B}$

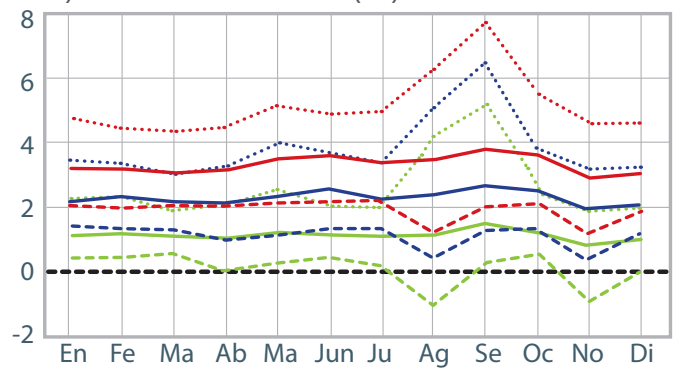

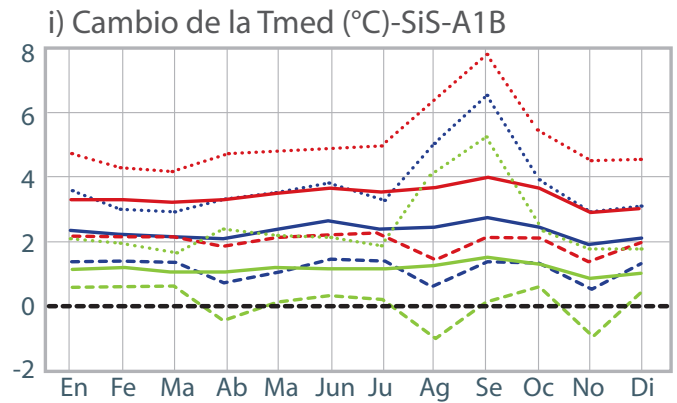

2030

2050

2070

Fuente: Elaboración propia.

Notas: a) Las líneas punteadas representan los valores máximos, las líneas continuas simbolizan los valores promedios, y las líneas con punto y raya señalan los valores mínimos; b)Las subregiones corresponden a costa norte (CN), sierra norte (SiN), selva norte (SeN), costa central (CC), sierra central (SiC), selva central (SeC), costa sur (CS), sierra sur (SiS) y altiplano (AI).

Las proyecciones presentadas están sujetas a diversas fuentes de incertidumbre. No obstante, el uso de múltiples modelos en este estudio constituye la mejor herramienta integrada para realizar las proyecciones del clima futuro a escala nacional, permitiendo contar con un rango de escenarios por zonas específicas para describir las probables proyecciones. Deben tomarse en cuenta siempre las incertidumbres inherentes al modelo de proyección, especialmente en la variable de precipitación. 


\section{Capítulo II}

\section{Escenarios macroeconómicos y demográficos}

A partir de la información disponible, el presente capítulo muestra cómo se desarrolló el modelo macroeconómico para la proyección de la senda base de la economía peruana por medio de la metodología de función de producción. En particular, se detallan la evolución histórica y la distribución geográfica del PBI en el Perú y se analizan los principales sectores productivos y su desarrollo. Finalmente, se presentan los resultados proyectados hacia fines de siglo que permitirán realizar las comparaciones entre la senda base económica, proyectada sin cambio climático y una modificada para los distintos escenarios de cambio climático analizados.

\section{A. Evolución histórica de la economía del Perú}

El crecimiento económico histórico del Perú ha sido positivo, aunque ha sufrido fluctuaciones importantes. Es cierto que, si bien se pueden observar varias contracciones significativas, el crecimiento económico ha sido sostenido, especialmente en el periodo comprendido entre 1970 y 1990 (Seminario et al., 2002). Además, a partir del nuevo siglo se observa una sustancial expansión del PBI. Actualmente, la economía peruana está caracterizada por una serie de reformas estructurales y de estabilización económica llevadas a cabo desde el año 1990 (Gonzales, 2006), con una estrategia de desarrollo basada en el modelo primario exportador y con una canasta diversificada compuesta principalmente por recursos naturales. A partir del año 2005 el grado de apertura comercial e integración económica del país se fue incrementando, tornándose más atractivo tanto para el comercio internacional como para las inversiones extranjeras, lo que ha contribuido a un aumento de la tasa de crecimiento del PBI.

Una comparación histórica, utilizando los datos de Maddison (véase gráfico II.1)5, permite apreciar cómo se ha producido esta variación del PBI desde el año 1901 hasta el 2008. El gráfico, muestra los períodos de crisis a lo largo de su historia. En particular se aprecian las tres situaciones más críticas, que fueron entre 1929-1932; 1982-1983 y 1987-1991.

5 Maddison (2011) señala que la fuente de sus datos para el Perú es el trabajo de Seminario y Beltrán (1998), titulado Crecimiento económico en el Perú, 1896-1995. 
GRÁFICO II.1

Variación interanual del PBI real, 1901-2008

(En porcentaje y dólares Geary-Khamis)

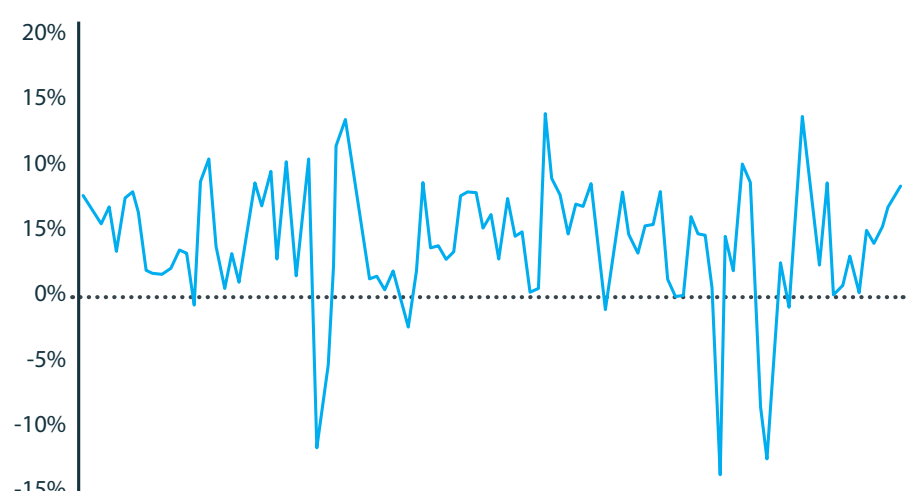

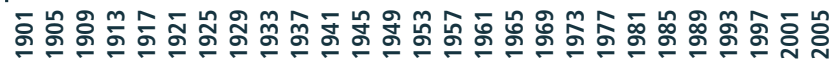

Fuente: Maddison (2011).

Nota: Los dólares Geary-Khamis corresponden a dólares ajustados por poder de pa-

ridad adquisitivo (PPA).

\section{Análisis de la evolución sectorial}

En términos de sus actividades productivas, la evolución de la economía peruana, desde el año 1950 hasta 2010, muestra que el principal sector de la economía peruana es "Otros servicios", que representa casi la mitad del PBI, seguido por "Manufactura"y "Comercio". Estos dos últimos suman el 34\% del PBI, aproximadamente (véase el gráfico II.2). El desarrollo productivo del Perú se ha enfocado en la exportación de materias primas, pasando de ser una economía con escasa transformación a ser economía que genera un mayor valor agregado y que establece mayores relaciones entre los sectores primarios y la economía nacional. Por lo tanto, es necesario tomar en cuenta la alta dependencia existente entre los sectores primarios y el resto de la economía al momento de analizar los impactos del cambio climático.

GRÁFICO II.2

Estructura productiva de la economía del Perú

(En porcentaje del PBI)

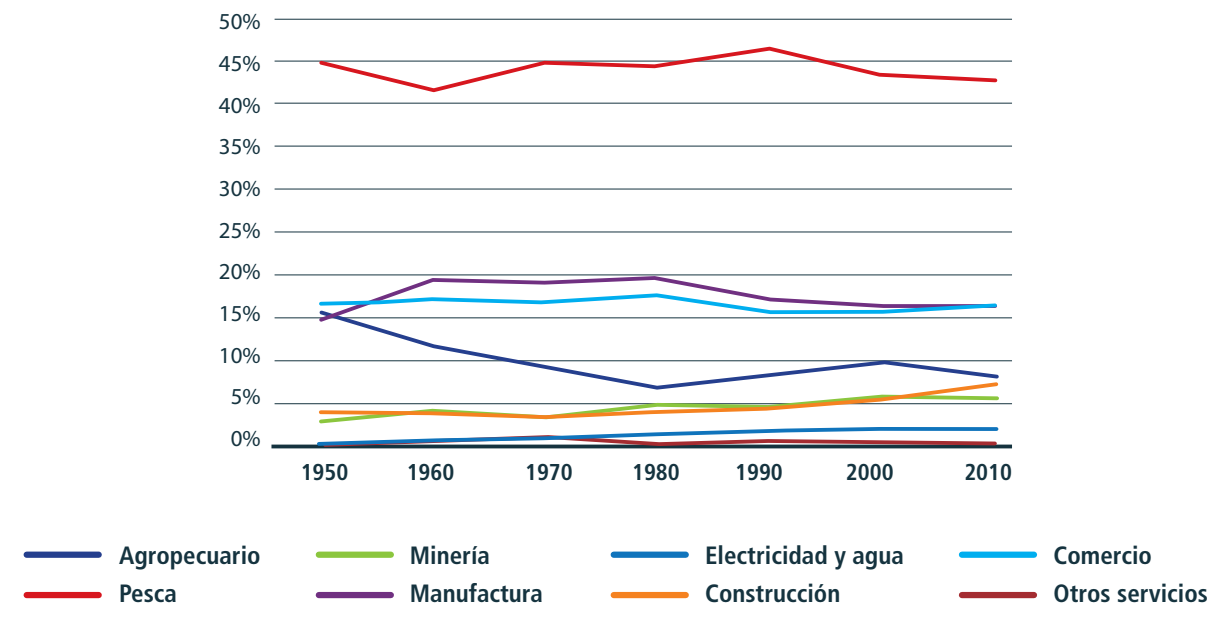

Fuente: Banco Central de Reserva del Perú (2011). 


\section{La producción departamental}

El Perú es un país diverso, con una geografía que impone condiciones de producción diferenciadas y con niveles de concentración de ingresos y centralismo bastante altos. Lima es su departamento más ilustrativo, ya que concentra cerca del 50\% del PBI nacional. El siguiente departamento en tamaño de PBI es Arequipa, representando casi una décima parte que Lima, a pesar de su incremento en los últimos años (véase el gráfico II.3). No obstante, la dependencia más fuerte de la provisión de los recursos naturales y servicios ecosistémicos se da en las poblaciones con menores ingresos, como los pequeños productores rurales, campesinos y comunidades nativas.

GRÁFICO II.3

PBI por departamento, 2001-2009

(En porcentaje)

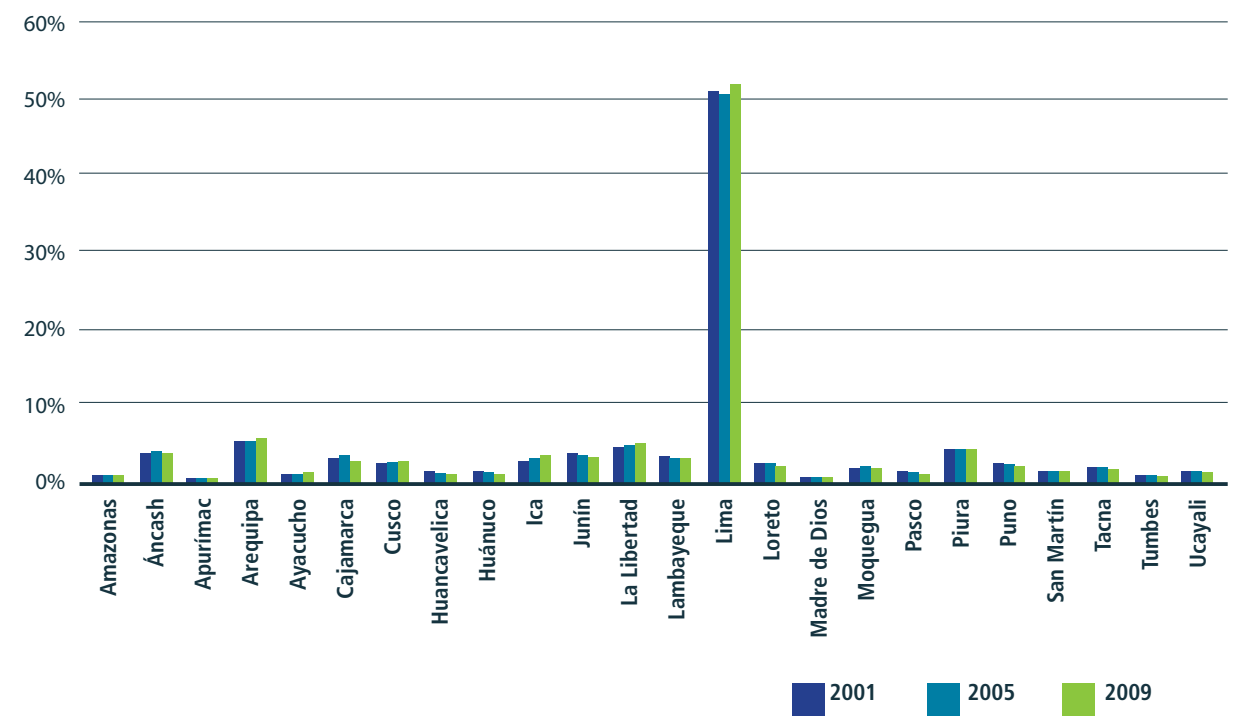

Fuente: Instituto Nacional de Estadística e Informática (2011).

La evolución económica por departamento depende del dinamismo de sus actividades productivas. Mientras que las regiones mineras muestran una reducción en sus tasas de crecimiento, las dedicadas al sector agrícola tienen una tendencia al incremento. Resulta importante notar que en el último quinquenio el crecimiento de las regiones con más aporte al PBI ha sido mayor al promedio.

\section{Demografía}

La población peruana alcanzó 30 millones 475 mil personas el 30 de junio de 2013. Se proyecta que para el año 2021 alcanzará 33 millones 149 mil habitantes, con un crecimiento promedio anual de 325 mil habitantes. En el año 2050 la población ascenderá a 40 millones 111 mil habitantes (INEI, 2014). Para final de siglo se espera que este crecimiento disminuya ligeramente, según las estimaciones del Centro Latinoamericano de Desarrollo (CELADE), (véase el gráfico II.4). 
GRÁFICO II.4

Población estimada del Perú, 2010-2100

(En miles de personas)

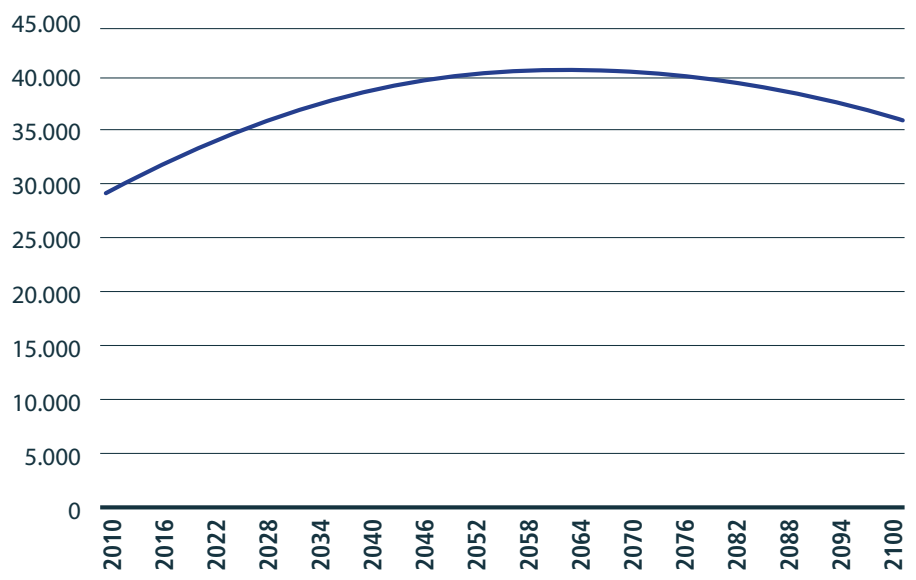

Fuente: Instituto Nacional de Estadística e Informática (2011).

La densidad de población nacional es de $24 \mathrm{hab} / \mathrm{km}^{2}$, y es mucho mayor en la Provincia Constitucional del Callao (6 mil 687 hab/km²) y en los departamentos ubicados en la costa del país. La provincias con mayor población son Lima (8 millones 617 mil 314 habitantes) y Callao (982 mil 800 habitantes); mientras que las ciudades con mayor crecimiento poblacional entre los años 2012 y 2013 han sido Cajamarca (con 3,45\%) y Moyobamba (con 3,27\%), (INEI, 2014).

La población económicamente activa (PEA) ha mostrado un incremento en los últimos años. El crecimiento económico sostenido ha sido responsable en gran medida de la creación de puestos de empleo, debido al aumento de la productividad laboral y al incremento de la inversión (IPEA, 2014). Según las mediciones del INEI, los trabajadores con empleo adecuado ${ }^{6}$ han pasado de ser solo el 22\% de la PEA en 2004 a ser el 48\% el año 2012.

\section{B. Construcción de escenarios macroeconómicos}

La estimación de los costos económicos asociados al impacto del cambio climático requiere del análisis de las variaciones de los PBI sectoriales, en ausencia y presencia del cambio climático.

Por tanto, es necesario, en primer lugar, determinar la senda que seguirá el país por el resto del siglo, sobre la base de la dinámica que la economía peruana ha presentado hasta el momento. Hacer pronósticos sobre este tipo de comportamiento es un ejercicio bastante complejo, que implica establecer la evolución de las variables que serán consideradas. Uno de los elementos que limita seriamente este tipo de esfuerzo está relacionado con la cantidad de datos necesarios para poder realizar pronósticos sólidos.

6 Se consideran como trabajadores adecuadamente empleados, aquellos que voluntariamente trabajan un número de horas menor a la duración de una jornada laboral normal y no desean trabajar más. En esta situación, también se encuentran los trabajadores que laboran igual o mayor número de horas consideradas en una jornada normal y obtienen ingreso igual o mayor al considerado como adecuado (INEI, 2000). 
Para realizar la proyección del PBI sin cambio climático al 2100 tanto en el contexto nacional como en el sectorial, se utilizaron distintos métodos estadísticos (Filtro de Hodrick y Prescott, Filtro de Baxter y King, Filtro de Christiano y Fitzgerald, Filtro de Kalman) y estructurales (función de producción) sobre la serie temporal 19502015 del PBI nacional?.

La ventaja de los métodos estadísticos radica en su simplicidad y en menor información requerida para su estimación (Seminario et al., 2008). Sin embargo, estos métodos no toman en cuenta la estructura económica del país y no distinguen la importancia relativa de los shocks de demanda y oferta. Asimismo, no es posible obtener una relación entre las medidas de política económica y el crecimiento de mediano plazo según el componente tendencial.

Por otro lado, los métodos estructurales tienen la ventaja de que permiten distinguir los shocks producidos por los ciclos económicos. Sin embargo, requieren de gran cantidad de información, mucha de la cual resulta sumamente difícil de encontrar.

Luego de la evaluación de los diversos métodos, para este estudio se consideró la aplicación del método de función de producción, pues permite identificar los impactos generados por variaciones de capital y de mano de obra sobre la economía a lo largo del período de análisis.

\section{Variables de la función de producción}

En el caso de la función de producción, es necesario estimar cuáles serían las evoluciones futuras de capital y mano de obra desde el presente hasta el año 2100. La proyección del PBI se desarrolló en millones de soles, a precios constantes del año 2010. Para ello se consideraron los siguientes supuestos:

- Para la mano de obra, se utilizó la tasa de crecimiento de la población correspondiente al grupo etario de entre 14 y 65 años como variable aproximativa de la variación de la PEA en base a los datos del CELADE (2012).

- Para el capital, se determinó una senda futura del PBI per cápita a partir del análisis de la evolución de las tasas de utilización de capital de países con mayores niveles de desarrollo que el Perú, cuyas sendas de crecimiento histórico han seguido patrones similares a los del país. Los países considerados en este análisis de convergencia fueron Austria, Noruega, Israel, Francia, Hong Kong y Suecia, los cuales formaron el patrón de comportamiento proyectado. Como estimador de la evolución del capital, se utilizó la variación de la inversión bruta. Los primeros 5 años (2011 a 2015) se desarrollaron a partir de las tasas estimadas por el Ministerio de Economía y Finanzas del Perú (MEF, 2013), y para el período 2016-2100 se incorporó la senda de crecimiento previamente calculada.

\section{Proyección de crecimiento del PBI}

A partir de los supuestos anteriores y de la estimación de función de producción se obtuvo la proyección del PBI y del PBI per cápita para finales de siglo (véase el cuadro II.1). Para el año 2100 el PBI podría alcanzar 3.323 miles de millones de soles, lo que, en términos per cápita, sería de 71.882 soles del año 2010.

A partir de la proyección del producto se estimaron los PBI sectoriales con la información oficial disponible del Banco Central de Reserva del Perú para el período 1950-2010. Para esto se consideró la participación porcentual promedio de los siguientes sectores: agropecuario, de manufactura, de pesca, de electricidad y agua, minero y de hidrocarburos, de construcción, de comercio, de servicios e impuestos, y de derechos de importación. Con esta información y a partir del uso de un modelo econométrico (modelo ARIMA, Autorregresive Integrated Moving Average) se proyectó la participación sectorial. Este modelo fue probado con diversas metodologías estadísticas con el fin de asegurar su robustez.

7 La serie de datos original considera el período 1950-2011. Para los años 2012-2015 se incorporaron las estimaciones realizadas por el MEF publicadas en el Marco Macroeconómico Multianual 2013-2015 (MEF, 2013). 
CUADRO II.1

Proyección del PBI y PBI per cápita del Perú al 2100

\begin{tabular}{|lcc|}
\hline Año & PBI (en millones de soles de 2010) & PBI per cápita (soles de 2010) \\
\hline 2010 & 444.873 & 12.164 \\
\hline 2020 & 711.736 & 17.753 \\
\hline 2030 & 1.047 .724 & 23.895 \\
\hline 2040 & 1.437 .547 & 30.197 \\
\hline 2050 & 1.850 .073 & 37.865 \\
\hline 2060 & 2.273 .311 & 45.366 \\
\hline 2070 & 2.659 .375 & 53.069 \\
\hline 2080 & 2.976 .549 & 61.277 \\
\hline 2090 & 3.202 .325 & 67.659 \\
\hline 2100 & 3.322 .924 & 71.882 \\
\hline
\end{tabular}

Fuente: Elaboración propia.

En los gráficos II.5 y II.6 se aprecia la evolución sectorial del PBI a 2100 tanto en millones de soles como en la participación porcentual del PBI nacional. Se puede observar que la economía pasará por un proceso de tercerización hacia fines de siglo, por lo que los sectores de servicios y comercio aumentarían su participación porcentual en desmedro de sectores primarios como agricultura y minería. Hay que notar que, si bien estos sectores disminuyen su participación relativa, su evolución es favorable para el período analizado.

Estas proyecciones, que no incluyen los efectos del calentamiento global, permitirán realizar las comparaciones entre escenarios económicos con y sin cambio climático para cuantificar los impactos de este fenómeno, objetivo de este trabajo. Estos impactos se miden a través de cambios relativos sobre el escenario proyectado, que es referencial.

GRÁFICO II.5

Proyección del PBI sectorial a 2100

(En millones de soles de 2010)

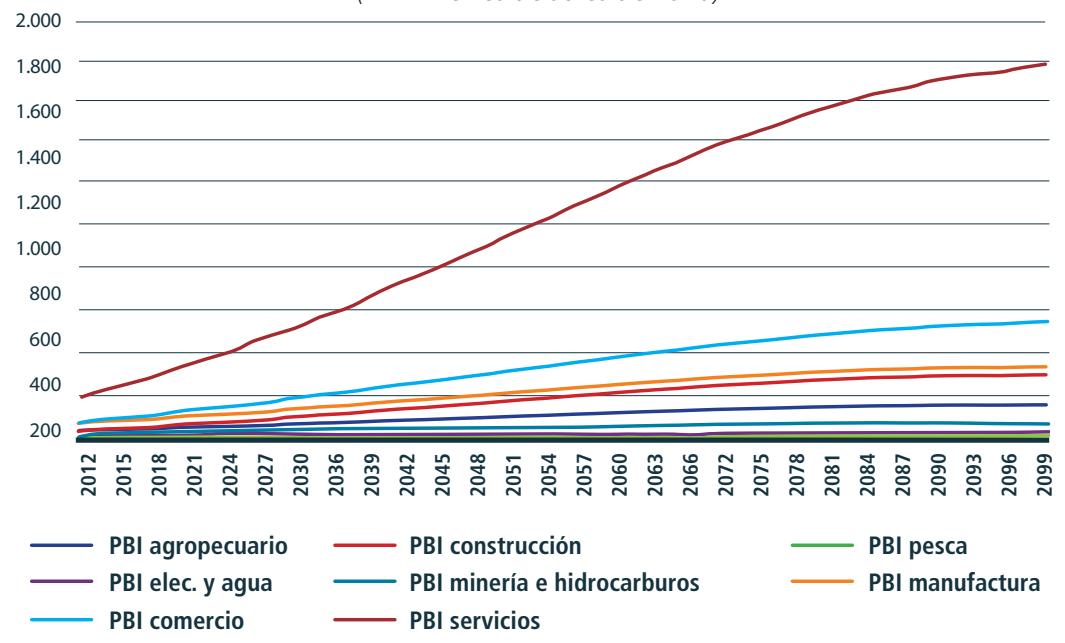

Fuente: Elaboración propia. 
GRÁFICO II.6

Participación sectorial en el PBI al 2100

(En porcentaje)

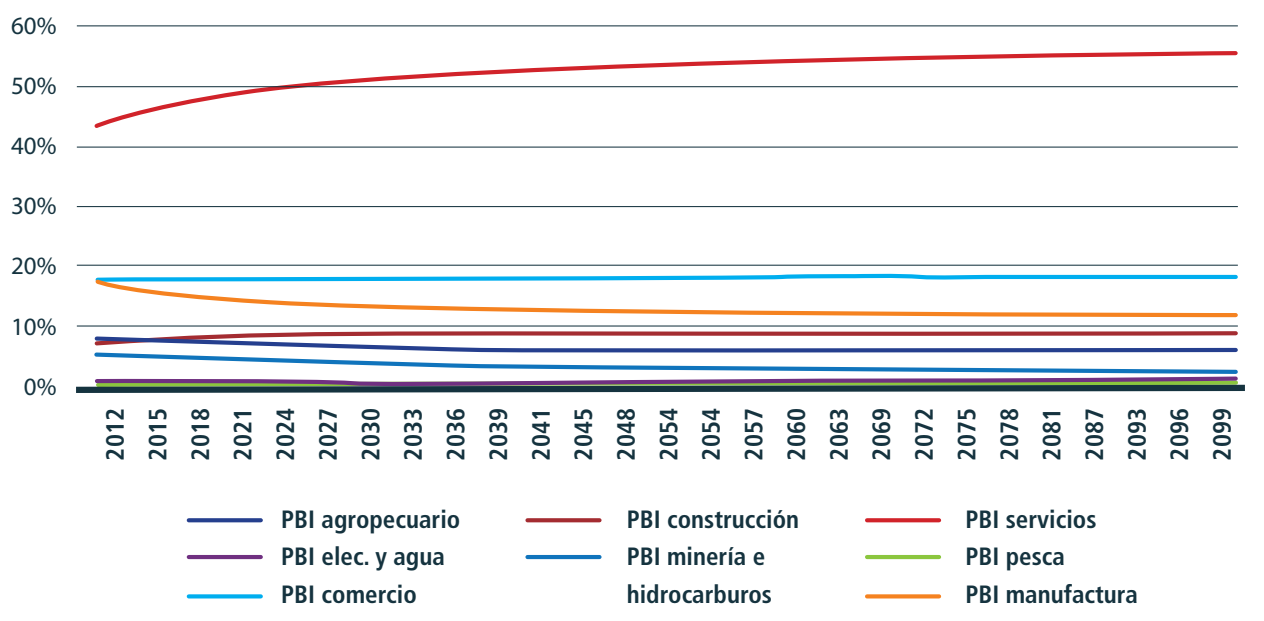

Fuente: Elaboración propia. 



\section{Capitulo III}

\section{Metodología y supuestos}

El impacto del cambio climático es un fenómeno con un alto grado de incertidumbre y que se manifestaría en mayor magnitud en el largo plazo, aunque en la actualidad ya se están presenciando algunos de sus efectos. La metodología empleada en este estudio integra el uso de proyecciones de escenarios climáticos y económicos. Los enfoques de modelación buscan identificar cómo los cambios en las condiciones de la atmósfera y del océano afectan los recursos naturales por medio de modificaciones en la temperatura, precipitación, disponibilidad de agua y propiedades de los ecosistemas. Todo ello repercute en la actividades socioeconómicas.

En este capítulo se sintetiza la metodología del estudio y los supuestos utilizados, explicando la secuencia de pasos que permitieron determinar los posibles impactos económicos del fenómeno en el país. El enfoque general de análisis consideró algunos de los elementos metodológicos de otros estudios similares realizados en América Latina y el Caribe, pero aplicando modificaciones y matices acordes con la dinámica del caso peruano.

El capítulo se divide en cinco secciones. En la primera se describen los aspectos generales metodológicos. En la segunda se resumen los principales pasos para la identificación de los impactos del cambio climático y los supuestos en los sectores seleccionados. En la tercera se describe la integración económica nacional. La cuarta sección sintetiza el proceso para la identificación de las medidas de adaptación sugeridas. Por último, se destacan las principales limitaciones de la metodología utilizada.

\section{A. El modelo conceptual: aspectos generales}

Este estudio tiene como objetivo central analizar cómo el cambio climático afectará la actividad económica en el Perú. Para ello se elaboró un modelo metodológico para el análisis de los impactos, el cual se detalla en el diagrama III.1. Este proceso consistió en evaluar cómo las variables climáticas podrían modificar los recursos naturales, las dinámicas marinas, la disponibilidad de agua y las propiedades de los ecosistemas. A partir de la información climática y física disponible se cuantificaron los cambios en el nivel de actividad de ocho sectores: agricultura, ganadería altoandina, minería, energía hidroeléctrica, turismo, pesca, infraestructura y salud. Estas 
relaciones se establecieron para áreas específicas del territorio nacional, con mayor o menor nivel de generalización en función de los sectores productivos.

Como cada sector responde a un proceso productivo distinto, las delimitaciones espaciales empleadas para evaluar el fenómeno climático se construyeron independientemente. Esto significa que la cuenca que alimenta a una central hidroeléctrica no es necesariamente la misma que sustenta a la zona agrícola aguas abajo de la central, y tampoco tiene que coincidir con la cuenca minera evaluada o con el distrito donde se analiza la incidencia de la malaria.

La suma del valor agregado de los sectores seleccionados representa alrededor de un tercio del PBI total y se asume que los demás sectores no serían afectados ${ }^{8}$. Se puede observar que la secuencia de resultados comienza a partir del análisis climático (precipitación y temperatura) para tres escenarios de emisión de gases de efecto invernadero a partir de GCM, a lo que le sigue el análisis de los impactos físicos en los sectores y su respectiva valoración económica. El análisis concluye con la propuesta de distintas opciones de política pública de adaptación al cambio climático tanto sectorial como transversal.

DIAGRAMA III.1

\section{Esquema metodológico general del estudio de impactos económicos para el Perú}

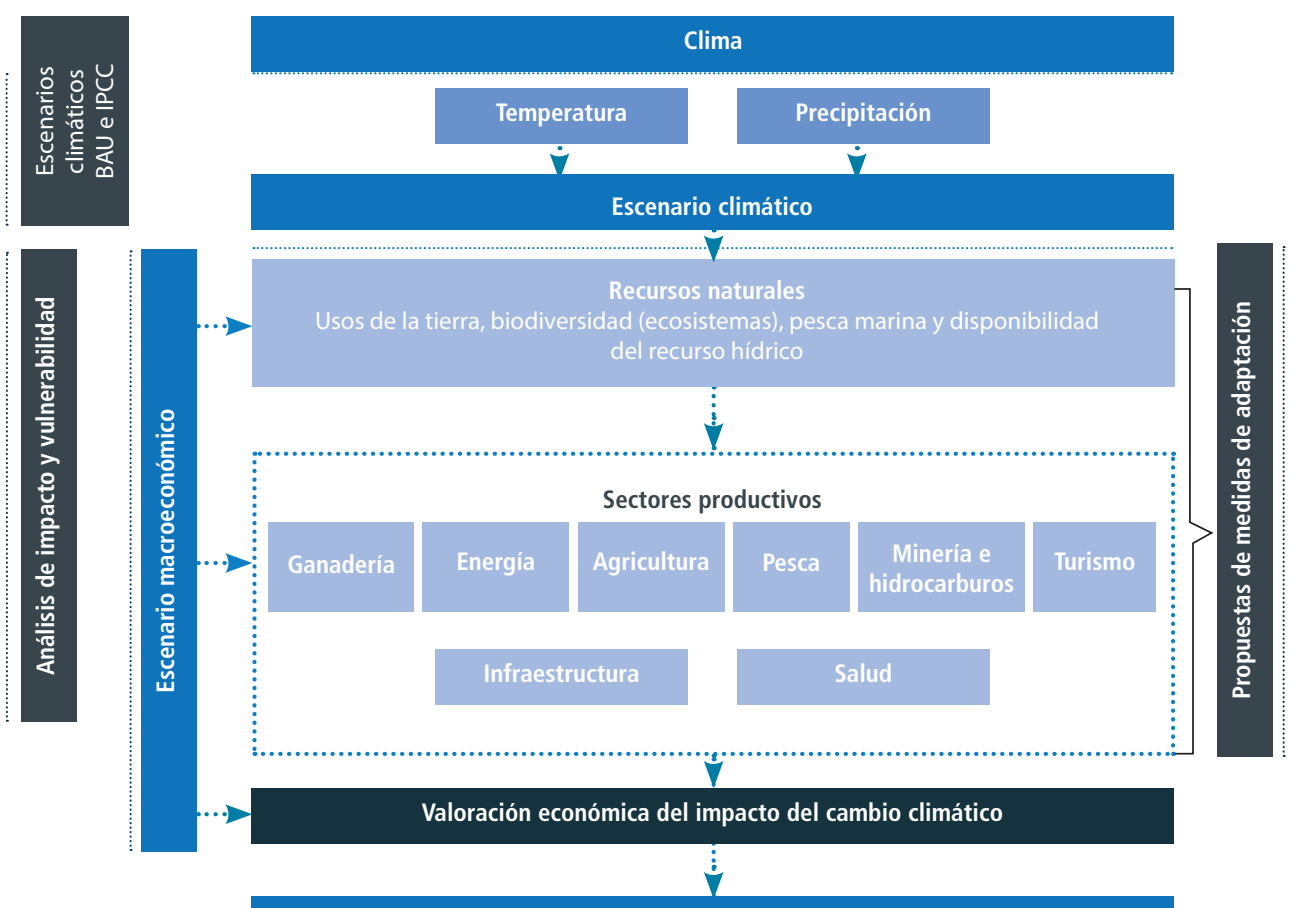

Propuestas de políticas públicas de adaptación

Fuente: Elaboración propia.

8 Este cálculo se realizó a partir de la Matriz de Insumo Producto del Perú para el año 2007 (INEl, 2007). Se consideraron los sectores de cultivos agrícolas, cría de animales, servicios agrícolas y ganaderos, pesca y acuicultura, extracción de minerales metálicos, actividades de apoyo a la extracción de minerales, procesamiento y conservación de carnes, elaboración y preservación de pescado, elaboración de harina y aceite de pescado, electricidad y gas, transporte terrestre, servicios complementarios de transporte, alojamiento, restaurantes y salud. 


\section{Supuestos generales}

\section{a) Supuestos transversales}

Dentro de los supuestos utilizados en el estudio destacan los que han sido empleados transversalmente en la construcción de escenarios macroeconómicos, climáticos y sectoriales, tales como los siguientes:

- Se asume que los precios reales del año base 2010 son constantes en el tiempo. A pesar de que en algunos sectores se emplearon los precios para determinar funciones de demanda, estos precios no fueron proyectados.

- Se emplea el supuesto de economía pequeña, lo que implica que el Perú es un tomador de precios en todo el mundo.

- Los costos del cambio climático se calculan en general como disminuciones en los ingresos sectoriales a causa de una menor productividad. En algunas ocasiones se estiman como costos de reparación y/o de mayor gasto fiscal.

- No existen procesos de adaptación al cambio climático. En los escenarios con cambio climático se considera que las personas y las instituciones no reaccionan a los cambios del clima, y mantienen su comportamiento habitual, por lo que no se espera adaptación autónoma de su parte (como el hecho de que los agricultores busquen una mejor zona para los cultivos o los reemplacen). Esto se debe a que no existe información suficiente para caracterizar los cambios, dado que es un proceso relativamente nuevo y no existe mayor evidencia de comportamientos que permita pronosticarlos hacia el futuro.

- El período analizado corresponde a los años 2010 a 2100. Sin embargo, para la observación del comportamiento del impacto del cambio climático en los sectores se consideraron períodos acumulados de treinta años (2010-2040, 2010-2070 y 2010-2100).

- Se consideraron tres tasas de descuento $(0,5 \%, 2 \%$ y $4 \%$ ) para actualizar los costos futuros del cambio climático y realizar las comparaciones económicas. A medida que la tasa de descuento aumenta, las pérdidas que ocurran más lejos en el tiempo reducen sustancialmente su ponderación en el cálculo del total. Por este motivo, la literatura sugiere una tasa de descuento social baja, decreciente (Weitzman, 1998) e incluso la posibilidad de que adopte valores negativos, especialmente para el contexto del cambio climático, en el que los inminentes efectos perjudiciales ocurrirán también en el largo plazo (Dasgupta, 2008) .

\section{b) Escenarios climáticos}

La aproximación general de los escenarios climáticos futuros para este estudio se basa en los últimos informes del IPCC (IPCC, 2001; IPCC, 2007a; e IPCC, 2014). Cabe recordar que los escenarios de emisión incorporan los niveles de cambio en las concentraciones de emisiones, ya sea moderado (A1B), alto (A2) o bajo (B1), y que a partir de ellos se estimaría la severidad de los impactos del cambio climático. Para tener la data a escala nacional, se incrementó la información de los GCM a través de un proceso de downscaling. El capítulo I resume la información existente sobre el componente climático en el ámbito nacional y detalla el método seguido para su análisis.

Para el caso peruano se emplearon los resultados de los GCM del IPCC para temperaturas mínimas, máximas, medias y de precipitación promedio, con datos hasta el año 2100 y para los escenarios climáticos A1B, A2 y el B1. Para todos los sectores, con excepción del pesquero, se realizaron estimaciones a partir de siete modelos climáticos

9 A comienzo de los estudios ERECC en la región la CEPAL y el BID, junto con los representantes de los países y con los expertos internacionales decidieron utilizar estas tres tasas de descuento. Valorar los impactos usando estas tasas permite comparar los costos económicos intertemporales del cambio climático bajo distintos supuestos de valoración. 
(BCM2.0, CSMK3.0, CSMK3.5, GIAOM, INCM3, MIHR, MIMR) en los escenarios A1B y B1. Bajo el escenario A2 se utilizaron los resultados de cinco modelos (BCM2.0, CSMK3.0, CSMK3.5, INCM3, MIMR). En el sector pesca se emplearon modelos y escenarios que dieran cuenta de los cambios de la biomasa de los recursos marinos, por medio de dos escenarios climáticos: uno de enfriamiento (local) y otro de calentamiento (global) del mar. Para este último se emplearon los escenarios RCP 4.5 y 8.5 del Quinto Reporte del IPCC.

\section{c) Escenario macroeconómico}

Como se describe en el capítulo Il, se construyó una senda base o proyección económica hasta el año 2100. A lo largo del estudio, este escenario se cita como "escenario base" o "sin cambio climático". Este representa una situación en la que el país mantiene su senda de desarrollo, asumiendo que el clima se mantiene durante todo el período con los valores de referencia (1970 a 2000). Es importante comparar los dos escenarios (con y sin cambio climático) para aislar el efecto del cambio climático en la senda de desarrollo.

La sección II.2 detalla los principales supuestos de construcción del escenario base, los cuales se relacionan con la elección de una función de producción para proyectar el PBI nacional. La función depende fundamentalmente de dos variables clave; la mano de obra y el capital. La primera evoluciona de acuerdo con las tasas demográficas proyectadas por el CELADE, mientras que para el capital se asume un criterio de convergencia relacionado con el crecimiento del PBI per cápita de otras economías.

Para descomponer el PBI nacional en los sectores se han empleado datos históricos y modelos econométricos autorregresivos con el fin de simular la evolución de la estructura productiva.

En función de la senda base económica y de la combinación de los escenarios climáticos se calcularon para cada uno de los sectores sendas alternativas que permitieran medir los impactos del cambio climático.

\section{Análisis de los recursos naturales}

Como se observa en el diagrama III.1, tanto los análisis climáticos como los escenarios macroeconómicos permitieron examinar cómo la provisión de recursos naturales y ecosistémicos impactan en las actividades productivas. En particular se estudiaron las dinámicas del cambio del uso del suelo, la biodiversidad, la pesca marina y la disponibilidad del recurso hídrico.

La modificación de los recursos naturales está vinculada con los efectos sobre los ocho sectores económicos analizados. Por ejemplo, minería e hidroenergía dependen del cambio en la disponibilidad hídrica, mientras que ganadería se relaciona con el cambio en el uso y en la extensión del suelo, así como con la variación de la precipitación y/o de temperatura de cada zona geográfica.

\section{a) Enfoque metodológico}

La metodología para representar los recursos naturales terrestres en el Perú se basa en la utilización de un enfoque que integra el uso de la tierra, la distribución de biomas y la disponibilidad hídrica a través de tres submodelos y un algoritmo de síntesis (véase el cuadro III.1).

El modelo de uso de la tierra determina la localización de las áreas afectadas por nuevas parcelas agrícolas debido al incremento en la demanda nacional. El modelo de biodiversidad (ecosistemas) establece el bioma más probable, dadas las condiciones climáticas para una localidad en particular donde no haya actividad humana ${ }^{10}$. El modelo hídrico define la precipitación efectiva mensual. Finalmente, el algoritmo

10 La información climática se interpoló empleando técnicas estadísticas y principios climatológicos generales para valores climáticos promedio. La información sobre las características del suelo no pudo ser incorporada. Ambos aspectos son importantes para entender la distribución de los ecosistemas a mayor resolución o cuando se requiere incorporar información de la variabilidad interanual. 
de síntesis recoge la información climática, de los usos de la tierra, de los biomas y del agua disponible, y la resume para localidades específicas del territorio nacional, para ser utilizada posteriormente por los modelos productivos sectoriales.

El Perú es un país altamente heterogéneo en su topografía y en el clima. Para incorporar estas condiciones en el estudio, se construyó una base de datos de resolución media de aproximadamente 1 kilómetro cuadrado para modelar los recursos naturales terrestres de $0,25^{\circ}$ para los ecosistemas marinos. Los cambios en el uso de la tierra se han representado por medio de mapas. Cada mapa se ha calculado para promedios multianuales ( \pm 15 años) en intervalos de cinco años desde 2005 hasta 2095. La información climática y de balance hídrico es mensual, mientras que la información de biomas y del uso de la tierra se representa anualmente.

Para las cuencas de Urubamba y Lima se desarrollaron modelos de flujo de escorrentía, que estiman los cambios en la ocurrencia de eventos extremos. Dado que el balance hídrico modelado no incorpora todos los detalles necesarios para hacer una estimación del flujo real, se asume que los componentes no explicitados tienen un efecto lineal.

\section{CUADRO III.1}

\section{Metodología de análisis de recursos naturales}

\section{Etapas Supuestos}

\section{Modelo de biomas}

1. Se evalúa la distribución de biomas empleando información bioclimática.

2. En las zonas con presencia de glaciares, mapa base a $1 \mathrm{~km}$, se determina si la temperatura mínima es mayor o menor que $1^{\circ} \mathrm{C}$. Si es menor, se conserva el glaciar; de otra forma, se asigna la clase de bioma más cercana.

3. Se asignan las condiciones de inundación registradas en el mapa base a $1 \mathrm{~km}$ para todas las clases.

\section{Modelo de uso de la tierra}

1. Se determina la demanda de superficie agrícola del año.

2. Se determina el mapa de probabilidad de la agricultura de secano y ganadería amazónica en función de clima, relieve, accesibilidad y presencia 0 ausencia de áreas naturales protegidas, empleando las regresiones logísticas calibradas.

3. Se modifica el mapa de probabilidades para incluir el efecto de la inercia en el uso de la tierra y de las áreas irrigadas.

4. Se identifican los lugares más probables de ser afectados por la agricultura de secano y la ganadería amazónica hasta completar la demanda de superficie agrícola requerida para ese año.

5. Se determina la cobertura de la tierra, sobreponiendo el mapa de uso de la tierra al mapa de biomas.
- Los usos de la tierra pueden migrar libremente por todo el territorio nacional.

- No hay inversiones en carreteras o irrigaciones más allá de las previstas actualmente.

- Las diferencias de accesibilidad entre distintos lugares se mantienen constantes.

- La evolución de la tecnología en el futuro será similar a la observada en los últimos años, por lo que no se afectarán las reglas que definen la distribución de la agricultura.

- La demanda por la superficie agrícola crecerá en forma proporcional al incremento del PBI agropecuario.

- Las condiciones topográficas se mantendrán inalteradas.

- Los cambios de temperatura y precipitación estarán adecuadamente explicados por la información provista por los modelos climáticos.

- La agricultura puede desarrollarse en todo el país, salvo en lugares donde hay déficit muy fuerte de agua, donde serán necesarias inversiones adicionales de riego. 


\section{Modelo de balance hídrico}

\section{Evapotranspiración de referencia para el futuro}

1. Se generaron mapas de evapotranspiración de referencia para el presente (ET_0^presente) en base a los mapas de precipitación y temperatura mínima, media y máxima, usando el método de FA0/Penman Monteith (Allen et al.,1998).

2. Se calculó la evapotranspiración potencial (ETp) para el presente (ET_p^ presente) y el futuro (ET_p^futuro) usando el método de Thornthwaite.

3. Luego se calculó la evapotranspiración de referencia para el futuro (ET_0^futuro) con el método FAO/Penman Monteith a partir de ET_ $0 \wedge$ presente,ET_p $\wedge$ futuro y ET_p^presente.

\section{Balance hídrico}

1. Para cada píxel se calcula la evapotranspiración de referencia a partir de la evapotranspiración de referencia (ET_0) y un coeficiente de vegetación (k_c).

2. Luego se calcula la evapotranspiración actual (ET_a) en base a la evapotranspiración potencial, la temperatura y la precipitación mensual usando la curva de Budyko (Oudin et al., 2008).

3. Finalmente, se define tanto la cantidad de agua disponible como la diferencia entre la precipitación y la evapotranspiración actual.

\section{Sintesis y traspaso de información}

1. Se compilan los mapas producidos al final de los modelos de biomas, uso de la tierra y balance hídrico.

2. Se estiman valores agregados (suma y promedio) para las distintas áreas de interés de cada uno de los sectores productivos.
- No hay ningún tipo de regulación estacional del agua.

- Los aspectos del balance hídrico de la cuenca no incorporados tienen un efecto lineal sobre el balance hídrico general (acuíferos subterráneos, lagos, regulación del agua superficial por la vegetación, entre otros).

Fuente: Elaboración propia.

\section{B. Metodologías específicas para los sectores seleccionados}

El impacto del cambio climático se analizó considerando dos tipos de enfoque. El primero se relaciona con los cambios promedio de las variables climáticas que afectarían las productividades sectoriales y el esfuerzo fiscal (agricultura, ganadería, pesca, minería, hidroenergía y salud). El segundo enfoque se vincula al análisis de variabilidad climática expresado en cambios en eventos extremos la que se reflejaría en mayores costos de reparación y menor afluencia de turistas (infraestructura y turismo). En el cuadro III.2 se resumen los principales supuestos sectoriales, como la estrategia para manejar la complejidad, la incertidumbre y las carencias de información, y la vinculación del cambio climático con los costos. 


\section{CUADRO III.2}

\section{Resumen de supuestos sectoriales}

Sector económico

Agricultura
Definición de productividad sectorial

Rendimiento de los cultivos

\section{Ganadería altoandina Variaciones de las unidades ovinas} equivalentes

\section{Supuestos}

- Se han seleccionado los cultivos papa, arroz, café, caña de azúcar, plátano, maíz amarillo duro y maíz amiláceo porque representan los siete cultivos más importantes en términos del VPB (47\%), PBI agrícola (37\%) y superficie cosechada (como un indicador aproximado de la absorción de empleo) a nivel nacional. No se contaba con información agrícola y climática del resto de cultivos.

- No hay mejoras tecnológicas en la producción.

- No se consideraron aspectos geográficos debido a la falta de información existente al momento del estudio.

- Se consideraron condiciones fenológicas de los cultivos.

- La precipitación no ha tenido un papel determinante porque se analizaron sistemas de irrigación regulados, donde no hay una dependencia directa con la precipitación local.

- La producción agrícola se determinó según la periodicidad mensual/anual según el cultivo.

- Los datos del clima se determinaron según el periodo de floración porque este captura de manera más precisa la relación entre indicadores climáticos y la producción agrícola.

- Para analizar los impactos en rendimientos se utiliza el modelo de función de producción que relaciona la producción de un cultivo con el cambio de la temperatura, precipitación y otras variables.

- El análisis de los rendimientos agrícolas y producción también se encuentra limitado a la disponibilidad de información climática.

- El impacto del cambio climático en agricultura se mide por la disminución de la producción agrícola debido a la variación climática.

- El análisis se ha enfocado en la ganadería extensiva de vacunos, ovinos, camélidos, caprinos y equinos en las zonas altoandinas del Perú que disminuirán su capacidad de carga y producción ganadera debido a la combinación entre los cambios en cobertura vegetal (bofedales, pajonales y arbustales), uso de la tierra y productividad.

- No se analiza la ganadería avícola y vacuna de costa o ganadería de selva.

- No considera desplazamiento de ganadería hacia zonas más altas pero sí el desplazamiento de la agricultura hacia zonas que actualmente son ganaderas.

- La producción de animales de cada unidad espacial (celdas de 1 km²) se midió en unidades ovino (U0), por ser la especie más adaptable en las zonas altas y por conveniencia metodológica.

- El supuesto para calcular las equivalencias entre especies animales es que el consumo de pasto por unidad de peso metabólico define la magnitud y equivalencia de la unidad.

- Las variaciones de productividad se estimaron a partir de alteraciones en el área neta de pastoreo, productividad de la biomasa y capacidad de carga estandarizada a unidades ovino.

- El impacto del cambio climático se mide por la reducción de la producción de animales debido a la variación de temperatura. 
- Se eligieron dos modelos del Quinto Informe del IPCC (RCP 4.5 y RCP 8.5), ya que los modelos elegidos del Cuarto Informe del IPCC no incluían el patrón de enfriamiento en aguas costeras.

- A solicitud del IMARPE se construyó un escenario de enfriamiento costero empleando la tendencia histórica de la temperatura superficial del mar obtenida del satélite de la NOAA entre los años 1982 y 1991, escenario denominado "local".

- En el escenario local se asumió que la concentración de oxígeno y la productividad primaria se mantendrán constantes a lo largo del tiempo.

- Se asume una política adecuada de pesca, donde una proporción constante de la biomasa existente es pescada.

- No se consideraron cambios en tecnología que pudieran incrementar la productividad de la anchoveta 0 el reemplazo de esta especie por otra menos impactada.

- Se calculó la capacidad productiva y generadora de PBI que ocurre en el océano Pacífico dentro de las 200 millas peruanas.

- Para este sector la disponibilidad de oxígeno disuelto tiene un efecto significativo.

- Para modelar la producción de anchoveta se asumió que su biomasa es proporcional a la idoneidad del lugar medida en función de las condiciones de temperatura, oxígeno disuelto y productividad primaria.

- Se asumió que la captura de anchoveta es proporcional a la biomasa disponible de esta especie.

- La proyección de anchoveta se convirtió en producción de harina de pescado. Con base a esta producción se determinó la pérdida de ingresos según los impactos del cambio climático.

$\begin{array}{ll}\text { Minería } & \text { Modificaciones en la disponibilidad de agua } \\ \text { - Se estimó la futura disponibilidad hídrica (DHCC) por cuenca minera para contrastarla con el } \\ \text { futuro consumo hídrico minero (CHM), que a su vez depende de las proyecciones de producción } \\ \text { metálica. } \\ \text { - Se identificaron las zonas con potencial minero y se evaluó cómo la futura disponibilidad } \\ \text { hídrica incidirá en la extracción/producción minera. } \\ \text { - Se asume que conforme a la normativa peruana, la disponibilidad hídrica debe satisfacer en } \\ \text { primer y segundo lugar, el consumo de agua para fines poblacionales y productivos, respectiva- } \\ \text { mente. } \\ \text { - Se asumió que el consumo hídrico poblacional aguas abajo de la cuenca minera sería satisfecho } \\ \text { por otras fuentes de agua. } \\ \text { - La futura disponibilidad hídrica fue estimada para los tres escenarios seleccionados por el } \\ \text { estudio y solo para los dos modelos extremos en cada caso porque estos modelos ofrecen } \\ \text { tendencias y resultados diferentes, y en algunos casos contradictorios. } \\ \text { - Al realizar el análisis de disponibilidad hídrica se encontró que solo habría déficit hídrico en las } \\ \text { cuencas mineras de cobre y zinc. Por ello el estudio se centra en estos dos metales. } \\ \text { - El impacto económico del cambio climático se estimó como la variación en los niveles de ex- } \\ \text { tracción/producción con y sin cambio climático, valorado por el precio sombra correspondiente. }\end{array}$


Sector económico

Hidroenergía
Definición de productividad sectorial

Modificaciones en la disponibilidad de agua

\section{Supuestos}

- Se ha seleccionado las 16 centrales hidroeléctricas más relevantes debido a su aporte de 85\% de la capacidad hidroenergética instalada y su aporte a la generación de electricidad para el SINAC.

- Solo se trabajó con las centrales existentes, dado que no se dispuso de la información necesaria para evaluar el cambio potencial en hidroenergía.

- Para cada una de las centrales se evaluó la capacidad de descarga hídrica mensual de sus respectivas cuencas.

- El estudio evalúa el efecto del cambio climático vía la precipitación efectiva, que es la diferencia entre la precipitación y la evapotranspiración estimada en virtud a la dependencia de los caudales frente a la temperatura y el tipo de cobertura vegetal, que incluye las tendencias de uso agrícola del suelo.

- Los efectos agregados ponen en evidencia una menor producción de electricidad por efectos de una menor disponibilidad de agua en las cuencas, aún sin efecto del cambio climático, básicamente por efecto de la expansión de la agricultura.

- Se asumió que un caudal cero genera una producción nula de energía y que existe un máximo teórico en la capacidad de producción definido al momento de construcción.

- Se asumió que la producción no decaería con caudales por encima del máximo de operación.

- Se asumió que las centrales analizadas funcionan óptimamente.

- El impacto del cambio climático se mide por el impacto en la reducción de ingresos en el mercado hidroenergético según la variabilidad en la producción de energía eléctrica.

\begin{tabular}{|c|c|c|}
\hline Infraestructura & Reposición de carreteras & $\begin{array}{l}\text { - Se utilizaron caudales medios diarios expresados en altura equivalente de agua del río Rímac y del } \\
\text { río Urubamba por periodos de } 30 \text { años para analizar la variación de sus caudales cada } 5 \text { años. } \\
\text { - Se analiza el aumento de fenómenos climáticos extremos que afectaría las vías de comunicación. } \\
\text { - Con el caudal y la estructura existente se determinó si cada obra de drenaje para cada tramo } \\
\text { permitía pasar el caudal o si se producía una falla. } \\
\text { - Se estimó el grado de reparación necesaria de carreteras y se asoció un costo a cada periodo de } \\
\text { retorno, que es la inversa de la probabilidad de ocurrencia. } \\
\text { - Para poder comparar cambios en las probabilidades de falla se tuvo que escoger una probabilidad } \\
\text { de falla representativa por encima de la cual estos costos no aumentan significativamente. } \\
\text { - Se asume que el impacto del cambio climático en este sector se relaciona con el presupuesto } \\
\text { público ante la necesidad de reposición de capital. }\end{array}$ \\
\hline Turismo & Demanda o número de turistas & $\begin{array}{l}\text { - Se consideró el turismo de vacaciones y ocio, que representa el } 52 \% \text { del total en el Perú, ya que } \\
\text { los otros tipos de turismo serían netamente urbanos e insensibles al cambio climático. } \\
\text { - Particularmente se centró en Machu Picchu por ser el atractivo turístico que capta la mayor } \\
\text { cantidad de turistas del circuito dominante del eje sur (Cusco, Puno y Arequipa). } \\
\text { - Se prioriza el análisis del turismo extranjero, en tanto que el turismo nacional se reacomodaría } \\
\text { en otros destinos del país. } \\
\text { - Se asume que la temperatura no influye en la decisión de viajar, pero sí los eventos extremos } \\
\text { (ruptura de vías de acceso a los destinos turísticos, inundaciones, entre otros). } \\
\text { - La metodología consideró los siguientes factores: causas externas por afectación económica en } \\
\text { los países abastecedores de turistas, y causas internas en la interrupción de vías de acceso y la } \\
\text { salubridad como consecuencia el aumento de fenómenos climáticos extremos que afectaría las } \\
\text { vías de comunicación hacia Machu Picchu. } \\
\text { - Se consideró la capacidad de carga de Machu Picchu como una restricción a la oferta de } \\
\text { turismo. } \\
\text { - Se determinaron los costos por una disminución de la afluencia de turistas. }\end{array}$ \\
\hline
\end{tabular}


Sector económico

Salud Definición de productividad sectoria

Tratamiento de malaria

\section{Supuestos}

- Se consideraron enfermedades transmitidas por vectores (malaria, leishmaniasis, dengue y fiebre amarilla) debido a la disponibilidad de datos para producir un análisis más riguroso, en contraste con las infecciones respiratorias cuya correlación con el cambio de temperatura no es evidente.

- Estas enfermedades que representan el mayor porcentaje de incidencia son transmitidas por mosquitos, cuyo ciclo de vida depende de la temperatura y la disponibilidad de agua para el desarrollo de las etapas larvarias.

- El estudio se centra particularmente en la malaria, dado el gran número de casos reportados (75\% de las enfermedades analizadas), así como los costos asociados a las medidas de prevención, diagnóstico y tratamiento.

- Se asume una correlación entre las condiciones del clima y la incidencia de malaria.

- Los datos de clima fueron promediados para los 12 meses del año de referencia.

Fuente: Elaboración propia.

A continuación se sintetizan las metodologías específicas para cada sector productivo (agricultura, ganadería altoandina, pesca, minería, hidroenergía, infraestructura, turismo y salud). Los insumos principales para este análisis se basan en los escenarios climáticos y macroeconómicos en disponibilidad de recursos naturales.

\section{Agricultura}

Para identificar el impacto del cambio climático en el sector agrícola se seleccionaron los principales cultivos en términos del PBI y del valor bruto de la producción (VBP) de 2009, que son papa, arroz, café, caña de azúcar, plátano, maíz amarillo duro y maíz amiláceo. Estos cultivos representaron en conjunto aproximadamente el 37,4\% del PBI del sector y un 47\% del VBP agrícola. Estos valores muestran que existe una amplia heterogeneidad en la distribución de los cultivos en cuanto a valor agregado el valor bruto de la producción en el total del área cosechada (véase el cuadro III.3). Se han excluido el espárrago y algodón, ambos considerados de importancia comercial, pues para ellos no se cuenta con suficientes datos climáticos ${ }^{11}$.

CUADRO III.3

Participación de los principales cultivos en el valor bruto de la producción agrícola y en la superficie sembrada, 2009

\begin{tabular}{|c|c|c|c|c|c|c|}
\hline \multirow{2}{*}{ Nombre } & \multirow{2}{*}{ Tipo decultivo } & \multirow{2}{*}{$\begin{array}{c}\text { Participación en el PBI } \\
\text { agrícola } \\
\text { (en porcentaje) }\end{array}$} & \multicolumn{2}{|c|}{$\begin{array}{c}\text { Valorbrutodelaproducción(VBP) } \\
\text { agrícola total }^{\text {a/ }}\end{array}$} & \multicolumn{2}{|c|}{ Superficie cosechada b/ } \\
\hline & & & Participación & Ranking & Enmilesdehectáreas & Ranking \\
\hline Papa & Transitorio & 10,55 & 13,3 & 1 & 289,9 & 4 \\
\hline Arroz & Transitorio & 7,46 & 9,4 & 2 & 388,7 & 1 \\
\hline Café & Permanente & 5,63 & 7,1 & 3 & 349,6 & 2 \\
\hline Caña de azúcar & Permanente & 4,84 & 6,1 & 4 & 77 & 7 \\
\hline Plátano & Permanente & 3,73 & 4,7 & 5 & 156,1 & 6 \\
\hline Maíz amarillo duro & Transitorio & 3,65 & 4,6 & 6 & 295,8 & 3 \\
\hline Maíz amiláceo & Transitorio & 1,51 & 1,9 & 7 & 201,3 & 5 \\
\hline TOTAL & - & 37,4 & 47,1 & - & - & - \\
\hline
\end{tabular}

Fuente: Elaboración propia a partir de datos del Ministerio de Agricultura y Riesgo (MINAG2011b) Notas: a) Dinámica agropecuaria 1997-2009; b)Ministerio de Ambiente del Perú (MINAM, 2011). 
Para determinar los cambios en el rendimiento de los cultivos se utilizaron las proyecciones de temperatura máxima y mínima del Centro de Datos para la Conservación (CDC-UNALM) para los escenarios A1B, B1 y A2 y para el período de análisis. Para los escenarios A1B y B1 se contó con siete GCM: GIAOM, MIHR, CSMK3.5, BCM2.0, CSMK3.0, MIMR y INCM3; y para el escenario A2 se dispuso de cinco GCM: CSMK3.5, INCM3, MIMR, BCM2.0 y CSMK3.0.

El modelo utilizado para analizar los impactos en rendimientos es el de función de producción, también llamado "modelo agronómico", que relaciona la producción de un cultivo con el cambio de la temperatura, la precipitación y otras variables. Esta aproximación agronómica presenta la ventaja de identificar los umbrales de temperatura y precipitación a partir de los cuales los efectos del cambio climático pueden ser beneficiosos o perjudiciales para el rendimiento de cada cultivo seleccionado (Ramírez et al., 2009; Ordaz et al., 2010; Mora et al., 2010) $)^{12}$.

El modelo agronómico muestra que la producción de un determinado cultivo depende básicamente de la superficie cosechada (S), de la temperatura (T) y de la precipitación (PP). Además, bajo el principio de los rendimientos marginales se puede identificar un umbral que representa la máxima producción posible. Por ello, la relación entre la producción (Q) del cultivo y las variables climáticas debería tener la forma de U invertida ${ }^{13}$, por lo que se modeló econométricamente a partir de una función cuadrática.

Para seleccionar y modelar las variables climáticas se han considerado las etapas fenológicas de cada cultivo, que se refieren a los períodos de siembra, emergencia, crecimiento, floración y maduración. Para la estimación econométrica se tuvo en cuenta información para todos los meses del año, debido a las diferencias en los períodos de desarrollo de cada etapa y en las zonas de producción analizadas.

Una de las especificaciones de la estimación econométrica utiliza datos anuales de producción. En cuanto a los datos climáticos, estos fueron empleados de acuerdo al período de floración de cada cultivo seleccionado. Al inclur el periodo de floración, se captura de manera más precisa la relación entre indicadores climáticos y la producción agrícola. Los resultados econométricos no mostraron que la precipitación fuera significativa en la explicación del comportamiento de los cultivos. Esto ocurre porque se analizan sistemas de irrigación regulados, donde no hay una dependencia directa con la precipitación local. Los supuestos econométricos para cada cultivo se muestran en el cuadro III.4.

\section{CUADRO III.4}

\section{Supuestos econométricos por cultivo}

\begin{tabular}{|c|c|c|}
\hline Cultivo & Descripción & Ecuación econométrica \\
\hline Рара & $\begin{array}{l}\text { La especificación escogida de la función de producción de la papa es el } \\
\text { modelo de mínimos cuadrados ordinarios (MCO) agrupado, que reporta } \\
\text { una temperatura óptima de } 14,32^{\circ} \mathrm{C} \text {. Este modelo presenta la temperatura } \\
\text { mínima como variable independiente. }\end{array}$ & $\begin{array}{l}\text { Qit }=-1336,649+13,83832 \text { Sit }+143,6632 \text { TNit } \\
-5,016227 \text { TNit2 + uit }\end{array}$ \\
\hline Arroz & $\begin{array}{l}\text { Los resultados de las especificaciones finales de las funciones de producción } \\
\text { del arroz indican que el modelo más adecuado es el MCO agrupado, usando la } \\
\text { temperatura máxima. Se concluye que la temperatura óptima para el modelo } \\
\mathrm{MCO} \text { agrupado es } 24,07^{\circ} \mathrm{C} \text {. Ante incrementos de dicha variable climática más } \\
\text { allá de ese nivel, el impacto sobre el rendimiento del cultivo será negativo. }\end{array}$ & $\begin{array}{l}\text { Qit }=-9894,98+7,86 \mathrm{Sit}+875,63 \mathrm{TMit} \\
-18,19 \mathrm{TMit} 2+\text { uit }\end{array}$ \\
\hline
\end{tabular}

Cuadro continúa en la siguiente página.

12 Otro enfoque existente es el método ricardiano, que consiste en estimar el valor de la tierra como función del ingreso neto agrícola y que requiere datos históricos de costos de insumos. Por disponibilidad de información no se adoptó este modelo.

13 Existe evidencia de una relación en forma convexa entre la producción las variables climáticas (Mendelsohn et al., 1994). 


\begin{tabular}{|c|c|c|}
\hline Cultivo & Descripción & Ecuación econométrica \\
\hline $\begin{array}{l}\text { Maíz amarillo } \\
\text { duro }\end{array}$ & $\begin{array}{l}\text { Los resultados de las especificaciones de las funciones de producción para } \\
\text { el maíz amarillo duro sugieren que el mejor modelo es el de MCO agrupado, } \\
\text { dado que los coeficientes son significativos. La función que relaciona la } \\
\text { producción y la temperatura mínima es cóncava, con una temperatura óptima } \\
\text { de } 17,56^{\circ} \mathrm{C} \text {. }\end{array}$ & $\begin{array}{l}\text { Qit }=-8720,37+4,74 \text { Sit }+1058,4 \text { TNit } \\
-30,12 \text { TNit2+uit }\end{array}$ \\
\hline Maíz amiláceo & $\begin{array}{l}\text { Los resultados de las funciones de producción para el maíz amiláceo sugieren } \\
\text { que el mejor modelo es el MCO agrupado (sin intercepto). La temperatura } \\
\text { máxima óptima es } 14,89^{\circ} \mathrm{C} \text {. Para la variable de precipitación, el valor óptimo } \\
\text { es } 150 \mathrm{~mm} \text {. }\end{array}$ & $\begin{array}{l}\text { Qit=0,87Sit+6,54TMit -0,23TMit2+0,- } \\
\text { 387PPit-0,001PPit2 + uit }\end{array}$ \\
\hline Café & $\begin{array}{l}\text { Para el caso del café, la especificación escogida es el modelo MCO agrupado, } \\
\text { la cual, a diferencia de los modelos de efectos fijos y aleatorios, tiene coefi- } \\
\text { cientes que son significativos al } 1 \% \text {, usando la temperatura máxima como } \\
\text { indicador climático, reportando una temperatura óptima de } 29,59^{\circ} \mathrm{C} \text {. }\end{array}$ & $\begin{array}{l}\text { Qit }=-320,49+0,94 \text { Sit }+21,24 \mathrm{TMit}-0,36 \mathrm{TMi}- \\
\text { t2+uit }\end{array}$ \\
\hline Caña de azúcar & $\begin{array}{l}\text { Los resultados de las funciones de producción para la caña de azúcar sugieren } \\
\text { como mejor modelo al de efectos fijos, dado que los coeficientes son signi- } \\
\text { ficativos en términos individuales y grupales. La temperatura óptima para el } \\
\text { modelo de efectos fijos es de } 21,30^{\circ} \mathrm{C} \text {. }\end{array}$ & $\begin{array}{l}\text { Qit }=-2986,36+9,24 \text { Sit +355,80TMit-8,33T- } \\
\text { Mit2+uit }\end{array}$ \\
\hline Plátano & $\begin{array}{l}\text { Los resultados de las especificaciones de las funciones de producción para el caso } \\
\text { del plátano sugieren que el mejor modelo es el de efectos fijos, dado que los } \\
\text { coeficientes son significativos en términos individuales y grupales al } 1 \% \text {. La tem- } \\
\text { peratura máxima óptima para el modelo de efectos fijos escogido fue } 17,84^{\circ} \mathrm{C} \text {. }\end{array}$ & $\begin{array}{l}\text { Qit }=-265,27+12,39 \text { Sit }+25,07 \text { TMit-0,70T- } \\
\text { Mit2+uit }\end{array}$ \\
\hline
\end{tabular}

Fuente: Elaboración propia.

Nota:Temperatura máxima (TM), temperatura mínima (TN), superficie cosechada (S), cultivo en el tiempo(it), precipitación (PP).

Con base en las estimaciones econométricas, se proyectaron los cultivos a partir de la agregación de la información distrital, provincial y departamental con datos climáticos disponibles. Para fines de este estudio, los resultados son presentados en el contexto nacional y no se consideraron mayores aspectos geográficos.

Utilizando los resultados de las especificaciones econométricas se calcularon las proyecciones de la producción por cultivo y escenario climático para el período de análisis, asumiendo que la producción está en función de las variables climáticas. A partir de estas proyecciones de rendimiento y producción se obtienen los ingresos con y sin cambio climático para cada cultivo, utilizando precios promedio del año 2010 y constantes hasta $2100^{14}$. Estos resultados se obtuvieron para cada modelo climático global y para cada escenario (A1B, A2 y B1). El impacto del cambio climático se obtiene mediante la diferencia entre los ingresos por escenario con y sin cambio climático.

\section{Ganadería altoandina}

El análisis del cambio climático en este sector se enfocó en la ganadería extensiva de vacunos, ovinos, camélidos, caprinos y equinos en las zonas altoandinas del Perú. La ganadería altoandina fue seleccionada considerando la vulnerabilidad de la PEA involucrada.

La producción de animales de cada unidad espacial (celdas de $1 \mathrm{~km}^{2}$ ) se midió en unidades ovino (UO), por ser la especie más adaptable en las zonas altas. Todas las especies pecuarias que hacen uso del ecosistema de la puna (tales como ovinos, vacunos, camélidos, equinos y caprinos), fueron transformadas a unidades ovino para simplificar el cálculo y el análisis de los datos. Asimismo, solo se consideraron las unidades ganaderas que no fueron afectadas por la expansión agrícola. La base teórica utilizada para calcular las equivalencias entre especies animales se enfoca en que el consumo de pasto por unidad de peso metabólico define la magnitud y la equivalencia de la unidad ovina. Por ejemplo, una vaca de $450 \mathrm{~kg}$ es igual a 5 unidades ovinas ${ }^{15}$.

14 Para cada cultivo seleccionado se obtuvo el precio del año 2010 según el MINAGRI.

15 Este enfoque ha sido utilizado por la American Society of Rural Appraisers para valorar tierras de pastoreo y por los economistas de pastizales para estimar el impacto económico de mejoras en el manejo de recursos naturales. 
La producción de carne de ovino para cada escenario se obtuvo luego de multiplicar el número de unidades ovinas, asumiendo que cada unidad ovina generaría 22 kilogramos de carne (Flores, 1996) ${ }^{16}$.

El estudio de ganadería utilizó, en primera instancia, la información sobre cambios en biomas obtenidos en el análisis de recursos naturales, en particular para la ecorregión de la puna. Las variaciones en productividad de los biomas se estimaron a partir de alteraciones de precipitación promedio anual y tasas de uso diferencial. La precipitación resulta un mejor predictor de cambios en la productividad primaria de los pastos que la temperatura. Para esta área se identificaron los distintos tipos de cobertura vegetal y usos del suelo (pastos, agricultura, forestal, cuerpos de agua, urbano y protección).

A partir de las coberturas se calcularon las áreas netas de pastoreo mediante un modelo dinámico determinístico que permitió analizar la capacidad de carga animal con y sin cambio climático a partir de las variaciones en precipitación. Las áreas netas de pastoreo se estimaron en función de mapas de uso actual, coberturas y pendiente del terreno a un 1 kilómetro de resolución espacial.

El análisis fue realizado para tres coberturas de vegetación: bofedales, pajonales y arbustales. Se utilizaron siete modelos climáticos globales seleccionados, para los tres escenarios de emisión de GEl y períodos de análisis. La información fue trabajada mediante el formato raster de cada capa, con el programa ArcGis 10 para la ecorregión puna.

La capacidad de carga se estimó en función de la clasificación elaborada por el Laboratorio de Ecología y Utilización de Pastizales de la UNALM para el estatus ecológico y el escenario de pastoreo para las 16 regiones políticas en la puna. El cambio temporal en la productividad de los biomas (arbustal, pajonal y bofedal) para los años 2040, 2070 y 2100 permitió estimar las variaciones en capacidad de carga y productos animales de los ecosistemas (Lau y Flores, 2011). Para predecir estos cambios en productividad se utilizó el modelo propuesto por Lieth (1973):

\section{$\mathrm{Y}=3000(1-\mathrm{e}-0,000664 X)$}

Donde $Y$ es productividad primaria neta y $X$ es la precipitación anual promedio. Esta ecuación permite calcular el cambio relativo en el estatus productivo de los ecosistemas, los cambios en capacidad de carga y los productos animales derivados de ella (Evans y Workman, 1994).

Finalmente, se obtuvieron las proyecciones de la producción ganadera a partir de los cambios en cobertura vegetal, uso de la tierra y productividad. Las variaciones de productividad del sector se estimaron a partir de alteraciones en el área neta de pastoreo, productividad de los biomas y capacidad de carga estandarizada a unidades ovino, considerando tres tipos de coberturas de pastizal (pajonales, bofedales y arbustales), tres escenarios de emisión (A2, A1B y B1) y siete modelos climáticos globales. Los cambios en productividad fueron posteriormente traducidos a cambios en cantidad y valor de los productos.

Posteriormente se realizó la valoración económica del impacto del cambio climático en el sector pecuario a partir de la diferencia de ingresos por carne de ovino sin cambio climático y con cambio climático. Los valores de producción de carne de ovino se multiplicaron por el precio de la carne de ovino, 4,46 soles por kilogramo (MINAGRI, 2011c) para obtener los ingresos en este sector ${ }^{17}$. Se empleó solo el precio de carne de ovino, pues no fue posible utilizar precios ponderados por falta de información por especie considerada. Por lo tanto, no se presenta el impacto desagregado para cada especie, sino solamente el efecto para todo el sector pecuario. Este punto debe profundizarse en estudios futuros.

16 También se consideró que del total de carne producida, solo $20 \%$ es ofertado al mercado (Flores, 2012) y el restante $80 \%$ sirve de autoconsumo, recordando que se trata de ganadería desarrollada en zonas de pobreza y extrema pobreza, con baja capacidad de insertarse al mercado.

17 Como no se contaba con información histórica de precios de carne de ovino, se convirtió el precio de este producto del año 1994 al año 2010 , a partir del Índice de Precios del Sector Pecuario y basados en CENAGRO. 
De acuerdo a esta información se determinó la reducción de la producción de carne de ovino en un escenario con cambio climático.

\section{Pesca}

El sector pesquero se enfoca en la capacidad productiva que ofrecen las 200 millas peruanas en el océano Pacífico. Esto implica que el análisis de su dinámica futura, en términos de capacidad productiva, requiere un enfoque distinto y variables diferentes al resto de sectores. En contraposición con la zona terrestre, la precipitación no tiene un efecto significativo en el ecosistema, mientras que la disponibilidad de oxígeno disuelto en el mar resulta un factor clave.

Los modelos climáticos globales del Cuarto Informe del IPCC (2007a) incluyen al océano en sus proyecciones. Sin embargo, solo algunos cuentan con información de concentración de oxígeno en el agua o la productividad primaria (producción de biomasa generada por plantas o algas). Al momento de elaborar el presente estudio, nuevos modelos climáticos se estaban desarrollando para el Quinto Informe del IPCC (2014). Desafortunadamente, ninguno de estos explica el patrón observado en la costa peruana asociado al enfriamiento de las aguas costeras (Gutiérrez et al., 2011). Ningún modelo global tiene la capacidad de explicar este patrón. Es por ello que fue necesario construir un modelo específico que permitiera proyectar esta situación.

Para explicar el patrón de enfriamiento de las aguas en la costa peruana se construyó un escenario local empleando la tendencia histórica de la temperatura superficial del mar. La información se obtuvo del satélite de la NOAA para el período 1982 a 1991. La inclusión del escenario local responde a la necesidad de incorporar aspectos particulares de las costas peruanas que no se pueden capturar en los escenarios globales ${ }^{18}$. En el escenario local se asumió que la concentración de oxígeno y la productividad primaria se mantendrán constantes a lo largo del tiempo ${ }^{19}$.

Para construir los escenarios futuros, se eligieron resultados disponibles del Quinto Informe del IPCC (2014), buscando dos escenarios relacionables con los escenarios de emisión de GEl elegidos del Cuarto Informe. En particular, se seleccionó el escenario RCP 4.5, que es similar al SRES B1 y el escenario RCP 8.5 donde se esperarían concentraciones similares al A1F1 y un poco mayores que el A2 (véase el recuadro I.1). Para cada escenario oceánico solo se utilizó un modelo climático, por lo que la incertidumbre vinculada al conocimiento de la dinámica oceánica no se analizó.

Respecto de los recursos potencialmente afectados, la anchoveta es la especie más importante del ecosistema pesquero y contribuye con más del 90\% en los desembarques. La abundancia promedio de

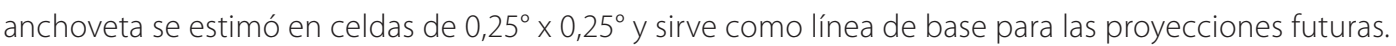
La biomasa de anchoveta fue estimada a partir de información histórica sobre temperatura superficial del mar y oxígeno superficial del mar, registrados en los cruceros de evaluación del Instituto del Mar del Perú (IMARPE) durante el período 1983 a 2006. Ello permitió proyectar la distribución de esta especie a causa de los cambios en la temperatura superficial del mar.

18 Los escenarios RCP proyectan calentamiento, que idóneo de este recurso contrastando con el hábitat preferido por la anchoveta, conducen a una menor abundancia, y por ende a una menor captura. En el caso de enfriamiento se observa un efecto positivo inicial en la abundancia de la anchoveta: incrementa la extensión del área idónea para la anchoveta en las primeras décadas, que luego disminuye debido a que las aguas son demasiado frías en relación con la temperatura del hábitat idóneo de este recurso.

19 El escenario local se proyectó solo con temperatura, ya que se tenían datos disponibles para hacer lo mismo que se efectuó en el escenario global. Se desconoce si el escenario local se mantendrá en el futuro o si solo es una transición al calentamiento dentro de la zona costera de Perú. Sin embargo, aun cuando no es comparable metodológicamente, es importante trabajar en el futuro este escenario con información adicional de productividad y oxígeno. 
Para modelar la producción de anchoveta se asumió que su biomasa es proporcional a las condiciones de temperatura, oxígeno disuelto y productividad primaria. Asimismo, se consideró que la captura es proporcional a la biomasa disponible de esta especie.

A partir de la determinación de la variación de captura de anchoveta a 2100, para los escenarios mencionados, se realizó la conversión de esta especie al principal derivado, que es la harina de pescado, y por tanto, se obtuvo la proyección de la producción de harina de pescado con y sin cambio climático. La valoración del impacto del cambio climático en el sector se midió considerando los cambios en los ingresos por harina de pescado ante la presencia y ausencia del cambio climático, manteniéndose los precios constantes del año 2010.

\section{Minería}

El sector minero es altamente sensible a la disponibilidad hídrica en las zonas donde se localizan sus unidades de producción, pues una disminución repercutiría directamente en los costos operativos. Por ello se asume que el principal impacto del cambio climático sobre el sector minero peruano estará vinculado a la disponibilidad de agua. El análisis metodológico para este sector se centró en identificar cómo el cambio climático afectaría la disponibilidad hídrica futura en las cuencas donde es relevante la extracción minera. Para ello se estimó el consumo hídrico poblacional20, agrícola y minero.

Para desarrollar el análisis de la disponibilidad hídrica futura, en primer lugar se seleccionaron las cuencas mineras con las suficientes reservas probadas y probables, que garanticen una extracción en el largo plazo, de los principales metales comerciales (oro, plata, cobre, plomo, zinc, hierro y estaño).

Posteriormente, se priorizaron las cuencas mineras a partir del estudio de Ecosecurities (2009) que fueron agrupadas y ajustadas por el Centro de Datos para la Conservación (CDC). Las cuencas mineras priorizadas en el estudio comprenden los siguientes metales: oro, cobre, zinc y hierro (véase el cuadro III.5). No se consideraron en forma explícita las cuencas de plata y plomo, ya que generalmente están vinculadas al oro y al zinc, respectivamente. El estaño tampoco fue incluido, ya que las reservas totales de este metal en el Perú para el año 2010 (MINEM, 2012) y conforme a las tasas de extracción de ese período no alcanzarían para un período extendido de tiempo.

CUADRO III.5

Cuencas mineras priorizadas por metal y ubicación geográfica

\begin{tabular}{|c|c|c|c|c|c|}
\hline Mineral & Unidad minera & Proyecto & Empresa & Distrito & Departamento \\
\hline \multirow{3}{*}{ Cobre } & Torata & Cuajone & $\begin{array}{l}\text { Southern Perú Cooper } \\
\text { Corporation }\end{array}$ & Torata & Moquegua \\
\hline & Toquepala & Toquepala & $\begin{array}{l}\text { Southern Perú Cooper } \\
\text { Corporation }\end{array}$ & Ilabaya & Tacna \\
\hline & Cerro Verde & Cerro Verde & $\begin{array}{l}\text { Sociedad Minera Cerro } \\
\text { Verde }\end{array}$ & Yanabamba & Arequipa \\
\hline \multirow[t]{2}{*}{ Oro } & Caylloma & El Diablo & $\begin{array}{l}\text { Goldplata } \\
\text { Resources Perú }\end{array}$ & Caylloma & Arequipa \\
\hline & Arcata & Arcata & Compañía Minera Ares & Cayarani & Arequipa \\
\hline
\end{tabular}

Cuadro continúa en la siguiente página. 


\begin{tabular}{|c|c|c|c|c|c|}
\hline Mineral & Unidad minera & Proyecto & Empresa & Distrito & Departamento \\
\hline Oro & Orcopampa & Orcopampa & $\begin{array}{l}\text { Compañía de Minas } \\
\text { Buenaventura }\end{array}$ & Orcopampa & Arequipa \\
\hline Hierro & Marcona & Marcona & Shougang Hierro Perú & Marcona & Ica \\
\hline \multirow{9}{*}{ Zinc } & Atacocha & Atacocha & $\begin{array}{l}\text { Compañía Minera } \\
\text { Atacocha }\end{array}$ & $\begin{array}{l}\text { San Francisco de Asís } \\
\text { de Yarusyacan }\end{array}$ & Pasco \\
\hline & El Porvenir & & Milpo & Yanacancha & Pasco \\
\hline & Colquijirca & Colquijirca & $\begin{array}{l}\text { Sociedad Anónima } \\
\text { Minera Brocal }\end{array}$ & Tinyahuarco & Pasco \\
\hline & Colquijirca & San Gregorio & $\begin{array}{l}\text { Sociedad Anónima } \\
\text { Minera Brocal }\end{array}$ & Simón Bolívar & Pasco \\
\hline & Colquijirca & Marcapunta & $\begin{array}{l}\text { Sociedad Anónima } \\
\text { Minera Brocal }\end{array}$ & Tinyahuarco & Pasco \\
\hline & Iscaycruz & & $\begin{array}{l}\text { Empresa Minera Los } \\
\text { Queñuales }\end{array}$ & Pachangara & Lima \\
\hline & Antamina & Antamina & $\begin{array}{l}\text { Compañía Minera } \\
\text { Antamina }\end{array}$ & San Marcos & Áncash \\
\hline & Chungar & Islay & $\begin{array}{l}\text { Empresa Administra- } \\
\text { dora Chungar }\end{array}$ & Huayllay & Pasco \\
\hline & Chungar & Animon & $\begin{array}{l}\text { Empresa Administra- } \\
\text { dora Chungar }\end{array}$ & Huayllay & Pasco \\
\hline \multirow{6}{*}{ Oro } & Santa Rosa & Santa Rosa & $\begin{array}{l}\text { Compañía Minera } \\
\text { Aurífera Santa Rosa }\end{array}$ & Angasmarca & La Libertad \\
\hline & Rosario de Belén & & $\begin{array}{l}\text { Century Mining } \\
\text { Corporation }\end{array}$ & Angasmarca & La Libertad \\
\hline & Lagunas Norte & Lagunas Norte & Barrick & Quiruvilca & La Libertad \\
\hline & La Virgen & La Virgen & $\begin{array}{l}\text { Compañía Minera San } \\
\text { Simón }\end{array}$ & Cachicadan & La Libertad \\
\hline & Yanacocha & Tinajas & Minera Yanacocha & $\begin{array}{l}\text { San Silvestre de } \\
\text { Conchán }\end{array}$ & La Libertad \\
\hline & Cerro Corona & Cerro Corona & Golden Field La Cima & Hualgayoc & Cajamarca \\
\hline
\end{tabular}

Fuente: Elaboración propia.

El gráfico III.1, similar al enfoque utilizado por CEPAL (2009a) y Ecosecurities (2009). Para un determinado metal de una cuenca priorizada, la disponibilidad hídrica en condiciones actuales de clima constante (sin cambio climático) se representa a través de la línea $\mathrm{DH}^{\mathrm{SC}}$, que equivale a la oferta hídrica actual y debería mantenerse en el tiempo sin mayores distorsiones ambientales o antropocéntricas. Por ello, se asume que la línea $\mathrm{DH}^{\mathrm{Sc}}$ sea una recta con pendiente nula, a fin de representar una oferta hídrica constante.

Por otro lado, la disponibilidad hídrica con cambio climático se grafica con la línea DH ${ }^{\complement c}$. En este caso se asume una reducción de la oferta hídrica representada por su pendiente negativa $\mathrm{CH}^{\mathrm{M}}$. Mientras que el consumo hídrico requerido para la producción del metal es la línea $\mathrm{CH}^{\mathrm{M}}$. La recta $\mathrm{CH}^{\mathrm{m}}$ tiene pendiente positiva para representar niveles crecientes de extracción metálica.

A modo de ejemplo y para los puntos del período de tiempo $\mathrm{tl}$-tF, el consumo hídrico $\mathrm{CH}^{\mathrm{M}}$ debería ser satisfecho por la disponibilidad hídrica constante $\mathrm{DH}^{\mathrm{sc}}$ (segmento AB). Sin embargo, debido al cambio climático, la disponibilidad hídrica será el segmento $\mathrm{AC}$ de la línea $\mathrm{DH}^{\complement c}$. El déficit hídrico significará la disminución de cierto nivel de extracción y producción (equivalente al triángulo $\mathrm{ABC}$ ). Este es el impacto económico asociado al cambio 
climático para la industria del metal analizado durante el período señalado. Además, el polígono BDFC también constituye un costo para la industria, puesto que la oferta hídrica futura bajo un contexto de cambio climático (segmento CF) será menor al consumo hídrico proyectado (segmento BD). Sin embargo, el triángulo BDE no es un costo asociado al cambio climático, sino a las expectativas de una mayor extracción y producción por parte de la industria.

El impacto del cambio climático asociado al déficit hídrico está representado por las áreas ABC y BEFC. En este caso particular, se asume que la dotación hídrica futura ( $\mathrm{DH}^{\mathrm{CC}}$ ) será menor en comparación con la actual. Esto no necesariamente se cumplirá en todo el periodo de análisis, lo cual dependerá de las proyecciones de oferta hídrica. El supuesto es solo para efectos demostrativos.

\section{GRÁFICO III.1}

\section{Modelación del impacto del cambio climático sobre el sector minero}

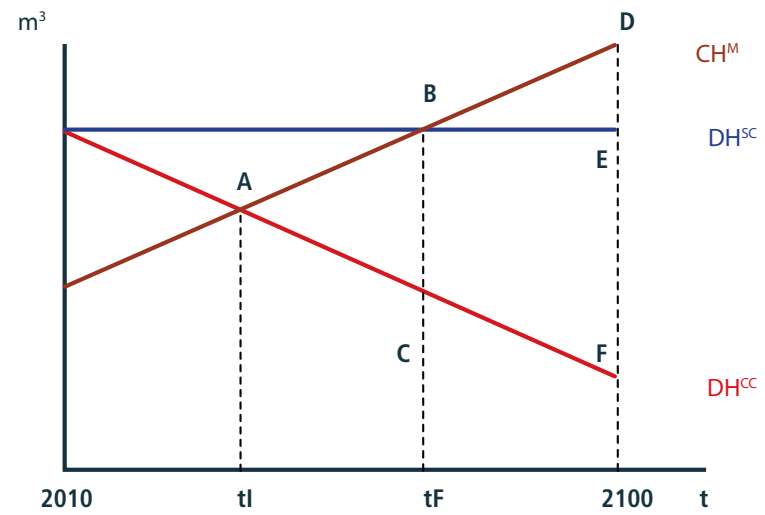

Fuente: Elaboración propia.

El ejemplo teórico presentado en el gráfico III.1 anterior permitió identificar las principales variables que deben ser consideradas en el análisis para el Perú. Las proyecciones de disponibilidad hídrica anual DH $\mathrm{DH}^{\mathrm{SC}}$ y $\mathrm{DH}^{\mathrm{Cc}}$ en cada una de las cuencas mineras priorizadas y para el horizonte 2010-2100 se obtuvieron en metros cúbicos por año sobre la base de información del CDC. Además, para cada una de las cuencas mineras se establecieron las proyecciones de consumo hídrico, que comprende el consumo humano $(\mathrm{CHH})$, agrícola $(\mathrm{CHA})$ y minero $(\mathrm{CHM})$.

El consumo humano $(\mathrm{CHH})$ se calculó a partir de la población localizada en las cuencas mineras priorizadas. La tasa de crecimiento poblacional fue estimada en base a la información desagregada de INEI (2012). El consumo hídrico agrícola CHA se construyó desde el uso consuntivo agrícola de las administraciones locales de agua (ALA) de las cuencas hidrográficas vinculadas a los principales cursos de agua de las cuencas mineras priorizadas. Esta información corresponde al período 2011 y fue obtenida del INEI (2012).

El consumo hídrico minero (CHM) se relaciona con el nivel de extracción. Una vez proyectado el nivel de extracción por metal, se procedió a estimar el CHM, utilizando un factor proporcional equivalente al consumo de agua por unidad de extracción. Este factor es calculado para las empresas mineras representativas en la producción de cada metal, las cuales poseen un nivel de tecnología superior al promedio nacional, de manera que el factor estimado puede asumirse como de largo plazo ${ }^{21}$.

21 Se considera que en el largo plazo la tecnología de todo el sector minero debe converger a los niveles actuales que poseen las empresas mineras más grandes y eficientes. 
La proyección de la producción metálica se realizó a partir de la información de la proyección del PBI minero para el período 2012 a 2100, según los escenarios macroeconómicos del estudio y de la producción metálica total de los minerales analizados durante el período 1950 a 2011 , de donde se obtiene la producción minera sin cambio climático.

Posteriormente, se estimó la futura disponibilidad hídrica con cambio climático ( $\left.\mathrm{DH}^{\mathrm{CC}}\right)$ por cuenca minera, para contrastarla con el futuro $\mathrm{CH}^{\mathrm{M}}$. La futura disponibilidad hídrica fue estimada para los tres escenarios climáticos seleccionados y solo para los dos modelos extremos de cada caso.

Al realizar el análisis de disponibilidad hídrica se encontró que solo habría déficit hídrico en las cuencas mineras de cobre y de zinc, por ello la valoración del impacto del cambio climático se realizó para esos dos metales.

El diferencial de extracción con y sin cambio climático determinado por la variación en la disponibilidad hídrica fue valorado con el precio sombra del agua para fines mineros (en base a datos de 2010). Este precio se calculó a partir de la estimación de una función de costos de producción para el cobre y el zinc, para los períodos 1994 a 2010 y 1995 a 2010, respectivamente. El precio del cobre y del zinc fue de 1,02 soles y de 1,6 soles por metro cúbico.

\section{Hidroenergía}

El impacto del cambio climático es medido por la reducción de los ingresos provenientes del mercado hidroenergético a través de la variación de la producción de energía eléctrica, según los escenarios de cambio climático para los diferentes modelos desarrollados. Este estudio estima la magnitud de estos efectos para cada una de las centrales hidroeléctricas más relevantes, y el agregado para el actual parque hidroeléctrico del Sistema Interconectado Nacional (SINAC), en tres escenarios climáticos y siete GCM, hasta el año 2100.

Las características físicas de las centrales se asumen como constantes y con un funcionamiento óptimo. El único cambio sería en la capacidad productiva, dado por variaciones en el flujo de agua disponible para la producción hidroeléctrica de las centrales existentes. Por ello, para cada central se estimó 1) una función que vincule el caudal del río en la bocatoma de la central con la energía eléctrica generada y, 2) el caudal de agua que circulará por la bocatoma en el futuro, para lo cual se empleó el flujo promedio actual y los cambios esperados en los próximos años.

El primer paso consistió en cuantificar la capacidad de generación de electricidad de una central hidroeléctrica a partir del caudal de agua disponible en la fuente. El volumen de agua que puede pasar por las turbinas y ser aprovechado para generar electricidad está limitado por la forma y el tamaño de las turbinas, así como por el diseño de canales, sistemas de captación, entre otros.

En un sistema en operación se espera que haya un mínimo de agua que debe recorrer por el punto de captación para que el sistema pueda capturar el agua, ya sea por condiciones de diseño de ingeniería o por restricciones ambientales. Para validar la hipótesis de comportamiento de la generación de energía eléctrica en base al caudal disponible en la fuente, se evaluó para cada central, mediante mínimos cuadrados ordinarios, la relación funcional de caudales mensuales y la producción mensual la energía para cinco años (de 2005 al 2010).

En segundo lugar, se estimó el caudal presente y futuro para los escenarios con y sin cambio climático de acuerdo con la precipitación efectiva. En particular, el efecto del cambio climático se evaluó mediante el análisis de caudales que dependen de la precipitación efectiva (precipitación menos evapotranspiración), la temperatura y el tipo de cobertura vegetal, por lo que se incluyen las tendencias de uso agrícola del suelo. La precipitación efectiva futura se estimó utilizando siete modelos climáticos y para tres escenarios de emisión. 
La información base de caudales fue proporcionada por el Ministerio de Energía y Minas (MINEM) mediante series mensuales promedio. A su vez, la información de precipitación efectiva presente y futura, con y sin cambio climático, es la misma que la presentada en el capítulo I para todo el territorio del Perú a 1 km de resolución. Además, con la información de alturas se construyeron las cuencas de captación para cada central hidroeléctrica ${ }^{22}$, usando como punto de referencia la ubicación de la bocatoma de la misma. Posteriormente, para cada escenario y modelo climático, se estimó la suma de la precipitación efectiva en cada cuenca de forma independiente, por lo que fue posible calcular la variación en el caudal futuro.

A continuación se seleccionaron los sistemas de generación hidroeléctrica de mayor relevancia a partir de su aporte a la generación de electricidad para el SINAC. Se identificaron 16 centrales hidroeléctricas que representan aproximadamente el 85\% de la capacidad hidroenergética instalada (véase el cuadro III.6).

La siguiente etapa consistió en analizar la energía producible por las centrales, de acuerdo con sus patrones históricos de producción e interpolando valores quinquenales. Se realizó el mismo ejercicio para la situación con cambio climático para cada uno de los modelos y escenarios evaluados. Para tal fin, se asumió que un caudal cero genera una producción nula de energía y que existe un máximo teórico en la capacidad de producción definido al momento de construcción. También se asumió que la producción no decaería con caudales por encima del máximo de operación, aun cuando esto normalmente se reporta por la mayor cantidad de sedimentos y sólidos en suspensión transportados por el agua ${ }^{23}$.

\section{CUADRO III.6}

\section{Principales centrales hidroeléctricas del Sistema Interconectado Nacional del Perú}

\begin{tabular}{ll|lllll}
\hline Empresa & Central & $\begin{array}{c}\text { Potencia efectiva } \\
\text { (megavatios) }\end{array}$ & Cuenca & Río & Estación \\
\hline Electroperú & Mantaro & 670,66 & Mantaro & Mantaro & Mejorada \\
\hline EGENOR & Cañón del Pato & 263,49 & Santa & Santa & Balsas-Cedros \\
\hline EDEGEL & Huinco & 247,34 & Rímac & Santa Eulalia & Sheque \\
\hline Electroperú & Restitución & 215,36 & Mantaro & Mantaro & Mejorada \\
\hline EDEGEL & Chimay & $45 / 150,9\left(^{*}\right)$ & Tulumayo & Tulumayo & Chimay \\
\hline ENERSUR & Yuncan & 136,76 & Paucartambo & Paucartambo & Huallamayo- \\
\hline EDEGEL & Matucana & 128,58 & Rímac & Rímac & Uchuhuerta \\
\hline San Gabán & San Gabán II & 113,10 & San Gabán & San Gabán & Camatani \\
\hline EGENOR & Carhuaquero & 95,11 & Chancay & Chancay & Cirato \\
\hline EGEMSA & Machupicchu & 88,80 & Vilcanota & Vilcanota & Km 105 \\
\hline EDEGEL & Callahuanca & 80,43 & Rímac & Rímac & Sheque-Tamboraque \\
\hline EDEGEL & Moyopampa & 66,13 & Rímac & Rímac & Sheque-Tamboraque \\
\hline SN Power & Cahua & 43,11 & Pativilca & Pativilca & Cahua \\
\hline EDEGEL & Yanango & 42,61 & Tarma & Tarma & Yanango \\
\hline SN Power & Gallito Ciego & 38,15 & Jequetepeque & Jequetepeque & Ventanillas \\
\hline EDEGEL & Huampaní & 30,18 & Rímac & Rímac & Sheque-Tamboraque \\
\hline
\end{tabular}

Fuente: Elaboración propia a partir de Comité de Operación Económica del Sistema Interconectado Nacional COES-SINAC (2011). Nota: Las centrales seleccionadas son mayores a 20 megavatios de potencia instalada.

(*) Actualmente la central tiene fuertes problemas de vibración, por lo que la máxima potencia es de 45 MW, y la nominal, de 150,9 MW.

22 Se define a la cuenca como el área aguas arriba de su punto de captación.

23 No fue posible establecer la capacidad de regulación de agua provista natural o artificialmente. Tampoco se pudo incluir el efecto de los trasvases u otras obras de afianzamiento hídrico de las cuencas trabajadas. 
A partir de la producción de energía sin y con cambio climático se estimaron los cambios en ingresos mediante la diferencia de escenarios. Los ingresos se estiman en base a la producción de energía para cada escenario y empleando el precio de 311,98 mil soles por gigavatio al año.24 El efecto sectorial acumulado es la suma de las pérdidas o ganancias de todas las centrales hidroeléctricas para cada combinación de escenario y modelo. Como se mencionó anteriormente, el impacto del cambio climático en el sector hidroenergía refleja la variación de la producción de energía eléctrica por la menor disponibilidad de agua en las cuencas.

\section{Infraestructura}

El principal objetivo de este estudio es calcular los costos asociados a los cambios en la probabilidad de ocurrencia de eventos extremos que pudieran alterar la infraestructura vial del país en los escenarios A1B, A2 y B1. Para ello, se analizaron las carreteras asfaltadas que forman parte de la red vial nacional (RVN).

Para desarrollar este análisis, se identificaron dos zonas geográficas. El primer tramo se asocia con la vertiente occidental que atraviesa por ríos que desembocan en el océano Pacífico y que cruzan regiones de sierra y costa, específicamente el río Rímac. El segundo tramo son las carreteras de la vertiente oriental que cruzan las regiones sierra y selva y el río Urubamba.

El siguiente paso consiste en calcular los costos exógenos de mantener y reparar las vías. Estos costos son la suma de los costos de mantenimiento periódico más los costos asociados a emergencias. El mantenimiento periódico es definido como el conjunto de actividades para restaurar los elementos de la red vial a su condición original o promoverlos a un nivel más beneficioso ${ }^{25}$. La atención de emergencias son las actividades para restablecer la normalidad del tránsito vehicular en el menor tiempo posible, ante la ocurrencia de eventos intempestivos que afecten parte de la vía ${ }^{26}$.

El análisis del sector presentó limitaciones de disponibilidad de información por lo que se asumió que los costos exógenos de la carretera Central son representativos para la longitud total. El costo exógeno por kilómetro se calculó a partir de la estructura de costos promedio de cuatro tramos de la carretera Central, actualizados para 2010 (véase el cuadro III.7). A partir de esta información y de la longitud de las vías se estimó el costo anual de la senda base sin cambio climático. Este costo equivale a 715 millones de soles, aproximadamente ${ }^{27}$.

CUADRO III.7

Estructura de costos promedio de rehabilitación y mejoramiento de carreteras en el Perú

\begin{tabular}{|c|lcr|r|}
\hline N. & Concepto & Unidad & Total dólares & \multicolumn{1}{c|}{ Total soles } \\
\hline 1 & Bacheo & $\$ / \mathrm{m}^{2}$ & 15,77 & 55,21 \\
\hline 2 & Sello & $\$ / \mathrm{m}^{2}$ & 1,57 & 5,50 \\
\hline 3 & Refuerzo & $\$ / \mathrm{m}^{2}$ & 5,39 & 18,86 \\
\hline 4 & Mantenimiento rutinario & $\$ / \mathrm{km} / \mathrm{año}$ & $2.678,23$ & $9.373,82$ \\
\hline 5 & Exógenos (mantenimiento periódico + emergencias) & $\$ / \mathrm{km} / \mathrm{año}$ & $2.930,21$ & $10.255,73$ \\
\hline
\end{tabular}

Fuente: Elaboración propia a partir de Provías Nacional (2001).

Nota: Estos costos fueron calculados de acuerdo con la estructura de costos promedio de cuatro tramos de la carretera Central, actualizados para el año 2010.

En el escenario sin cambio climático se realizaron simulaciones de precipitación y escorrentía para estimar el caudal de las cuencas de los ríos Rímac y Urubamba, y se evaluó el efecto que tendría sobre las estructuras de drenaje de la vía. Con esta información se determinó si cada obra de drenaje en los tramos evaluados permitía pasar el caudal o si se producía una falla en la estructura (ruptura). Al realizar las simulaciones se pudo comprobar que se producían fallas con efectos significativos, con una probabilidad de ocurrencia de $1 \%$ en el caso de la cuenca del río Rímac y de $2 \%$ en el caso de la cuenca del río Urubamba.

24 El cálculo de este precio proviene de la ponderación de las tarifas eléctricas peruanas obtenidas de OSINERGMIN (2012), según tipo de uso (residencial, comercial e industrial) en dólares, posteriormente convertidas a nuevos soles, de acuerdo con la unidad de producción de energía.

25 Esto implica restaurar la carpeta asfáltica y las bermas al nivel de servicio original, reconstruir las obras de drenaje superficiales y subterráneas, reponer las señales de tránsito, acondicionar los taludes, etc.

26 Con el fin de reparar los efectos de huaicos, derrumbes, sismos, aluviones, inundaciones, etc.

27 El costo total se obtiene de multiplicar el costo exógeno unitario (S/. 10.255) por el total de carretera pavimentada, que equivale al 54\% de los $129.162 \mathrm{~km}$ de la red vial nacional. 
Utilizando los resultados de precipitación de los siete modelos y para los tres escenarios climáticos, se estimó la probabilidad de ruptura de vías con cambio climático en las cuencas del río Rímac (vertiente occidental) y del río Urubamba (vertiente oriental). Las probabilidades fueron proyectadas al año 2100. Para este cálculo se usó la metodología del análisis de los eventos extremos que se resume en el recuadro III.1.

\section{RECUADRO III.1}

\section{Análisis de eventos extremos}

El análisis de eventos extremos es desarrollado con el fin de calcular los cambios en las probabilidades de ocurrencia de estos eventos ante el fenómeno del cambio climático. Para el análisis del sector de infraestructura y de turismo se relaciona con la probabilidad de ruptura de las vías de comunicación. A continuación se resumen los pasos para este análisis.

a. Para cada mes del año, se estimó el cambio en la probabilidad de ocurrencia de eventos extremos, empleando las precipitaciones y las temperaturas diarias del modelo climático global para cada escenario climático seleccionado.

b. Luego se estima el efecto del cambio en la probabilidad de ocurrencia de eventos climáticos extremos del modelo climático global en la precipitación efectiva local, empleando los datos diarios de estaciones meteorológicas e hidrológicas.

c. Se determinó la probabilidad de ocurrencia de distintos flujos de agua en los puntos de la cuenca donde se requiere hacer las evaluaciones.

El principal supuesto de esta metodología es que los cambios en probabilidad de ocurrencia de una temperatura o nivel de precipitación a escala global se traducen linealmente a la escala local.

Fuente: Elaboración propia.

Para la valoración económica de los efectos del cambio climático se utilizaron los costos exógenos promedio presentados en el cuadro III.7. El costo con cambio climático se obtiene de multiplicar el costo total por el factor $(1+p)$, donde "p" es la probabilidad de ruptura de carreteras afectada por la acción de las variables climáticas. Si los efectos adversos del cambio climático se incrementan, esta probabilidad también debería aumentar. El costo obtenido sin cambio climático se asume constante. El diferencial entre ambas situaciones (con y sin cambio climático) resulta como los costos incrementales que se asumen como un gasto en el PBI.

\section{Turismo}

El análisis de este sector se enfoca en estudiar las posibles restricciones de acceso a la oferta turística ocasionados por los efectos del cambio climático. El estudio considera que el turismo de tipo cultural y geográfico que caracteriza al Perú es sensible a la interrupción de las vías de comunicación que dificultan o impiden el acceso a Machu Picchu, como principal atractivo turístico.

Para ello, en primer lugar se identificaron los principales atractivos turísticos del país. Posteriormente, se analizó la demanda y su estacionalidad. Este análisis se concentró únicamente en el turismo de vacaciones y ocio. Como se muestra en el cuadro III.8, este sector representa más del 52\% del total nacional, Además, se esperaría que la demanda de este tipo de turismo sea la más afectada por el cambio climático (Agueda et al., 2005). Por 
su menor dependencia de factores climáticos, se excluyeron las actividades de turismo de negocios, visita a familiares y amistades, salud, conferencias y seminarios, entre otros.

CUADRO III.8

Perfil del turista extranjero que viaja al Perú, 2010

(En porcentajes)

\begin{tabular}{|llll|}
\hline Motivo de viaje al Perú & & Modalidad de viaje al Perú & \\
\hline Vacaciones, recreación u ocio & 52 & Viaja por cuenta propia & \\
\hline Negocios & 20 & & 17 \\
\hline Visitar a familiares o amigos & 15 & Contrata agencia de viajes fuera del Perú & \\
\hline Salud & 3 & & \\
\hline Conferencias/congresos & 4 & Contrata agencia de viajes dentro del Perú & 1 \\
\hline
\end{tabular}

Fuente: PromPerú (2010), INEI (2011).

Posteriormente, se identificó la afluencia de turistas extranjeros que viajaron al Perú durante el período 2004-2012 (MINCETUR, 2013a). Como se puede apreciar en el cuadro III.9, el gasto promedio del turista extranjero que visita el Perú es de 109 dólares por día, con una estadía promedio de 12 días.

CUADRO III.9

Gasto y permanencia promedio de turistas extranjeros en el Perú, 2010

\begin{tabular}{|l|c|c|c|}
\hline Procedencia & $\begin{array}{c}\text { Permanencia } \\
\text { (en noches) }\end{array}$ & $\begin{array}{c}\text { Gasto diario } \\
\text { (en dólares) }\end{array}$ & $\begin{array}{c}\text { Gasto total promedio } \\
\text { (en dólares) }\end{array}$ \\
\hline $\begin{array}{l}\text { Reino Unido, Bélgica, Holanda, Francia, } \\
\text { Alemania, Italia, España y Suiza }\end{array}$ & 17,5 & 102,3 & $1.781,4$ \\
\hline Canadá y Estados Unidos & 13,2 & 105,4 & $1.383,9$ \\
\hline Japón & 9,3 & 145,5 & $1.350,0$ \\
\hline México & 9,4 & 115,9 & $1.092,4$ \\
\hline Brasil, Chile, Colombia y Argentina & 8,3 & 111,0 & 916,2 \\
\hline Ecuador, Bolivia & 6,6 & 105,6 & 693,2 \\
\hline Promedio & $\mathbf{1 2}$ & $\mathbf{1 0 9}$ & $\mathbf{1 . 2 7 8}$ \\
\hline
\end{tabular}

Fuente: Elaboración propia a partir de MINCETUR (2010).

Para la proyección del número de turistas sin cambio climático se consideró la capacidad de carga de la ciudadela inca, como una restricción a la oferta de este lugar. Se estimaron dos opciones, la carga 1 con 2.500 turistas al día o 912.500 visitantes al año y la carga 2 con 5.000 turistas al día o 1.825 .000 visitantes año.

La demanda del turismo receptivo de vacaciones se considera sensible, tanto al cambio climático como a la dinámica económica, social y política. Para analizar la repercusión de los impactos del cambio climático en la oferta y la demanda del turismo se analizó el vínculo entre la precipitación, la temperatura y el número de turistas que llegan a Machu Picchu, considerando que estas variables pudieran hacer menos propicia la visita a este lugar.

A partir de estas relaciones se analizó la probabilidad de interrupción del trayecto a Machu Picchu cuan- 
do las precipitaciones llegan a su máximo umbral, destruyendo la vía y causando pérdidas económicas ${ }^{28}$. Para proyectar los caudales futuros y analizar la probabilidad del corte de la vía por eventos extremos se utilizó el modelo de precipitación y escorrentía. Esta etapa de la metodología se desarrolló con seis modelos de mínimos y máximos para cada escenario (MIMR y CSMK3.0 en B1, MIMR y CSMK3.5 para A1B, MIMR y BCM2.0 en A2) y datos diarios promedio de caudales en la estación Pisac (Cusco) del río Vilcanota para 30 años. Con ello se generaron simulaciones de caudales futuros para analizar la probabilidad del corte de vía en intervalos de cinco años.

De este modo, los costos del cambio climático para los escenarios A2, A1B y B1 se calcularon mediante el diferencial entre el escenario sin y con cambio climático del número total de turistas de vacaciones que visitarían Machu Picchu y la pérdida de turistas por la probabilidad de ocurrencia de eventos extremos en escenarios máximos.

Finalmente, se identifican factores de incertidumbre que pudieran cambiar las proyecciones del turismo.

\section{Salud}

En este estudio se evalúa la correlación entre las condiciones del clima (temperatura y precipitación) y la incidencia de enfermedades transmitidas por vectores; en particular, la malaria.

Para ello se procedió a identificar las principales enfermedades transmitidas por vectores en el Perú (malaria, leishmaniasis, dengue y fiebre amarilla) cuyo ciclo de vida depende de la temperatura y de la disponibilidad de agua. Se seleccionó la malaria por representar el mayor porcentaje de incidencia de estas enfermedades (75\% del total de casos) en el período base analizado (véase el cuadro III.10).

CUADRO III.10

Casos registrados de enfermedades transmitidas por vectores en el Perú, 2000-2011

\begin{tabular}{l|c|c|} 
Enfermedad & $\begin{array}{c}\text { Monto acumulado 2000 - 2011 } \\
\text { (número de casos) }\end{array}$ & $\begin{array}{c}\text { Casos registrados } \\
\text { (porcentaje) }\end{array}$ \\
\hline Dengue & 137.544 & 14,83 \\
\hline Fiebre amarilla & 453 & 0,05 \\
\hline Leishmaniasis & 89.390 & 9,64 \\
\hline Malaria & 700.024 & 75,48 \\
\hline Total & $\mathbf{9 2 7 . 4 1 1}$ & $\mathbf{1 0 0}$
\end{tabular}

Fuente: Elaboración propia a partir de datos de la Dirección General de Epidemiología (DGE), MINSA.

Se calculó la población infectada con malaria en escenarios sin y con cambio climático. Para el escenario sin cambio climático se dispuso de datos del clima para los 715 distritos donde se han reportado casos de malaria. Con esto se calculó la incidencia anual promedio por cada 100.000 habitantes para el período de estudio a partir de la información del Censo Nacional del año 2007.

Este análisis permitió identificar los departamentos que concentran la mayor incidencia de casos y que fueron seleccionados para el presente estudio: Loreto, Ucayali, Madre de Dios, Amazonas, San Martín, Tumbes y Piura.

Se estimó que existe una correlación entre las condiciones del clima y la incidencia de malaria. Para identificar esta relación en el escenario base se realizaron interpolaciones en el ámbito distrital de las variables 
climáticas (temperatura máxima, mínima y media, y precipitación) para la mayor parte de los distritos del país con datos del año 2005 como representativos del período 2000-2011.

Los términos lineales para todas las variables climáticas evaluadas son significativos. La densidad de población no muestra una asociación estadísticamente significativa con la incidencia de malaria, y por lo tanto, fue descartada. Para evaluar relaciones no lineales, se agregaron términos cuadráticos y cúbicos para cada una de las variables climáticas. De este modo, el modelo de incidencia que mejor explica esta relación se presenta a continuación:

\section{$\left\{\right.$ Incidencia $=\exp \left\{3,10+0,015 p p-2,861 t \_\min +0,589 t \_\max -0,698 t \_\right.$mean $\left.+0,326 t \_\min \wedge 2-0,009 t \_\min \wedge 3\right\}$}

Donde la incidencia es el número de casos anuales de malaria por cada 100.000 habitantes, la pp es la precipitación promedio, tmin es la temperatura mínima, tmax es la temperatura máxima y tmean es la temperatura media.

Este modelo se aplicó a las proyecciones de clima para tres escenarios (A1B, A2 y B1) y siete GCM (BCM2.0, CSMK3.0, CSMK3.5, GIAOM, INCM3, MIHR, MIMR). Se evaluaron 19 de las 21 posibles combinaciones de escenarios y GCM. Se usaron proyecciones quinquenales en el entorno distrital desde 2010 hasta 2095.

Las proyecciones del número de casos de malaria para los departamentos de alta incidencia se calcularon sumando los casos esperados para cada uno de sus distritos en el año de referencia. Por su parte, los costos del tratamiento contra la malaria se calcularon tomando como referencia el estudio Relación costos - efectividad del uso de pruebas rápidas para el diagnóstico de malaria en la Amazonía peruana (Proyecto VIGIA et al., 2006). De acuerdo con esta fuente, los costos actualizados a 2010 son 73,45 soles por persona infectada.

De este modo, se procedió a estimar los costos del tratamiento de malaria con y sin cambio climático.

\section{Agregación de impactos sectoriales en el PBI nacional}

El cálculo de los impactos económicos del cambio climático en el país se ha realizado a partir de la agregación de los costos que se generarían sobre las actividades productivas más sensibles ante este fenómeno. Los sectores seleccionados fueron agricultura, ganadería, pesca, minería, hidroenergía, salud, turismo e infraestructura, que representan alrededor de un tercio del PBI nacional.

Como se describe en los puntos anteriores, para cada sector se desarrollaron funciones de producción relacionadas con variables económicas y climáticas. Fue desde estas relaciones que se determinaron niveles de actividad tendenciales y se asumió que el clima mantenía sus patrones históricos. Al mismo tiempo, se establecieron escenarios alternativos que contemplaban cambios en las condiciones climáticas, afectando las productividades o incrementando los gastos sectoriales.

En particular, los sectores de agricultura, ganadería, pesca, minería e hidroenergía fueron analizados a través de los cambios en sus ingresos productivos; mientras que infraestructura, turismo y salud se analizaron por medio de los mayores gastos que el cambio climático les ocasionaría. Finalmente, los costos sectoriales se calcularon como la diferencia entre los escenarios con cambio climático y sin él.

El análisis de la situación climática se realizó sobre la base de información disponible para tres escenarios de emisión (A2, A1B y B1) y siete modelos climáticos globales (GCM). Dependiendo del sector, se eligieron los mo- 
delos climáticos que representaban los máximos y mínimos impactos. Sin embargo, no siempre los modelos de mayor o menor afectación fueron los mismos entre sectores, por lo que se utilizaron los promedios de los modelos climáticos para evaluar los escenarios de emisión.

Un caso particular se dio en el sector de pesca, donde fue necesario utilizar escenarios distintos y que profundicen en el comportamiento del océano. Se emplearon los escenarios globales RCP 8.5 y RCP 4.5, además de un escenario basado en datos locales. Para realizar el proceso de agregación, el escenario RCP 4.5 se asimiló al escenario B1 y el RCP 8.5 al A1F1, cercano al A2 hasta el año 2100. El escenario equivalente al A1B para ese sector se calculó promediando los impactos obtenidos a partir de RCP 4.5 y RCP 8.5, ya que, en términos de emisiones, el escenario A1B se encontraría en un punto intermedio.

Los costos económicos sectoriales del impacto del cambio climático permitieron la agregación nacional, expresada en millones de soles del año 2010. Además, para comparar estos costos intertemporales se han empleado tasas de descuento de $0,5 \%, 2 \%$ y 4\%. Con el fin de identificar los impactos de mediano y largo plazo se han elegido tres períodos de corte en el tiempo 2010-2040, 2010-2070 y 2010-2100.

Solo se cuantificaron los impactos sectoriales directos. No se incluyeron los impactos indirectos. Tampoco se consideraron procesos de retroalimentación entre los sectores. A partir de lo anterior, se asume que el resto de la economía no será afectada, por lo que los resultados presentados son conservadores y representan una cota mínima de los impactos económicos que podrían originarse en el país.

En el capítulo $V$ se resumen los impactos totales para cada escenario de emisión, presentados en montos absolutos y en relación con el PBI nacional del año 2010.

\section{Propuestas de adaptación}

Sobre la base del análisis de los impactos en cada uno de los sectores seleccionados se identificaron las principales acciones de adaptación que deberían llevarse a cabo para ayudar a enfrentar y a aminorar los costos de este fenómeno.

Se distinguieron los esfuerzos realizados en el país por el gobierno en los ámbitos nacional, regional y local y por el sector privado. Posteriormente, se propusieron algunas estrategias, políticas y medidas alternativas como complemento a los esfuerzos que se están realizando actualmente en el Perú. Estas medidas se agruparon en investigación, desarrollo de capacidades y tecnología.

Luego, se determinaron las necesidades de mejora (como la inclusión de prácticas y conocimientos ancestrales) y las opciones de financiamiento y de desarrollo de estrategias del uso de los recursos que permitan la implementación de las medidas propuestas.

\section{E. Limitaciones de la metodología utilizada}

La primera limitación del estudio está asociada con la descripción del clima futuro, ya que aún no existe suficiente entendimiento de las dinámicas del clima global y existe incertidumbre relacionada con el desarrollo futuro de las emisiones globales de GEI. Con el fin de abordar de cierta forma estas incertidumbres, se utilizan distintos modelos climáticos globales y escenarios. 
No existe un único modelo climático globales que represente todo el territorio nacional29. Ahí radica la importancia de reconocer directamente la incertidumbre e incorporarla en los documentos y estrategias de toma de decisión como se ha hecho en los trabajos del IPCC (2007a y 2007b) y en otros asociados (Lempert et al., 2004; Smith y Stern, 2011).

La escala de los modelo globales y el proceso de regionalización aplicado en este estudio no reflejan completamente las diferencias topográficas del país. Por ejemplo, la información de los escenarios climáticos futuros, representada en los modelos climático globales, se encuentra en escalas entre 100 km y 400 km.

Además, gran parte de la información socioeconómica está desagregada en unidades político-administrativas que no reflejan necesariamente los límites naturales utilizados y que, en ocasiones, tampoco muestran las infraestructuras que han sido un insumo para calibrar y validar los modelos sectoriales. Por ejemplo, las estadísticas agrarias o de salud suelen estar disponibles en unidades político-administrativas, mientras que el área de captación de una represa responde a una delimitación de cuenca. Así, el análisis vinculado a eventos extremos para los sectores de infraestructura y turismo se enfocó en limitadas cuencas, dada la reducida información y la necesidad de un análisis espacial adicional.

No se incluyeron los posibles cambios que se podrían producir en la calidad de los bienes y servicios, debido a la insuficiente información estadística actual. Asimismo, tampoco se estableció una senda del comportamiento futuro de los precios ni cambios en los precios relativos.

No obstante, la incertidumbre asociada a los escenarios climáticos y a los socioeconómicos, los resultados permiten ofrecer una primera luz sobre algunos de los impactos del cambio climático que afectarán al Perú.

29 Construir un modelo ensamblando varios "modelos óptimos" es una opción que soportaría gran cantidad de problemas, como la falta de información de estaciones meteorológicas en grandes sectores del país para definir cuál resultaría un buen modelo, así como la ausencia de criterios objetivos para definir los límites entre los modelos. Asimismo, promediar o ponderar los modelos climáticos podría llevar a eliminar patrones espaciales significativos. 


\section{Capítulo IV}

\section{Impactos sobre los recursos naturales: ecosistemas, uso de la tierra y disponibilidad hídrica}

La Evaluación de los Ecosistemas del Milenio reconoció el rol fundamental de los servicios ambientales en la generación del bienestar humano (Millennium Ecosystem Assessment, 2005). En el Perú, donde el clima puede tener impactos significativos en distintas regiones del territorio, analizar este vínculo posibilita la toma de decisiones adecuadas para enfrentar el cambio climático. Por ello, en este estudio se busca representar la relación entre el cambio en el clima y sus efectos en los recursos naturales de los que dependen distintas actividades productivas.

En el caso de los ecosistemas terrestres, uno de los servicios ecosistémicos más importantes es la provisión de agua. El recurso hídrico disponible en una localidad depende tanto de la precipitación como de la escorrentía, la que a su vez depende de la precipitación, pero también del tipo de suelo por el que atraviesa, ya sea cobertura natural o modificada por el hombre.

La agricultura es el uso del suelo que ocupa la mayor superficie del Perú, y afecta las características del ecosistema natural y los servicios ambientales que se generan en cada región, entre ellos, la captación y regulación del agua. Este recurso también es importante para otros sectores, como la minería y la hidroenergía, que dependen del agua y de otros servicios ambientales.

Por ello, es importante representar las variaciones en la dotación de recursos naturales por efecto del cambio climático, para entender cómo este fenómeno puede afectar a distintos sectores productivos. En particular, en este capítulo se analizan los efectos en el uso del suelo, la disponibilidad del agua y la distribución de los ecosistemas que ocupan un área con clima similar (denominados biomas).

La metodología para representar los recursos naturales terrestres en el Perú se basa en la utilización de un enfoque que integra el uso de la tierra, la distribución de biomas y la disponibilidad hídrica a través de tres modelos y un algoritmo de síntesis (véase Capítulo III, sección A, acápite 2). 


\section{A. Cambios proyectados en los biomas}

Si bien los procesos que condicionan la distribución de los biomas a escala global son climáticos, las condiciones locales sobre la vegetación producen un efecto sustancial. Por ejemplo, en regiones montañosas es común encontrar diferencias importantes en la vegetación entre dos laderas contiguas, debido a diferencias en la exposición de los rayos solares o en la precipitación generada por el aire húmedo o seco soplando sobre las laderas, entre otros. Esto último puede producir efectos como la sombra de lluvia. Los efectos locales también resultan cruciales en glaciares, lomas costeras o bosques inundados, en los que la topografía local se combina con el clima del lugar para generar condiciones únicas.

Considerando la distribución actual de glaciares y zonas inundables de bosques y de puna (bofedales), y las condiciones definidas para cada escenario y modelo climático utilizados en este estudio (véase Capítulo I), se generaron mapas que representan los cambios en la distribución de los biomas para los periodos 2010-2039, 2040-2069 y 2070-2099. A modo de ejemplo, en el mapa IV.1 se presentan los cambios generados bajo el escenario A2 y el modelo MIMR.

El modelo representa las características esenciales de la distribución de los biomas en el ámbito nacional para el clima actual: una región con mucha vegetación en la vertiente oriental, tanto en la llanura como en las yungas. También se observan bosques secos, intercalados en las yungas, que caracterizan áreas de marcada estacionalidad en la precipitación. En la costa norte se extienden bosques similares, pero hacia la costa centro y sur lo que caracteriza el paisaje es el desierto costero del Pacífico.

Hacia la parte más alta de la región andina la vegetación va reduciendo su tamaño; aparecen arbustales, luego la puna (más seca hacia el sur y el oeste, y más húmeda hacia el este y hacia el norte) y, finalmente, áreas completamente afectadas por el frío, donde no hay vegetación y pueden o no observarse glaciares.

Cada uno de estos grandes tipos de vegetación, o biomas, puede estar afectado localmente por inundaciones periódicas, como ocurre en pequeña escala en los bofedales de la puna o de los manglares. También se pueden observar efectos a gran escala, como en los bosques inundables de Loreto.

En los escenarios climáticos futuros se observarían cambios significativos en varios de estos biomas. Por ejemplo, se encontraría un incremento de la superficie arbustiva en extensas áreas de la puna. Esta tendencia es consistente entre los distintos modelos climáticos. Lo mismo ocurre con los páramos, el desierto costero del Pacífico, la Amazonía y el bosque montano estacional y xerofítico.

Por otro lado, los glaciares, el área suprandina (que ocupa la zona entre los glaciares y la puna), la puna y el bosque de yungas mostrarían grandes reducciones de extensión consistentes entre todos los modelos ${ }^{30}$.

En general, se observaría un ascenso en las bandas de vegetación que caracterizan los Andes, pero la puna sería remplazada por arbustales y no por bosques de yungas. El avance proyectado de áreas desérticas y xéricas impactaría la disponibilidad hídrica local y, en las partes bajas de esas zonas, se reduciría la capacidad de proveer servicios ambientales. Este panorama sugiere un mayor riesgo de estrés hídrico en la región costera y en algunos valles interandinos.

El modelo no detecta cambios significativos asociables a una "savanización"en la región amazónica. Cabe resaltar, además, que podrían existir procesos que el modelo no detecta. Por ejemplo, en la pérdida paulatina de biomasa (conocida como muerte regresiva), donde no se da un cambio en la fisonomía del ecosistema

30 El análisis en general se ha realizado a partir de la información climática que se podía recuperar de modo homogéneo de los GCM y de las estadísticas nacionales. La información generada requiere ser validada en mayor detalle y con información local. 
pero se mantiene la estructura boscosa, produciéndose un cambio en la composición y en la estructura del bosque. Para analizar estas variaciones se necesitan mapas que representen los ecosistemas con mayor resolución y detalle. Por otro lado, el modelo es incapaz de evaluar lo que ocurre fuera del territorio nacional, por lo que no se consideran los procesos actuales de deforestación en Brasil, que podrían reducir la cantidad de agua desde el Atlántico, atravesando la Amazonía a causa de los vientos alisios.

MAPA IV.1

Cambios proyectados en biomas para el escenario A2 y el modelo MIMR

a) Clima actual

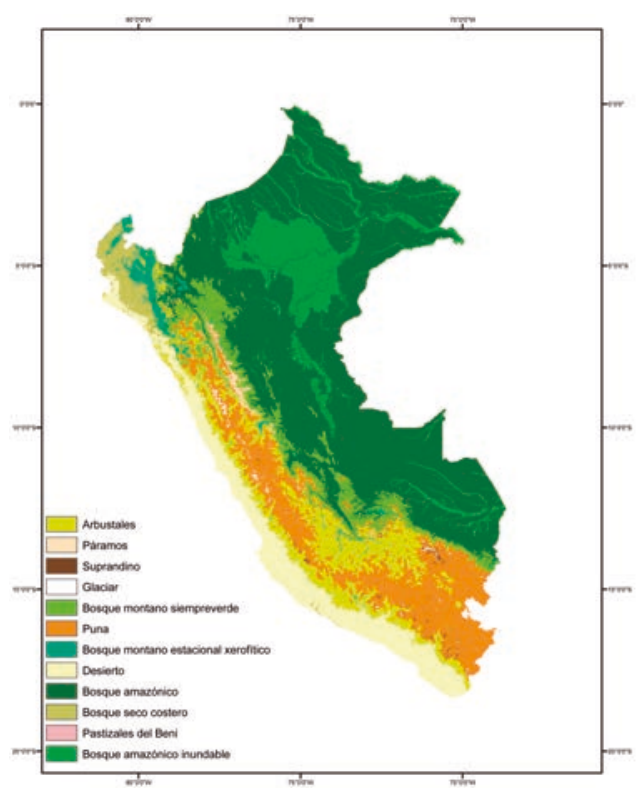

c) $2040-2069$

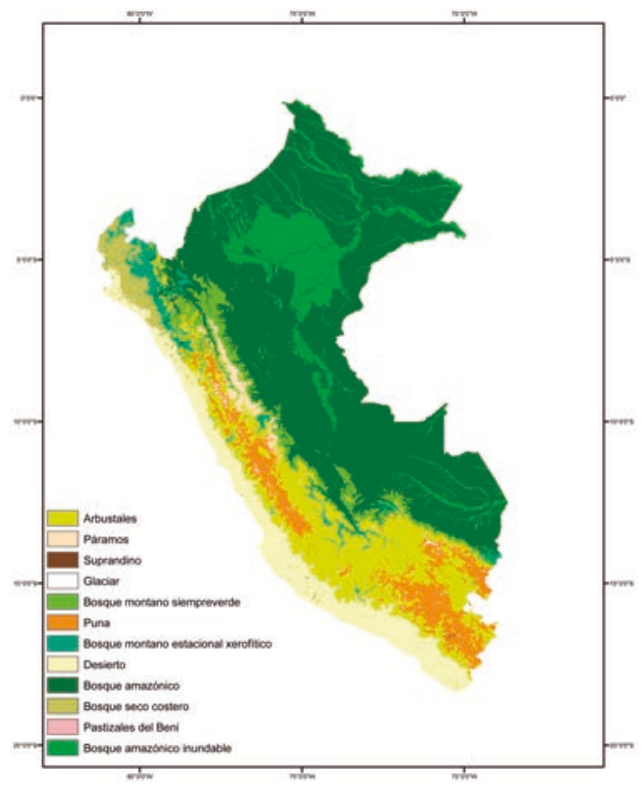

b) $2010-2039$

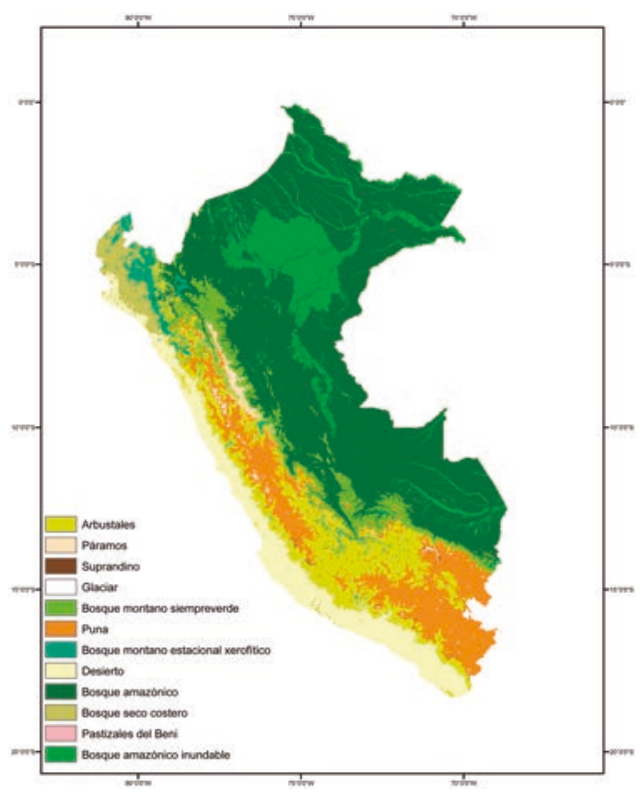

d) 2070-2099

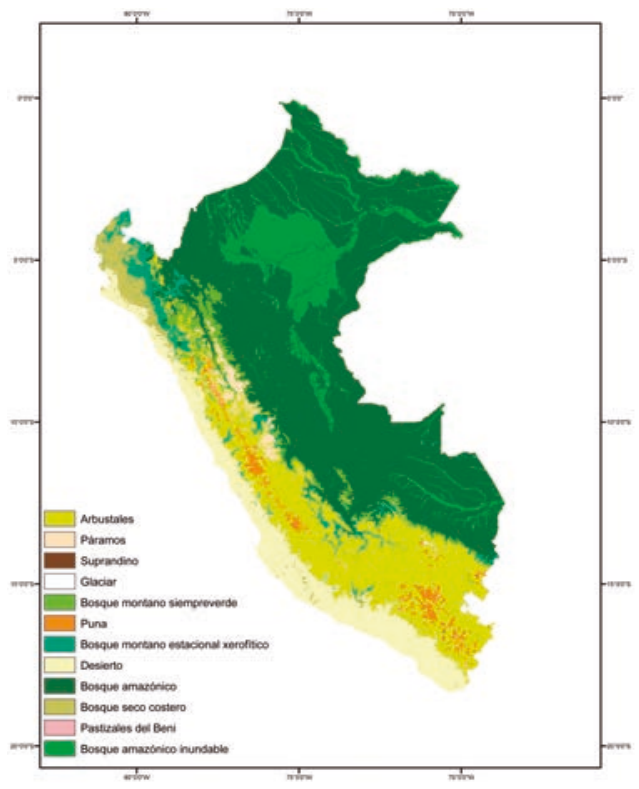

Fuente: Elaboración propia. 


\section{B. Cambios en el uso de la tierra}

A nivel nacional, la agricultura y la ganadería son las principales causas de transformación de la superficie terrestre. Ambas se desarrollan desde hace miles de años en gran parte del territorio, configurando el paisaje andino como los paisajes de los valles costeros, y en menor intensidad, el amazónico. Actualmente, esta última región es la que presenta mayor dinámica de crecimiento y transformación de la frontera agrícola, aunque no la única, dada la existencia de proyectos de irrigación y afianzamiento hídrico en la sierra y en la costa. Otros tipos de uso de la tierra como las áreas urbanas, minería y cuerpos de agua son poco representativos para la escala de trabajo nacional o no fue posible modelar su dinámica.

Existen tres aspectos claves al momento de evaluar los cambios en la distribución de los usos de la tierra y su impacto en el territorio: 1) las características del territorio, que pueden ser tanto naturales (temperatura, precipitación, pendiente, fertilidad, entre otros) como dependientes de las actividades humanas (por ejemplo, facilidad de acceso o si coincide con un área natural protegida); 2) la demanda de productos agropecuarios, ya que aun con suelos y condiciones climáticas adecuadas, si nadie desea consumirlos, no se sembrarían ni se cosecharían; 3) la disponibilidad y utilización de tecnologías, como, por ejemplo, los invernaderos, que permiten cultivar hortalizas a gran altura o fertilizantes que nutren el suelo.

A partir de estas consideraciones y en línea con los datos históricos, el modelo de cambio de uso del suelo, aún sin incluir el cambio climático, muestra un significativo avance de la agricultura. Comparada con la superficie del año 2005, la superficie agrícola se incrementaría en torno a 39\%, 86\% y 133\% para los años 2035, 2065 y 2095, respectivamente (véase el mapa IV.2).

Los resultados muestran, además, que la mayor parte del crecimiento del área bajo influencia agrícola se orientará hacia la Amazonía y hacia la sierra norte, generando un cambio significativo del territorio nacional, abarcando incluso el interior de áreas naturales protegidas.

El nivel de transformación del territorio también puede afectar la capacidad productiva de la agricultura, ya que, si avanza sobre áreas importantes para la regulación del agua (bofedales, bosques amazónicos de llanura, entre otros) o la regulación del suelo (vegetación de ladera), se puede comprometer el desarrollo agrícola de algunas áreas del país.

Al considerar los cambios en el clima y sin incluir variaciones en la demanda agrícola, se observa un leve incremento en la vocación agrícola de secano y ganadería. Por otro lado, al evaluar el efecto simultáneo del cambio climático y la variación de la demanda agrícola, el modelo reporta cambios sutiles en la distribución de los usos de la tierra. Este efecto se ejemplifica en el mapa IV.3, donde se aprecian las comparaciones entre el escenario sin cambio climático al año 2095 y los escenarios con cambio climático (A1B, A2 y B1) según el modelo CSMK3.5. 
MAPA IV.2

Cambios proyectados en el uso de suelo bajo un escenario sin cambio climático

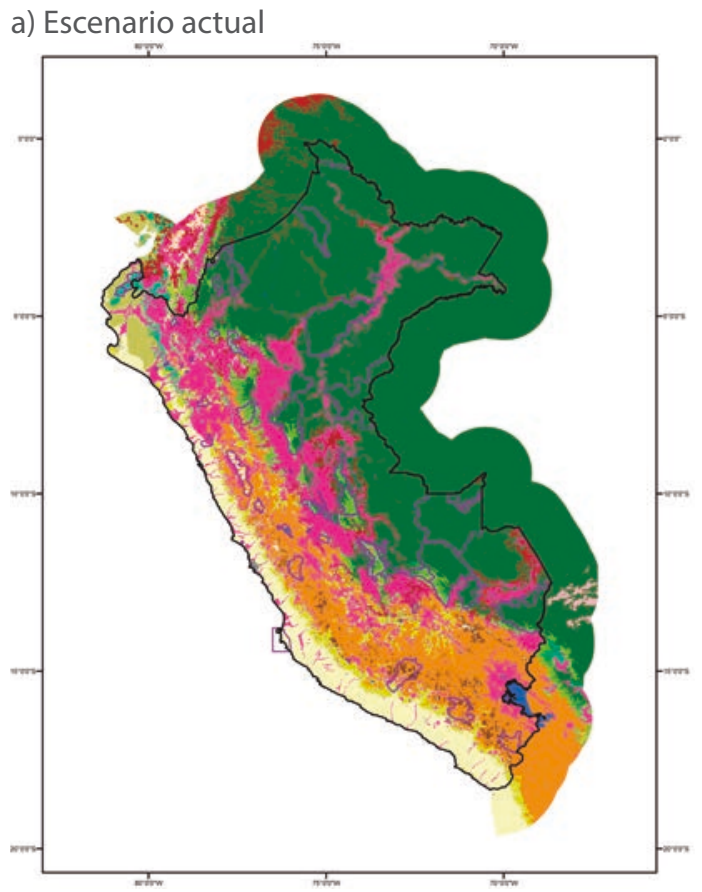

b) 2035

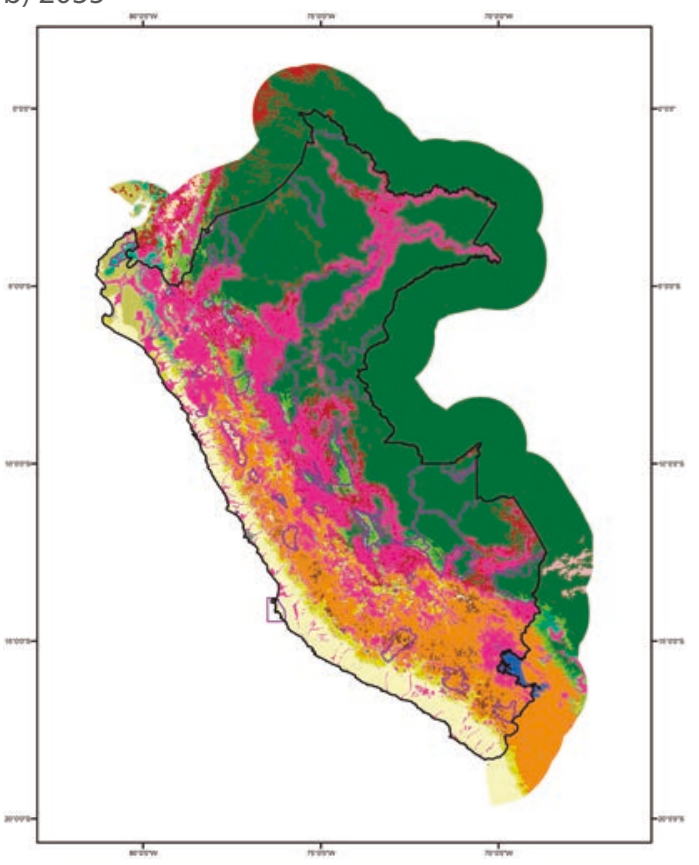

c) 2065

d) 2095
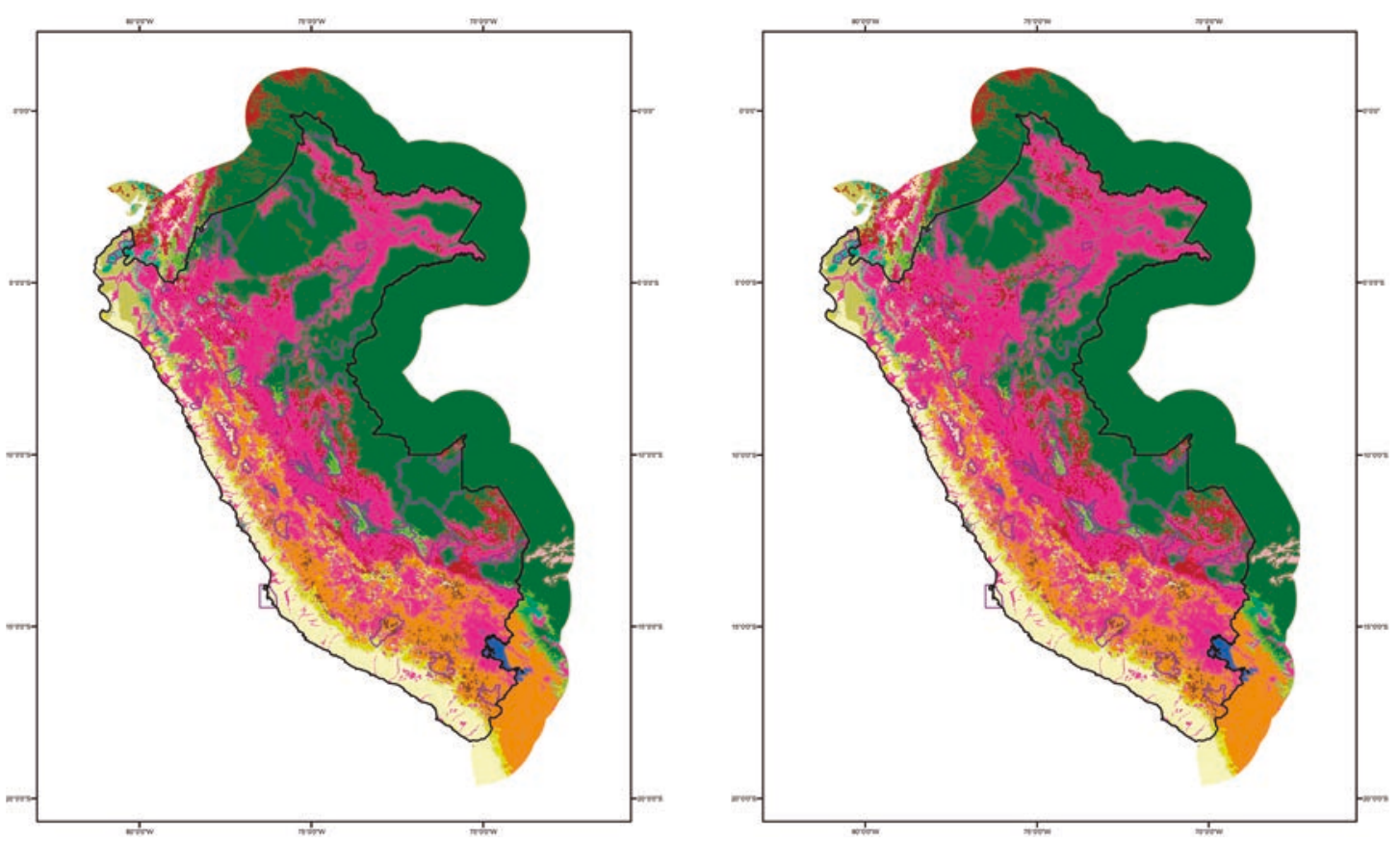

Fuente: Elaboración propia. 
MAPA IV.3

Cambios en el uso del suelo bajo los escenarios A1B, A2 y B1, modelo CSMK3.5

a) $A 1 B$

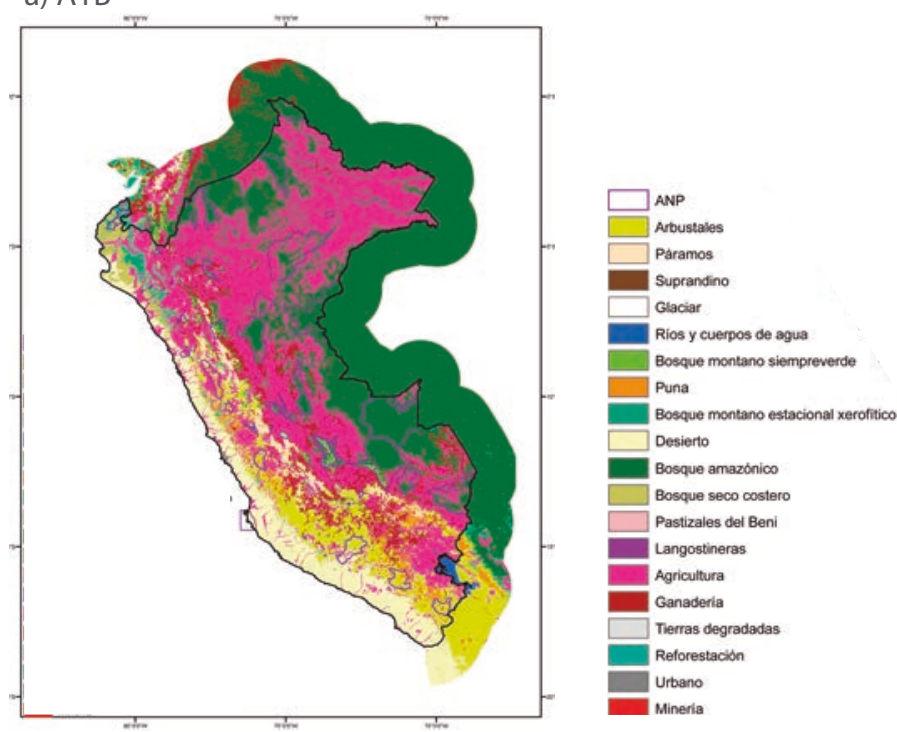

b) $\mathrm{A} 2$

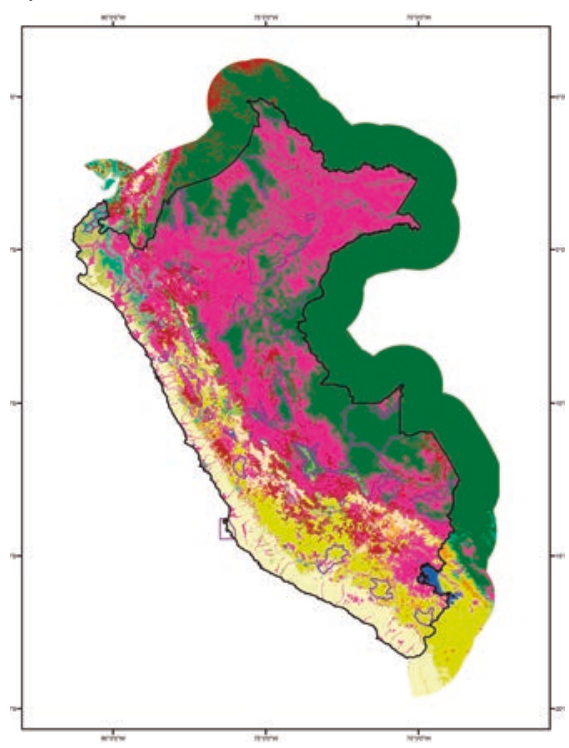

Fuente: Elaboración propia.

Nota: Los colores representan las mismas clases que en el mapa IV.2. c) B1

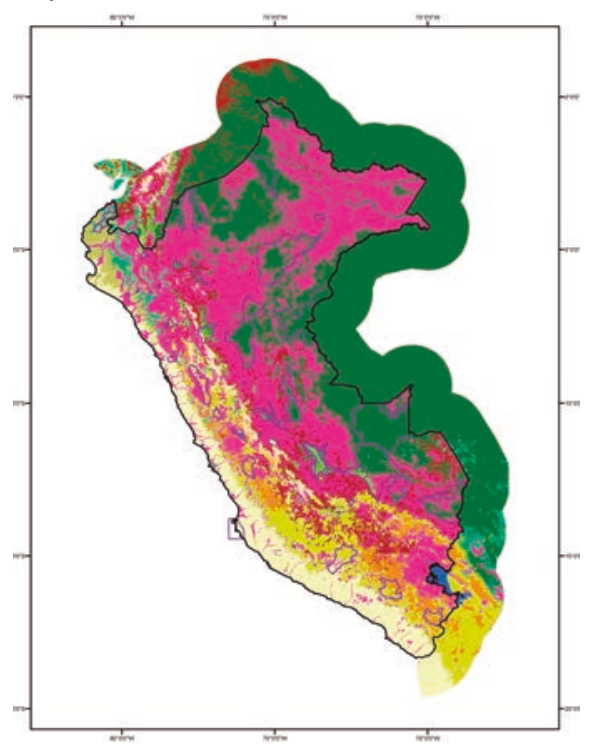

El efecto combinado del cambio en el uso de la tierra y en los biomas se aprecia en el gráfico IV.1, donde se muestra el impacto del avance agrícola (Agr) sobre los biomas y el de la ganadería (Pst) sobre las pasturas. El fenómeno climático generaría alteraciones considerables en la composición de los ecosistemas actuales, debido a la reducción de la puna (Pun) y de los glaciares (Gla), la expansión de arbustales (Arb) y del bosque montano estacional y xerofítico (Bmex).

Es decir, no solo se esperan modificaciones en el paisaje por transformación humana, sino que, como consecuencia del cambio climático, la vegetación remanente cambiaría significativamente de un tipo a otro. Esto podría tener implicaciones para la conservación y la forma en que las poblaciones locales interactúan con los recursos naturales, especialmente para las prácticas culturales y los modos de sustento. 
GRÁFICO IV.1

Cambio en la extensión de los biomas bajo el efecto combinado del cambio climático y la agricultura, 2010-2100

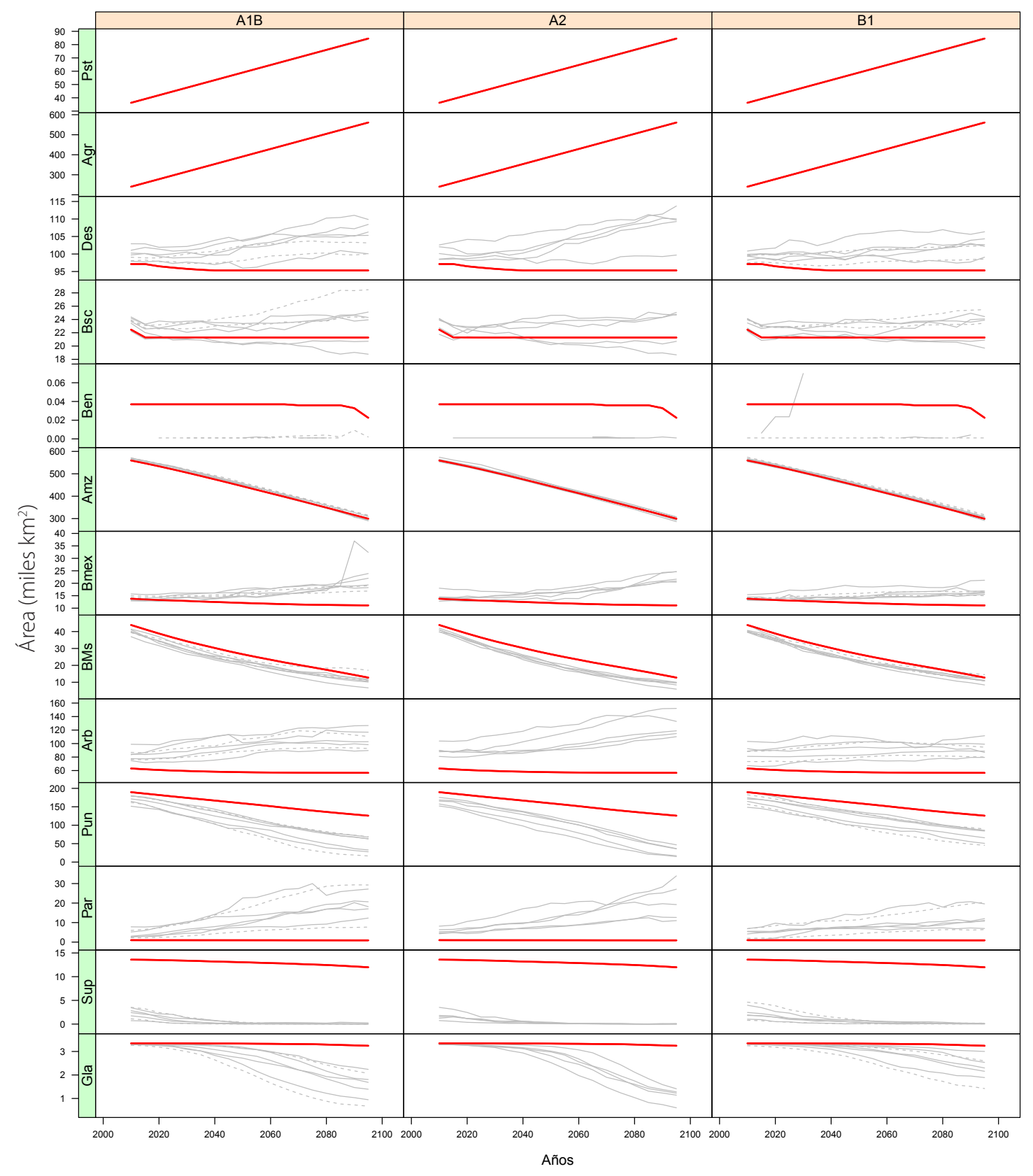

Presente

Modelos: BCM20, CSMK30, CSMK35, GIAOM, INCM3, MIHR,MIMR

Fuente: Elaboración propia.

Nota: Las coberturas corresponden a: Pst (Pastos para ganadería), Agr (agropecuario genérico), Des (desierto), Bsc (bosque seco costero), Beni (Beni), Amz (bosque amazónico), Bmex (bosque montano estacional y xerofítico), BMs (bosque montano siempreverde), Arb (arbustales), Pun (puna), Par (páramos), Sup (suprandino), Gla (glaciar). 


\section{Cambios sobre el balance hídrico}

A partir del ciclo de agua terrestre se pueden identificar tres flujos principales: precipitación, evapotranspiración y escorrentía ${ }^{31}$. La precipitación que no se pierde por evapotranspiración y contribuye a los reservorios de agua representa el agua disponible para procesos que ocurren en la tierra y se le denomina "precipitación efectiva". Por lo tanto, para el análisis se consideraron las variaciones en la precipitación efectiva generadas por el cambio climático que afectan los recursos hídricos de dos maneras: 1) variaciones directas en el régimen de la precipitación (intensidad y frecuencia) y 2) un aumento de la evapotranspiración causado por incremento de la temperatura.

Estos impactos se incluyeron en un modelo de balance hídrico acoplado a las proyecciones de los GCM de clima a través de una desagregación estadística (método Delta Change, Fowler et al., 2007; Maraun et al., 2010). El modelo regional de balance hídrico tiene una resolución espacial de 5 kilómetros.

En el mapa IV.4 se presentan los resultados obtenidos de la aplicación del modelo de balance hídrico en los distintos escenarios climáticos. La mediana de los modelos climáticos permite observar una reducción del agua disponible en la mayor parte del país, en particular en la costa y la selva.

Estos resultados están relacionados con el aumento de la temperatura, que genera un incremento de la evapotranspiración, con mayor intensidad en las zonas bajas que en las regiones de mayor elevación. La disminución del agua disponible es mayor en la costa debido a que en esta zona una reducción de la precipitación agravaría el aumento de la evapotranspiración. En contraste, en la sierra el aumento de la evapotranspiración sería menor, mientras que en las vertientes orientales de los Andes la pérdida de agua por evapotranspiración se vería compensada por un aumento en la precipitación. Este análisis revela tendencias consistentes con los patrones a escala continental (Buytaert et al., 2010), relevantes para el manejo de recursos hídricos.

Los resultados también muestran una tendencia hacia una mayor estacionalidad en las precipitaciones y una fuerte reducción del agua disponible durante el mes más seco, lo que se vincula a que los modelos globales proyectan temporadas secas y húmedas más intensas, con un efecto directo en la intensificación del ciclo del agua en el mundial (Bates et al., 2008).

Como ya se discutió previamente, una de las tendencias esperadas sería la fuerte expansión de la agricultura. Si a sus efectos se añade la reducción en la disponibilidad hídrica, causada por el fenómeno climático, se esperaría una mayor reducción en la superficie de biomas y de los reservorios naturales que favorecen la regulación estacional del agua.

31 Dado que en el aspecto regional resulta difícil separar la escorrentía superficial y subsuperficial, en este estudio se consideran de manera conjunta. Las escorrentías superficial y subsuperficial determinan la disponibilidad de agua en los reservorios. 
MAPA IV.4

Cambios en la disponibilidad promedio de agua bajo los escenarios A2, A1B y B2, 2010-2100

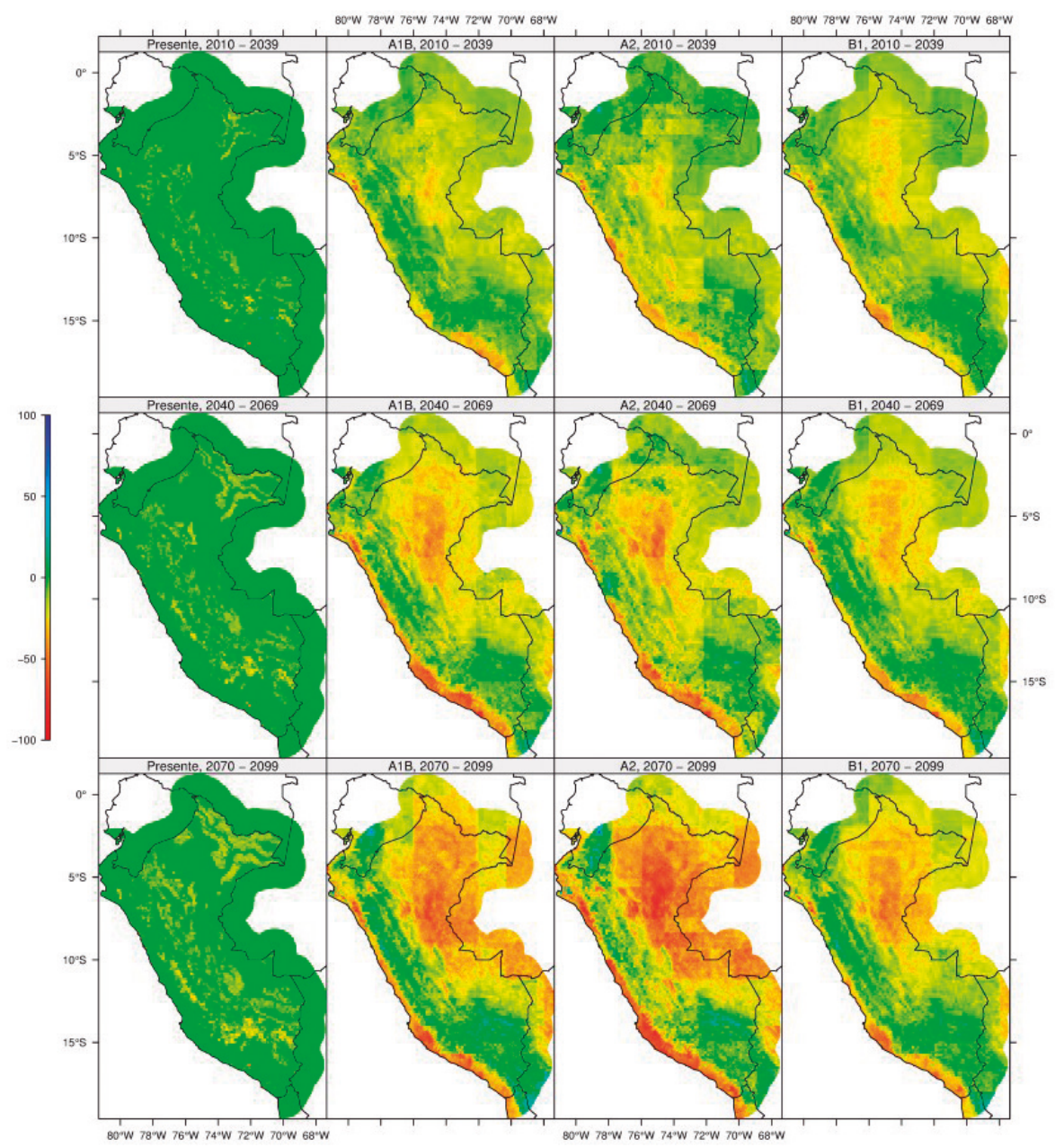

Fuente: Elaboración propia.

Nota: El gráfico muestra la mediana del ensamble de modelos del IPCC seleccionados.

Dada la gran variabilidad de las proyecciones, ciertos modelos anuncian una disminución importante de la disponibilidad del agua. El extremo más seco de los siete modelos considerados proyecta una disminución mayor al 50\% de la disponibilidad de agua. Dado que el modelo "más seco" para cada localidad puede ser distinto, de estos mapas no se puede concluir que todo el país podría enfrentar un estrés hídrico de esa magnitud al mismo tiempo, pero sí que cualquier lugar del territorio nacional, en algún momento, lo podría enfrentar. A pesar de la alta incertidumbre en las proyecciones de los cambios de la disponibilidad de agua, los resultados del estudio permiten observar tendencias consistentes para el manejo del recurso hídrico en el futuro. 



\section{Capitulo V}

\section{Valoración del impacto del cambio climático en sectores productivos seleccionados}

La valoración económica del impacto del cambio climático de acuerdo a sectores se realizó a partir de un análisis de escenarios con y sin cambio climático. Para ello se elaboraron modelos específicos para cada sector (véase el capítulo III sección B), donde se vinculaba la relación entre las variables climáticas, las características físicas del sector y su nivel de producción. Los resultados del modelo de recursos naturales descritos en el capítulo anterior sirvieron como insumo de las características físicas de algunos sectores evaluados.

Los resultados que se presentan en este capítulo se construyen como la diferencia entre el PBI sectorial sin y con cambio climático para diferentes tasas de descuento y años de corte hasta fines de siglo. En los cuadros numéricos, los impactos se consideran negativos (pérdidas o costos), salvo que se expresen con signo negativo.

El análisis del impacto del cambio climático en los sectores seleccionados se realizó para los sectores de agricultura, ganadería altoandina, minería, energía hidroeléctrica, turismo, pesca, infraestructura y salud. Finalmente, a partir de la evaluación sectorial, se integran los resultados y se muestra el impacto del cambio climático sobre la economía nacional.

\section{A. Agricultura}

El sector agropecuario representa alrededor del 8\% del PBI nacional (MINAGRI. 2011c), proporción mantenida desde hace al menos una década. Emplea alrededor del 26\% de la PEA nacional y es el segundo sector con mayor absorción de empleo, luego de servicios.

En el gráfico VII.1 se aprecia la evolución del PBI agropecuario y su participación porcentual en la estructura productiva nacional desde el año 1950 hasta 2010. El sector agropecuario ha presentado un importante crecimiento desde mediados de la década de 1990. Particularmente, el sector agrícola empresarial desarrolló un ciclo de expansión significativo desde 1995. También se aprecia que el sector agropecuario ha disminuido su participación en el porcentaje del PBI nacional durante este período, aunque su comportamiento es variable. 
GRÁFICO V.1

PBI agropecuario y participación porcentual del sector en el PBI nacional

(En millones de soles de 2010 y en porcentaje)

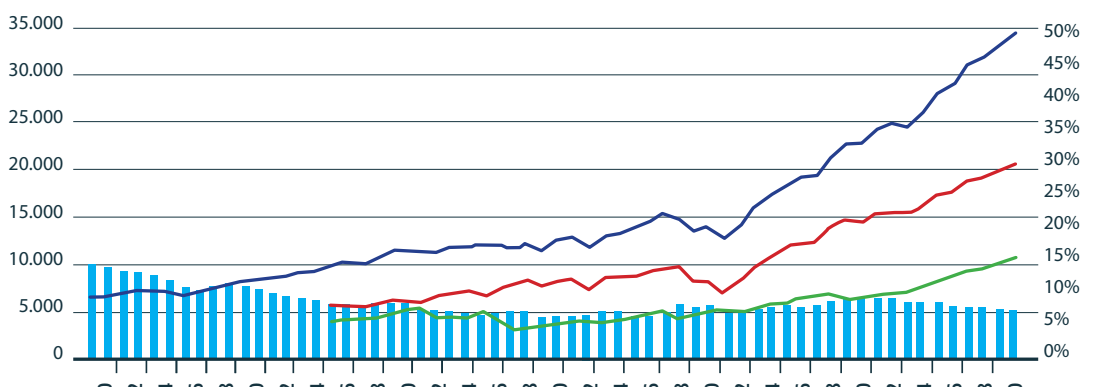

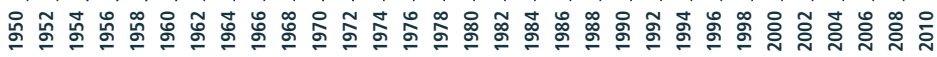

\% agropecuario $\longrightarrow$ PBI agropecuario $\quad$ PBI agrícola $\quad$ PBI pecuario

Fuente: Elaboración propia sobre la base del Banco Central de Reserva del Perú (2011).

El comportamiento del PBI agropecuario se podría explicar más por un aumento en los volúmenes de la producción, que por el incremento de precios. Otros factores que han influido en el desempeño de los últimos años se asocian con condiciones climáticas favorables; la tendencia hacia la tecnificación de la producción con el uso de semillas mejoradas; el crecimiento de la oferta agrícola, generado por la implementación de proyectos de inversión, como Chavimochic o Chira-Piura; el incremento en la exportación de productos hortofrutícolas y de frutas frescas. Finalmente, el crecimiento del sector también se ha debido a la apertura hacia mercados externos, además de precios internacionales favorables de los principales productos exportados.

Según el III Censo Nacional Agropecuario, la superficie total cultivable del país asciende a 5,48 millones de hectáreas (870 mil hectáreas en la costa, 2,83 millones en la sierra y 1,77 millones en la selva) 32. Del total de superficie cultivable, aproximadamente 2,11 millones de hectáreas se destinan a cultivos transitorios, y 892,3 miles son para cultivos permanentes.

Los principales cultivos en términos de VBP del 2009 son: papa, arroz, café, caña de azúcar, plátano, maíz amariIlo duro y maíz amiláceo. Estos cultivos representaron, en conjunto, aproximadamente el 47\% del VBP agrícola, como se muestra en el cuadro III.3.

\section{Relación del sector con las variables climáticas}

En el Perú la actividad agrícola es un sector vulnerable a las variaciones climáticas causadas por eventos anómalos (como inundaciones, granizadas o heladas, y eventos ENSO, que afectan el rendimiento de los cultivos).

El 34\% de la superficie agrícola está bajo riego y se concentra en la costa, con mayor infraestructura que en el resto del país. El 66\% de la agricultura se desarrolla bajo secano, dependiendo exclusivamente de las Iluvias, y se localiza principalmente en la sierra y la selva. La sierra presenta un déficit de infraestructura de almacenamiento de agua y de riego, a pesar de contar con un mayor volumen de lluvias. Además, no posee un alto potencial de nuevos suelos para el cultivo, por su accidentado territorio. Es por ello que las sequías tienen efectos muy negativos en esta zona. Finalmente, la selva presenta altas precipitaciones durante seis meses al año, y cuenta con pocas áreas propicias para cultivos y con restricciones de orden natural para esta actividad (MINAM, 2010).

32 El III CENAGRO fue realizado en 1994 y constituye el más reciente al momento de la elaboración del estudio. 
En el capítulo metodológico (véase el capitulo III, sección B, acápite 1) se establecieron relaciones entre los rendimientos agrícolas y los umbrales de temperatura y precipitación, a partir de los cuales los efectos del cambio climático pueden ser beneficiosos o perjudiciales, dependiendo de la fenología del cultivo y de las condiciones climáticas locales. Se destaca que la variable de precipitación solo fue significativa para el caso del maíz amiláceo.

El gráfico V.2 presenta las relaciones encontradas entre el rendimiento de los cultivos seleccionados y las temperaturas máximas y mínimas e identifica los umbrales óptimos.

\section{GRÁFICO V.2}

Función de producción de cultivos en relación con la temperatura

(En tonelada métrica y en grados centígrados)

a) Papa

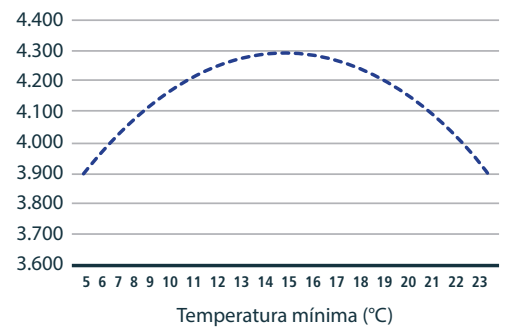

c)Maíz amarillo duro

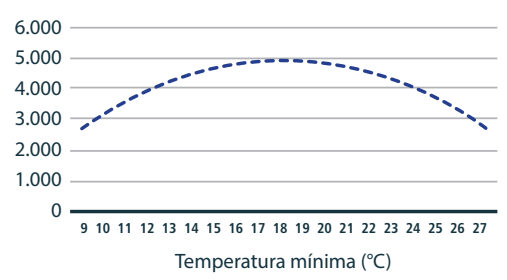

e) Caña de azúcar

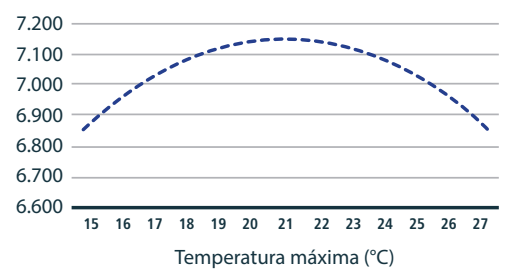

\section{b) Arroz}

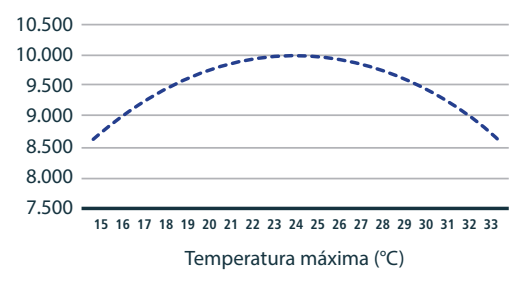

d) Maíz amiláceo

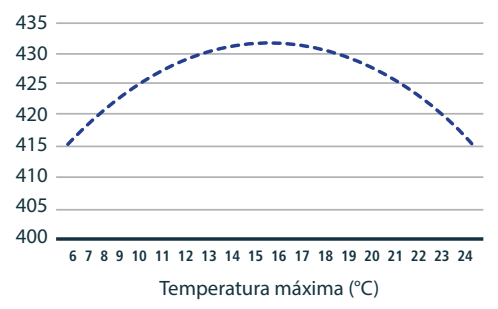

f) Café

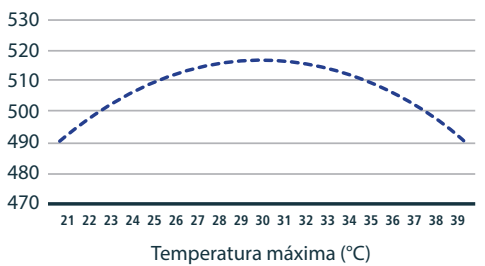

\section{g) Plátano}

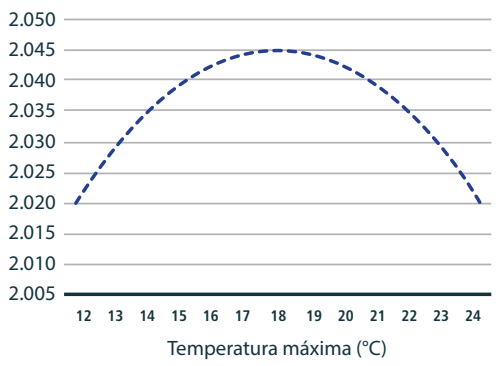




\section{Impactos del cambio climático en el sector agrícola}

A partir de las relaciones calculadas en el punto anterior, se establecieron los impactos en los rendimientos y en el valor de la producción de los cultivos seleccionados para los escenarios climáticos. Las proyecciones indican que el impacto del cambio climático en la agricultura generaría disminuciones en la producción para casi todos los cultivos y para todos los escenarios, siendo más severo en el escenario A2 (ver gráfico V.3). La única excepción es el café, que presentaría un comportamiento distinto, pues en los primeros años la producción crecería levemente, para luego disminuir. Esto se debe a que las condiciones climáticas óptimas para la maximización de la producción se alcanzarían en los años siguientes, ya que este cultivo presenta mejores niveles de producción a mayores temperaturas. En el gráfico también se muestra que la producción del cultivo de arroz sería la más afectada por el cambio climático en los tres escenarios.

GRÁFICOV.3

Impacto del cambio climático en el valor de la producción de los cultivos seleccionados bajo los escenarios A1B, A2 y B1, 2010-2100

(En variación porcentual)

a) Papa

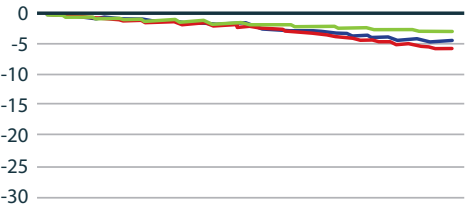

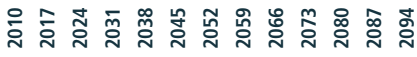

$-\mathrm{A} 1 \mathrm{~B}-\mathrm{A} 2-\mathrm{B} 1$

c)Maíz amarillo duro

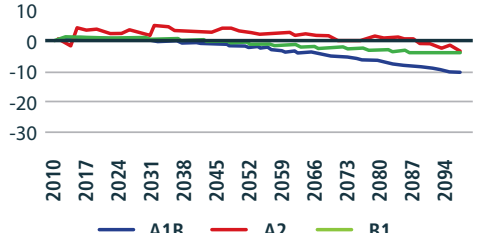

e) Caña de azúcar

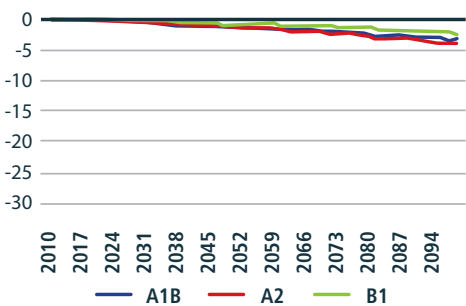

Gráfico continúa en la siguiente página. b) Arroz

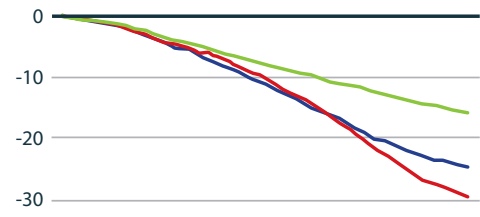

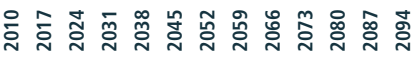

$-\mathrm{A} 1 \mathrm{~B}-\mathrm{A2}-\mathrm{B} 1$

d) Maíz amiláceo

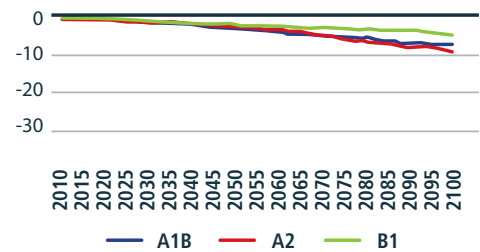

f) Café

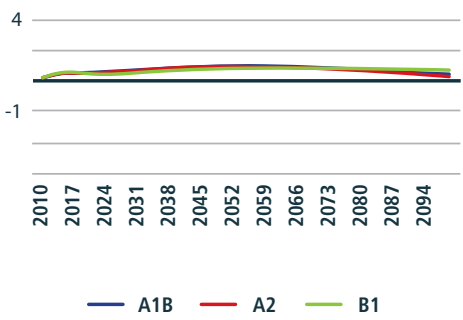




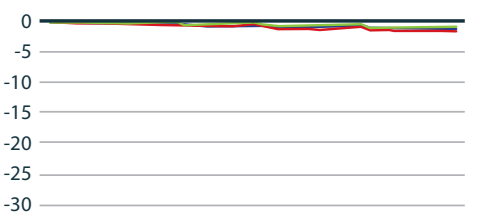

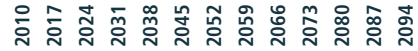

$-\mathrm{A} 1 \mathrm{~B}-\mathrm{A} 2-\mathrm{B} 1$

Fuente: Elaboración propia.

A partir de los impactos en los rendimientos de los cultivos se analizaron los cambios en los ingresos del sector agrícola usando el precio promedio de cada cultivo. Como los cultivos seleccionados (papa, arroz, maíz amarillo duro, café, caña de azúcar, plátano y maíz amiláceo) representan únicamente el 37,4\% del PBI agrícola, fue necesario realizar una extrapolación de estos resultados para el total del PBI agrícola y, de este modo, obtener una cifra más representativa.

Los impactos agregados para el sector se muestran en el gráfico V.4, donde se aprecia que el impacto en este sector, ya sea en cifras absolutas o como variación porcentual del PBI agrícola, es negativo y va aumentando a lo largo del tiempo. El mayor impacto sería en los escenarios A1B y A2.

GRÁFICO V.4

Impacto económico del cambio climático en agricultura

a) Millones de soles del 2010

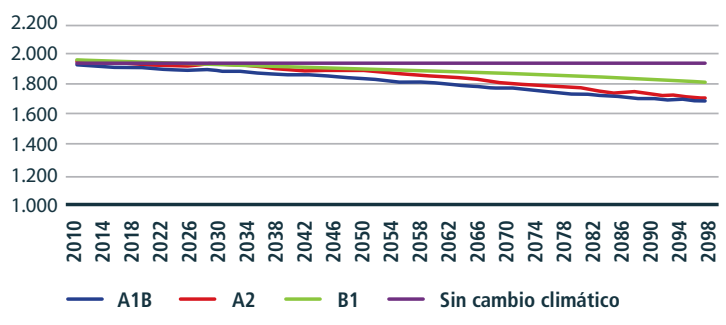

b) Variación porcentual con respecto al año base

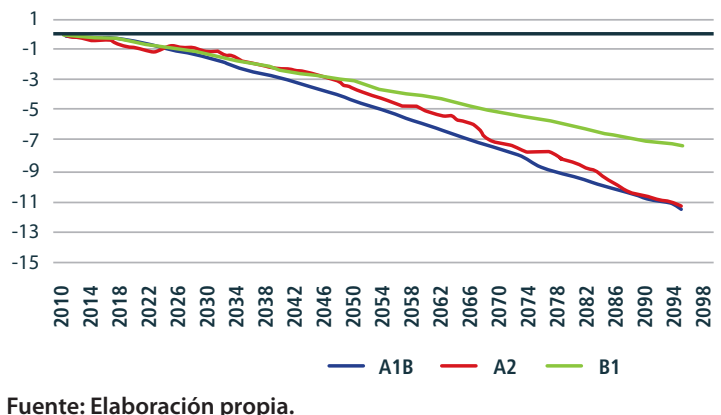


El cuadro V.1 muestra las pérdidas sectoriales acumuladas y actualizadas a las tasas de descuento, escenarios y cortes temporales seleccionados. Asimismo, el cuadro V.2, expone las pérdidas acumuladas como porcentaje del PBI agrícola del año base. Por último, el cuadro V.3 indica las pérdidas acumuladas como porcentaje del PBI nacional. Las pérdidas se presentan en los tres escenarios climáticos considerados (A1B, A2, B1).

Las mermas son incrementales en el tiempo. Al acumularse, superarían los 6.000 de soles millones para finales del siglo XXI, considerando una tasa de 0,5\%, lo cual significa hasta 33\% en pérdidas del PBI agrícola del año base. El escenario menos pesimista es el B1, que arroja pérdidas de casi 5.000 millones de soles (a la misma tasa de descuento), implicando el 24\% en pérdidas del PBI agrícola del año base.

CUADRO V.1

Impacto económico del cambio climático en agricultura

(En millones de soles de 2010)

\begin{tabular}{|l|c|c|c|c|c|c|c|c|c|}
\hline \multirow{2}{*}{ Escenario } & \multicolumn{3}{|c|}{$\mathbf{2 0 1 1 - 2 0 4 0}$} & \multicolumn{3}{|c|}{$\mathbf{2 0 1 1 - 2 0 7 0}$} & \multicolumn{3}{|c|}{$\mathbf{2 0 1 1 - 2 1 0 0}$} \\
\cline { 2 - 10 } & $\mathbf{0 , 5} \%$ & $\mathbf{2 \%}$ & $\mathbf{4} \%$ & $\mathbf{0 , 5} \%$ & $\mathbf{2} \%$ & $\mathbf{4} \%$ & $\mathbf{0 , 5} \%$ & $\mathbf{2} \%$ & $\mathbf{4} \%$ \\
\hline A1B & 616 & 453 & 309 & 2.849 & 1.568 & 768 & 6.619 & 2.797 & 1.058 \\
\hline A2 & 583 & 443 & 316 & 2.429 & 1.360 & 692 & 5.991 & 2.515 & 962 \\
\hline B1 & 563 & 418 & 288 & 2.271 & 1.276 & 644 & 4.789 & 2.097 & 838 \\
\hline
\end{tabular}

Fuente: Elaboración propia.

CUADRO V.2

Impacto del cambio climático en agricultura con respecto al PBI sectorial del año 2010

(En porcentaje)

\begin{tabular}{|l|c|c|c|c|c|c|c|c|c|}
\hline \multirow{2}{*}{ Escenario } & \multicolumn{3}{|c|}{$\mathbf{2 0 1 1 - 2 0 4 0}$} & \multicolumn{3}{|c|}{$\mathbf{2 0 1 1 - 2 0 7 0}$} & \multicolumn{3}{|c|}{$\mathbf{2 0 1 1 - 2 1 0 0}$} \\
\cline { 2 - 10 } & $\mathbf{0 , 5} \%$ & $\mathbf{2} \%$ & $\mathbf{4} \%$ & $\mathbf{0 , 5} \%$ & $\mathbf{2} \%$ & $\mathbf{4} \%$ & $\mathbf{0 , 5} \%$ & $\mathbf{2} \%$ & $\mathbf{4} \%$ \\
\hline A1B & 3,1 & 2,3 & 1,5 & 14,2 & 7,8 & 3,8 & 33,1 & 14,0 & 5,3 \\
\hline A2 & 2,9 & 2,2 & 1,6 & 12,1 & 6,8 & 3,5 & 29,9 & 12,6 & 4,8 \\
\hline B1 & 2,8 & 2,1 & 1,4 & 11,3 & 6,4 & 3,2 & 23,9 & 10,5 & 4,2 \\
\hline
\end{tabular}

Fuente: Elaboración propia.

CUADRO V.3

Impacto del cambio climático en agricultura con respecto al PBI nacional del año 2010

(En porcentaje)

\begin{tabular}{|l|c|c|c|c|c|c|c|c|c|}
\hline \multirow{2}{*}{ Escenario } & \multicolumn{3}{|c|}{$\mathbf{2 0 1 1 - 2 0 4 0}$} & \multicolumn{3}{|c|}{$\mathbf{2 0 1 1 - 2 0 7 0}$} & \multicolumn{3}{c|}{$\mathbf{2 0 1 1 - 2 1 0 0}$} \\
\cline { 2 - 10 } & $\mathbf{0 , 5} \%$ & $\mathbf{2} \%$ & $\mathbf{4} \%$ & $\mathbf{0 , 5} \%$ & $\mathbf{2} \%$ & $\mathbf{4} \%$ & $\mathbf{0 , 5} \%$ & $\mathbf{2} \%$ & $\mathbf{4} \%$ \\
\hline A1B & 0,14 & 0,13 & 0,13 & 0,64 & 0,51 & 0,55 & 1,49 & 1,08 & 1,35 \\
\hline A2 & 0,10 & 0,09 & 0,10 & 0,35 & 0,29 & 0,31 & 0,63 & 0,47 & 0,57 \\
B1 & 0,07 & 0,06 & 0,07 & 0,17 & 0,14 & 0,16 & 0,24 & 0,19 & 0,22 \\
\hline
\end{tabular}

Fuente: Elaboración propia. 
El impacto del cambio climático en la agricultura afectaría la producción de la mayoría de los productos analizados. Los resultados apuntan a que el impacto del cambio climático en la agricultura generará disminuciones en la producción para todos los cultivos y escenarios, siendo más severo en los escenarios A1B y A2, con excepción del café, que presenta un comportamiento distinto, pues en los primeros años crecerá la producción y luego disminuirá levemente.

\section{B. Ganadería altoandina}

En general, la producción ganadera está dedicada al mercado interno, dada la predominancia de la crianza en minifundios. Como se mostró en el gráfico V.1 (sección agricultura), el PBI pecuario ha crecido en los últimos años, pero reduciendo su aporte relativo al PBI nacional, como consecuencia del mayor crecimiento de otros sectores.

El sector pecuario es bastante concentrado. Los subsectores de producción avícola y vacuna son más relevantes, por su aporte en el Valor Bruto de la Producción (VBP) ${ }^{33}$. Aproximadamente un $80 \%$ de la ganadería nacional se encuentra en la sierra y en la selva, bajo sistemas de producción extensiva o semi intensiva. El restante 20\% se localiza en la costa, con crianza intensiva (MINAGRI, 2011c).

La crianza de camélidos y ovinos se despliega principalmente bajo sistemas extensivos, de alta dependencia ante las condiciones climáticas para la generación del forraje que los alimenta y para la salud de los animales. Por otro lado, las principales actividades del sector pecuario están relacionadas con los sistemas de producción estabulados o en granjas, que se desarrollan bajo condiciones climáticas óptimas para la crianza de los animales, como en el caso de las aves de corral.

La ganadería del Perú se conforma por aproximadamente 5,5 millones de vacunos, 14 millones de ovinos, 4,2 millones de alpacas, 2 millones de cabras, 1,2 millones de llamas y 203.000 vicuñas. Se destaca en particular que las alpacas del Perú representan más del 85\% de la población mundial (MINAGRI, 2011c). Por otro lado, la mayor parte del ganado doméstico es "criollo", ya que son animales rústicos con bajos niveles de mejoramiento genético y de alimentación, y que generan baja productividad (Flores et al., 2007).

Si bien el sector pecuario muestra una participación en el PBI nacional menos significativa que otros sectores, su actividad resulta vital para un sector poblacional importante. Hay que notar que este estudio se enfocará únicamente en la ganadería altoandina, que representa el 12\% del PBI pecuario. Hasta fines de 2010 existían en el Perú 6.609 comunidades campesinas reconocidas, caracterizadas por su alto nivel de pobreza y dedicadas principalmente a la ganadería extensiva de pastizales. Estas familias campesinas constituyen aproximadamente $69 \%$ de las familias rurales y $30 \%$ del total de las familias del país (Flores et al., 2007).

La mayoría de vacunos, ovinos y camélidos en el Perú se localizan entre los 2.200 y 4.500 metros sobre el nivel del mar (msnm), y están en manos de las comunidades campesinas, que utilizan los pastizales como recurso básico para la alimentación de sus animales. La ecorregión Puna, donde se desarrolla la mayoría de la ganadería extensiva, abarca un área de más de 21 millones de hectáreas, de pastizales, humedales, glaciares, cuerpos de agua y zonas de protección, y es un ecosistema clave para la economía nacional, por los productos y servicios ambientales que brinda a la sociedad (Brown y MacLeod, 2011). Debido a la fragilidad de los ecosistemas que alberga esta zona y a los altos índices de pobreza que exhibe, ha sido considerada como una zona de alta vulnerabilidad a los impactos del cambio climático (Vidal y Muñoz; 2010, Flores et al., 2012).

33 La producción de aves es el 18,5\% del VBP agropecuario y ha experimentado un explosivo crecimiento en las últimas décadas, siendo el subsector con mayor generación de empleo. Asimismo, posee un alto nivel de desarrollo tecnológico, con avances en los indicadores productivos (genética, equipos y alimentación). El otro subsector importante es el vacuno, que representa el 7,5\% del total (MINAGRI, 2011c). 


\section{Relación del sector con las variables climáticas}

El cambio de uso de la tierra y la composición de las coberturas fue parte central del modelo conceptual desarrollado para analizar el impacto futuro del cambio climático en la ganadería, ya que los pajonales ${ }^{33}$, los bofedales ${ }^{34}$ y los arbustales no solo tienen diferentes capacidades de carga, sino que cambiarán su superficie debido al efecto del retroceso glaciar, el aumento en los índices de temperatura y la expansión de áreas agrícolas. Es necesario señalar además que la dinámica de la población de ganado (vacuno, ovino y camélido), junto con la condición ecológica, la intensidad de pastoreo y la capacidad de carga animal, resultan fundamentales, conjuntamente con la composición vegetal, para estimar la estructura, los niveles y la magnitud de los cambios en los valores económicos de la producción (Evans y Workman, 1994).

Como se detalla en la metodología (capítulo III, sección B, acápite 2), mediante el análisis de la productividad de los biomas y la capacidad de carga animal en unidades ovino (UO) se calcula el valor económico de la producción pecuaria en la ecorregión puna, fruto de los impactos del cambio climático en las áreas exclusivas de pastoreo ${ }^{36}$ se estimaron a partir de mapas de uso actual, coberturas y pendiente del terreno a un $1 \mathrm{~km}$ de resolución espacial. Para ello se analizó el impacto sobre la cobertura vegetal (arbustal, pajonal y bofedal) del fenómeno climático dado por los escenarios A1B, A2 y B1. Las áreas netas de pastoreo se estimaron a partir de los mapas de uso actual, coberturas y pendiente del terreno a un 1 km de resolución espacial.

\section{Impactos del cambio climático en el sector de ganadería altoandina}

Los resultados indican que en este subsector se esperan cambios importantes por efecto del cambio climático, tanto por la disminución de las tierras de pastoreo como por la competencia espacial con el sector agrícola, debido a los desplazamientos que podría tener la producción agraria hacia zonas de mayor altitud.

Dichos resultados muestran una significativa reducción en la extensión de tierras de pastoreo. Esta área, que está conformada por pajonales, bofedales y arbustales, y que en 2010 representó el 77,6\% de la extensión total de la puna, iría reduciéndose hasta quedar en aproximadamente un 50\% para fines de siglo. En el caso de los pajonales, estos reducirían su extensión, pasando de 15,4 a 4,6 millones de hectáreas, mientras que los bofedales pasarían de 0,5 a 0,2 millones de hectáreas. A su vez, los arbustales incrementarían sustancialmente su extensión a lo largo del tiempo, aumentando de 2,8 a 7,1 millones hectáreas (véase el mapa V.1). Hay que notar que el aumento en la proporción de arbustales no se traduciría necesariamente en incrementos de la carga animal, debido a que estos toleran menores niveles de uso y producen menos forraje que los otros tipos de vegetación.

La reducción en la extensión de los pajonales, junto con la menor productividad relativa de la vegetación arbustiva y la expansión de la agricultura, reduciría la capacidad de carga y el aporte relativo de la ganadería al PBI. Sumado a esto, la reducción en los bofedales -recurso estratégico, ya que constituyen una importante fuente de forraje durante los períodos de sequía- dificultaría el desarrollo de la ganadería. Esto es particularmente cierto en aquellas zonas áridas donde estos espacios son la principal fuente de abastecimiento de agua en períodos críticos o de ausencia de lluvias, como en la puna seca.

Para facilitar el análisis del impacto del cambio climático en la ganadería altoandina fue necesario transformar a unidades ovino (UO) todas las especies pecuarias (ovinos, vacunos, camélidos, equinos, caprinos)

34 Los pajonales son densas agrupaciones en matas de gramíneas de hojas duras, en algunos casos punzantes, conocidos con los nombres comunes de ichu o paja en el territorio altoandino. Este tipo de pastizal es dominado por gramíneas altas entre las que destacan los géneros Festuca, Calamagrostis y Stipa.

35 Los bofedales están constituidos por especies vegetales propias de ambientes húmedos de carácter permanente o temporal, y constituyen fuentes de forraje durante los periodos de sequía. Su composición florística la dominan especies de porte almohadillo de los géneros Distichia, Plantago, Calamagrostis, Hipochoeris y Alchemilla.

36 Todas las especies pecuarias que hacen uso del ecosistema de puna (ovinos, vacunos, camélidos, equinos, caprinos) fueron transformadas a unidades ovino para simplificar el cálculo y análisis de los datos. 
que hacen uso del ecosistema de la puna para, de este modo, determinar la variación de la producción de la carne, considerando los efectos del fenómeno (véase el capítulo III, sección B, acápite 2).

MAPA V.1

Impactos del cambio climático en las áreas de pastoreo, 2010-2100

A. (2010)

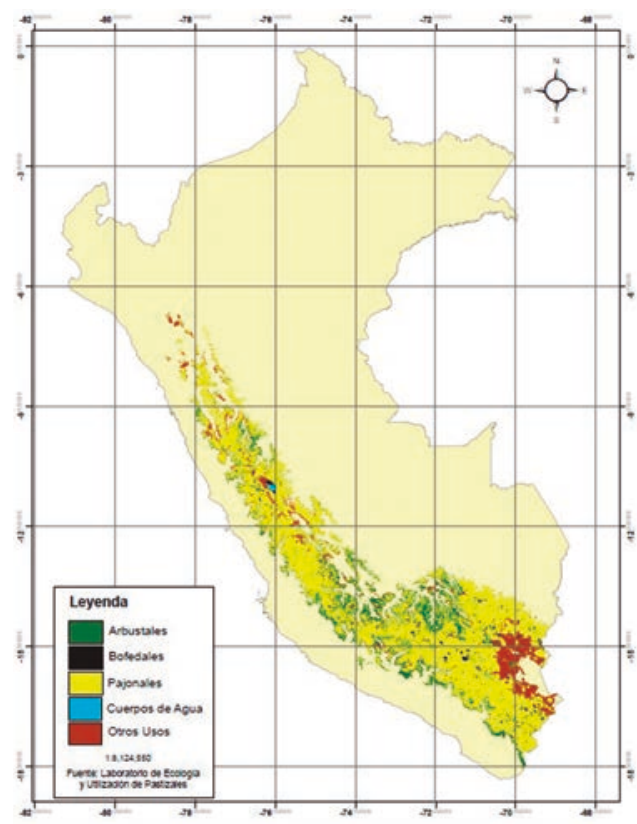

C. (2070)

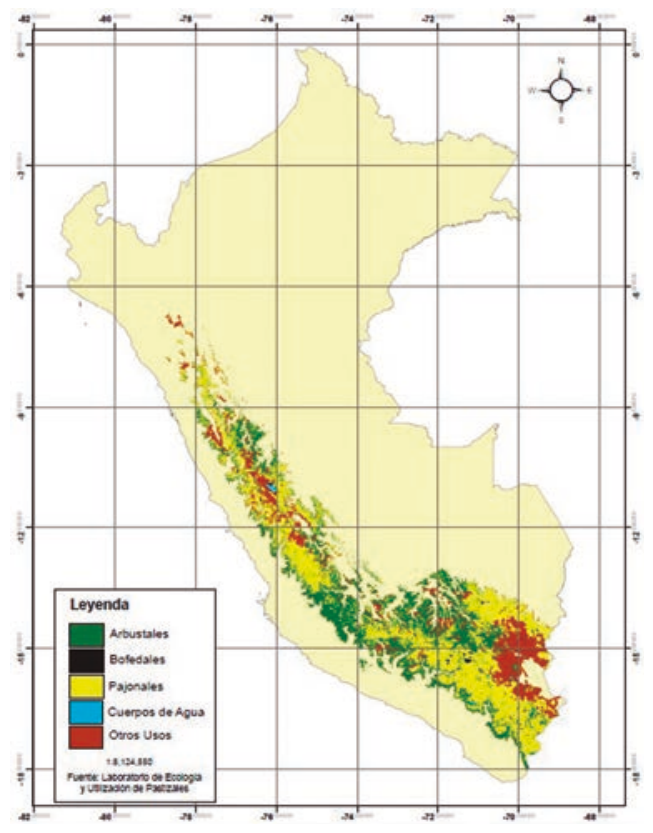

B. (2040)

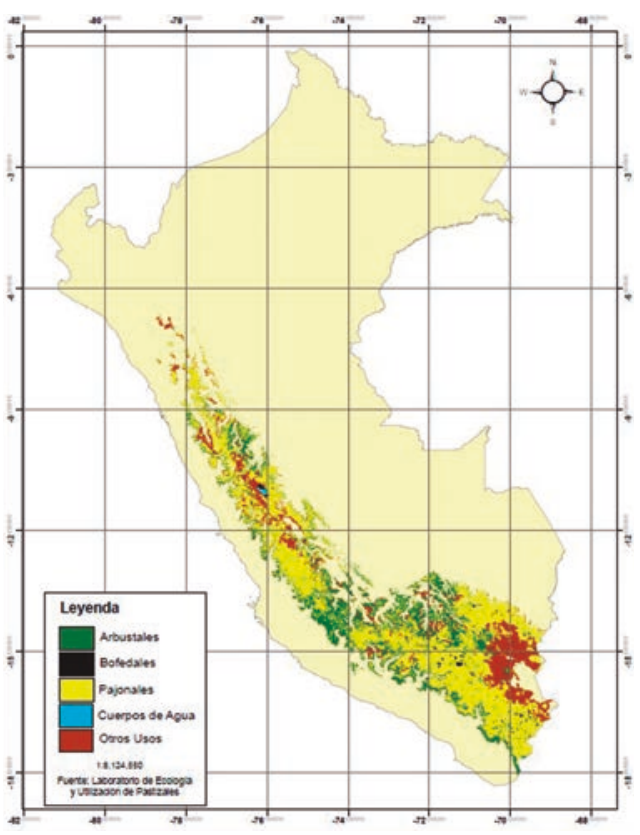

D. (2100)

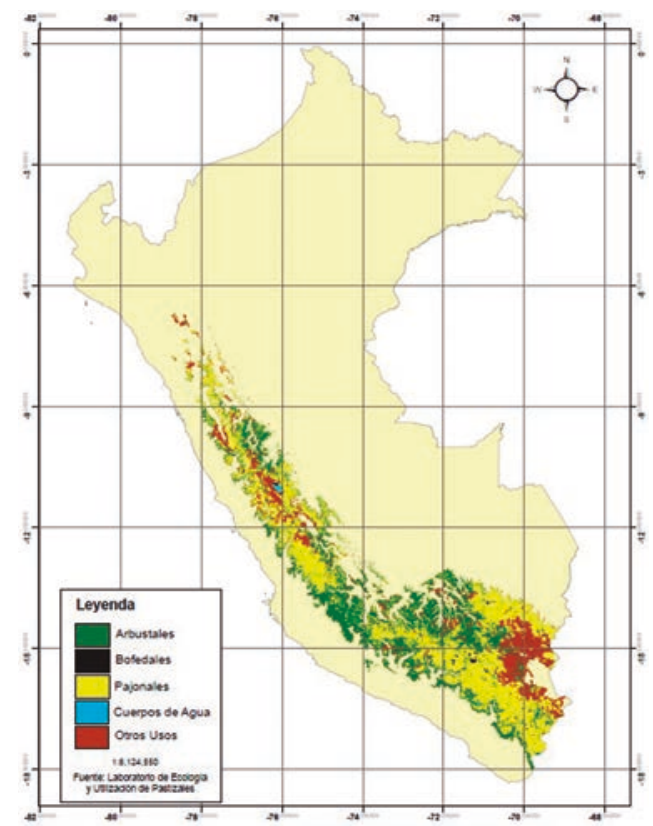

Fuente: Elaboración propia. 
Los resultados para el análisis de los tres escenarios climáticos sugieren una reducción progresiva de la capacidad de carga de los ecosistemas y una disminución en la superficie disponible de tierras de pastoreo. El mayor impacto sería para el escenario A2, donde las unidades ovinas pasarían de 45 millones en 2010 a 19 millones para finales de siglo. Le seguiría el escenario A1B, con reducciones que irían entre 45 millones a 21 millones para el mismo período. Por último, con menores impactos, estaría el escenario B1 (véase el gráfico V.5).

GRÁFICO V.5

Impacto del cambio climático en la carga animal total para la puna

(En millones de unidades ovinas)

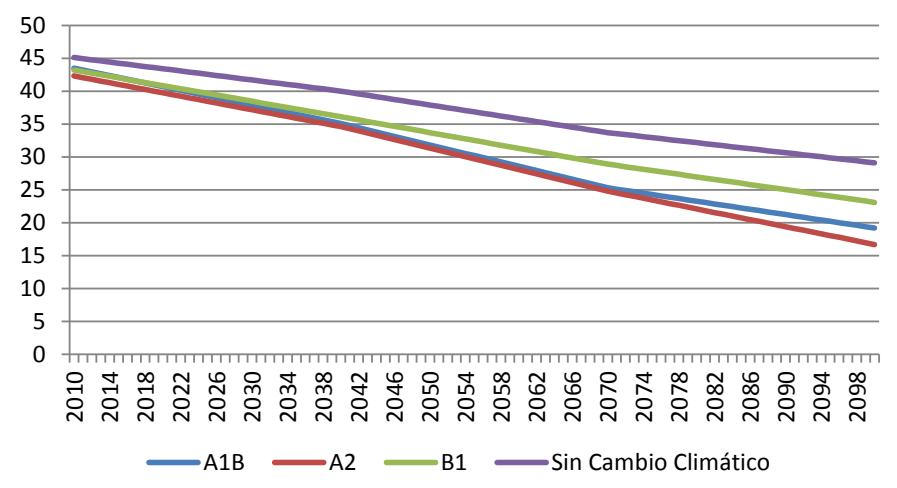

Fuente: Elaboración propia.

Para valorar el impacto económico fue necesario convertir el número de unidades ovinas, a su equivalente en carne, tal como se detalla en la metodología. A partir de esta información, se determinó la reducción de la producción de carne de ovino en un escenario con cambio climático. Posteriormente, se realizó la valoración económica del impacto del cambio climático en el sector pecuario, determinando la variación en los ingresos por carne de ovino, como se muestra en el gráfico V.6.

GRÁFICO V.6

Impacto del cambio climático en el ingreso de la ganadería altoandina

a) Millones de soles del 2010

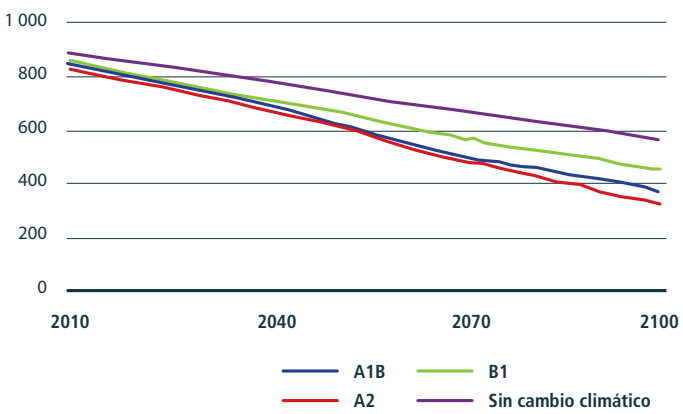

b) Variación porcentual con respecto al base

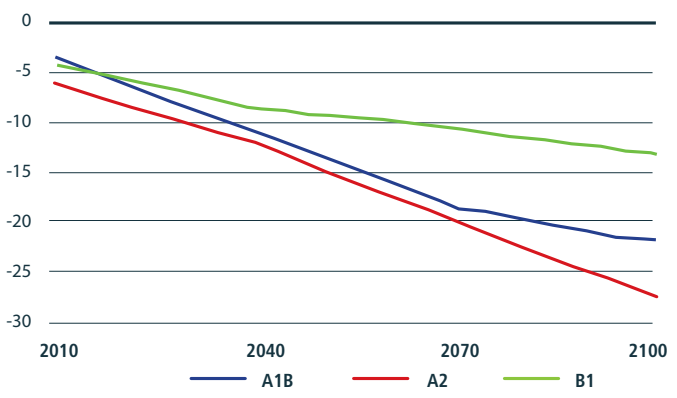

Fuente: Elaboración propia. 
En el cuadro V.4 se muestran las pérdidas acumuladas en millones de soles, actualizadas por medio de distintas tasas de descuento, para diversos escenarios de emisión y cortes temporales. La estimación representa las pérdidas en el sector pecuario altoandino, particularmente para las especies ganaderas de altura. El cuadro V.5 presenta las pérdidas acumuladas como porcentaje del PBI pecuario del año base (2010). En todas las proyecciones se observa que los tres escenarios climáticos futuros ocasionarían impactos negativos. En especial en el escenario A2, los impactos serían mayores y se incrementarían en el tiempo, llegando a acumularse, hasta fines de siglo, una pérdida por más de 9.000 millones de soles a una tasa de 0,5\%. Lo anterior implicaría una perdida equivalente al 90\% del PBI pecuario del año base.

Los distintos escenarios presentan pérdidas acumuladas que podrían variar dependiendo de la tasa de descuento seleccionada. Con una tasa de 0,5\% se tendrían pérdidas que oscilarían entre 57\% y 90\% del PBI pecuario de 2010, mientras que para una tasa de 4\% las pérdidas se situarían alrededor del 16\% y $22 \%$ del PBI.

\section{CUADRO V.4}

Impacto económico del cambio climático en ganadería altoandina

(En millones de soles de 2010)

\begin{tabular}{|l|c|c|c|c|c|c|c|c|c|}
\hline \multirow{2}{*}{ Escenario } & \multicolumn{3}{|c|}{$\mathbf{2 0 1 1 - 2 0 4 0}$} & \multicolumn{3}{c|}{$\mathbf{2 0 1 1 - 2 0 7 0}$} & \multicolumn{3}{c|}{$\mathbf{2 0 1 1 - 2 1 0 0}$} \\
\cline { 2 - 10 } & $\mathbf{0 , 5} \%$ & $\mathbf{2} \%$ & $\mathbf{4} \%$ & $\mathbf{0 , 5} \%$ & $\mathbf{2} \%$ & $\mathbf{4} \%$ & $\mathbf{0 , 5} \%$ & $\mathbf{2} \%$ & $\mathbf{4} \%$ \\
\hline A1B & 1.812 & 1.413 & 1.046 & 4.942 & 2.999 & 1.712 & 8.644 & 4.218 & 2.004 \\
\hline A2 & 2.297 & 1.820 & 1.376 & 5.662 & 3.527 & 2.096 & 9.181 & 4.548 & 2.240 \\
\hline B1 & 1.624 & 1.283 & 968 & 3.668 & 2.332 & 1.415 & 5.854 & 3.050 & 1.586 \\
\hline
\end{tabular}

Fuente: Elaboración propia.

CUADRO V.5

Impacto del cambio climático en ganadería altoandina con respecto al PBI sectorial del año 2010

(En porcentaje)

\begin{tabular}{|l|c|c|c|c|c|c|c|c|c|}
\hline \multirow{2}{*}{ Escenario } & \multicolumn{3}{|c|}{$\mathbf{2 0 1 1 - 2 0 4 0}$} & \multicolumn{3}{c|}{$\mathbf{2 0 1 1 - 2 0 7 0}$} & \multicolumn{3}{c|}{$\mathbf{2 0 1 1 - 2 1 0 0}$} \\
\cline { 2 - 10 } & $\mathbf{0 , 5} \%$ & $\mathbf{2} \%$ & $\mathbf{4} \%$ & $\mathbf{0 , 5} \%$ & $\mathbf{2} \%$ & $\mathbf{4} \%$ & $\mathbf{0 , 5} \%$ & $\mathbf{2} \%$ & $\mathbf{4} \%$ \\
\hline A1B & 17,7 & 13,8 & 10,2 & 48,3 & 29,3 & 16,7 & 84,5 & 41,2 & 19,6 \\
\hline A2 & 22,5 & 17,8 & 13,5 & 55,4 & 34,5 & 20,5 & 89,8 & 44,5 & 21,9 \\
\hline B1 & 15,9 & 12,5 & 9,5 & 35,9 & 22,8 & 13,8 & 57,2 & 29,8 & 15,5 \\
\hline
\end{tabular}

Fuente: Elaboración propia.

CUADRO V.6

Impacto del cambio climático en ganadería altoandina con respecto al PBI nacional del año 2010

(En porcentaje)

\begin{tabular}{|l|c|c|c|c|c|c|c|c|c|}
\hline \multirow{2}{*}{ Escenario } & \multicolumn{3}{|c|}{$\mathbf{2 0 1 1 - 2 0 4 0}$} & \multicolumn{3}{c|}{$\mathbf{2 0 1 1 - 2 0 7 0}$} & \multicolumn{3}{c|}{$\mathbf{2 0 1 1 - 2 1 0 0}$} \\
\cline { 2 - 11 } & $\mathbf{0 , 5} \%$ & $\mathbf{2} \%$ & $\mathbf{4} \%$ & $\mathbf{0 , 5} \%$ & $\mathbf{2} \%$ & $\mathbf{4} \%$ & $\mathbf{0 , 5} \%$ & $\mathbf{2} \%$ & $\mathbf{4} \%$ \\
\hline A1B & 0,41 & 0,32 & 0,24 & 1,11 & 0,67 & 0,38 & 1,94 & 0,95 & 0,45 \\
\hline A2 & 0,52 & 0,41 & 0,31 & 1,27 & 0,79 & 0,47 & 2,06 & 1,02 & 0,50 \\
B1 & 0,36 & 0,29 & 0,22 & 0,82 & 0,52 & 0,32 & 1,32 & 0,69 & 0,36
\end{tabular}

Fuente: Elaboración propia. 
En resumen, los resultados de las proyecciones revelan que la capacidad de carga de la ganadería de la ecorregión Puna se vería afectada negativamente a causa del cambio climático, cuyos efectos se manifestarían en las variaciones en cobertura vegetal y uso de la tierra. La contribución de esta zona a la economía nacional disminuiría notablemente y se vería comprometida la seguridad alimentaria de los grupos poblacionales que dependen de esta actividad. Por lo anterior, se recomienda desarrollar índices de vulnerabilidad de los ecosistemas y estrategias de adaptación.

\section{Pesca}

El área marina de la costa peruana es una de las más ricas del mundo en términos de biomasa y diversidad. Se ha estimado que cuenta con una biodiversidad marina de aproximadamente 900 especies de peces (Chirichigno y Vélez, 1998). Sin embargo, la gran riqueza de este ecosistema está marcada por la producción de una especie en particular, la anchoveta peruana (Engraulis ringens).

El sector pesquero ha crecido en los últimos cincuenta años con oscilaciones importantes. La industrialización de la pesca se inició en 1950 con la harina de pescado, elaborada en base a anchoveta, convirtiendo al Perú en el principal productor mundial (ICEX, 2010) ${ }^{37}$. En ese entonces la pesca se realizaba sin considerar la reproducción de la especie y extrayendo por encima de la máxima captura sostenible ${ }^{38}$. Además de la sobrepesca, hubo un fuerte desequilibrio en la biomasa ocasionado por el fenómeno El Niño de 1972-1973, lo que provocó una fuerte disminución de la anchoveta y el consecuente colapso de la industria.

GRÁFICO V.7

$\mathrm{PBI}$ pesquero y participación porcentual del sector en el PBI nacional

(En millones de soles de 2010 y en porcentaje)

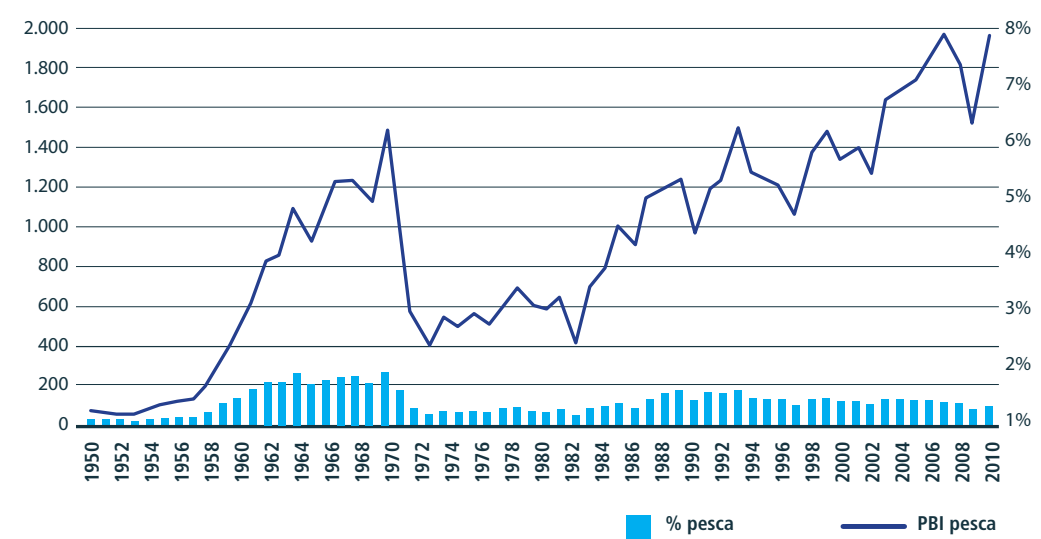

Fuente: Elaboración propia sobre la base del Banco Central de Reserva del Perú (2011).

A partir de los años noventa, el comportamiento de la actividad pesquera mejoró, acompañado de reformas para erradicar las prácticas depredatorias (véase el gráfico V.7). Por ejemplo, el año 2009 se promulgó un sistema de cuotas de pesca. Además, los precios se han incrementado sostenidamente entre los años 2000 y 2011 por la mayor demanda China (Gallardo, 2006). Otro factor relevante para el comportamiento variable de este

37 Las principales contribuciones de la actividad pesquera son la generación de divisas por la exportación de productos y la capacidad de empleo (FAO 2012).

38 Entre 1968 y 1971 se capturaron cerca de 10,5 millones de Tm de anchoveta por año, lo que equivale a más de 75\% de lo actualmente permitido (ICEX 2010). 
sector ha sido el consumo humano indirecto en el cual la anchoveta representa casi la totalidad del consumo ${ }^{39}$. Por otro lado, el consumo humano directo presenta una participación menor en el desembarque total. Dicha participación es menos fluctuante y su tendencia de largo plazo es más estable y predecible (véase el gráfico V.8.)

\section{GRÁFICOV.8}

Desembarque total de recursos hidrobiológicos según tipo de consumo, 1994-2013

(En miles de toneladas métricas)

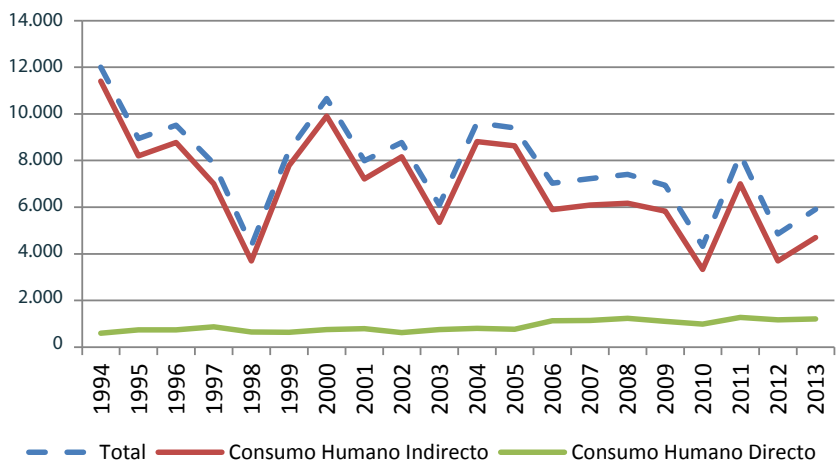

Fuente: Elaboración propia sobre la base del Instituto Nacional de Estadística e Informática (2014).

Históricamente, la anchoveta ha sido el principal producto del sector pesquero, aunque su importancia relativa ha variado. Por ejemplo, ante la depredación de la anchoveta y el fenómeno El Niño de 1972-1973, su espacio fue ocupado por la sardina. Así, a inicios de la década de 1990 esta última tenía una participación relativamente significativa, que fue disminuyendo en el tiempo. El gráfico V.9, muestra el comportamiento del sector pesquero por especies.

\section{GRÁFICO V.9}

\section{Desembarque total de recursos hidrobiológicos según tipo de especie, 1994-2013}

(En porcentaje)

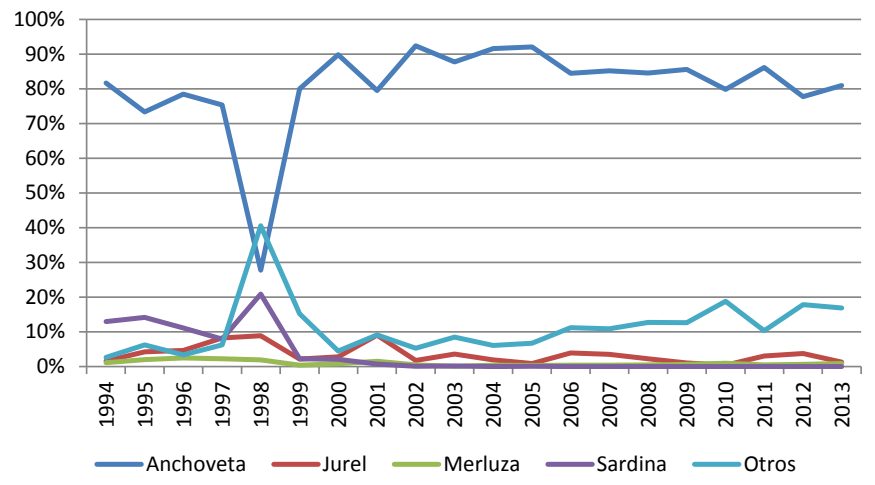

Fuente: Elaboración propia sobre la base del Ministerio de la Producción e Instituto Nacional de Estadística e Informática (2014b).

39 Generalmente, las actividades del sector pesquero se dividen entre producción para Consumo Humano Directo (CHD) y Consumo Humano Indirecto (CHI). Las exportaciones realizadas a partir del CHI se consideran "tradicionales", y las de CHD son "no tradicionales". La producción para CHI se realiza mediante embarcaciones industriales, mientras que la destinada al CHD se concentra en productos frescos para el mercado interno, con exclusividad de pesca dentro de las cinco millas de mar costero. 
Hoy día, la anchoveta sigue siendo la especie más importante del ecosistema pesquero y contribuye con más del 90\% en los desembarques. La producción de harina de pescado contribuye con aproximadamente el 70\% del PBI pesquero. Debido a su bajo nivel trófico ${ }^{40}$ y su gran valor social y económico como producto de la pesca, se considera que un cambio radical en los tamaños de su población, por efecto de impactos de origen antropogénico (pesca, contaminación, cambio climático) o natural (El Niño) causaría cambios en otros recursos costeros que dependen de esta especie. Es por ello que se consideró de suma importancia conocer el posible impacto del cambio climático sobre esta especie fundamental en el ecosistema marino peruano. Por lo anterior, dicho impacto se midió a partir de la variación de la captura de anchoveta y de la producción de harina de pescado. El sector pesca requirió una aproximación distinta a los sectores productivos terrestres, por enfocarse en las 200 millas del océano Pacífico.

\section{Relación del sector con las variables climáticas}

Las observaciones empíricas y el uso de modelos climáticos desarrollados por el IPCC indican que las temperaturas medias globales han aumentado en los últimos 100 años, y se estima que la temperatura superficial del mar seguirá aumentando a un ritmo de alrededor de $0,13^{\circ} \mathrm{C}$ por década. Este incremento repercutirá ampliamente en los ecosistemas.

El efecto del cambio climático sobre la productividad de los recursos pesqueros se da a diferentes niveles. Por un lado, afecta el funcionamiento de los organismos en las diversas etapas del ciclo biológico, manifestándose en la fisiología, la morfología y el comportamiento de los individuos (Cochrane et al. 2012). A nivel poblacional, las perturbaciones se dan en la abundancia e intensidad de las interacciones entre especies (depredación, competencia, entre otros.). Esta combinación de repercusiones en las especies origina a alteraciones en la distribución, la biodiversidad y los procesos microevolutivos (Harley et al., 2006).

En general, la información sobre las repercusiones del cambio climático en los ecosistemas marinos es escasa. Pese a ello, existen en la actualidad pruebas significativas de cambios observados en los sistemas físicos y biológicos en respuesta al cambio climático en todos los continentes, aunque la documentación acerca de los cambios observados en regiones tropicales y en el hemisferio sur es sumamente limitada (Parry et al., 2007). Solo unos pocos estudios modelan los cambios locales o regionales, como el de Moerlein y Carothers (2012) en Alaska y el de Cheung et al. (2011) en el Atlántico nordeste.

Por todo lo anterior, el análisis presentado en este documento para el impacto del cambio climático en el sector pesquero se enfoca únicamente en las variaciones de captura de anchoveta, a partir de la información biológica y oceanográfica disponible. Cabe mencionar que la disponibilidad de oxígeno disuelto en el mar y la temperatura se identificaron como los factores clave que tienen un efecto significativo en el ecosistema marino. Es por ello que se consideraron estas dos variables para estimar la idoneidad de las condiciones marinas para el desarrollo de la anchoveta.

\section{Impactos del cambio climático en el sector pesquero}

La información de base para realizar las proyecciones que permitan analizar la abundancia futura de la anchoveta se presenta en el mapa V.2. Los datos del periodo 1983-2006 indican que la mayor abundancia de esta especie se encuentra en la zona norte centro de la costa peruana (aproximadamente 6-14 º y su extensión abarca casi las 200 millas.

40 El nivel trófico de un organismo es su posición dentro de la cadena alimentaria. Los productores primarios (plantas) están en el nivel 1; los herbívoros, en el nivel 2; los depredadores, en el 3; y los carnívoros o grandes carnívoros, en los niveles 4 o 5. 
MAPA V.2

Abundancia promedio anual estimada de la anchoveta en la costa peruana, 1983-2006

(En toneladas)

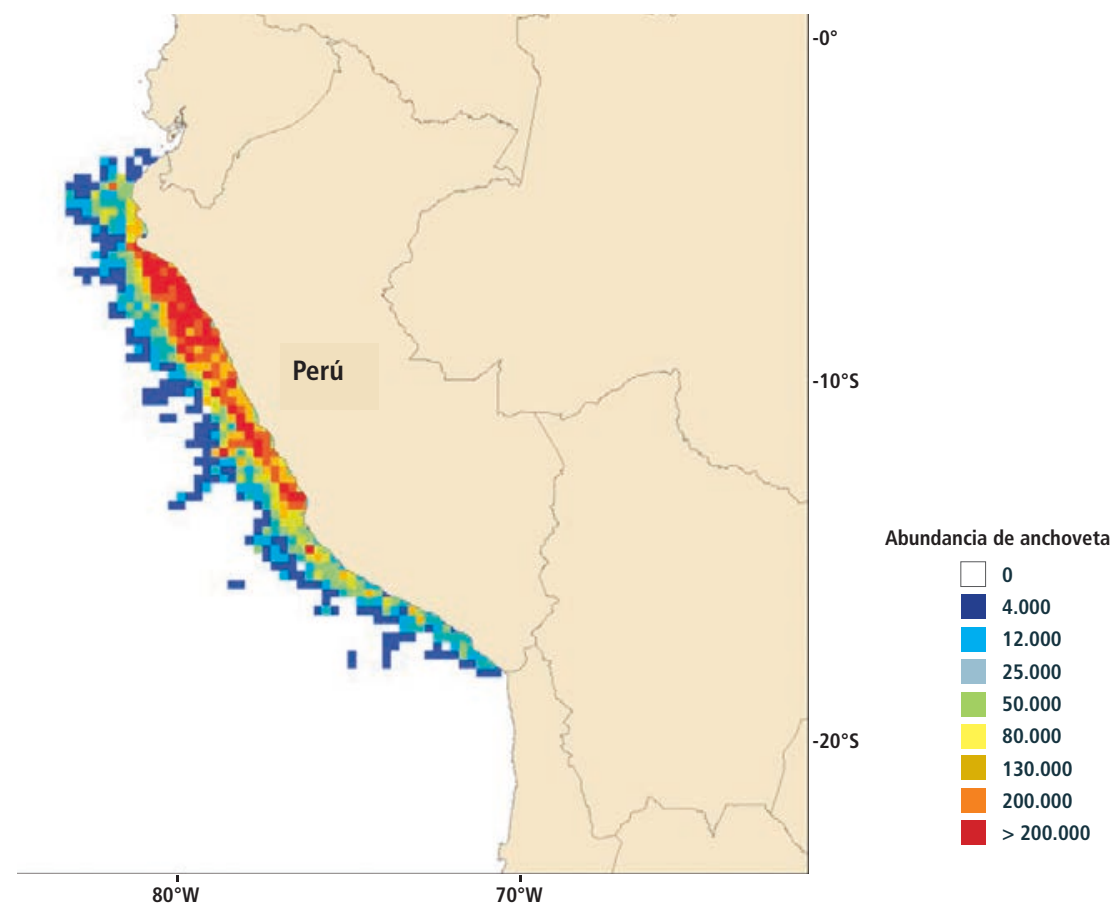

Fuente: IMARPE (2011).

Nota: Estimación realizada para celdas de 0,250 × 0,250

Como se describe en el apartado metodológico correspondiente (véase el capítulo III, sección B, acápite 3), para la proyección de las capturas de anchoveta se seleccionaron dos escenarios climáticos globales, apoyados en el análisis de series de datos disponibles o generados para este propósito ${ }^{41}$. El primer escenario es el RCP 4.5, donde los cambios no son tan drásticos y se esperaría una leve reducción de las capturas hasta el año 2100. En el segundo escenario, RCP 8.5, los cambios serían mayores debido a las altas concentraciones de emisiones esperadas ${ }^{42}$. El escenario RCP 4.5 considera concentraciones equivalentes al escenario B1 de acuerdo con el Quinto Informe del IPCC.

Adicionalmente, se construyó un escenario con información local, que muestra las tendencias de la temperatura en el hábitat de la anchoveta, ya que los aspectos particulares de las costas peruanas no se pueden apreciar en el escenario global.

El análisis de tendencias para el escenario local muestra un cambio positivo en la distribución de la abundancia de la anchoveta hacia el norte de la costa peruana. De acuerdo con estos resultados, la anchoveta se desplazaría hacia el norte en más de un grado de latitud para fines del siglo XXI. Por lo tanto, la captura total proyectada (proporcional a la abundancia total) se incrementaría ligeramente en los años 2050, para luego disminuir hacia el 2100 hasta los mismos niveles del año 2006; mientras que para los escenarios globales se aprecia que la abundancia de la anchoveta se mantiene en los $11^{\circ} \mathrm{S}$.

41 Estos escenarios han sido seleccionados en base a cambios en la temperatura en la costa peruana y en la temperatura global. En la actualidad no es posible anticipar cuál de ellos se mantendrá en el futuro, ya que existen muy pocos trabajos relacionados con proyecciones de temperatura en áreas de afloramiento o a nivel local. Ello también ha llevado a considerar el uso de escenarios diferentes a los del IPCC.

42 En el Quinto Informe del IPCC, la construcción de escenarios de GEl cambia de aproximación, tras concluir que distintas historias posibles generan similares concentraciones de emisiones en la atmósfera. Información más actualizada se puede consultar en la página web del IPCC: www.ipcc.ch 
Como se aprecia en el gráfico V.10, las proyecciones de captura del escenario local revelan un comportamiento muy similar al escenario base ${ }^{43}$. Para los escenarios globales (RCP 4.5 y RCP 8.5), la captura de anchoveta proyectada presentaría una tendencia decreciente, más negativa en el escenario RCP 8.5.

GRÁFICO V.10

Impacto del cambio climático en la captura de anchoveta

(En miles de toneladas)

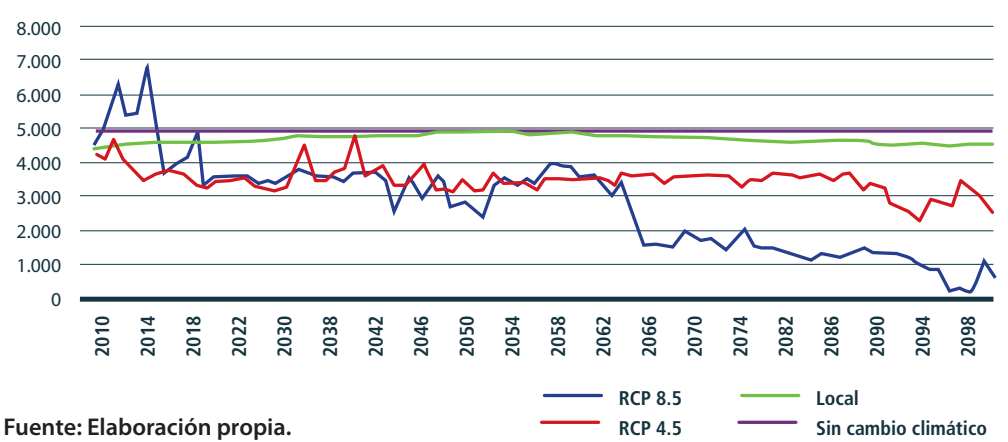

Los datos de la proyección en la captura de anchoveta hasta 2100 se convirtieron a su equivalente en producción de harina de pescado, que es su principal derivado. De este modo se proyectó la producción de harina de pescado con y sin cambio climático, y la respectiva variación en los ingresos (véase el gráfico V.11). Se aprecia que el ingreso por ventas de harina de pescado disminuiría en todos los escenarios. En el escenario RCP 8.5, especialmente, se esperan pérdidas incrementales que superarían el $80 \%$ en promedio para fines de siglo.

GRÁFICO V.11

\section{Impacto del cambio climático en el ingreso por harina de pescado}

a) Millones de soles del 2010

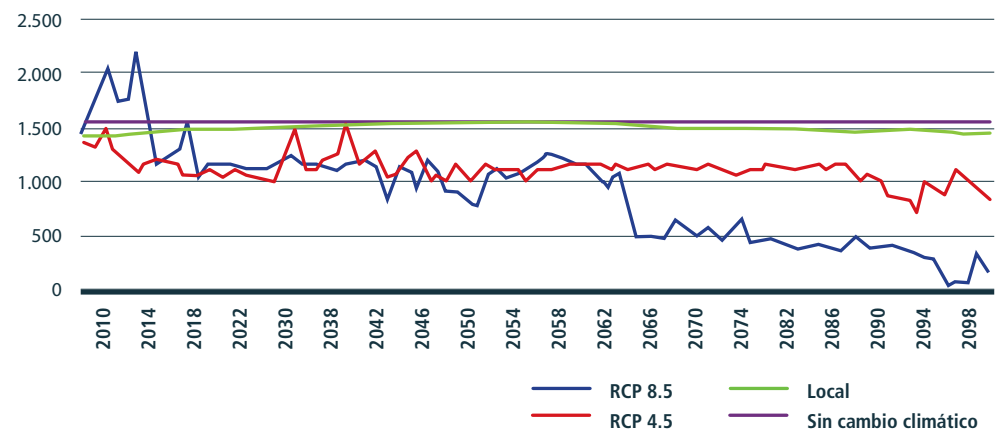

Gráfico continúa en la siguiente página.

43 Cabe consignar que el escenario local, a diferencia de los escenarios globales, no incluye la variable de oxígeno disuelto en el mar. 
b) Variación porcentual con respecto al base

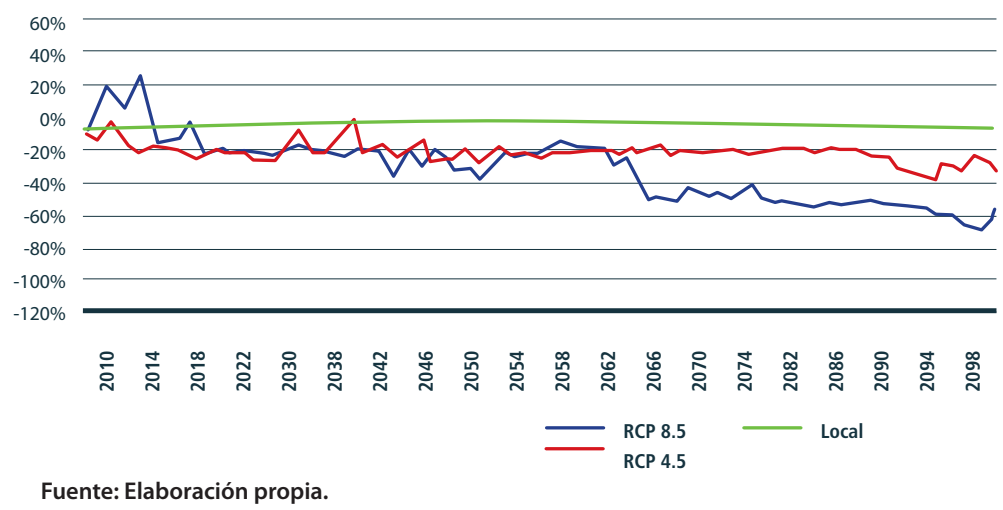

A partir de estos resultados se calculó el impacto del cambio climático en términos de valores presentes y se compararon estos posibles costos con el PBI pesquero y el PBI nacional del año 2010.

Para el período 2011a 2100, como se ve en el cuadro V.7, el escenario que presenta mayores pérdidas acumuladas es el RCP 8.5, con un monto superior a 46.000 millones de soles, evaluado a una tasa de descuento de $0,5 \%$. Por otro lado, para el primer período, las mayores pérdidas se darían en el escenario RCP 4.5, donde se alcanzarían montos cercanos a 11.000 millones de soles. Al comparar con el PBI pesquero del año 2010 (véase el cuadro V.8), se aprecia que el impacto acumulado en el escenario con mayores pérdidas sería 30 veces el producto del sector. Es importante notar que, para la misma tasa de descuento y período de análisis, estos impactos podrían variar. En relación con el PBI nacional el impacto acumulado hasta finales de siglo podría llegar a ser 10\% del producto del año 2010 (véase el cuadro V.9).

CUADRO V.7

Impacto económico del cambio climático en el sector pesca

(En millones de soles de 2010)

\begin{tabular}{|l|c|c|c|c|c|c|c|c|c|}
\hline \multirow{2}{*}{ Escenario } & \multicolumn{3}{|c|}{$\mathbf{2 0 1 1 - 2 0 4 0}$} & \multicolumn{3}{c|}{$\mathbf{2 0 1 1 - 2 0 7 0}$} & \multicolumn{3}{c|}{$\mathbf{2 0 1 1 - 2 1 0 0}$} \\
\cline { 2 - 10 } & $\mathbf{0 , 5 \%}$ & $\mathbf{2 \%}$ & $\mathbf{4} \%$ & $\mathbf{0 , 5} \%$ & $\mathbf{2 \%}$ & $\mathbf{4} \%$ & $\mathbf{0 , 5} \%$ & $\mathbf{2 \%}$ & $\mathbf{4} \%$ \\
\hline RCP 8.5 & 7.373 & 5.309 & 3.441 & 21.975 & 12.662 & 6.520 & 46.293 & 20.618 & 8.406 \\
\hline RCP 4.5/ SRES B1 & 10.951 & 8.822 & 6.791 & 21.637 & 14.370 & 9.196 & 32.350 & 17.841 & 10.009 \\
\hline Escenario local & 2.227 & 1.924 & 1.619 & 2.925 & 2.262 & 1.753 & 4.962 & 2.922 & 1.908
\end{tabular}

Fuente: Elaboración propia.

CUADROV.8

Impacto del cambio climático en pesca con respecto al PBI sectorial del año 2010

(En porcentaje)

\begin{tabular}{|l|c|c|c|c|c|c|c|c|c|}
\hline \multirow{2}{*}{ Escenario } & \multicolumn{3}{|c|}{$\mathbf{2 0 1 1 - 2 0 4 0}$} & \multicolumn{3}{c|}{$\mathbf{2 0 1 1 - 2 0 7 0}$} & \multicolumn{3}{c|}{$\mathbf{2 0 1 1 - 2 1 0 0}$} \\
\cline { 2 - 10 } & $\mathbf{0 , 5} \%$ & $\mathbf{2 0} \%$ & $\mathbf{4} \%$ & $\mathbf{0 , 5} \%$ & $\mathbf{2} \%$ & $\mathbf{4} \%$ & $\mathbf{0 , 5} \%$ & $\mathbf{2} \%$ & $\mathbf{4} \%$ \\
\hline RCP 8.5 & 484,3 & 348,8 & 226,0 & $1.443,5$ & 831,8 & 428,3 & $3.040,9$ & $1.354,4$ & 552,2 \\
\hline RCP 4.5/ SRES B1 & 719,4 & 579,5 & 446,1 & $1.421,3$ & 943,9 & 604,1 & $2.125,1$ & $1.172,0$ & 657,5 \\
\hline Escenario local & 146,3 & 126,4 & 106,4 & 192,1 & 148,6 & 115,2 & 325,9 & 192,0 & 125,3
\end{tabular}

Fuente: Elaboración propia. 
CUADROV.9

Impacto del cambio climático en pesca con respecto al PBI nacional del año 2010

(En porcentaje)

\begin{tabular}{|l|c|c|c|c|c|c|c|c|c|}
\hline \multirow{2}{*}{ Escenario } & \multicolumn{3}{|c|}{$\mathbf{2 0 1 1 - 2 0 4 0}$} & \multicolumn{3}{c|}{$\mathbf{2 0 1 1 - 2 0 7 0}$} & \multicolumn{3}{c|}{$\mathbf{2 0 1 1 - 2 1 0 0}$} \\
\cline { 2 - 10 } & $\mathbf{0 , 5} \%$ & $\mathbf{2 \%}$ & $\mathbf{4} \%$ & $\mathbf{0 , 5} \%$ & $\mathbf{2 \%}$ & $\mathbf{4 \%}$ & $\mathbf{0 , 5} \%$ & $\mathbf{2 \%}$ & $\mathbf{4 \%}$ \\
\hline RCP 8.5 & 1,66 & 1,19 & 0,77 & 4,94 & 2,85 & 1,47 & 10,41 & 4,63 & 1,89 \\
\hline RCP 4.5/ SRES B1 & 2,46 & 1,98 & 1,53 & 4,86 & 3,23 & 2,07 & 7,27 & 4,01 & 2,25 \\
\hline Escenario local & 0,50 & 0,43 & 0,36 & 0,66 & 0,51 & 0,39 & 1,12 & 0,66 & 0,43
\end{tabular}

Fuente: Elaboración propia.

Los resultados de las proyecciones muestran que la disponibilidad de la anchoveta se vería afectada negativamente por el cambio climático. El impacto sería más profundo en los escenarios RCP 8.5 y RCP 4.5, y se manifestaría por variaciones en las condiciones de temperatura, oxígeno disuelto y productividad primaria. Por tanto, la contribución económica del sector pesquero a la economía nacional disminuiría de manera importante.

\section{Minería}

El sector minero contribuye significativamente al crecimiento económico de la economía peruana, especialmente por el dinamismo mostrado en las últimas décadas. Este sector generó el 58\% del valor de las exportaciones totales durante el período 2003-2012 (BCRP, 2014). En el año 2008, los trabajadores directos de este sector representaron el 0,9\% de la PEA, y en forma indirecta, se crearon empleos equivalentes al 3,5\% de la PEA de ese año ${ }^{44}$. Además, debido a sus efectos multiplicativos, induce ingresos en otras actividades productivas relacionadas (IIMP, 2010). Cabe destacar que el Perú presenta un liderazgo en el escenario mundial en la extracción minera, destacando la producción de zinc, plomo, estaño, plata y oro ${ }^{45}$.

En el gráfico V.12 se presenta la evolución del PBI del sector minero desde 1950 hasta 2010, con un marcado crecimiento desde comienzos de los años noventa. En la última década, el aporte de la minería al PBI nacional está en torno al 6\%, en promedio. Este crecimiento se puede explicar por el dinamismo y el auge del subsector de la minería metálica. Igualmente, el subsector de hidrocarburos, que en los años ochenta evidenció una importante contracción, ha mostrado en la última década un marcado aumento en el número de proyectos y en su PBI.

44 Porcentajes que en el año 2008 equivalían a 127.228 y 508.912 trabajadores, respectivamente (IIMP 2010, INEI 2013).

45 En América Latina ocupa el primer lugar en la extracción de zinc, plomo, estaño, plata y oro, y el segundo en cobre. En el contexto mundial; Perú se ubica en el primer lugar en extracción de plata (16,48\%), en el tercer lugar en zinc (12,15\%), cobre (6,86\%), y estaño en el cuarto lugar en plomo (9,52\%); y en el quinto lugar en oro (8,01\%) (Dammert y Molinelli 2007). 


\section{GRÁFICO V.12}

PBI minero y participación porcentual del sector en el PBI nacional

(En millones de soles de 2010 y en porcentaje)

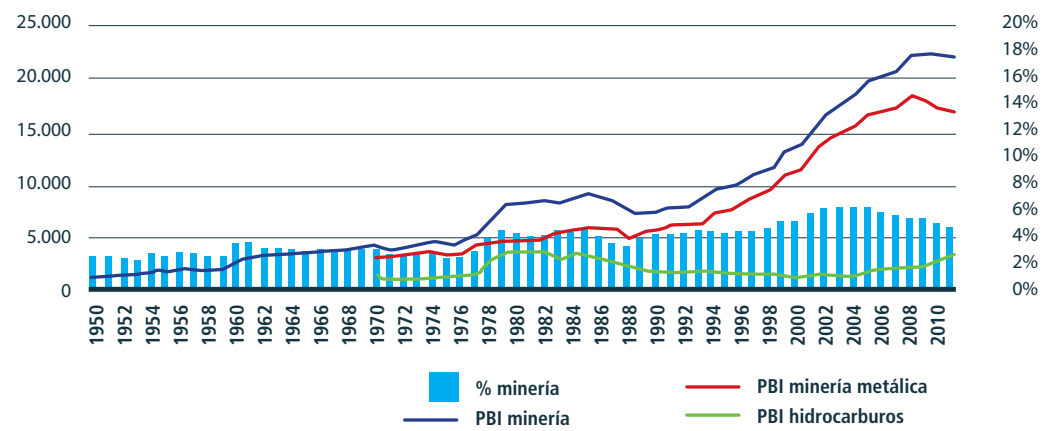

Fuente: Elaboración propia sobre la base del Banco Central de Reserva del Perú (2011).

Durante la década de 1990 se promovió fuertemente la inversión privada con nuevas adquisiciones y fusiones, generando cambios en la organización industrial y promoviendo el uso de nuevas tecnologías. Estos incentivos permitieron un auge en la cantidad de proyectos y en el mineral explotado en el país. En los años posteriores los precios de los metales descendieron, aunque esta situación fue compensada por el crecimiento sostenido de la demanda de los países asiáticos, en particular de China.

La fluctuación de precios en este sector se relaciona con el comportamiento de los principales productos mineros que el Perú exporta. Como se puede apreciar en el gráfico V.13, los precios de los minerales de exportación más importantes muestran un marcado incremento desde mediados de la década de 2000 y una alta variabilidad en los últimos años.

GRÁFICO V.13

Evolución de precios de los principales productos mineros peruanos, 1995-2012

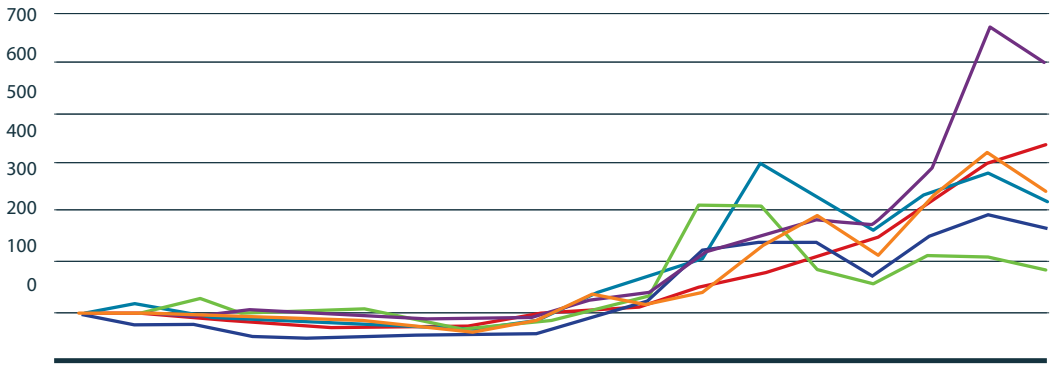

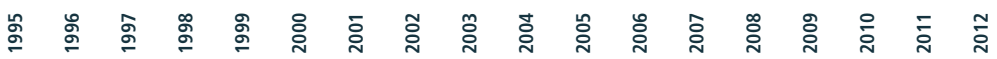

\begin{tabular}{ll}
- Cobre (Ctvs. US\$/lb) & - Plomo (Ctvs. US\$//b) \\
Plata (US\$/Oz. tr.) & - Zinc (Ctvs. US\$/lb) \\
\hline Oro (US\$/Oz. tr.) & - Estaño (Ctvs. US\$/lb)
\end{tabular}

Fuente: MINEM $(2012,2013)$.

Nota: Se normalizaron los precios, usando el año 1995 como base para el cálculo. 


\section{Relación del sector con las variables climáticas}

El nivel de actividad de la minería depende de diversos elementos, como los precios internacionales, la ley del mineral y la disponibilidad de recursos productivos. Un importante insumo para este sector, y que se relaciona con el fenómeno climático, es la disponibilidad de agua. Una posible reducción en el recurso hídrico generaría mayores costos operativos en las empresas mineras. Por ello, se espera que el principal impacto del cambio climático sobre el sector minero peruano esté vinculado a la disponibilidad hídrica en las zonas donde se localizan las actividades extractivas.

El análisis se concentró en aquellas probables zonas que con suficientes reservas probadas y que garanticen una extracción significativa en el largo plazo. Las cuencas mineras estudiadas abarcan la minería de oro, cobre, zinc y hierro. Como se describe en la sección metodológica (véase el capítulo III, sección B, acápite 4), la disponibilidad hídrica futura se analizó en cuencas donde es relevante la extracción minera, estimando en estas zonas el consumo hídrico poblacional, agrícola y minero. En particular, la producción del sector y su evolución proyectada hasta fines de siglo se correlacionó con el consumo hídrico minero. A su vez, la oferta hídrica se definió a partir de las condiciones climáticas presentes y futuras. El eventual superávit o déficit del recurso hídrico se analizó por medio de la comparación entre oferta y demanda para las condiciones hídricas actuales y futuras.

\section{Impactos del cambio climático en el sector minero}

La futura disponibilidad hídrica se estimó para los escenarios A1B, A2 y B1 a partir de dos modelos más extremos (mínimo y máximo) para cada uno de los cuatro minerales estudiados. A partir de este análisis, se identificó que únicamente habría déficit hídrico en las cuencas mineras de cobre y de zinc; por lo tanto, la valoración del impacto del cambio climático se centró en estos dos metales, para los escenarios y los modelos seleccionados.

En el caso de la cuenca minera de cobre, se prevé que la disponibilidad hídrica sin cambio climático (DHSC) cubra los requerimientos de consumo hídrico total, entre ellos, el minero. Para esta cuenca, solo el modelo extremo mínimo (CSMK3.5) arrojó resultados que pronostican futuros déficits hídricos vinculados al cambio climático, que afectarían al sector minero. Los períodos de posible ocurrencia varían dependiendo del modelo aplicado (véase el gráfico V.14 a, b y c). El modelo extremo máximo para cada escenario (MIHR para A1B y BCM2.0 para A2 y B1) no sugiere un déficit hídrico futuro para fines mineros ${ }^{46}$.

Para la cuenca minera de zinc, se encontró que los modelos extremos máximos y mínimos prevén déficit hídrico, no solo para el sector minero sino incluso para fines agrícolas. Las proyecciones más acentuadas se aprecian para el escenario A2 y B1 de la cuenca minera de zinc, en donde se prevería déficit hídrico por los modelos extremos mínimo y máximo (véase el gráfico V.14 d, e y f).

46 Todos los gráficos omiten el consumo poblacional, el cual es considerablemente menor en comparación con los dos consumos restantes. 
GRÁFICO V.14

Déficit hídrico estimado para las cuencas mineras de cobre y zinc, 2010-2100

(En millones de metros cúbicos)

Cobre

a) Escenario $A 1 B$

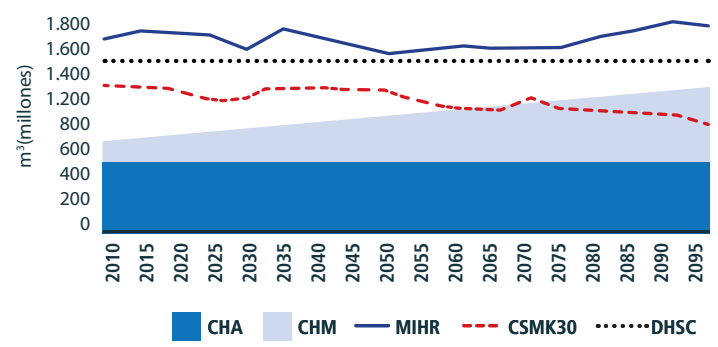

b) Escenario $\mathrm{A} 2$

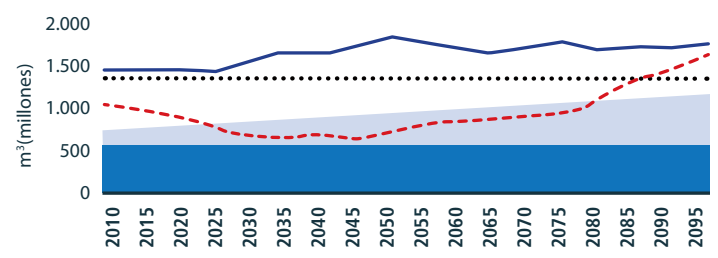

CHA CHM - BCM20 --- CSMK35 …....DHSC

c) Escenario B1

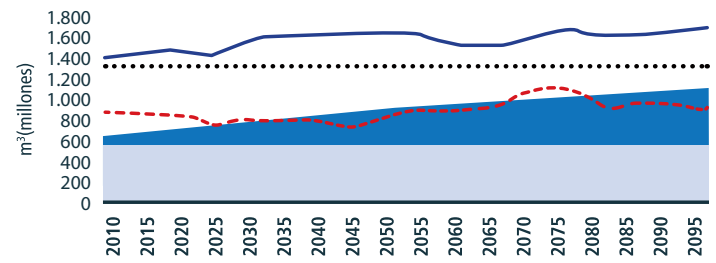

CHA CHM - BCM20 --- CSMK35 …....DHSC
Zinc

d) Escenario A1B

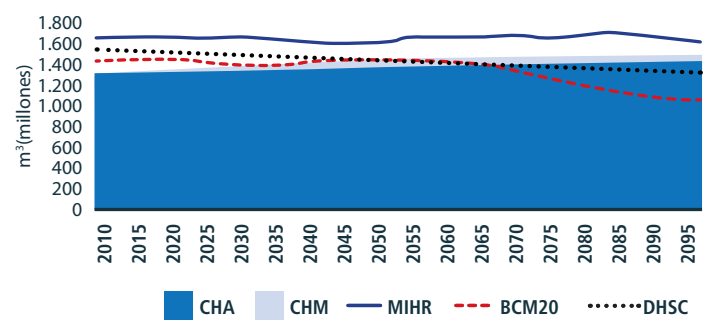

e) Escenario A2

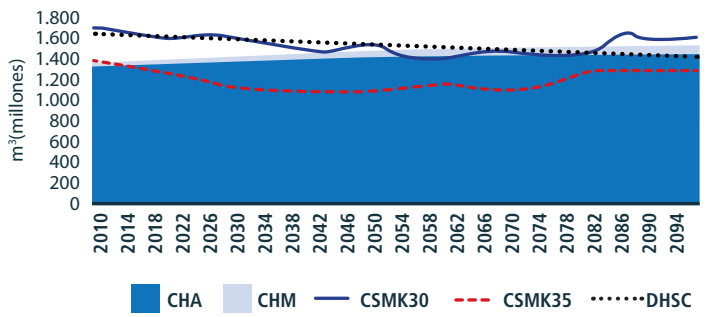

f) Escenario B1

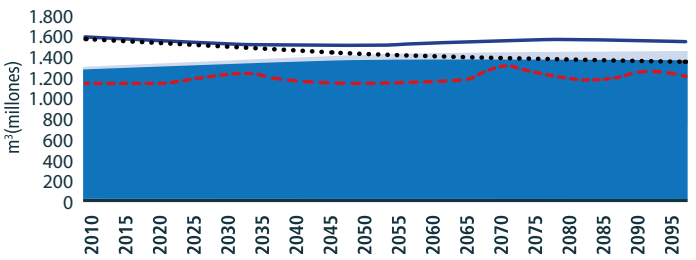

CHA CHM - GIAOM --- CSMK35 ….... DHSC

Fuente: Elaboración propia.

Nota: Los resultados comparan el consumo hídrico agrícola (CHA) y el consumo hídrico minero (CHM). Disponibilidad hídrica sin cambio climático (DHSC).

Una vez proyectados la disponibilidad y el déficit hídrico para efectos mineros, se calcularon los costos del cambio climático por cuenca minera priorizada. El diferencial de producción determinado por el cambio en la disponibilidad hídrica fue valorado por el precio sombra del agua para fines mineros. Con este precio se determinó el costo del cambio climático o la pérdida de beneficios para cobre y zinc para los tres períodos de análisis. 
Para facilitar la presentación de los resultados, se optó por promediar el costo de todas las cuencas para los dos modelos extremos. Los costos acumulados para fines de siglo para el sector son mostrados en el cuadro V.10, sugiriendo que las pérdidas se dan para los tres escenarios que son relativamente mayores en el escenario A2 e incrementales en el tiempo. Estos costos podrían oscilar entre 1.100 millones de soles y 3.500 millones de soles para los escenarios A1B y A2 a una tasa de descuento de 0,5\%, respectivamente. Estos costos equivaldrían a una fracción del PBI sectorial de hasta 15\% para el escenario A2 (véase el cuadro V.11). Los otros dos escenarios presentarían impactos menores. Sobre la base de las estimaciones, el impacto de este sector en el PBI nacional acumulado para el período 2011 a 2100 sería poco significativo, pues las pérdidas oscilarían entre 0,3\% y 0,8\% del PBI nacional del año 2010 (véase el cuadro V.12).

CUADROV.10

Impacto económico del cambio climático en minería

(En millones de soles de 2010)

\begin{tabular}{|l|r|r|r|r|r|r|r|r|r|}
\hline \multirow{2}{*}{ Escenario } & \multicolumn{3}{|c|}{$\mathbf{2 0 1 0 - 2 0 4 0}$} & \multicolumn{3}{c|}{$\mathbf{2 0 1 0 - 2 0 7 0}$} & \multicolumn{3}{c|}{$\mathbf{2 0 1 0 - 2 1 0 0}$} \\
\cline { 2 - 10 } & $\mathbf{0 , 5} \%$ & $\mathbf{2 0} \%$ & $\mathbf{4} \%$ & $\mathbf{0 , 5} \%$ & $\mathbf{2 \%}$ & $\mathbf{4} \%$ & $\mathbf{0 , 5} \%$ & $\mathbf{2} \%$ & $\mathbf{4} \%$ \\
\hline A1B & 0 & 0 & 0 & 59 & 26 & 9 & 1.137 & 375 & 90 \\
\hline A2 & 1.166 & 860 & 592 & 3.456 & 2.099 & 1.157 & 3.591 & 2.152 & 1.172 \\
B1 & 647 & 506 & 377 & 1.789 & 1.142 & 676 & 2.599 & 1.397 & 732 \\
\hline
\end{tabular}

Fuente: Elaboración propia.

CUADROV.11

Impacto del cambio climático en minería con respecto al PBI sectorial del año 2010

(En porcentaje)

\begin{tabular}{|l|c|c|c|c|c|c|c|c|c|}
\hline \multirow{2}{*}{ Escenario } & \multicolumn{3}{|c|}{$\mathbf{2 0 1 0 - 2 0 4 0}$} & \multicolumn{3}{c|}{$\mathbf{2 0 1 0 - 2 0 7 0}$} & \multicolumn{3}{c|}{$\mathbf{2 0 1 0 - 2 1 0 0}$} \\
\cline { 2 - 11 } & $\mathbf{0 , 5} \%$ & $\mathbf{2} \%$ & $\mathbf{4} \%$ & $\mathbf{0 , 5} \%$ & $\mathbf{2 \%}$ & $\mathbf{4} \%$ & $\mathbf{0 , 5} \%$ & $\mathbf{2} \%$ & $\mathbf{4} \%$ \\
\hline A1B & 0,00 & 0,00 & 0,00 & 0,25 & 0,11 & 0,04 & 4,87 & 1,61 & 0,39 \\
\hline A2 & 5,00 & 3,69 & 2,54 & 14,81 & 8,99 & 4,96 & 15,39 & 9,22 & 5,02 \\
\hline B1 & 2,77 & 2,17 & 1,61 & 7,67 & 4,89 & 2,90 & 11,14 & 5,99 & 3,14
\end{tabular}

Fuente: Elaboración propia.

CUADRO V.12

Impacto del cambio climático en minería con respecto al PBI nacional del año 2010

(En porcentaje)

\begin{tabular}{|l|c|c|c|c|c|c|c|c|c|}
\hline \multirow{2}{*}{ Escenario } & \multicolumn{3}{|c|}{$\mathbf{2 0 1 0 - 2 0 4 0}$} & \multicolumn{3}{c|}{$\mathbf{2 0 1 0 - 2 0 7 0}$} & \multicolumn{3}{c|}{$\mathbf{2 0 1 0 - 2 1 0 0}$} \\
\cline { 2 - 10 } & $\mathbf{0 , 5} \%$ & $\mathbf{2 \%}$ & $\mathbf{4} \%$ & $\mathbf{0 , 5} \%$ & $\mathbf{2 \%}$ & $\mathbf{4 \%}$ & $\mathbf{0 , 5} \%$ & $\mathbf{2} \%$ & $\mathbf{4} \%$ \\
\hline A1B & 0,00 & 0,00 & 0,00 & 0,01 & 0,01 & 0,00 & 0,26 & 0,08 & 0,02 \\
\hline A2 & 0,26 & 0,19 & 0,13 & 0,78 & 0,47 & 0,26 & 0,81 & 0,48 & 0,26 \\
B1 & 0,15 & 0,11 & 0,08 & 0,40 & 0,26 & 0,15 & 0,58 & 0,31 & 0,16
\end{tabular}

Fuente: Elaboración propia. 
No obstante, para la mayor parte de las cuencas mineras analizadas, los impactos del cambio climático por la futura disponibilidad hídrica no serían significativos. La mayor parte de los modelos extremos de este estudio no sugieren déficit hídrico para el grueso de las cuencas mineras. Por lo tanto, únicamente se esperarían costos para las cuencas mineras de cobre y de zinc.

Una mayor eficiencia en el uso y en el consumo del agua para fines poblacionales y agrícolas contribuiría a reducir futuras disputas por el recurso hídrico, lo cual ayudaría a garantizar la dotación de este recurso para la minería, considerando que legalmente la prioridad para el consumo del agua se encuentra primero en lo humano y luego en el consumo agrícola.

Es recomendable realizar un estudio más profundo para determinar con precisión en qué medida los volúmenes de agua de las fuentes hídricas lograrían satisfacer el consumo poblacional aguas abajo de las cuencas mineras priorizadas, dado que una significativa merma futura en el caudal de estas fuentes podría reducir la disponibilidad hídrica para fines mineros.

\section{E. Hidroenergía}

En el Perú, el crecimiento del sector eléctrico ha estado altamente relacionado con el desempeño económico nacional, tal como se aprecia en el gráfico V.15. En el período 1990 a 2011 la generación eléctrica se ha incrementado a una tasa promedio de 5,3\%, de manera muy similar al crecimiento del PBI nacional (4,9\%), lo que muestra la alta relación entre estas variables.

Como se muestra en el gráfico V.16, en términos de generación del producto el sector energético ha aportado históricamente con casi 2\% del PBI del Perú. A partir de la década de 1980 se aprecia un importante incremento en el PBI sectorial, que superó 9.000 millones de soles el año 2010. Con respecto al empleo, al año 2012 este sector contrató aproximadamente a 7.900 trabajadores, de los cuales el 54\% se asociaban a distribución, 39\% a generación y 7\% a transmisión (MINEM, 2014).

\section{GRÁFICO V.15}

PBI nacional y generación de energía eléctrica, 1976-2011

(En millones de soles de 2010 y en gigavatio-hora)

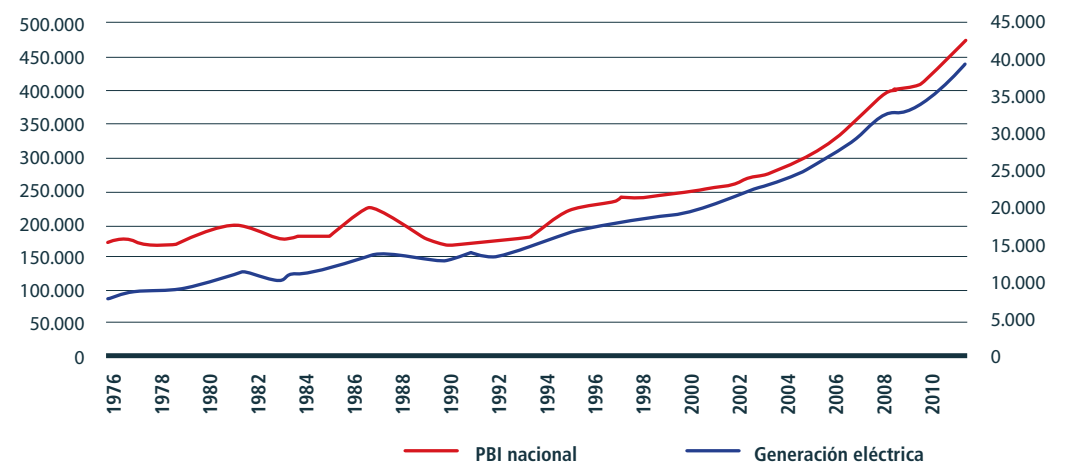

Fuente: Elaboración propia sobre la base del Banco Central de Reserva del Perú (2011) y del MINEM (2014). 
GRÁFICO V.16

PBI de electricidad y participación porcentual del sector en el PBI nacional

(En millones de soles de 2010 y en porcentaje)

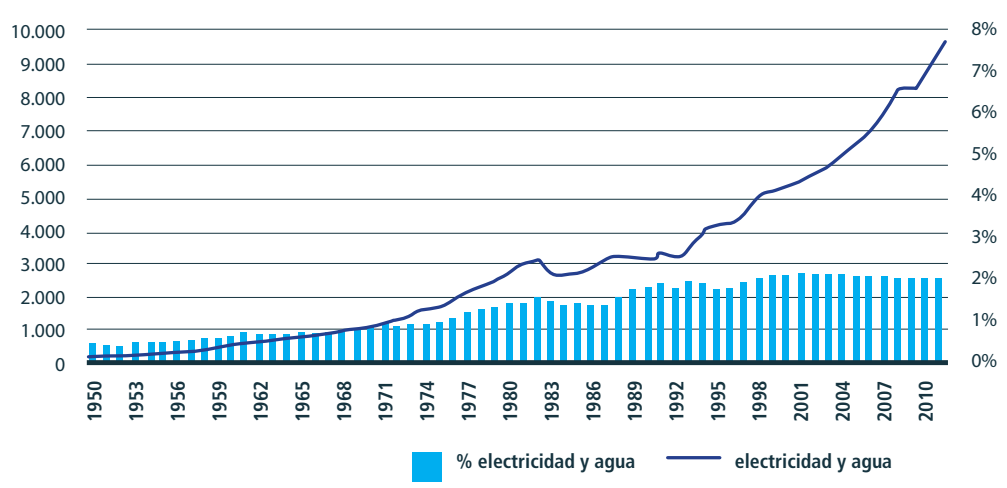

Fuente: Elaboración propia sobre la base del Banco Central de Reserva del Perú (2011). Nota: El PBI presentado incluye el valor de electricidad y agua.

El sector eléctrico peruano está formalmente constituido alrededor del Sistema Eléctrico Interconectado Nacional (SEIN) que distribuye alrededor del 92\% del total de la energía eléctrica comercializada en el país. Este sistema es el espacio donde interactúan las empresas de generación, transmisión, distribución y usuarios libres. La producción de electricidad del sistema en el año 2011 estaba compuesta en un 58\% por energía hidroeléctrica y en un 42\% por termoeléctrica, respecto del total generado (véase el gráfico V.17.). En la última década se observa un importante crecimiento de la generación eléctrica basada en fuentes térmicas (MINEM, 2014).

GRÁFICO V.17

Generación de energía eléctrica por tipo de fuente, 1976-2011

(En gigavatios-hora)

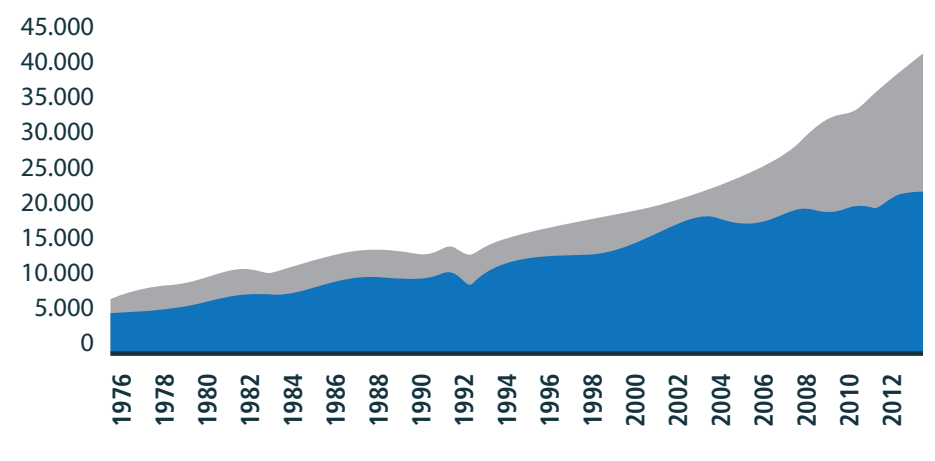

Hidráulica

Térmica

Fuente: Elaboración propia sobre la base del MINEM (2014).

Dada la importancia que tiene la generación hidroeléctrica en el país, este estudio analiza el impacto del cambio climático sobre este tipo de energía y sus implicaciones en el abastecimiento del SEIN. El efecto del cambio climático estaría asociado tanto a la energía que dejaría de ser producida con recursos renovables como a los mayores costos de generación. 


\section{Relación del sector con las variables climáticas}

La producción eléctrica del sector de hidroenergía está fuertemente ligada con la disponibilidad de agua en las cuencas. Por ello, el cambio climático podría afectar el nivel de actividad de este sector a través de la variación en las condiciones de precipitación efectiva que ocasione en dichas zonas.

Como se detalla en el capítulo metodológico (capítulo III, sección B, acápite 5), este estudio compara los cambios en la disponibilidad hídrica de las cuencas donde se emplazan las centrales hidroeléctricas más relevantes del actual parque hidroeléctrico del Sistema Interconectado Nacional (SINAC). En particular, el análisis se enfocó en centrales hidroeléctricas que representan aproximadamente el 85\% de la capacidad hidroenergética instalada y que se ubican en las cuencas de los ríos Mantaro, Rímac, Santa y Mayo, entre otras.

La relación entre el nivel de actividad de este sector, y las variables climáticas, se expresa a través de cómo la capacidad de descarga hídrica de cada central se afecta con la precipitación y la evapotranspiración. También se analiza la relación de los caudales con la temperatura y el tipo de cobertura vegetal, incluyendo las tendencias de uso agrícola del suelo.

A partir de estas relaciones se determinó el escenario base de producción energética siguiendo los patrones históricos. La producción energética con cambio climático se estimó a partir de las condiciones de cada escenario y modelo climático.

\section{Impactos del cambio climático en el sector hidroenergético}

El impacto del cambio climático es medido a través de la variación de la producción de energía eléctrica entre los escenarios sin y con cambio climático para los diferentes modelos desarrollados. Se estimaron los cambios en los ingresos a partir de las diferencias de producción energética de cada central. De este modo, el efecto sectorial acumulado corresponde a la suma de las pérdidas o ganancias de todas las centrales hidroeléctricas.

Hay que resaltar que, aun sin cambio climático, la producción de hidroelectricidad tiende a disminuir por efecto de la expansión de la agricultura. El incremento de la superficie agrícola implicará una mayor evapotranspiración, dejando menos agua disponible en las cuencas para la generación hidroeléctrica. Por este motivo, la producción de hidroelectricidad disminuirá en términos acumulados en 7\% durante el período 20102100 sin cambio climático (véase el gráfico V.18.).

Al analizar cada central en forma individual se encuentran efectos heterogéneos, dependiendo del modelo y del escenario climático evaluado hasta el año 2100, aunque la tendencia general es producir menos energía hidroeléctrica. En el cuadro V.13 se presentan los efectos del cambio climático para cada central. Se distinguen centrales que mostrarían una disminución de su producción, independientemente del modelo y escenario, tales como Moyopampa, Machu Picchu, Huampaní, San Gabán y Huinco. También se aprecian otras centrales, que si bien experimentarán reducciones en su producción, presentan algunos escenarios de crecimiento, como Yanango, Mantaro, Restitución y Matucana.

Dentro de las centrales que se verían beneficiadas destacan las que actualmente poseen factores de planta inferiores a 72\%, que en el futuro tendrían más probabilidades de incrementar su producción de energía, como Cahua, Carhuaquero, Cañón del Pato y Gallito Ciego, entre otras. 
CUADROV.13

Impacto promedio del cambio climático por central hidroeléctrica, 2010-2100

(En porcentaje)

\begin{tabular}{|c|c|c|c|c|c|c|c|c|c|c|c|c|c|c|c|c|c|c|c|c|}
\hline Central & $\begin{array}{l}\text { Factor } \\
\text { de } \\
\text { planta }\end{array}$ & 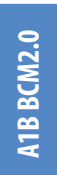 & 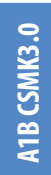 & 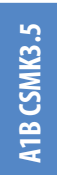 & $\begin{array}{l}\frac{5}{0} \\
\text { 눈 } \\
\frac{0}{c}\end{array}$ & $\frac{\sum}{\frac{m}{z}}$ & 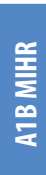 & 鯗 & 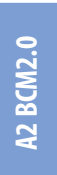 & $\begin{array}{l}0 \\
\frac{0}{5} \\
\frac{y}{y} \\
z\end{array}$ & $\begin{array}{l}\frac{n}{2} \\
\frac{y}{y} \\
\frac{y}{z}\end{array}$ & $\frac{m}{z}$ & 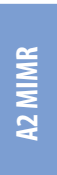 & 这 & $\frac{0}{\frac{0}{y}}$ & $\frac{n}{\frac{m}{y}}$ & $\frac{2}{\frac{2}{6}}$ & $\frac{m}{3}$ & $\frac{\text { 呈 }}{\underline{\Sigma}}$ & $\frac{\frac{\alpha}{2}}{\frac{\alpha}{2}}$ \\
\hline Moyopampa & 94 & -14 & -19 & -23 & -4 & -21 & -3 & -23 & -16 & -26 & -34 & -19 & -17 & -13 & -19 & -33 & -4 & -20 & -6 & -20 \\
\hline Mantaro & 93 & -11 & -12 & -5 & -7 & -15 & 5 & -14 & -14 & -19 & -14 & -14 & -5 & -13 & -12 & -16 & -7 & -14 & 4 & -12 \\
\hline Machu Picchu & 92 & -10 & -14 & -29 & -3 & -7 & -13 & -18 & -12 & -19 & -31 & -5 & -12 & -12 & -10 & -29 & -4 & -8 & -11 & -15 \\
\hline Restitución & 90 & -11 & -13 & -5 & -7 & -14 & 4 & -14 & -14 & -19 & -14 & -13 & -6 & -13 & -12 & -16 & -7 & -14 & 3 & -12 \\
\hline Huampaní & 88 & -15 & -19 & -24 & -6 & -24 & -2 & -25 & -18 & -28 & -36 & -22 & -17 & -15 & -20 & -34 & -6 & -23 & -5 & -21 \\
\hline Callahuanca & 87 & -14 & -18 & -23 & -6 & -25 & 0 & -24 & -18 & -27 & -37 & -22 & -15 & -15 & -19 & -34 & -5 & -24 & -2 & -20 \\
\hline Matucana & 75 & -13 & -10 & -17 & -8 & -26 & 7 & -19 & -16 & -22 & -36 & -22 & -5 & -15 & -17 & -34 & -9 & -28 & 3 & -16 \\
\hline Cahua & 72 & -8 & -1 & 5 & 3 & -11 & 11 & 2 & -11 & -1 & 1 & -9 & 4 & -14 & -1 & -2 & 3 & -10 & 10 & 0 \\
\hline San Gabán & 71 & -7 & -8 & -21 & -10 & -13 & -10 & -17 & -9 & -11 & -26 & -9 & -12 & -8 & -5 & -24 & -12 & -13 & -10 & -13 \\
\hline Carhuaquero & 67 & -7 & 3 & -8 & 1 & -2 & 16 & 12 & -9 & 3 & -19 & -3 & 5 & -12 & 3 & -19 & 1 & -4 & 15 & 13 \\
\hline Yuncán & 66 & -8 & 1 & 11 & -5 & -10 & -3 & 5 & -10 & 0 & 5 & -9 & 10 & -13 & 1 & 3 & -8 & -12 & -1 & 5 \\
\hline Cañón del Pato & 61 & 3 & 11 & 31 & 8 & -6 & 51 & 17 & 16 & 10 & 24 & -6 & 14 & 10 & 5 & 8 & 6 & -12 & 44 & 15 \\
\hline Chimay & 60 & -8 & -9 & -8 & -6 & -11 & -1 & -7 & -10 & -15 & -26 & -10 & 8 & -10 & -8 & -17 & -7 & -11 & -1 & -2 \\
\hline Yanango & 57 & -8 & -11 & -6 & -5 & -12 & 1 & -6 & -11 & -17 & -27 & -12 & 9 & -12 & -11 & -21 & -7 & -14 & 2 & -1 \\
\hline Huinco & 50 & -15 & -19 & -24 & -6 & -24 & -2 & -25 & -18 & -28 & -36 & -22 & -17 & -15 & -20 & -34 & -6 & -23 & -5 & -21 \\
\hline Gallito Ciego & 47 & -5 & 22 & 21 & 5 & -4 & 33 & 30 & -10 & 21 & 2 & -10 & 25 & -8 & 18 & 3 & 3 & -12 & 25 & 32 \\
\hline
\end{tabular}

Fuente: Elaboración propia sobre la base del MINEM (2014).

Nota: Los casilleros azules representan caídas de la producción de electricidad y los grises incremento por encima de la situación sin cambio climático.

Los efectos agregados muestran que el cambio climático ocasionaría una menor producción de electricidad, debido a una menor disponibilidad de agua en las cuencas. El gráfico V.18 presenta la generación de energía eléctrica para los escenarios ante la ausencia y la presencia del cambio climático donde todos los escenarios muestran disminuciones en la producción energética.

GRÁFICO V.18

Impacto del cambio climático en la producción hidroenergética

(En gigavatios por hora-año)

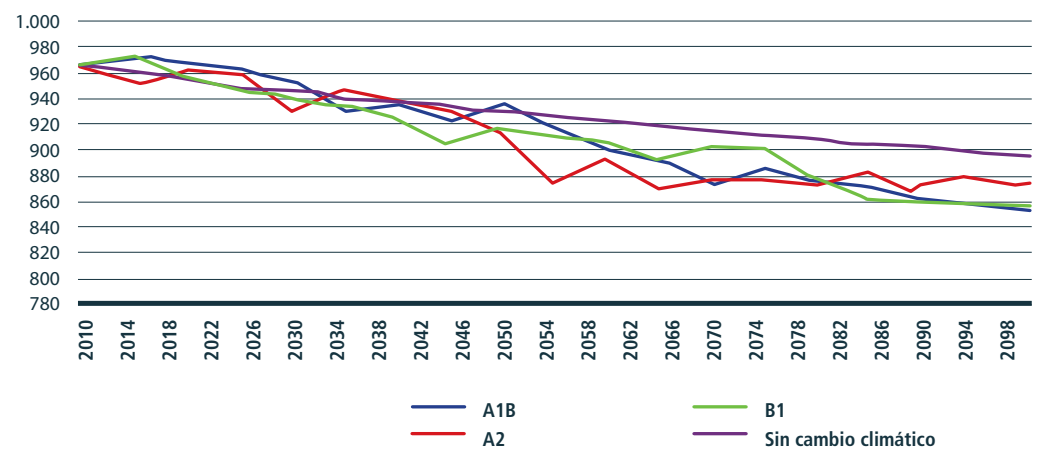

Fuente: Elaboración propia. 
Luego de estimar los distintos niveles de producción de energía para los escenarios sin y con cambio climático, se calcularon los ingresos por generación. Para ello se empleó el precio de la energía que se obtuvo a partir de la ponderación de las tarifas eléctricas peruanas. En el gráfico V.19 se presentan los ingresos para cada escenario climático y las variaciones porcentuales con respecto al escenario sin cambio climático.

GRÁFICO V.19

Impacto del cambio climático en el valor de la producción hidroenergética, 2010-2100

a) Millones de soles del 2010

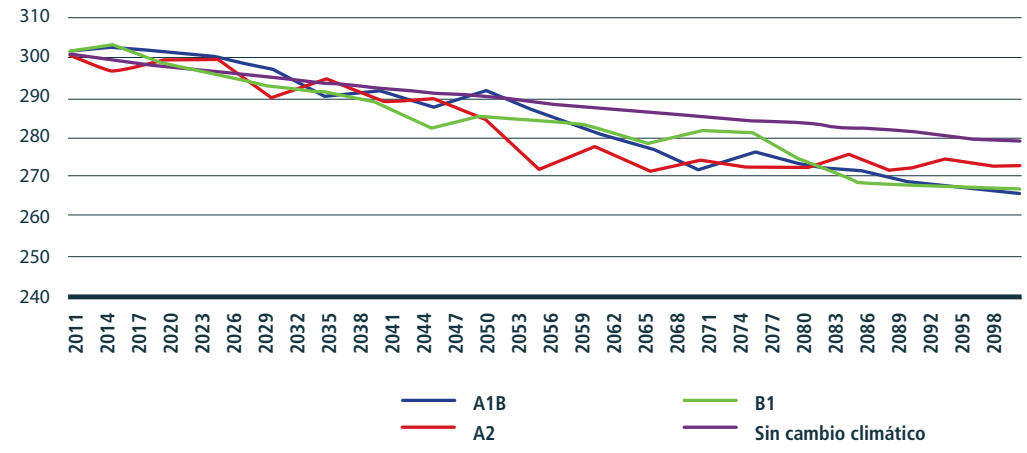

b) Variación porcentual con respecto al año base

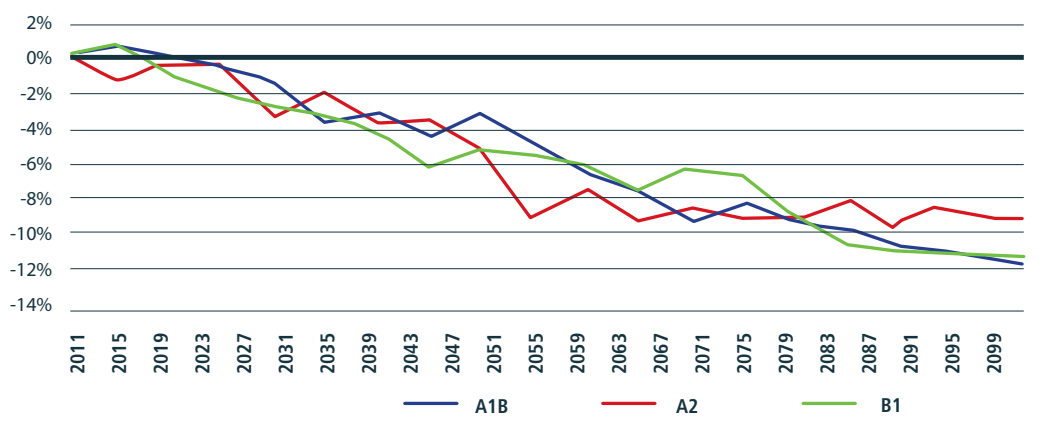

Fuente: Elaboración propia.

Los costos acumulados se presentan en el cuadro V.14, donde se aprecian pérdidas en todos los escenarios climáticos. Si bien el escenario A1B muestra beneficios iniciales, todos los escenarios ostentan costos incrementales en el tiempo, destacando los escenarios A2 y B1 con los mayores costos acumulados al año 2100. Para todo el horizonte de análisis, los costos podrían oscilar entre 297 millones de soles y 443 millones de soles para los escenarios A1B y A2, con un descuento del 0,5\%, respectivamente. En el mismo período (2010 a 2100), el rango de pérdida fluctuaría entre 3,3\% y 5\% del PBI de energía y agua del año base (véase el cuadro V.15) ${ }^{47}$. A su vez, el impacto en el PBI nacional acumulado oscilaría entre 0,07\% y 0,10\% del PBI nacional del año 2010 (véase el cuadro V.16).

47 Ante la ausencia de información sobre el PBI exclusivamente hidroenergético, la participación en el PBI sectorial es una aproximación que puede afinarse. 
CUADRO V.14

Impacto económico del cambio climático en hidroenergía

(En millones de soles de 2010)

\begin{tabular}{|l|c|c|c|c|c|c|c|c|c|}
\multirow{2}{*}{ Escenario } & \multicolumn{3}{|c|}{$\mathbf{2 0 1 0 - 2 0 4 0}$} & \multicolumn{3}{c|}{$\mathbf{2 0 1 0 - 2 0 7 0}$} & \multicolumn{3}{c|}{$\mathbf{2 0 1 0 - 2 1 0 0}$} \\
\cline { 2 - 11 } & $\mathbf{0 , 5} \%$ & $\mathbf{2} \%$ & $\mathbf{4} \%$ & $\mathbf{0 , 5} \%$ & $\mathbf{2} \%$ & $\mathbf{4} \%$ & $\mathbf{0 , 5} \%$ & $\mathbf{2} \%$ & $\mathbf{4} \%$ \\
\hline A1B & -43 & -40 & -35 & 64 & 11 & -16 & 297 & 88 & 3 \\
\hline A2 & 24 & 19 & 14 & 252 & 132 & 60 & 443 & 198 & 77 \\
B1 & 10 & 2 & -4 & 152 & 77 & 29 & 363 & 145 & 45 \\
\hline
\end{tabular}

Fuente: Elaboración propia.

CUADROV.15

Impacto del cambio climático en hidroenergía con respecto al PBI sectorial del año 2010

(En porcentaje)

\begin{tabular}{|l|c|c|c|c|c|c|c|c|c|}
\hline \multirow{2}{*}{ Escenario } & \multicolumn{3}{|c|}{$\mathbf{2 0 1 0 - 2 0 4 0}$} & \multicolumn{3}{c|}{$\mathbf{2 0 1 0 - 2 0 7 0}$} & \multicolumn{3}{c|}{$\mathbf{2 0 1 0 - 2 1 0 0}$} \\
\cline { 2 - 10 } & $\mathbf{0 , 5} \%$ & $\mathbf{2} \%$ & $\mathbf{4} \%$ & $\mathbf{0 , 5} \%$ & $\mathbf{2} \%$ & $\mathbf{4} \%$ & $\mathbf{0 , 5} \%$ & $\mathbf{2} \%$ & $\mathbf{4} \%$ \\
\hline A1B & $-0,49$ & $-0,45$ & $-0,40$ & 0,72 & 0,13 & $-0,17$ & 3,33 & 0,99 & 0,03 \\
\hline A2 & 0,27 & 0,21 & 0,16 & 2,83 & 1,48 & 0,68 & 4,97 & 2,22 & 0,86 \\
\hline B1 & 0,11 & 0,03 & $-0,04$ & 1,70 & 0,86 & 0,33 & 4,07 & 1,63 & 0,50 \\
\hline
\end{tabular}

Fuente: Elaboración propia.

\section{CUADRO V.16}

Impacto del cambio climático en hidroenergía con respecto al PBI nacional del año 2010

(En porcentaje)

\begin{tabular}{|l|c|c|c|c|c|c|c|c|c|}
\hline \multirow{2}{*}{ Escenario } & \multicolumn{3}{|c|}{$\mathbf{2 0 1 0 - 2 0 4 0}$} & \multicolumn{3}{c|}{$\mathbf{2 0 1 0 - 2 0 7 0}$} & \multicolumn{3}{c|}{$\mathbf{2 0 1 0 - 2 1 0 0}$} \\
\cline { 2 - 10 } & $\mathbf{0 , 5} \%$ & $\mathbf{2} \%$ & $\mathbf{4} \%$ & $\mathbf{0 , 5} \%$ & $\mathbf{2} \%$ & $\mathbf{4} \%$ & $\mathbf{0 , 5} \%$ & $\mathbf{2} \%$ & $\mathbf{4} \%$ \\
\hline A1B & $-0,010$ & $-0,009$ & $-0,008$ & 0,014 & 0,003 & $-0,003$ & 0,067 & 0,020 & 0,001 \\
\hline A2 & 0,005 & 0,004 & 0,003 & 0,057 & 0,030 & 0,014 & 0,100 & 0,044 & 0,017 \\
\hline B1 & 0,002 & 0,001 & $-0,001$ & 0,034 & 0,017 & 0,007 & 0,082 & 0,033 & 0,010 \\
\hline
\end{tabular}

Fuente: Elaboración propia.

El análisis desarrollado muestra una disminución en la capacidad de generación hidroeléctrica nacional, aunque se distinguen algunas cuencas donde se podrían mejorar las condiciones de producción de hidroenergía. Los principales problemas surgirían en las centrales del sur peruano, donde la estacionalidad actual tiende a incrementarse en el tiempo. A su vez, las centrales que hoy presentan bajos factores de planta podrían aumentar su producción de energía en el futuro. 


\section{F. Infraestructura}

Para un país es fundamental contar con una infraestructura extensiva y eficiente que asegure el funcionamiento efectivo de la economía, que es un factor muy importante en la localización de la actividad económica y en los tipos de sectores productivos que se pueden desarrollar (WEF, 2011). La relevancia del sector infraestructura en el desarrollo económico de los países es evaluada con un enfoque internacional en el Reporte Global de Competitividad del Foro Económico Mundial (WEF, por sus siglas en inglés). El Perú ha experimentado una mejora en el índice de calidad de la infraestructura vial de 2008 a 2013, con un índice para el último año de 3,3, cifra superior en $27 \%$ a la medición del año $2008^{48}$.

La infraestructura vial se encuentra muy ligada al sector de transporte, lo que permite mejorar la logística del país en términos de reducción de costos, además de aumentar la conectividad. Muestra de ello es que el PBI de transporte, para el período 2004 a 2013, ha crecido a una tasa similar a la del PBI nacional (véase el gráfico V.20).

\section{GRÁFICO V.20}

PBI de transporte y participación porcentual del sector en el PBI nacional, 2004-2013

(En millones de soles de 2010 y en porcentaje)

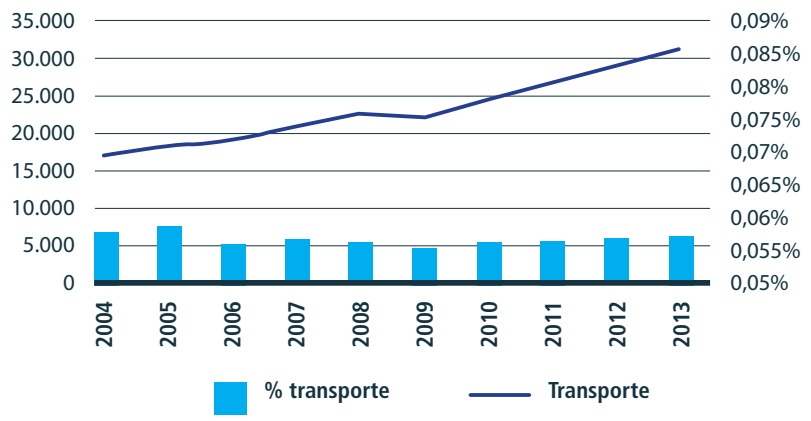

Fuente: Elaboración propia a partir del INEI, del Banco Central de Reserva del Perú y del Ministerio de Transporte y Comunicaciones (MTC, 2013).

Las inversiones asociadas a la infraestructura vial se relacionan con la habilitación de nuevos caminos y con el mantenimiento, la rehabilitación y la mejora de las vías existentes. El presupuesto ejecutado para proyectos de inversión del Ministerio de Transportes y Comunicaciones (MTC) ha aumentado en casi seis veces para el período 2004 a 2013, pasando de 938 millones de soles hasta casi 5.366 millones de soles corrientes (MTC-OGPP-Oficina de Presupuesto, 2014).

El sistema nacional de carreteras peruano (SINAC) está conformado por tres categorías: i) la red vial nacional, ii) la red vial departamental y iii) la red vial vecinal.

La red vial nacional está compuesta por las grandes rutas longitudinales de costa, sierra y selva, además de sus variantes, ramales y ejes transversales. La red departamental considera carreteras circunscritas que unen a las principales capitales provinciales de cada departamento. Finalmente, la red vecinal incluye los caminos que comunican los pueblos o caseríos pequeños. Como se puede apreciar en el cuadro V.17, la red vecinal destaca por el alto porcentaje de kilómetros de carretera construida. Esto se debe a que a fines de 2006 se reestructuró el sistema de administración y de inversiones de carreteras, por medio con la creación de Provías Descentralizado, así como de leyes de flexibilización, hecho que se ve reflejado en el importante aumento de kilómetros en el sistema departamental (a partir de 2008) y vecinal (desde 2009) ${ }^{49}$.

48 El Reporte Global de Competitividad mide la calidad de infraestructura vial a través de la pregunta en su país, ¿cómo evaluaría la infraestructura de caminos?, donde 1 es extremadamente subdesarrollada y 7 es extensiva y eficiente.

49 Para más información, véase Lineamientos para promover la inversión en infraestructura en el Perú 2012-2016, (CAPECO, 2012) 
CUADRO V.17

Longitud de la red vial según sistema de carretera en el Perú, 2005-2012

(En kilómetros)

\begin{tabular}{|l|r|r|r|r|r|r|r|r|}
\hline $\begin{array}{l}\text { Sistema de } \\
\text { carretera }\end{array}$ & $\mathbf{2 0 0 5}$ & $\mathbf{2 0 0 6}$ & $\mathbf{2 0 0 7}$ & $\mathbf{2 0 0 8}$ & $\mathbf{2 0 0 9}$ & $\mathbf{2 0 1 0}$ & $\mathbf{2 0 1 1}$ & $\mathbf{2 0 1 2}$ \\
\hline Nacional & 16.857 & 17.857 & 23.838 & 23.903 & 24.500 & 23.596 & 23.319 & 24.593 \\
\hline Departamental & 14.251 & 14.251 & 14.437 & 19.695 & 24.391 & 25.774 & 25.598 & 24.235 \\
\hline Vecinal & 47.398 & 47.398 & 42.050 & 38.189 & 75.935 & 75.674 & 80.244 & 91.844 \\
\hline Total & $\mathbf{7 8 . 5 0 6}$ & $\mathbf{7 9 . 5 0 6}$ & $\mathbf{8 0 . 3 2 5}$ & $\mathbf{8 1 . 7 8 7}$ & $\mathbf{1 2 4 . 8 2 6}$ & $\mathbf{1 2 5 . 0 4 4}$ & $\mathbf{1 2 9 . 1 6 2}$ & $\mathbf{1 4 0 . 6 7 2}$ \\
\hline
\end{tabular}

Fuente: INEI (2013).

En el presente estudio se asume que tanto la habilitación de nuevas vías como su mantenimiento no variarán como consecuencia del fenómeno climático; es decir, las variables climáticas no afectarán las decisiones políticas asociadas a la infraestructura. Por ello, el impacto económico del cambio climático en el sector de infraestructura es medido a través del aumento en el costo generado por las mayores necesidades de rehabilitación y el mejoramiento de las vías.

\section{Relación del sector con las variables climáticas}

Según la metodología explicada en el capítulo III, sección B, acápite 6, el sector de infraestructura se vería afectado por la presencia de eventos climáticos extremos, especialmente por los relacionados con precipitaciones.

Se esperaría que el aumento de lluvias causado por el fenómeno climático genere la modificación de los caudales hídricos cercanos a las redes viales, afectando las estructuras de drenaje y aumentado la probabilidad de ruptura de vías. Lo anterior significaría un incremento en las reparaciones viales, y por tanto, en los costos asociados al mantenimiento periódico y a las emergencias.

El mantenimiento periódico implica principalmente las siguientes actividades: i) la restauración de la carpeta asfáltica y de las bermas al nivel del servicio original, ii) la reconstrucción de las obras de drenaje superficial y subterráneo, iii) la reposición de las señales de tránsito, iv) el acondicionamiento de los taludes, entre otras. La atención de emergencias comprende el conjunto de actividades destinadas a restablecer la normalidad del tránsito vehicular en el menor tiempo posible, ante la ocurrencia de eventos que afecten parte de la vía.

Los costos adicionales producidos por el cambio climático se relacionarán con un incremento del gasto público ante la necesidad de reposición del capital, para asegurar el buen funcionamiento de la estructura vial del país.

\section{Impactos del cambio climático en el sector de infraestructura}

Los impactos del cambio climático en infraestructura se analizaron mediante el efecto que los eventos extremos causados por precipitación generarían sobre la infraestructura vial. Particularmente, se estudiaron dos cuencas, la del río Rímac y la del río Urubamba. El análisis se basó en los cambios que experimentarían los caudales de ambos ríos por el efecto climático, estimándose para cada cinco años y a partir de las variaciones esperadas en escorrentía.

La cuenca del río Rímac, ubicada en la costa central del Perú, forma parte de la vertiente del Pacífico. El efecto orográfico de esta cuenta es sumamente marcado. Hasta 1.000 msnm, las precipitaciones son cercanas a cero. Sin embargo, a partir de esta elevación, las precipitaciones aumentan hasta llegar a 900 mm/año. En esta 
cuenca el impacto del cambio climático es variado. En el escenario A1B, tres de los siete modelos sugieren un posible aumento de caudales. Incluso uno de ellos proyecta que los caudales aumentarían al doble. Por el contrario, dos modelos indican que los caudales disminuirían en el período 2005 a 2099 y otros modelos no presentan variaciones significativas. En el escenario A2, los caudales aumentan en un modelo, mientras que en otros tres disminuyen. Finalmente, para el escenario B1, tres modelos presentarían aumentos de caudales (uno de ellos más del doble) y otros tres muestran que los caudales disminuirían en el período analizado. El cuadro V.18, resume los resultados para los tres escenarios.

\section{CUADRO V.18}

Cambios en los caudales del río Rímac ante los escenarios climáticos, 2005-2100

\begin{tabular}{l|c|c|c|c|c|c} 
Escenario & BCM2.0 & CSMK3.0 & CSMK3.5 & GIAOM & INCM3 & MIHR \\
\hline A1B & + & ++ & $=$ & $=$ & + & - \\
A2 & + & - & - & N/D & $=$ & N/D \\
B1 & + & ++ & - & $=$ & + & - \\
\end{tabular}

Fuente: Elaboración propia.

Nota: (+) los caudales aumentan hasta $100 \% ;(++)$ los caudales aumentan en más del $100 \%$; $(=)$ los caudales permanecen aproximadamente constantes; (-) los caudales disminuyen.

El río Urubamba se localiza en la vertiente amazónica o vertiente del Atlántico, enclavado en los Andes del sur del Perú. El análisis de caudales se enfocó en las cuenca alta y media de este río. En el cuadro V.19 se muestran los cambios ante los escenarios climáticos. En el escenario A1B, cinco modelos proyectan una tendencia de aumento de caudales, mientras que dos sugieren una disminución. En el escenario A2, los caudales se incrementan bajo dos de los modelos y se reducen en los otros dos casos. En el escenario B1, cuatro modelos proyectan un aumento de caudal (uno de ellos de más de 100\%), mientras que dos modelos asumen una disminución.

CUADRO V.19

Cambios en los caudales del río Urubamba ante los escenarios climáticos, 2005-2100

\begin{tabular}{l|c|c|c|c|c|c|} 
Escenario & BCM2.0 & CSMK3.0 & CSMK3.5 & GIAOM & INCM3 & MIHR \\
\hline A1B & + & + & + & + & + & - \\
A2 & + & - & + & N/D & $=$ & N/D \\
B1 & + & ++ & + & + & + & -
\end{tabular}

Fuente: Elaboración propia.

Nota: (+) los caudales aumentan hasta un $100 \%$; (++) los caudales aumentan en más de $100 \%$; (=) los caudales permanecen aproximadamente constantes; (-) los caudales disminuyen.

En función de los cambios en estos caudales se esperarán resultados heterogéneos en la probabilidad de ruptura de las carreteras, dependiendo del modelo del escenario simulado. Se debe notar que si los efectos adversos del cambio climático se incrementan, esta probabilidad también lo hace. El gráfico V.21 muestra el aumento de la probabilidad de ruptura asociado con el cambio climático. Se puede apreciar que, en general, las estimaciones adicionales de ruptura promedio no superan el $4 \%$ en los tres escenarios. Sin embargo, los escenarios con mayores rupturas son A1B y B1. 
GRÁFICO V.21

Probabilidad de ruptura de carreteras para modelos y escenarios A1B, A2 y B1 con respecto al escenario base (En porcentaje)

a) Escenario A1B

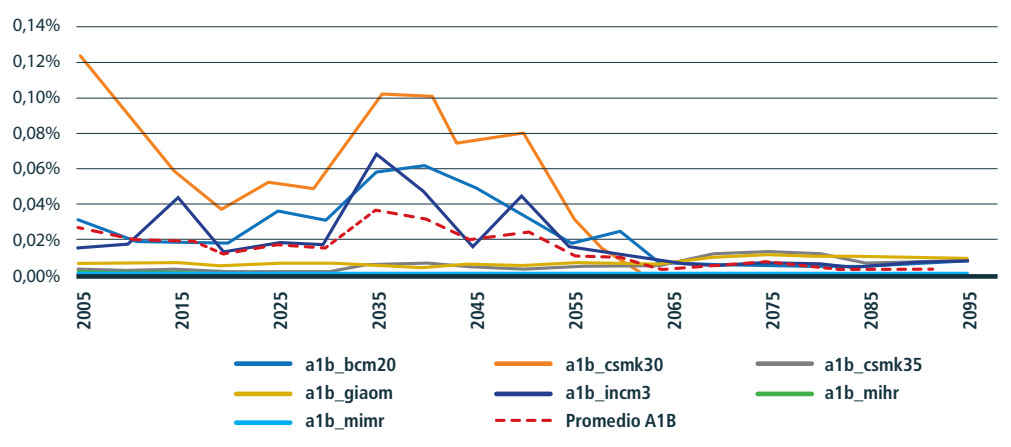

b) Escenario A2

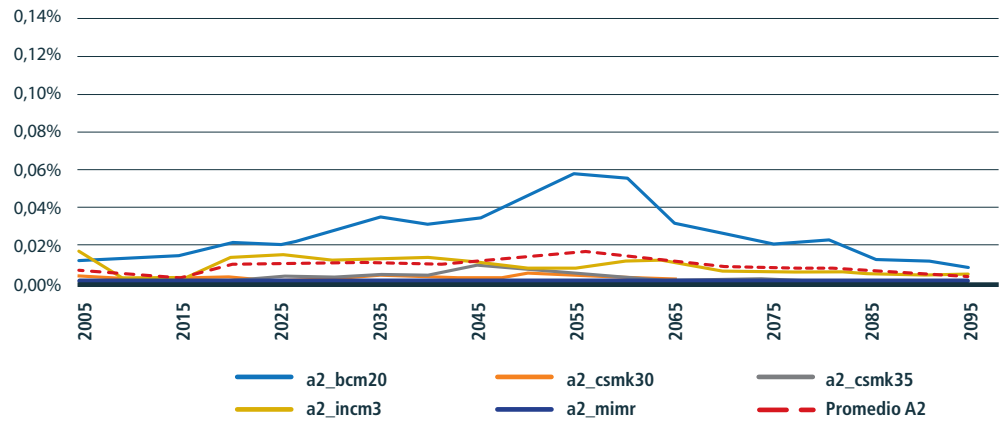

c) Escenario B1

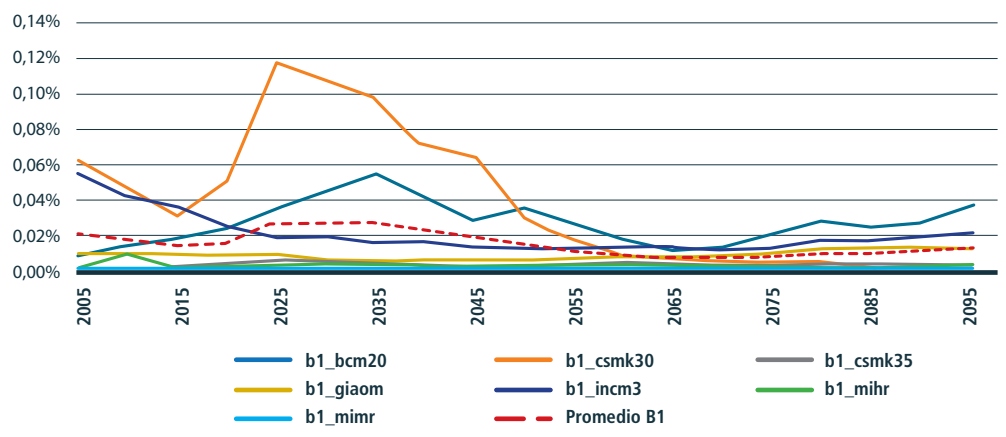

Fuente: Elaboración propia. 
A partir de la información de probabilidad de ruptura de carreteras se calculó el costo de rehabilitación y reparación para los escenarios con y sin cambio climático. El costo sin cambio climático considera la rehabilitación de cuatro tramos de la carretera central y más de 50\% de la red vial nacional correspondiente a carreteras asfaltadas. En particular, el valor anual de reparación para toda la vía fue de 715 millones de soles del año 2010. El costo con cambio climático se obtuvo al incluir el costo extra de rehabilitación asociado a la probabilidad de ruptura de carreteras relacionada el fenómeno climático. En el gráfico V.22.a se muestran los costos promedio para el escenario base y de los tres escenarios climático, mientras que en el gráfico V.22.b, se presenta el diferencial porcentual de costos con respecto al escenario base donde se presenta el aumento en los costos.

GRÁFICO V.22

Impacto del cambio climático en la reposición de vías nacionales

a) Millones de soles del 2010

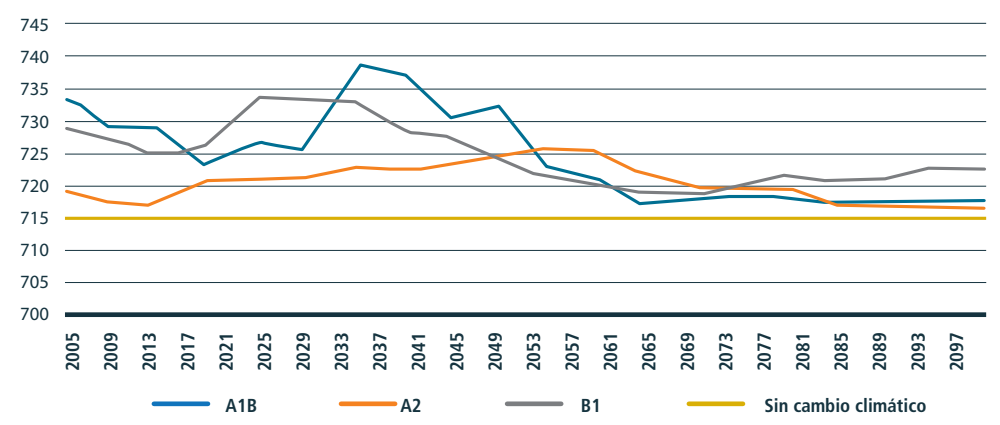

b) Variación porcentual con respecto al año base

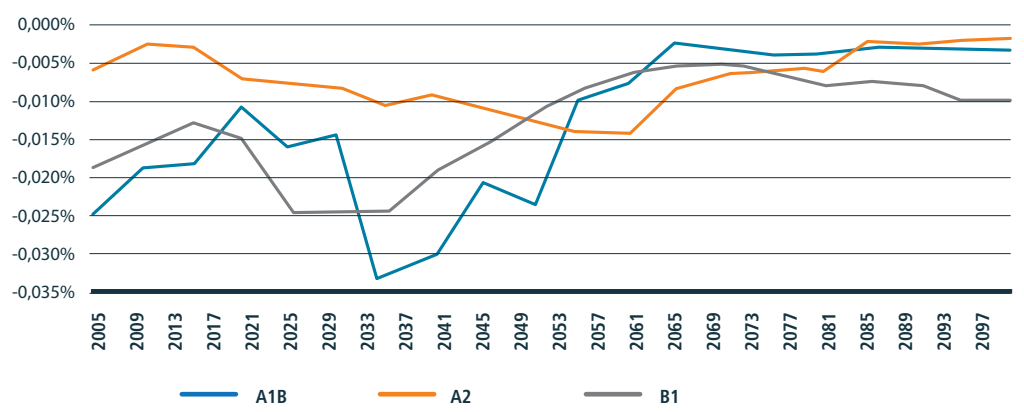

Fuente: Elaboración propia.

Los costos acumulados se presentan en el cuadro V.20, donde se aprecian pérdidas en todos los escenarios climáticos. Si bien todos los escenarios muestran costos incrementales en el tiempo, destacan los escenarios B1 y A1B con los mayores costos acumulados al año 2100. Para todo el horizonte de análisis los costos podrían oscilar entre 401 millones y 707 millones de soles para los escenarios considerados, con un descuento de 0,5\%, respectivamente. En el mismo período (2010 a 2100), el rango de pérdida fluctuaría entre $1,6 \%$ y 2,8\% del PBI de transporte del año base (véase el cuadro V.21). A su vez, el impacto en el PBI nacional acumulado oscilaría entre 0,09\% y 0,16\% del PBI nacional del año 2010 (véase el cuadro V.22). 
CUADRO V.20

Impacto económico del cambio climático en infraestructura vial

(En millones de soles de 2010)

\begin{tabular}{|l|c|c|c|c|c|c|c|c|c|}
\multirow{2}{*}{ Escenario } & \multicolumn{3}{|c|}{$\mathbf{2 0 1 0 - 2 0 4 0}$} & \multicolumn{3}{c|}{$\mathbf{2 0 1 0 - 2 0 7 0}$} & \multicolumn{3}{c|}{$\mathbf{2 0 1 0 - 2 1 0 0}$} \\
\cline { 2 - 10 } & $\mathbf{0 , 5} \%$ & $\mathbf{2 \%}$ & $\mathbf{4} \%$ & $\mathbf{0 , 5} \%$ & $\mathbf{2 \%}$ & $\mathbf{4} \%$ & $\mathbf{0 , 5} \%$ & $\mathbf{2 \%}$ & $\mathbf{4} \%$ \\
\hline A1B & 411 & 324 & 245 & 647 & 455 & 307 & 701 & 473 & 311 \\
\hline A2 & 145 & 113 & 82 & 343 & 215 & 127 & 401 & 236 & 132 \\
B1 & 411 & 326 & 246 & 586 & 421 & 290 & 707 & 460 & 299 \\
\hline
\end{tabular}

Fuente: Elaboración propia.

CUADRO V.21

Impacto del cambio climático en infraestructura vial con respecto al PBI de transporte del año 2010

(En porcentaje)

\begin{tabular}{|l|c|c|c|c|c|c|c|c|c|}
\hline \multirow{2}{*}{ Escenario } & \multicolumn{3}{|c|}{$\mathbf{2 0 1 0 - 2 0 4 0}$} & \multicolumn{3}{c|}{$\mathbf{2 0 1 0 - 2 0 7 0}$} & \multicolumn{3}{c|}{$\mathbf{2 0 1 0 - 2 1 0 0}$} \\
\cline { 2 - 11 } & $\mathbf{0 , 5} \%$ & $\mathbf{2} \%$ & $\mathbf{4} \%$ & $\mathbf{0 , 5} \%$ & $\mathbf{2 \%}$ & $\mathbf{4 \%}$ & $\mathbf{0 , 5} \%$ & $\mathbf{2} \%$ & $\mathbf{4} \%$ \\
\hline A1B & 1,62 & 1,28 & 0,96 & 2,55 & 1,80 & 1,21 & 2,76 & 1,87 & 1,23 \\
\hline A2 & 0,57 & 0,44 & 0,32 & 1,35 & 0,85 & 0,50 & 1,58 & 0,93 & 0,52 \\
\hline B1 & 1,62 & 1,28 & 0,97 & 2,31 & 1,66 & 1,14 & 2,79 & 1,82 & 1,18
\end{tabular}

Fuente: Elaboración propia.

CUADROV.22

Impacto del cambio climático en infraestructura vial con respecto al PBI nacional del año 2010

(En porcentaje)

\begin{tabular}{|l|c|c|c|c|c|c|c|c|c|}
\hline \multirow{2}{*}{ Escenario } & \multicolumn{3}{|c|}{$\mathbf{2 0 1 0 - 2 0 4 0}$} & \multicolumn{3}{c|}{$\mathbf{2 0 1 0 - 2 0 7 0}$} & \multicolumn{3}{c|}{$\mathbf{2 0 1 0 - 2 1 0 0}$} \\
\cline { 2 - 10 } & $\mathbf{0 , 5} \%$ & $\mathbf{2} \%$ & $\mathbf{4} \%$ & $\mathbf{0 , 5} \%$ & $\mathbf{2} \%$ & $\mathbf{4} \%$ & $\mathbf{0 , 5} \%$ & $\mathbf{2} \%$ & $\mathbf{4} \%$ \\
\hline A1B & 0,092 & 0,073 & 0,055 & 0,145 & 0,102 & 0,069 & 0,158 & 0,106 & 0,070 \\
\hline A2 & 0,033 & 0,025 & 0,018 & 0,077 & 0,048 & 0,029 & 0,090 & 0,053 & 0,030 \\
\hline B1 & 0,092 & 0,073 & 0,055 & 0,132 & 0,095 & 0,065 & 0,159 & 0,104 & 0,067 \\
\hline
\end{tabular}

Fuente: Elaboración propia.

En suma, el sector de infraestructura podría ver un costo incremental a lo largo del siglo, debido a crecientes casos de ruptura de carreteras. Sin embargo, las proyecciones de flujo de agua y de ruptura difieren entre modelos, por lo que el resultado es incierto y el promedio tiende a cancelar los impactos. Los órdenes de magnitud encontrados serían bajos.

Hay que considerar que los impactos son calculados únicamente sobre carreteras asfaltadas, por lo que los resultados representan una primera aproximación bastante conservadora en cuanto a la magnitud del fenómeno. 


\section{G. Turismo}

En el año 2013 los ingresos mundiales por turismo internacional alcanzaron la cifra de 1.159 miles de millones de dólares. Se espera que el número de turistas internacionales en todo el mundo crezca en 3,3\% promedio hasta el año 2030 (UNWTO, 2014). Dado el crecimiento económico de los países, el aumento poblacional y la promoción del turismo, resulta previsible el incremento de su demanda, con cambios entre turismo de corta, media y larga distancia. Sin embargo, la necesidad de reducir emisiones de gases de efecto invernadero podría impactar en los costos del transporte aéreo e inducir sustituciones entre destinos distantes y otros atractivos más cercanos al lugar de origen (Agueda et al., 2005; Lipman, 2007; UNWTO, 2008).

El Perú es un país con gran patrimonio histórico-cultural, con bienes y sitios históricos declarados Patrimonio de la Humanidad por la UNESCO ${ }^{50}$. Además alberga numerosas especies animales, tiene un amplio número de áreas naturales protegidas y es uno de los doce países megadiversos (MINCETUR, 2008). Sus atractivos naturales y culturales situaron al país, en el año 2012, en el puesto 73 del mundo y séptimo en relación con los países de América Latina y el Caribe del Índice de Competitividad de Viajes y Turismo del Foro Económico Mundial (MINCETUR, 2013b; WEF, 2013).

El turismo se ha convertido en un sector muy importante para la economía peruana, ya que es una fuente generadora de empleos y divisas; promueve el comercio, la inversión e infraestructura, y genera efectos indirectos a través de sus encadenamientos productivos con otros sectores de la economía. Como se aprecia en el gráfico V.23 desde el año 2007, y hasta 2013, el producto del sector turismo, en promedio, ha representado el 3,8\% del PIB nacional. Además, en el año 2012 este sector fue el cuarto generador de divisas en el país (MINCETUR, 2012).

GRÁFICOV.23

PBI nominal del sector Turismo y como porcentaje del PBI Nacional, 1991-2013

(En millones de soles constantes de 2010 y en porcentaje)

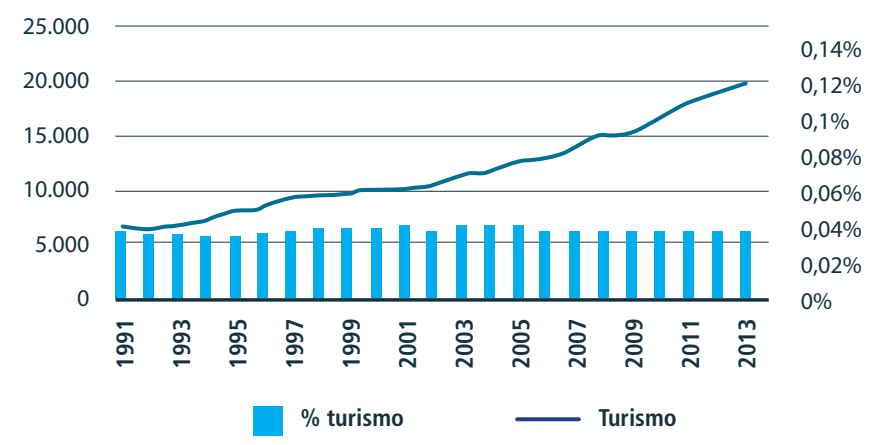

Fuente: Elaboración propia sobre la base de BADATUR-OTP (2014), INEI (2013).

50 En el Perú destacan sitios como el Parque Nacional Río Abiseo, el Parque Nacional Huascarán, el sitio arqueológico Chavín, la zona arqueológica de Chan Chan, el centro histórico de Lima, el Santuario Histórico de Machu Picchu, la ciudad del Cusco, las líneas y los geoglifos de Nasca y las pampas de Jumana, el Parque Nacional del Manu y el centro histórico de Arequipa. 


\section{Relación del sector con las variables climáticas}

El turismo es un sector sensible a los efectos del cambio climático. Se prevé que en especial el turismo de playa, el de deportes en nieve y el de tipo ecológico serían los más afectados (Organización Mundial del Turismo et al., 2007). Las estimaciones sugieren impactos en la competitividad de los destinos turísticos y en la estacionalidad, la continuidad y la regularidad del flujo turístico, dado que muchos lugares basan sus atractivos en recursos ambientales y en el clima (Andrade, 1998).

La repercusión directa del cambio climático para los destinos turísticos se relaciona con los factores de temperatura, precipitación, viento, humedad y aumento de nivel del mar, así como con la ocurrencia de eventos climáticos extremos, entre otros (Sánchez y Dalle; 2005, IPCC, 2007a). Estos cambios afectarán al sector turístico, ya que causan daños sobre la infraestructura, lo que demandaría medidas suplementarias ante eventos de emergencia, y la consecuente alza de gastos en seguros, sistemas de reserva para agua, electricidad y evacuaciones, que interrumpirían la actividad comercial. Esto repercutiría en la competitividad, demanda turística, estacionalidad y gastos para adaptación y mitigación (OMT et al., 2007). En cuanto a los efectos indirectos del cambio climático para el sector está la variación en la disponibilidad de agua, alteraciones en los ecosistemas, pérdida de biodiversidad, deshielos, retroceso de los bosques, erosión, inundaciones, deslizamientos, proliferación de enfermedades, incendios forestales, y una mayor vulnerabilidad para el patrimonio histórico, entre otros (WWF, 2001).

El Informe Stern (2007) concluye que el cambio climático perjudicaría el crecimiento económico por sus repercusiones negativas para el sector turístico. Cabe mencionar que esto no se explica únicamente por las variables climáticas; además pueden influir diversos factores, como el atractivo turístico, el crecimiento del PBI mundial, la inestabilidad política, la agitación social, el riesgo de desastres naturales y la delincuencia. Por lo tanto, resulta difícil individualizar el peso de las condiciones climáticas en la elección de un destino turístico ya que también influyen, el ambiente natural y la seguridad personal (Hamilton, 2005b; Agueda et al. 2005; OMT et al. 2007 e IPCC, 2007a).

Diversos estudios (Hamilton et al., 2005 y 2005b; OMT, et al. 2007) sugieren que es probable que el turismo se desplace hacia latitudes y altitudes superiores, o bien hacia el climas más propicios. La redistribución geográfica y estacional es más marcada hacia mediados y fines de siglo. Esto ocasionaría pérdidas significativas en algunas zonas ${ }^{51}$.

El objetivo de este estudio es establecer los factores explicativos de la oferta y la demanda de turismo en el Perú y calcular los costos económicos del cambio climático sobre ese sector en los escenarios climáticos para el país.

\section{Impactos del cambio climático en el sector de turismo}

Como se detalla en el capítulo III, sección g el impacto del cambio climático sobre el sector de turismo se estudió a partir de los factores de la estacionalidad en la demanda y la repercusión climática en la demanda y oferta de turismo.

Respecto a la demanda de turismo, el análisis se concentró únicamente en el turismo de vacaciones y ocio, ya que este sector representa más del 52\% del total nacional y se espera que la demanda de este tipo de turismo sea la más afectada por el cambio climático (Agueda et al. 2005).

51 También se afectaría a los prestadores de servicios, como alojamientos y agencias situados en zonas vulnerables que atraen turistas con menor capacidad de gasto, sobre todo en países en desarrollo, donde hay menor capacidad de adaptación (IPCC 2007a), en tanto los flujos de turistas al desplazarse a otras zonas pueden seguir generando beneficios económicos similares. Sin embargo, el efecto neto en la demanda turística sería limitado a escala mundial (Perry 2000, Agueda et al. 2005). 
Se identificó la afluencia de turistas extranjeros que viajaron al Perú en el período 2004 a 2012 con un gasto promedio de 109 dólares por día y con una permanencia promedio de 12 días.

En cuanto a la oferta de rutas turísticas en el país, destaca el circuito sur, compuesto por las zonas de Cusco, Puno y Arequipa ${ }^{52}$, que fue visitado en el año 2010 por 69\% de turistas extranjeros. De esta ruta, se identificó que el principal atractivo es la ciudadela inca de Machu Picchu, que en el año 2011 recibió 300.683 turistas nacionales y 670.959 extranjeros (Morales et al., 2011). Cabe destacar que el turismo en Machu Picchu también beneficia a otros destinos turísticos aledaños.

Para analizar la repercusión de los impactos del cambio climático en la oferta y la demanda del turismo, se analizó el vínculo entre la precipitación, la temperatura y los turistas que llegan a Machu Picchu, considerando que un cambio en estas variables podría hacer menos propicia la visita a este lugar.

Los resultados mostraron una correlación negativa con la afluencia de visitantes y la temperatura ${ }^{53}$. En cuanto a la relación con la época lluviosa (diciembre a marzo) se observó que los turistas disminuyen, pero en la época seca (mayo a setiembre) estos aumentan. Se identificó una correlación positiva entre la precipitación registrada en Machu Picchu y el número de interrupciones en la vía férrea Ollantaytambo-Aguas Calientes, que es la única vía de transporte hacia este sitio. En los años que las Iluvias alcanzan ciertos umbrales, la interrupción de la vía férrea es mayor (véase el gráfico V.24).

\section{GRÁFICO V.24}

Precipitación mensual e interrupciones en la vía férrea hacia la ciudadela de Machu Picchu por causas ambientales, 2004-2011 (En milímetros al mes y en número de interrupciones)

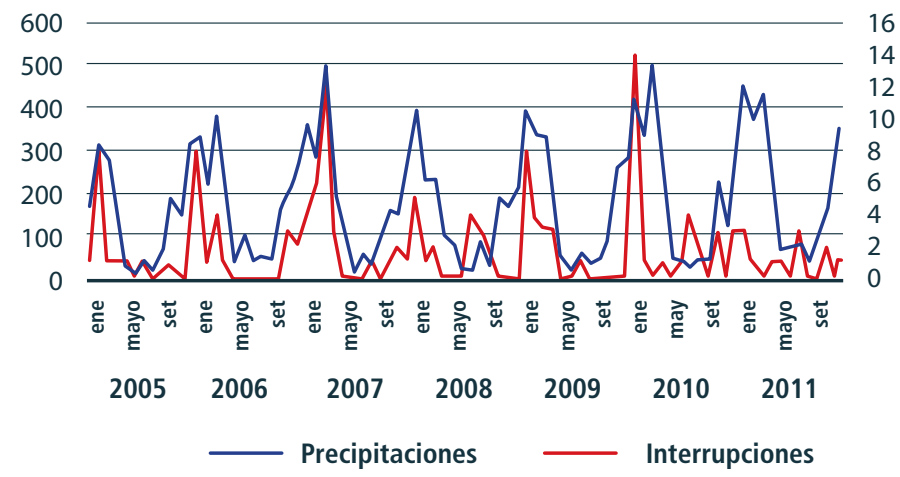

Fuente: Elaboración propia a partir de datos de la estación meteorológica de Machu Picchu, Cusco.

52 A estas rutas les siguen las de Ica y Tacna (por el tránsito de ciudadanos chilenos); Loreto y Madre de Dios en la Amazonía; y, en el circuito norte, La Libertad y Piura. Los registros de alojamiento en Lima y Callao son los más significativos, pero son catalogados como turismo de negocios y de tránsito.

53 La variabilidad entre la temperatura máxima y la mínima en MachuPicchu(Cusco) es de $8,75^{\circ} \mathrm{C}$ en verano y de $11,93{ }^{\circ} \mathrm{C}$ en invierno (período 2002 a 2010). 
Esta correlación hace suponer que el turismo de tipo cultural y geográfico que caracteriza al Perú sería sensible a la probabilidad de interrupción de las vías de comunicación por el incremento de las lluvias, lo que dificultaría el acceso a Machu Picchu, que es el principal atractivo turístico nacional. La posibilidad de máxima ocurrencia es en el período de diciembre a marzo, cuando las precipitaciones pueden ocasionar que el caudal del río Vilcanota-Urubamba llegue a su umbral máximo y se desborde, causando pérdidas económicas por los ingresos no percibidos durante el tiempo que se demore en reparar las vías de comunicación. El estudio priorizó el análisis de los ingresos por turismo extranjero ${ }^{54}$, ya que se espera que el turista nacional se reacomode a otros destinos del país.

Se estimó la proyección de turistas para fines de siglo sin cambio climático con un escenario base, considerando como factores explicativos el PBI per cápita de los Estados Unidos y el PBI per cápita de Chile, que son los países con mayor número de turistas que viajan al Perú. Este escenario también contempló dos posibles trayectorias en relación con la capacidad de carga de turistas en la ciudadela. La primera estimación consideró una restricción máxima de 2.500 turistas/día (carga 1) y la segunda de 5.000 turistas/día (carga 2). Los resultados de esta proyección se pueden apreciar en el gráfico V.25.

\section{GRÁFICO V.25}

Proyección de turistas de vacaciones y capacidad de carga a Machu Picchu al año 2100, escenario base

(En número de turistas)

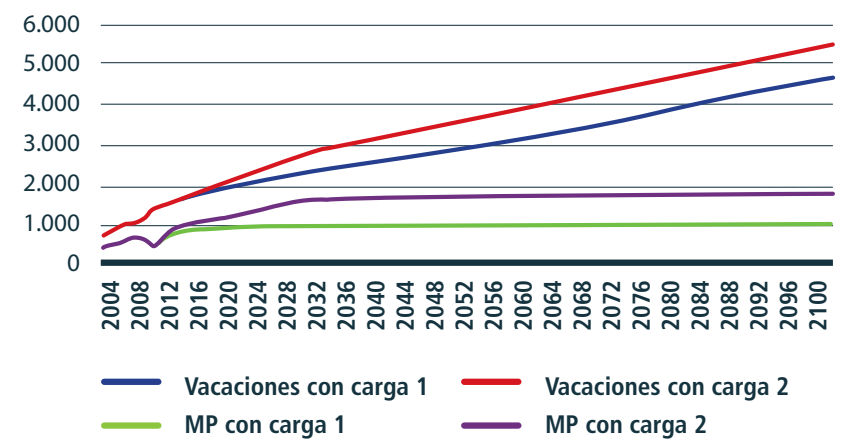

Fuente: Elaboración propia.

Notas: a) Vacaciones con carga 1 y 2 se asocia al turismo; y ocio total y MP con carga

1 y 2 se asocia a el turismo y ocio en Machu Picchu;

b) El turismo de vacaciones a Machu Picchu con carga 1 considera el ingreso de máximo 2.500 visitantes/día, con carga 2 considera el ingreso máximo de 5.000

visitantes/día.

Para generar las simulaciones de caudales futuros y analizar la distribución de probabilidades del corte de vía, se utilizó un modelo de precipitación-escorrentía con seis modelos globales máximos para cada escenario climático y usando datos medios diarios de caudales en la estación Písac (Cusco) del río Vilcanota.

Los gráficos V.26 a y b muestran la proyección de llegada de turistas a Machu Picchu a partir de la probabilidad de ruptura en las vías de acceso por eventos extremos de precipitación. Se ofrecen resultados en quinquenios para los escenarios climáticos B1, A1B y A2 durante el período 2010-2100. Se esperaría que el retorno de un evento extremo fuera cada 50 años (máximo caudal derivado de una fuerte precipitación que señala el umbral). 
GRÁFICO V.26

Turistas que visitan Machu Picchu con probabilidad de eventos extremos de precipitación y capacidades de carga 1 y 2

(En miles)

a) Carga 1

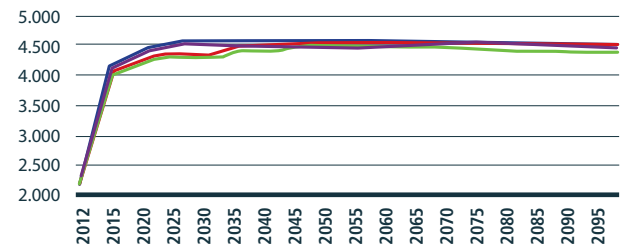

- $\mathrm{BAU}-\mathrm{BU}^{\mathrm{B}}-\mathrm{A} 1 \mathrm{~B}-\mathrm{A} 2$ b) Carga 2

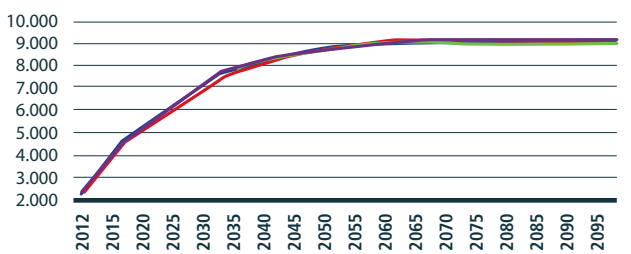

- $\mathrm{BAU}-\mathrm{B}_{1}-\mathrm{A} 1 \mathrm{~B}-\mathrm{A} 2$

Fuente: Elaboración propia.

Nota: El turismo de vacaciones a Machu Picchu con carga 1 considera el ingreso de máximo 2.500 visitantes/día. Con carga 2 considera el ingreso máximo de 5.000 visitantes/día.

Estas proyecciones se multiplicaron por el gasto promedio de 1.278 dólares que cada visitante extranjero realiza el país. Con esa información se calculó el ingreso que se podría ver afectado por la disminución de turistas. Para facilitar la presentación de los resultados se promediaron los de la capacidad de carga 1 con los de la 2 de la ciudadela inca. En los cuadros V.23-V.25, se presentan los costos económicos por disminución del número de turistas atribuidos al cambio climático.

CUADRO V.23

Impacto económico del cambio climático en turismo

(En millones de soles de 2010)

\begin{tabular}{|l|r|r|r|r|r|r|r|r|r|}
\hline \multirow{2}{*}{ Escenario } & \multicolumn{3}{|c|}{$\mathbf{2 0 1 0 - 2 0 4 0}$} & \multicolumn{3}{c|}{$\mathbf{2 0 1 0 - 2 0 7 0}$} & \multicolumn{3}{c|}{$\mathbf{2 0 1 0 - 2 1 0 0}$} \\
\cline { 2 - 10 } & $\mathbf{0 , 5} \%$ & $\mathbf{2 0} \%$ & $\mathbf{4} \%$ & $\mathbf{0 , 5} \%$ & $\mathbf{2 \%}$ & $\mathbf{4} \%$ & $\mathbf{0 , 5} \%$ & $\mathbf{2 \%}$ & $\mathbf{4} \%$ \\
\hline A1B & 1.747 & 1.438 & 1.140 & 2.971 & 2.089 & 1.432 & 5.029 & 2.792 & 1.608 \\
\hline A2 & 690 & 568 & 450 & 1.991 & 1.261 & 761 & 2.541 & 1.448 & 808 \\
\hline B1 & 2.970 & 2.445 & 1.938 & 3.592 & 2.776 & 2.086 & 3.939 & 2.894 & 2.116 \\
\hline
\end{tabular}

Fuente: Elaboración propia.

CUADRO V.24

Impacto del cambio climático en turismo con respecto al PBI sectorial del año 2010

(En porcentaje)

\begin{tabular}{|l|c|c|c|c|c|c|c|c|c|}
\hline \multirow{2}{*}{ Escenario } & \multicolumn{3}{|c|}{$\mathbf{2 0 1 0 - 2 0 4 0}$} & \multicolumn{3}{c|}{$\mathbf{2 0 1 0 - 2 0 7 0}$} & \multicolumn{3}{c|}{$\mathbf{2 0 1 0 - 2 1 0 0}$} \\
\cline { 2 - 11 } & $\mathbf{0 , 5} \%$ & $\mathbf{2 0} \%$ & $\mathbf{4} \%$ & $\mathbf{0 , 5} \%$ & $\mathbf{2} \%$ & $\mathbf{4} \%$ & $\mathbf{0 , 5} \%$ & $\mathbf{2} \%$ & $\mathbf{4} \%$ \\
\hline A1B & 10,47 & 8,62 & 6,83 & 17,81 & 12,53 & 8,58 & 30,15 & 16,74 & 9,64 \\
\hline A2 & 4,14 & 3,41 & 2,70 & 11,94 & 7,56 & 4,56 & 15,23 & 8,68 & 4,84 \\
B1 & 17,81 & 14,66 & 11,62 & 21,53 & 16,64 & 12,51 & 23,62 & 17,35 & 12,69
\end{tabular}

Fuente: Elaboración propia. 
CUADRO V.25

Impacto del cambio climático en turismo con respecto al PBI nacional del año 2010

(En porcentaje)

\begin{tabular}{|l|c|c|c|c|c|c|c|c|c|}
\hline \multirow{2}{*}{ Escenario } & \multicolumn{3}{|c|}{$\mathbf{2 0 1 0 - 2 0 4 0}$} & \multicolumn{3}{c|}{$\mathbf{2 0 1 0 - 2 0 7 0}$} & \multicolumn{3}{c|}{$\mathbf{2 0 1 0 - 2 1 0 0}$} \\
\cline { 2 - 10 } & $\mathbf{0 , 5} \%$ & $\mathbf{2} \%$ & $\mathbf{4} \%$ & $\mathbf{0 , 5} \%$ & $\mathbf{2} \%$ & $\mathbf{4} \%$ & $\mathbf{0 , 5} \%$ & $\mathbf{2} \%$ & $\mathbf{4} \%$ \\
\hline A1B & 0,39 & 0,32 & 0,26 & 0,67 & 0,47 & 0,32 & 1,13 & 0,63 & 0,36 \\
\hline A2 & 0,16 & 0,13 & 0,10 & 0,45 & 0,28 & 0,17 & 0,57 & 0,33 & 0,18 \\
\hline B1 & 0,67 & 0,55 & 0,44 & 0,81 & 0,62 & 0,47 & 0,89 & 0,65 & 0,48
\end{tabular}

Fuente: Elaboración propia.

Como se aprecia en el cuadro V.23, las pérdidas acumuladas durante el período 2011-2100 en el sector turismo podrían rebasar los 5.000 millones de soles en el escenario A1B, con una tasa de descuento de 0,5\%. Al analizar todos los escenarios y las tasas de descuento, se observa que las pérdidas acumuladas durante todo el período oscilarían entre 808 y 5.000 millones de soles. Estas cifras representarían entre 5\% y 30\% del PBI de turismo del año 2010, según la tasa de descuento considerada (véase el cuadro V.24). Al analizar estos mismos impactos con respecto al PBI nacional del año 2010, se aprecia que representarían menos de 1\% (véase el cuadro V.25).

Lo anterior muestra que el potencial impacto del cambio climático sería poco significativo para el PBI sectorial y nacional, considerando una mayor tasa de crecimiento de los ingresos generados por turismo, la limitación que impone la capacidad de carga en Machu Picchu y la probabilidad de ocurrencia de eventos extremos de lluvia cada 50 años.

Se debe recordar que existen otros factores de incertidumbre que podrían afectar indirectamente estos resultados y que no han sido considerados, como la posibilidad de que el aumento de enfermedades tropicales pudiera afectar negativamente el turismo. También se debe tener en cuenta que en el contexto externo, el desempeño futuro del PBI per cápita de los principales países abastecedores (Chile y Estados Unidos) podría impactar la demanda de turistas, a partir de los propios escenarios climáticos y de emisiones de cada país, lo que afectaría el arribo de extranjeros al Perú, repercutiendo en los ingresos del sector. Por último, podrían existir otras posibles variaciones no contempladas, como modificaciones en la capacidad de carga de Machu Picchu, el aumento de los precios a esa atracción y el crecimiento de otros destinos que pongan en valor lugares promisorios al turismo arqueológico y paisajístico.

\section{H. Salud}

El sector de salud puede ser considerado de importancia transversal para toda la sociedad. Por ello, el cambio climático representa una amenaza tanto para él como para la economía en general, y puede impactar a la población de manera directa, al modificar la frecuencia y la distribución de enfermedades transmitidas por vectores, de manera indirecta, al empeorar la economía del hogar.

El gasto total en salud en el Perú es un indicador que se ha incrementado en los últimos años. Este monto comprende el gasto privado y el gasto público designado para la prestación de servicios de salud (preventivos y curativos), para las actividades de planificación familiar y de nutrición, para la asistencia de emergencias (Banco Mundial, 2012). 
Como se aprecia en el gráfico V.27, entre 1994 y 2011 el gasto en salud aumentó más de 140\%. Se evidencia, además, que luego del año 1998 el gasto presentó un leve incremento, posiblemente a causa de que El Niño ocasionó mayores enfermedades o aumentó la contaminación del agua, o bien se dieron las condiciones favorables para la proliferación de la malaria. También se puede notar que a partir del año 2007 se elevó el gasto en salud por el aumento de la población asegurada en el Seguro Integral de Salud (SIS), y por una mayor adquisición de medicamentos, facilitada por los tratados de libre comercio.

\section{GRÁFICO V.27}

Gasto en salud total y como porcentaje del PBI nacional

(En millones de soles de 2010 y en porcentaje)

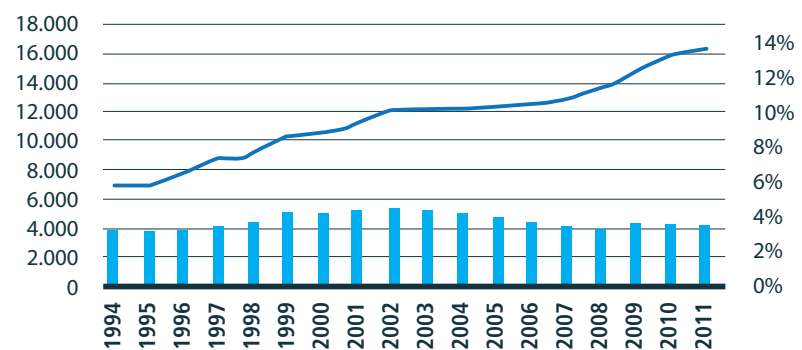

$\% \mathrm{PBI} \quad$ Gasto en salud del Gobierno central

Fuente: Elaboración propia sobre la base del INEI (2014).

\section{Relación del sector con las variables climáticas}

La literatura indica que los factores climáticos afectan la incidencia de las enfermedades transmitidas por vectores, ya sea de manera directa o indirecta. Directamente, alteran la frecuencia de los vectores (Stern et al., 2011) e incluso la evolución de la enfermedad (Park, 2011). Indirectamente repercuten en la distribución y el comportamiento de los vectores que transmiten las enfermedades (Lindsay et al., 1998; Manoukis et al., 2011). Los eventos climáticos extremos también pueden contribuir en la incidencia de otras enfermedades. Por ejemplo, en el Perú se ha observado que el fenómeno de El Niño estuvo asociado a un incremento en los casos de diarrea en Lima (Bennett et al., 2012) y posiblemente también a la epidemia de cólera de 1991 (Seas et al., 2000).

Son enfermedades de particular importancia en el Perú la malaria, la leishmaniasis, el dengue y la fiebre amarilla. Todos estos males son transmitidos por mosquitos, cuyo ciclo de vida depende de la temperatura y de la disponibilidad de agua para el desarrollo de las etapas larvarias ${ }^{55}$.

La malaria es una enfermedad vectorial en la que interviene como agente el mosquito Anopheles, que se desarrolla en lugares de altas temperaturas y donde exista agua suficiente para su reproducción. Como la leishmaniasis, la malaria es causada por parásitos unicelulares y ambas son curables mediante la administración de drogas antiparasitarias. El dengue y la fiebre amarilla son, por otro lado, enfermedades causadas por virus, para los que en la actualidad no existe cura. Ambas son potencialmente mortales, en particular la fiebre amarilla; pero para esta existe una vacuna efectiva, que probablemente es responsable del relativamente bajo número de casos reportados en estos doce años.

55 Las cuatro enfermedades son de reporte obligatorio, de acuerdo con las directivas del Ministerio de Salud del Perú. 
La variación en las enfermedades, resultante del cambio climático, dependerá de varios factores (tales como costo del tratamiento, acceso a agua limpia y a servicios de salud, cambios en la distribución de la población o resultados de campañas previas de erradicación), pero, dada la gran disponibilidad de datos, este estudio se concentra únicamente en el análisis de las enfermedades transmitidas por vectores, específicamente en la malaria.

\section{Impactos del cambio climático}

El impacto del cambio climático en la salud se estimó a partir de las principales enfermedades transmitidas por vectores. La malaria ha representado el 75\% del total de casos en el período de estudio, porcentaje que se muestra como el de mayor incidencia de estas enfermedades. Por esta razón el análisis del impacto del cambio climático se enfoca en esta enfermedad.

Como se explica en el capítulo III, sección B, acápite 8, se analizó la incidencia de la malaria en la mayor parte de los distritos del país. Luego se establecieron correlaciones entre la enfermedad y las condiciones del clima expresadas en las variables de precipitación y temperatura.

Para el período 2000 a 2011 se reportaron casos de malaria en 715 de los 1.837 distritos del Perú. Con esta información y a partir de la población distrital se calculó la incidencia anual promedio de la malaria para el período de estudio ${ }^{56}$.

En el mapa V.3 se puede observar que existe un menor número de casos en los distritos del centro del Perú, debido a que la cordillera de los Andes actúa como una barrera natural. En contraste, la mayor incidencia de casos se concentra en los departamentos de la selva y en el extremo norte de la costa. Las grandes extensiones de desierto deshabitado a lo largo de la costa representan también una barrera que impide la expansión del parásito en dirección al sur. Este aislamiento relativo sugiere una falta de correlación entre la temperatura, la precipitación y la incidencia de malaria. Por esta razón, el análisis se concentró únicamente en los departamentos de mayor relevancia de la enfermedad: Loreto, Ucayali, Madre de Dios, Amazonas, San Martín, Tumbes y Piura.

MAPA V.3

Incidencia anual de la malaria por distrito, 2000-2011

(Casos por cada 100.000 habitantes)

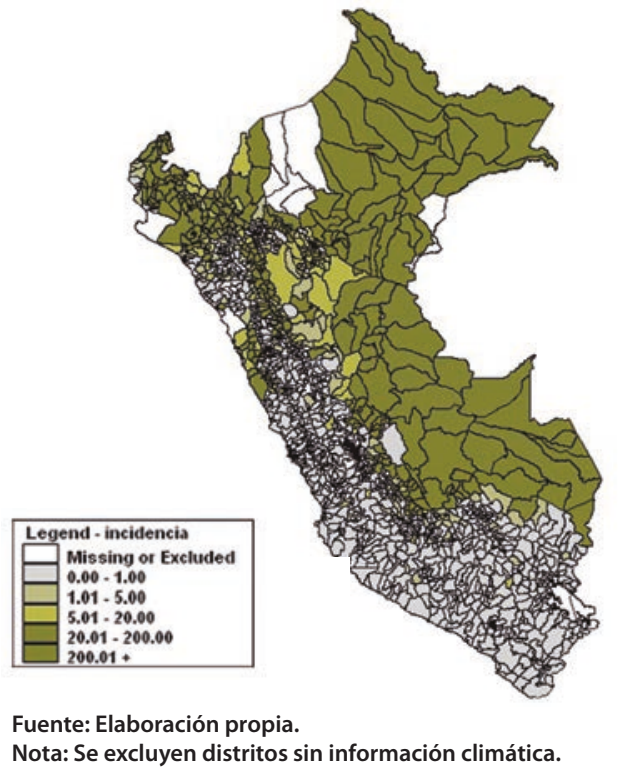

56 En base a los datos de población del Censo Nacional del año 2007. 
En cuanto al análisis de correlación de la malaria con las condiciones del clima, se identificó que su relación con la precipitación y con las temperaturas máxima y media es lineal, mientras que con la temperatura mínima se observó que la incidencia aumenta y alcanza un crecimiento significativo a $17{ }^{\circ} \mathrm{C}$, aunque va disminuyendo con temperaturas mínimas mayores, como lo muestra el gráfico V.28. Esto supone que la variabilidad en la temperatura podría implicar un incremento en la incidencia de malaria, pero que si se exceden las condiciones climáticas óptimas para la transmisión del parásito, se observaría una reducción en la ocurrencia de este evento.

\section{GRÁFICOV.28}

Incidencia de malaria a partir de la temperatura mínima

$$
\text { (Incidencia estimada/10^5 y grados centígrados) }
$$

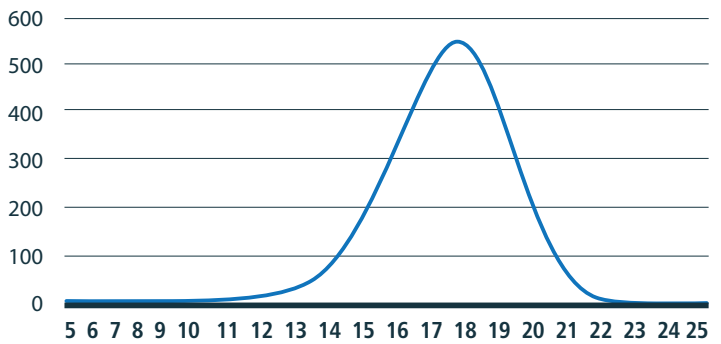

Fuente: Elaboración propia.

Nota: Estas condiciones son en situaciones de precipitación (188 mm), temperatura media $\left(24^{\circ} \mathrm{C}\right)$ y máxima $\left(30^{\circ} \mathrm{C}\right)$ constantes.

A partir de estas premisas se calcularon los probables casos de incidencia de malaria para fines de siglo. Se consideraron las proyecciones de clima para cada distrito bajo los distintos escenarios A1B, A2 y B1, y los modelos seleccionados para el estudio. Los gráficos V.29, b y c presentan las proyecciones del número de casos de malaria para los escenarios y modelos estudiados.

\section{GRÁFICO V.29}

Proyecciones de casos de malaria para los escenarios A1B, A2 y B1, 2010-2100

\section{(En número de casos)}

\section{a) Escenario A1B}

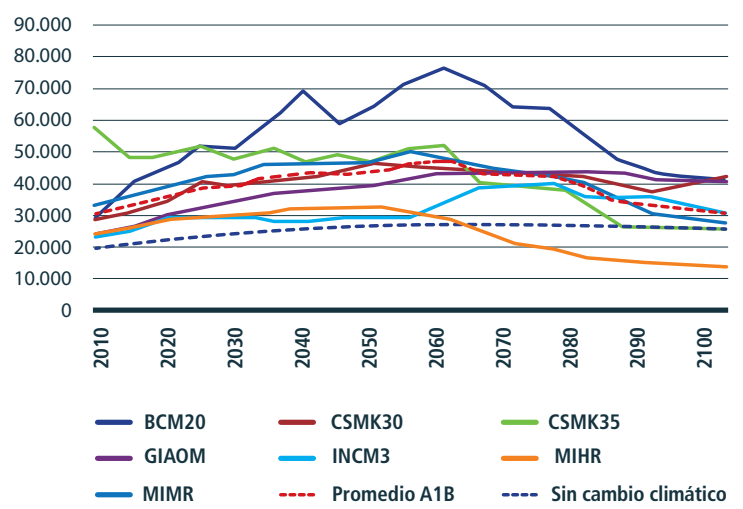




\section{b) Escenario $\mathrm{A} 2$}

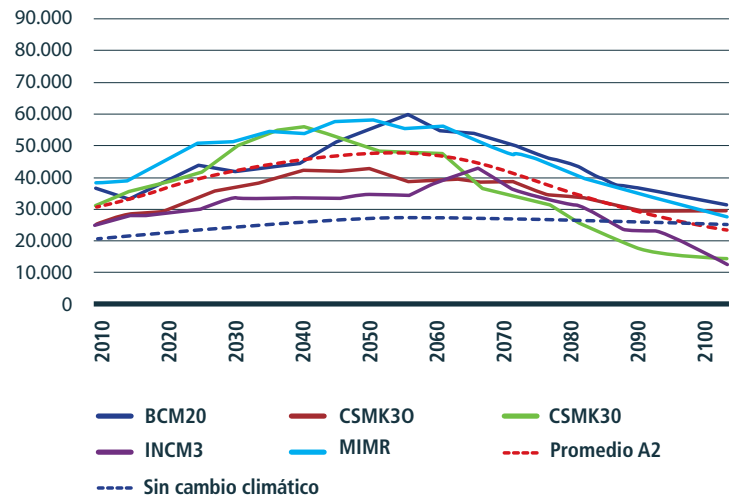

c) Escenario B1

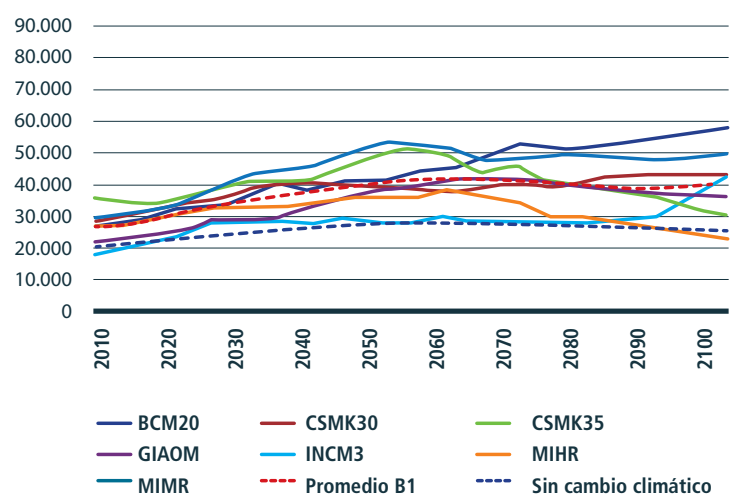

Fuente: Elaboración propia.

En el escenario A1B, para el promedio de los modelos se observaría una cifra máxima en torno a los 46.000 casos en el año 2060. El modelo BCM2.0 muestra un máximo de 80.000 casos de malaria en ese momento, siendo la cifra anual más alta para todas las combinaciones de escenarios y modelos evaluadas (véase el gráfico V.29a). Para el escenario A2, en todos los modelos evaluados hay un incremento de casos de la enfermedad para los primeros años y hasta mediados de siglo, pero esta evolución disminuye para los últimos años (véase el gráfico V.29b). La evolución de los casos de malaria para los diferentes modelos evaluados con el escenario B1 es variada (véase gráfico 5.29c). La tendencia promedio en la incidencia de casos sería de aumento en los primeros años del período, pero con estabilización a fines de siglo.

A partir de las proyecciones del número de casos de malaria se estimaron los costos del tratamiento ${ }^{57}$ en situaciones sin y con cambio climático, así como su respectivo efecto en el PBI. El gráfico V.30a muestra la valoración del impacto estimado para cubrir el tratamiento de los casos infectados con malaria en los tres escenarios con y sin cambio climático para todo el período. El gráfico V.30b expone la variación porcentual de los costos con respecto al escenario base para tratar al número de infectados con esta enfermedad. Se aprecia que la evolución de estos costos sería coincidente con los cambios en incidencia antes descritos. 
a) Millones de soles de 2010

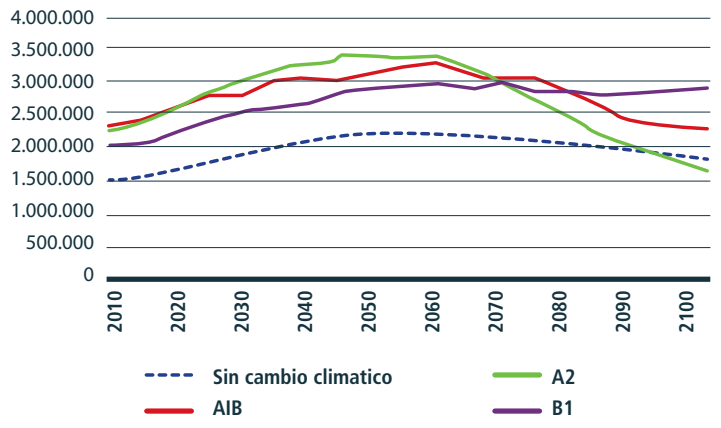

b)Variaciónporcentualconrespectoalañobase

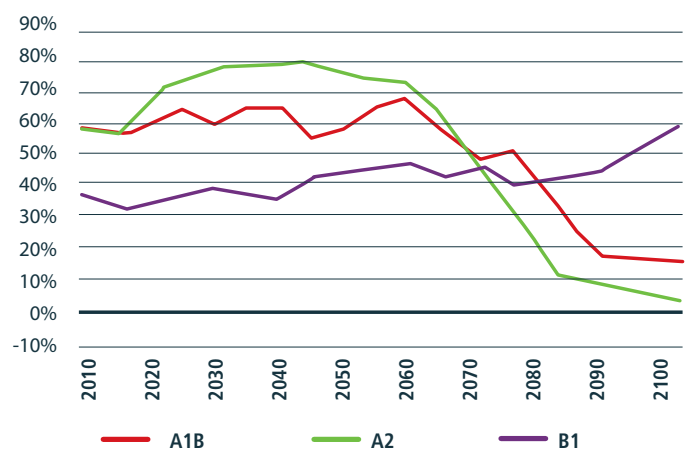

Fuente: Elaboración propia.

El análisis del sector de la salud para el período acumulado 2010 a 2100 revela que el impacto del cambio climático podría generar costos de hasta 75 millones de soles en el escenario A1B, a una tasa de descuento de $0,5 \%$, representando el 0,02\% del PBI nacional (véanse los cuadros V.26 y V.27). El costo acumulado de los escenarios A1B y A2 es similar, mientras que para el escenario B1 se presentarían costos ligeramente menores. De este modo, los costos acumulados al año 2100 para todos los escenarios oscilarían entre 63 millones de soles y 75 millones de soles. Cabe recordar que los costos señalados reflejan únicamente el análisis en el tratamiento de la malaria a los costos unitarios actuales.

CUADRO V.26.

Impacto económico del cambio climático en salud

(En millones de soles de 2010)

\begin{tabular}{|l|c|c|c|c|c|c|c|c|c|}
\hline \multirow{2}{*}{ Escenario } & \multicolumn{3}{|c|}{$\mathbf{2 0 1 0 - 2 0 4 0}$} & \multicolumn{3}{c|}{$\mathbf{2 0 1 0 - 2 0 7 0}$} & \multicolumn{3}{c|}{$\mathbf{2 0 1 0 - 2 1 0 0}$} \\
\cline { 2 - 10 } & $\mathbf{0 , 5} \%$ & $\mathbf{2 0} \%$ & $\mathbf{4} \%$ & $\mathbf{0 , 5} \%$ & $\mathbf{2} \%$ & $\mathbf{4} \%$ & $\mathbf{0 , 5} \%$ & $\mathbf{2} \%$ & $\mathbf{4} \%$ \\
\hline A1B & 30,2 & 24,2 & 18,5 & 59,9 & 39,5 & 25,1 & 74,9 & 44,7 & 26,4 \\
\hline A2 & 32,9 & 26,0 & 19,6 & 66,9 & 43,7 & 27,4 & 74,1 & 46,4 & 28,1 \\
B1 & 19,6 & 15,5 & 11,8 & 43,0 & 27,6 & 17,0 & 63,2 & 33,7 & 18,0
\end{tabular}

Fuente: Elaboración propia. 
CUADROV.27

Impacto del cambio climático en salud con respecto al PBI nacional del año 2010

(En porcentaje)

\begin{tabular}{|l|c|c|c|c|c|c|c|c|c|}
\hline \multirow{2}{*}{ Escenario } & \multicolumn{3}{|c|}{$\mathbf{2 0 1 0 - 2 0 4 0}$} & \multicolumn{3}{c|}{$\mathbf{2 0 1 0 - 2 0 7 0}$} & \multicolumn{3}{c|}{$\mathbf{2 0 1 0 - 2 1 0 0}$} \\
\cline { 2 - 10 } & $\mathbf{0 , 5} \%$ & $\mathbf{2} \%$ & $\mathbf{4} \%$ & $\mathbf{0 , 5} \%$ & $\mathbf{2} \%$ & $\mathbf{4} \%$ & $\mathbf{0 , 5} \%$ & $\mathbf{2} \%$ & $\mathbf{4} \%$ \\
\hline A1B & 0,007 & 0,005 & 0,004 & 0,013 & 0,009 & 0,006 & 0,017 & 0,010 & 0,006 \\
\hline A2 & 0,007 & 0,006 & 0,004 & 0,015 & 0,010 & 0,006 & 0,017 & 0,010 & 0,006 \\
\hline B1 & 0,004 & 0,003 & 0,003 & 0,010 & 0,006 & 0,004 & 0,014 & 0,008 & 0,004 \\
\hline
\end{tabular}

Fuente: Elaboración propia.

Por lo anterior, es posible concluir que el cambio climático generaría modificaciones en la frecuencia y en la distribución de enfermedades transmitidas por vectores, en particular por la malaria. Las proyecciones indican que habría un alto incremento en el número de casos de malaria para los departamentos endémicos del Perú. Es importante tener en cuenta que un aumento que exceda la temperatura óptima para el desarrollo del vector podría ocasionar también una reducción en el número de casos observados.

\section{Agregación de impactos sectoriales del cambio climático en el PBI nacional}

En la presente sección se muestra la agregación en el ámbito nacional de los impactos económicos del cambio climático en ocho sectores productivos. Los impactos asociados se estimaron como la diferencia entre un escenario sin cambio climático y otro afectado por distintas condiciones climáticas bajo tres escenarios de emisión según el Cuarto Informe del IPCC (A1B, A2 y B1).

Los sectores considerados en la agregación de costos se caracterizan por ser los que probablemente se verían más afectados por las alteraciones en el clima, y son los siguientes: 1) agricultura, 2) ganadería, 3) pesca, 4) minería, 5) hidroenergía, 6) infraestructura, 7) turismo y 8) salud. Tal como se describe en los capítulos previos, la mayoría de los sectores fueron modelados a partir de formas funcionales propias y considerando las variables climáticas. El cambio en el clima afectaría las capacidades productivas y generaría costos o una mayor necesidad de inversión. A continuación se detallan las principales características de los impactos sectoriales incluidos en esta agregación:

- Agricultura: los impactos económicos se calcularon de acuerdo con cambios en los rendimientos agrícolas.

- Ganadería: se valoraron los impactos económicos en la ganadería altoandina relacionando los cambios en la disponibilidad de forraje, en el rendimiento y en el ingreso ganadero.

- Pesca: el cambio climático generaría variaciones en la captura de anchoveta por cambios en el oxígeno disuelto y en la temperatura del mar. A partir de la menor biomasa capturada se extrapolan pérdidas por producir menos harina de pescado ${ }^{58}$.

- Minería: los impactos del cambio climático se estiman según una menor disponibilidad de recursos hídricos, lo que aumentaría los costos de operación del sector.

58 Para el sector pesquero se utilizaron escenarios climáticos diferentes de los otros sectores, aunque equivalentes (RCP 4.5 y RCP 8.5). 
- Hidroenergía: se midió el cambio en la producción energética y en el ingreso hidroenergético a causa de una menor disponibilidad de agua en las cuencas.

- Infraestructura: se calculó el costo de reposición de vías asfaltadas como producto de una mayor probabilidad de ruptura asociada a inundaciones.

- Turismo: se estimaron los costos asociados con las menores visitas a Machu Picchu por problemas de accesibilidad, a causa de una mayor probabilidad de ruptura en la vía de acceso.

- Salud: se determinó el costo de acuerdo con el mayor gasto generado por incrementos de los casos de malaria.

Se han agregado todos los impactos estimados del cambio climático independientemente de las características propias de cada sector. Hay que notar que estos impactos no son los únicos que se podrían considerar. Por ejemplo, en ganadería solo se analizó el impacto para la zona altoandina y no se calcularon los costos ocasionados por posibles olas de calor. Tampoco se incluyeron otros daños distintos de las vías asfaltadas en infraestructura, y en turismo solo se consignó el efecto en Machu Picchu. En suma, se analizaron aspectos específicos dentro de los sectores seleccionados, que no agotan los impactos del cambio climático ni en ellos ni en la economía en general.

Cabe destacar que, si bien el análisis sectorial de impactos de este fenómeno incluía todos los modelos climáticos globales, la agregación presentada en esta sección se ha realizado para el promedio de modelos de circulación global en cada escenario climático ${ }^{59}$.

El sector de pesca fue analizado a partir de los escenarios de emisión RCP 8.5 y RCP 4.5, que son equivalentes a los escenarios del Cuarto Informe del IPCC utilizados mayoritariamente en este estudio. En particular, el escenario RCP 4.5 corresponde al escenario B1 y el RCP 8.5 al A1F1, que se ha asimilado al A2 con objeto de la agregación de resultados. Para calcular el escenario equivalente al A1B se promediaron los impactos obtenidos con RCP 4.5 y RCP 8.5, ya que en términos de emisiones el escenario A1B se encontraría en un punto intermedio.

A continuación se presentan los impactos económicos sectoriales promedio del cambio climático agrupados por escenario de emisión. Se han valorado en soles del año 2010 y los análisis comparativos se realizaron con respecto al PBI del año 2010 para tres períodos (2010-2040, 2010-2070 y 2010-2100). El impacto total considera los costos acumulados del período de evaluación 2010 a 2100.

La incertidumbre del fenómeno climático implica que estos resultados tengan una validez condicionada. Para relativizar en cierta forma la incertidumbre de los cálculos, se considera que los impactos tienen mayor valor en el presente que en el futuro. Para ello se usan tasas de descuento del 0,5\%, $2 \%$ y $4 \%$ anual.

\section{Análisis de resultados agregados}

El cuadro V.28 muestra que para el período 2010 a 2040 el impacto acumulado del cambio climático equivaldría a una pérdida que variaría entre 2,8\% y 3,9\% del PBI del año 2010, para una tasa de descuento de $0,5 \%$. La mayoría de los sectores se verían afectados negativamente, a excepción del sector de hidroenergía en el que se podrían presentar resultados positivos frente a la presencia del cambio climático en el corto plazo, que se revierten posteriormente. En particular, los sectores más perjudicados serían los de pesca, ganadería y agricultura, donde se concentra casi el 90\% de las pérdidas totales del escenario A2. Dichos resultados son esperables, dado que estos sectores se encuentran más directamente expuestos a las condiciones naturales del entorno que sus pares. A modo de ejemplo,

59 Se trató de evaluar los resultados máximos y mínimos; sin embargo, dado que cada sector presenta un desarrollo particular, no es posible identificar un determinado modelo climático global como máximo o mínimo. 
se puede decir que para el sector de ganadería (altoandina), en el período 2010-2040 descontando al 0,5\% bajo el escenario A2, la pérdida promedio sería de 2.297 millones de soles.

En el largo plazo, estos resultados son aún más negativos, debido a la tendencia incremental de los costos del cambio climático en el tiempo. De esta forma, para el período 2010-2100 todos los sectores presentarían pérdidas acumuladas, como se aprecia en el cuadro V.29, siendo el escenario A2 el que muestra los mayores impactos. El efecto acumulado del cambio climático para una tasa de descuento del 0,5\% variaría entre 50.700 millones de soles y casi 69.000 millones de soles, lo que equivaldría a una pérdida de 11\% y 15\% del PBI del año 2010, para los escenarios B1 y A2, respectivamente.

\section{CUADRO V.28}

Impacto acumulado del cambio climático, 2010-2040

(En millones de soles de 2010)

\begin{tabular}{|c|c|c|c|c|c|c|c|c|c|}
\hline \multirow[t]{2}{*}{ Sector } & \multicolumn{3}{|c|}{ Tasa de descuento de $0,5 \%$} & \multicolumn{3}{|c|}{ Tasa de descuento de $2 \%$} & \multicolumn{3}{|c|}{ Tasa de descuento de $4 \%$} \\
\hline & A1B & A2 & B1 & A1B & A2 & B1 & A1B & A2 & B1 \\
\hline Agricultura & 616 & 583 & 563 & 453 & 443 & 418 & 309 & 316 & 288 \\
\hline Ganadería & 1.812 & 2.297 & 1.624 & 1.413 & 1.820 & 1.283 & 1.046 & 1.376 & 968 \\
\hline Pesca & 9.162 & 7.373 & 10.951 & 7.066 & 5.309 & 8.822 & 5.116 & 3.441 & 6.791 \\
\hline Minería & 0 & 1.166 & 647 & 0 & 860 & 506 & 0 & 592 & 377 \\
\hline Hidroenergía & -43 & 24 & 10 & -40 & 19 & 2 & -35 & 14 & -4 \\
\hline Infraestructura & 411 & 145 & 411 & 324 & 113 & 326 & 245 & 82 & 246 \\
\hline Turismo & 1.747 & 690 & 2.970 & 1.438 & 568 & 2.445 & 1.140 & 450 & 1938 \\
\hline Salud & 30,2 & 32,9 & 19,6 & 24,2 & 26,0 & 15,5 & 18,5 & 19,6 & 11,8 \\
\hline Total nacional & 13.733 & 12.312 & 17.195 & 10.678 & 9.158 & 13.817 & 7.838 & 6.292 & 10.615 \\
\hline $\begin{array}{l}\text { Como porcentaje del } \\
\text { PBI de } 2010\end{array}$ & $3,1 \%$ & $2,8 \%$ & $3,9 \%$ & $2,4 \%$ & $2,1 \%$ & $3,1 \%$ & $1,8 \%$ & $1,4 \%$ & $2,4 \%$ \\
\hline
\end{tabular}

Fuente: Elaboración propia.

Como se aprecia en los gráficos V.31 a, b y c, la distribución de los impactos sectoriales acumulados en el PBI nacional es relativamente estable, con independencia del escenario climático. Por ejemplo, el sector de pesca representaría un 67\% de las pérdidas del escenario A2 y un 64\% tanto en A1B como en B1, considerando una tasa de descuento cercana a cero. Por otro lado, agricultura y ganadería sumarían el $25 \%$ de las pérdidas del escenario A1B, mientras que en el B1 representarían el 21\%. Si bien el tamaño de los impactos relativos no varía significativamente según el escenario contemplado, es importante tomar en cuenta la gama de resultados que entregan todos los escenarios al momento de evaluar medidas preventivas de adaptación. 
CUADRO V.29

Impacto acumulado del cambio climático, 2010-2100

(En millones de soles de 2010)

\begin{tabular}{|c|c|c|c|c|c|c|c|c|c|}
\hline \multirow[t]{2}{*}{ Sector } & \multicolumn{3}{|c|}{ Tasa de descuento de $0,5 \%$} & \multicolumn{3}{|c|}{ Tasa de descuento de $2 \%$} & \multicolumn{3}{|c|}{ Tasa de descuento de $4 \%$} \\
\hline & A1B & A2 & B1 & A1B & A2 & B1 & A1B & A2 & B1 \\
\hline Agricultura & 6.619 & 5.991 & 4.789 & 2.797 & 2.515 & 2.097 & 1.058 & 962 & 838 \\
\hline Ganadería & 8.644 & 9.181 & 5.854 & 4.218 & 4.548 & 3.050 & 2.004 & 2.240 & 1.586 \\
\hline Pesca & 39.322 & 46.293 & 32.350 & 19.229 & 20.618 & 17.841 & 9.207 & 8.406 & 10.009 \\
\hline Minería & 1.137 & 3.591 & 2.599 & 375 & 2.152 & 1.397 & 90 & 1.172 & 732 \\
\hline Hidroenergía & 297 & 443 & 363 & 88 & 198 & 145 & 3 & 77 & 45 \\
\hline Infraestructura & 701 & 401 & 707 & 473 & 236 & 460 & 311 & 132 & 299 \\
\hline Turismo & 5.029 & 2.541 & 3.939 & 2.792 & 1.448 & 2.894 & 1.608 & 808 & 2.116 \\
\hline Salud & 75 & 74 & 63 & 45 & 46 & 34 & 26 & 28 & 18 \\
\hline Total nacional & 61.824 & 68.515 & 50.666 & 30.017 & 31.761 & 27.919 & 14.307 & 13.825 & 15.644 \\
\hline $\begin{array}{l}\text { Como porcentaje del } \\
\text { PBI de } 2010\end{array}$ & $13,9 \%$ & $15,4 \%$ & $11,4 \%$ & $6,7 \%$ & $7,1 \%$ & $6,3 \%$ & $3,2 \%$ & $3,1 \%$ & $3,5 \%$ \\
\hline
\end{tabular}

Fuente: Elaboración propia.

GRÁFICO V.31

Participación sectorial en los impactos acumulados al año 2100, descontados al 0,5\%

(En porcentaje)

$\mathrm{A} 1 \mathrm{~B}$

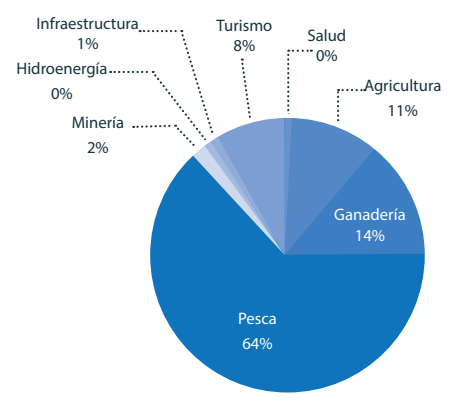

A2

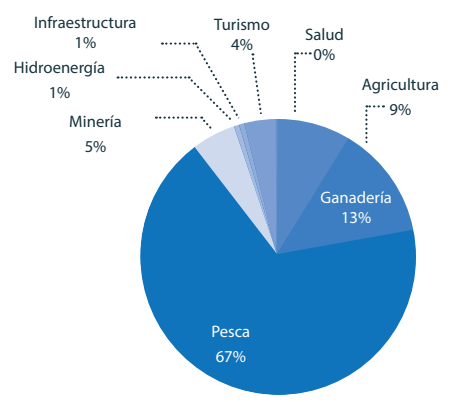

B1

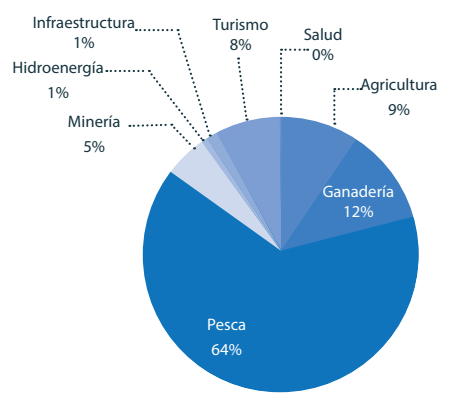

Fuente: Elaboración propia.

Los cuadros V.30 y V.31 muestran la evolución en el tiempo de los impactos acumulados según el escenario climático considerado. Dependiendo del horizonte de análisis, los escenarios pueden presentar distintas magnitudes en sus impactos relativos.

En el caso del escenario A2, se espera que los impactos sean mayores, ya que se asume un mundo bastante heterogéneo, donde el crecimiento económico por habitante y el cambio tecnológico serían fraccionados, presentando mayores emisiones. Este escenario entregaría las mayores pérdidas económicas en el Perú a medida que se incrementa el horizonte de análisis. Durante el período acumulado 2010 a 2070 los resultados muestran un impacto en relación con el PBI nacional de 2010 de 8,1\%, y para el período 2010 a 2100 de $15,4 \%$ del PBI, en ambos casos con tasas de descuento cercanas a cero. 
En el escenario A1B se esperaría un valor intermedio de impactos, ya que asume un rápido crecimiento económico, con una población mundial que alcanza su valor máximo hacia mediados del siglo y que disminuye posteriormente, al introducirse tecnologías nuevas y más eficientes. Es así que para fines de siglo los impactos acumulados alcanzarían el 13,9\% del PBI nacional del año 2010.

Finalmente, el escenario B1 presenta los menores impactos económicos en el Perú, con efectos acumulados del 11,4\% del PBI nacional del año base. Esto es consistente con los supuestos asociados a un mundo convergente, con una población mundial que alcanza su valor máximo hacia mediados del siglo, un uso menos intensivo de materiales, la introducción de tecnologías limpias, un aprovechamiento eficaz de los recursos y menores emisiones.

CUADRO V.30

Impacto acumulado del cambio climático para distintos períodos

(En millones de soles de 2010)

\begin{tabular}{|l|c|c|c|c|c|c|c|c|c|}
\hline \multirow{2}{*}{ Escenario } & \multicolumn{3}{|c|}{$\mathbf{2 0 1 0 - 2 0 4 0}$} & \multicolumn{3}{c|}{$\mathbf{2 0 1 0 - 2 0 7 0}$} & \multicolumn{3}{c|}{$\mathbf{2 0 1 0 - 2 1 0 0}$} \\
\cline { 2 - 10 } & $\mathbf{0 , 5} \%$ & $\mathbf{2} \%$ & $\mathbf{4} \%$ & $\mathbf{0 , 5} \%$ & $\mathbf{2 \%}$ & $\mathbf{4} \%$ & $\mathbf{0 , 5} \%$ & $\mathbf{2 \%}$ & $\mathbf{4} \%$ \\
\hline A1B & 13.733 & 10.678 & 7.838 & 33.397 & 20.705 & 12.096 & 61.824 & 30.017 & 14.307 \\
\hline A2 & 12.312 & 9.158 & 6.292 & 36.176 & 21.301 & 11.439 & 68.515 & 31.761 & 13.825 \\
\hline B1 & 17.195 & 13.817 & 10.615 & 33.739 & 22.420 & 14.354 & 50.666 & 27.919 & 15.644 \\
\hline
\end{tabular}

Fuente: Elaboración propia.

CUADRO V.31

Impacto acumulado del cambio climático sobre el PBI nacional para distintos períodos

(En porcentajes del PBI de 2010)

\begin{tabular}{|l|c|c|c|c|c|c|c|c|c|}
\hline \multirow{2}{*}{ Escenario } & \multicolumn{3}{|c|}{$\mathbf{2 0 1 0 - 2 0 4 0}$} & \multicolumn{3}{c|}{$\mathbf{2 0 1 0 - 2 0 7 0}$} & \multicolumn{3}{c|}{$\mathbf{2 0 1 0 - 2 1 0 0}$} \\
\cline { 2 - 11 } & $\mathbf{0 , 5} \%$ & $\mathbf{2} \%$ & $\mathbf{4} \%$ & $\mathbf{0 , 5} \%$ & $\mathbf{2} \%$ & $\mathbf{4} \%$ & $\mathbf{0 , 5} \%$ & $\mathbf{2} \%$ & $\mathbf{4} \%$ \\
\hline A1B & 3,1 & 2,4 & 1,8 & 7,5 & 4,7 & 2,7 & 13,9 & 6,7 & 3,2 \\
\hline A2 & 2,8 & 2,1 & 1,4 & 8,1 & 4,8 & 2,6 & 15,4 & 7,1 & 3,1 \\
\hline B1 & 3,9 & 3,1 & 2,4 & 7,6 & 5,0 & 3,2 & 11,4 & 6,3 & 3,5 \\
\hline
\end{tabular}

Fuente: Elaboración propia.

\section{Consideraciones para la interpretación de resultados}

Es importante reiterar que los impactos antes descritos no deben considerarse como pronósticos exactos, dado que existen altos márgenes de incertidumbre en la realización de los cálculos. Sin embargo, estos resultados son indicativos de las tendencias, lo que permite entender y anticiparse a las nuevas dinámicas climáticas.

La dimensión de los impactos presentados depende de múltiples variables y podría ser mayor, ya que el cambio climático, podría afectar a todos los sectores socioeconómicos de manera directa, indirecta o inducida. En este estudio, el análisis se llevó a cabo para un subconjunto de sectores, ya sea por la falta de herramientas para evaluar los impactos de manera física o bien, por la carencia de información detallada para realizar una evaluación económica. Es importante destacar que los cálculos realizados representan 
una visión conservadora de la evaluación completa de los impactos económicos probables para el país. Dentro de las principales razones están las siguientes:

- Los promedios de modelos climáticos limitan los escenarios extremos; por lo tanto, una evaluación basada en promedios puede subvalorar los impactos reales.

- Se ha considerado que los impactos afectan en forma directa únicamente a sectores que equivalen a un tercio del PBI nacional; se asume que el resto no sería afectado.

- En este caso no se han considerado los efectos indirectos ni inducidos asociados con los impactos sectoriales del cambio climático.

Los resultados presentados muestran el valor de analizar en forma interdisciplinaria las implicaciones de este fenómeno, integrando modelos climáticos, hídricos, físicos, biológicos y económicos. Cabe resaltar que estos resultados son válidos en la medida que se entiendan los supuestos sobre los que se sostienen los modelos detallados a lo largo del estudio. Debido a que los costos sectoriales se calculan a partir de metodologías específicas a cada sector, su agregación es un ejercicio que debe considerarse con cautela. No obstante, este análisis muestra un panorama general que permite prever el posible impacto del cambio climático sobre la economía nacional y anticipar medidas adaptativas.

La complejidad de proyectar resultados a tan largo plazo lleva implícita la elección de una tasa de descuento para comparar los costos futuros con los valores actuales. La elección de una tasa de descuento dependerá de una apreciación de equidad intergeneracional, ya que el efecto del cambio climático se distribuye entre diferentes generaciones y es incremental en el tiempo. Utilizar una determinada tasa de descuento supone una decisión moral sobre los problemas que el cambio climático impone a las generaciones futuras y un punto de vista para la formulación de políticas públicas actuales. Al emplearse tasas de descuento bajas, la responsabilidad de los problemas causados por el cambio climático es asumida por las actuales generaciones. Cuando se imponen tasas altas, se asume que el futuro tendría menos relevancia en el presente. En este estudio se han empleado tres tasas de descuento, tomando en consideración los puntos anteriores $(0,5 \%, 2 \%$ y $4 \%)$.

Las tasas de descuento del estudio podrían parecer relativamente bajas si se considera la tasa del 9\% asignada por el Sistema Nacional de Inversión Pública (SNIP) a las inversiones públicas para períodos de 20 años. Sin embargo, a largo plazo es razonable sostener que las tasas sean menores, dado que el riesgo país y la convergencia de la economía deberían tener como resultados tasas reducidas. 



\section{Capítulo Vl}

\section{Recomendaciones para las medidas de adaptación}

El objetivo central de este capítulo es plantear la discusión sobre los esfuerzos realizados y examinar las necesidades en materia de adaptación al cambio climático en el Perú. Asimismo, se presentan algunas alternativas que se desarrollaron en base al análisis efectuado en el capítulo $V$ y que son consideradas como un complemento a los esfuerzos que se están realizando actualmente en el país para aminorar los impactos de este fenómeno.

La adaptación al cambio climático consiste en el proceso de ajuste a las condiciones climáticas actuales o esperadas y a sus efectos. En el caso de los efectos esperados sobre el medio humano, la adaptación busca moderar el daño o aprovechar las oportunidades beneficiosas, mientras que, en el caso de los sistemas naturales, la intervención humana puede facilitar el ajuste al clima futuro esperado (IPCC, 2014). La aplicación de las capacidades adaptativas es un proceso que demanda recursos; pero, si estas no se implementaran, los costos de los impactos podrían incluso superar los de dichas medidas de adaptación. Como explica el Informe Stern (2007), esperar el agravamiento de situaciones climáticas y de sus efectos significaría implementar medidas probablemente más costosas, incluyendo la afectación de las poblaciones más vulnerables.

La construcción de estrategias de adaptación es y será un aspecto crucial para el desarrollo de los países (CEPAL, 2010). Es importante destacar que el cambio climático puede afectar en mayor medida a las poblaciones más pobres, dado que se encuentran ubicadas en zonas de alta vulnerabilidad y viven bajo condiciones de mayor fragilidad en términos ambientales, socioeconómicos e institucionales (African Development Bank et al., 2003). La relación entre pobreza y cambio climático genera un desafío adicional para el cumplimiento de los Objetivos de Desarrollo del Milenio (ODM), debido a que este fenómeno podría afectar las metas de algunos objetivos, tales como la erradicación de la pobreza extrema y el combate de enfermedades como la malaria. Es por ello que, en el momento de establecer medidas de adaptación, se deben considerar los potenciales efectos que estas pueden tener en las metas de desarrollo del país (Adger et al., 2003; Ansohn y Pleskovic, 2011).

Un desafío adicional al analizar, identificar y diseñar las medidas de adaptación es reconocer la incertidumbre asociada a los modelos y escenarios climáticos futuros (véase el capítulo I) (CEPAL- Chile, 2009). Además, 
como se ha descrito anteriormente, hay una gran variedad de modelos disponibles, lo que amplía el rango de escenarios de variables climáticas a los cuales se verían expuestos los distintos sectores productivos y grupos de población (Watkiss, 2012).

Algunas formas de hacer frente a la incertidumbre son evitar ejercer el control total de la amenaza, crear mayor capacidad de respuesta ante el cambio y las condiciones poco predecibles y asumir escenarios y proyecciones. Así, las estrategias de adaptación serán más robustas en la medida en que incorporen una mayor diversidad de alternativas, como una forma de absorber la falta de certeza existente en las distintas variables futuras.

Otro mecanismo utilizado por los países para disminuir los potenciales costos asociados a la incertidumbre es el desarrollo de intervenciones "sin arrepentimiento" (no regret). Estos esfuerzos se definen como el conjunto de estrategias que conllevan beneficios, independientemente de las tendencias futuras en escenarios climáticos (Heltberg et al., 2009). Generalmente, estos esfuerzos están enfocados a abordar problemas actuales que no son causados por el cambio climático, pero que se verían incrementados por este fenómeno (por ejemplo, acceso a agua potable en comunidades vulnerables o mejoras en infraestructura).

Las propuestas de medidas de adaptación que se presentan a continuación se diseñaron a partir de la incertidumbre climática antes descrita, tomando en consideración la implicancia que su implementación puede tener en el desarrollo del Perú.

\section{A. Esfuerzos de adaptación al cambio climático en el Perú}

El cambio climático presenta una serie de retos para el Perú, vinculados principalmente a la reducción de vulnerabilidad; pero, al mismo tiempo, ofrece oportunidades importantes, relacionadas sobre todo con el desarrollo bajo en carbono. Para ello, entonces, se hace necesaria una gestión del cambio climático integrada en la planificación del desarrollo y en las decisiones de inversión del país ${ }^{60}$.

En los últimos años, a través del Plan Bicentenario y del Informe de la Comisión Multisectorial, se ha dado mayor importancia a la temática del cambio climático. Adicionalmente, el Marco Macroeconómico Multianual, desde 2011, reconoce la importancia de la variable climática en la economía, dando un mayor sustento a la temática no solo en los planes de desarrollo, sino también desde el punto de vista económico ${ }^{61}$.

Algunos sectores están involucrándose en la adaptación al cambio climático. Por ejemplo, el Ministerio de Economía y Finanzas, en el marco del Sistema Nacional de Inversión Pública, ha elaborado instrumentos metodológicos utilizados en el diseño de proyectos de inversión pública (PIP), tales como las Pautas para la Incorporación del Análisis de Riesgo en PIP, los Conceptos Asociados a la Gestión de Riesgos en un Contexto de Cambio Climático, y un conjunto de guías metodológicas para que se tomen en consideración variables climáticas en el diseño de PIP en los sectores de turismo, agricultura y energía. La implementación del fondo Mi Riego, que cuenta con una inversión inicial de 1.000 millones de soles, espera irrigar 40.000 hectáreas, beneficiando a 250.000 familias y priorizando a los pequeños agricultores. Estas y otras medidas permiten la adaptación al cambio climático.

60 MINAM, 2012. 
Mediante asociaciones público-privadas (APP), se ha invertido en la construcción de la segunda línea del tren eléctrico, así como en la creación de distintas plantas de tratamiento de aguas residuales, como Taboada y La Chira. El Ministerio de Agricultura y Riego (MINAGRI) cuenta con el Plan Nacional de Gestión del Riesgo y Adaptación a los Efectos Adversos del Cambio Climático en el Sector Agrario (PLANGRACC-A), en proceso de implementación; el Ministerio de la Producción (PRODUCE) viene formulando la Estrategia de Adaptación al Cambio Climático en Pesca y Acuicultura; mientras que el Ministerio de Salud (MINSA) se encuentra diseñando la Estrategia de Cambio Climático y Salud; todos ellos alineados a la Estrategia Nacional de Cambio Climático, lo cual conlleva a un avance progresivo y gradual de la transectorialización de la condición climática62.

Adicionalmente al incremento progresivo de la transectorialidad del cambio climático, y según el estudio del Ministerio del Ambiente (MINAM, 2013), existen diferentes mecanismos de financiamiento e incentivos para movilizar inversiones que contribuyan a la adaptación a este fenómeno. Entre los más utilizados en el Perú se hallan 1) el presupuesto público, 2) los proyectos de inversión pública (que, en el marco del SNIP, consideran la gestión del riesgo en un contexto de cambio climático), 3) las instituciones multilaterales proveedoras de fondos de desarrollo y 4) la cooperación bilateral ${ }^{63}$.

Dicho estudio resalta, también, los diversos proyectos relacionados con la adaptación al cambio climático, realizados tanto con fondos públicos como con fondos provenientes de agencias multilaterales y de cooperación bilateral. El MINAM (2013) indica que, de acuerdo con un estudio efectuado en 2011, las agencias multilaterales y de cooperación bilateral aportaban el 51\% de los aproximadamente 808,7 millones de dólares asignados a un total de 88 programas, proyectos y actividades de gestión del cambio climático en el Perú. Sin embargo, solo el $17 \%$ de los recursos aportados por estas instituciones eran donaciones; el resto de ellos eran préstamos ${ }^{64}$.

En los últimos diez años se han implementado diversos proyectos relacionados con la adaptación al cambio climático en los distintos sectores con apoyo de la cooperación internacional (se destacan PACC, IPACC, Glaciares 513, IMACC, TACC, EbA Montaña, PRAA, PROCLIM, AMICAF y Humboldt). Este apoyo ha promovido y facilitado procesos en ámbitos nacionales, regionales y locales en componentes vinculados al fortalecimiento institucional, generación de herramientas e información técnico-científica, capacidades, sensibilización, mecanismos financieros e implementación de medidas piloto en sectores vulnerables al cambio climático ${ }^{65}$.

\section{Esfuerzos a nivel regional}

En el marco de la Ley Orgánica de Gobiernos Regionales-Ley № 27.867, los gobiernos regionales tienen como una de sus competencias la formulación e implementación de estrategias regionales de cambio climático (ERCC). A la fecha, trece de estos gobiernos cuentan con una ERCC aprobada: Amazonas, Apurímac, Arequipa, Ayacucho, Cusco, Loreto, Lambayeque, Junín, Piura, La Libertad, Puno, Cajamarca y Ucayalii.

Todas las ERCC señalan propuestas de desarrollo de capacidades y necesidades de investigación, de tecnología y de organización e institucionalidad. Los aspectos mencionados son requeridos para una adecuada implementación y para el consecuente logro de los objetivos de las ERCC. Las regiones con mayores avances en los aspectos señalados son Piura y Cusco. Es importante destacar que Piura es la primera en contar con un sistema de monitoreo y evaluación. Cusco, por su parte, es actualmente la única región que aborda la temática del cambio climático de manera integrada en su Plan de Desarrollo Regional Concertado ${ }^{67}$.

62 DGCCDRH-MINAM, 2014.

63 MINAM, 2012.

64 Ídem.

65 DGCCDRH-MINAM, 2014.

66 Ídem.

67 Documento en construcción: Balance regional sobre los avances en la gestión del cambio climático. InterCLIMA. DGCCDRH-MINAM, 2013. 


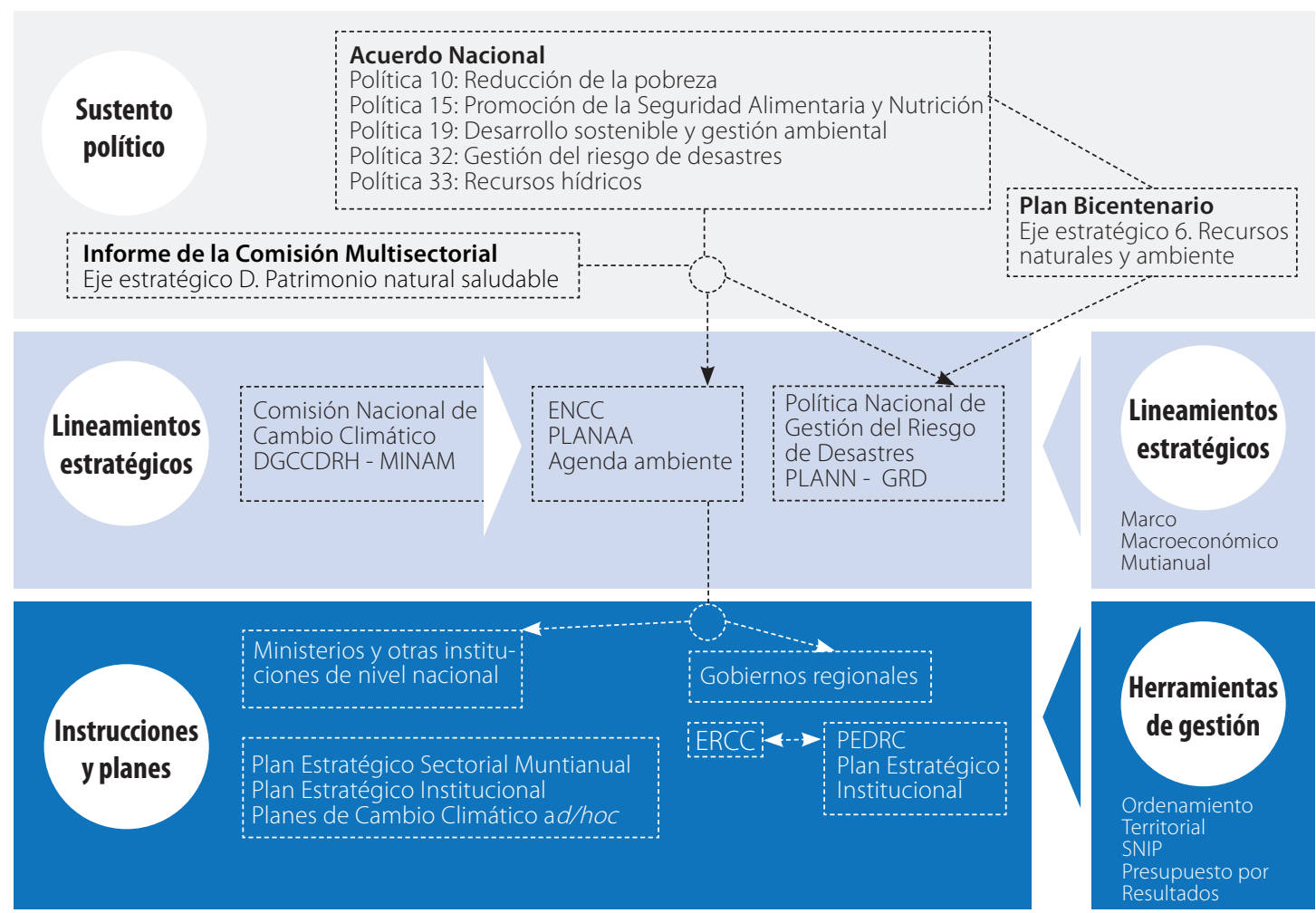

Fuente: MINAM, 2012.

\section{Esfuerzos en el sector privado}

Es importante resaltar que las empresas que se encuentran en sectores sensibles al cambio climático tienen un interés directo en la adaptación, ya que los riesgos climáticos podrían socavar la infraestructura, las fuentes de energía y las redes de transporte necesarias para que las compañías puedan operar normalmente, lo que afectaría sus perfiles futuros de riesgo crediticio y las tasas de retorno de sus negocios. Los riesgos climáticos pueden traducirse en menos ingresos disponibles y en cuotas de mercado reducidas, mientras que los riesgos asociados a la salud pueden perjudicar la productividad de la fuerza de trabajo. La reducción o la gestión de estos riesgos se convertiría en una ventaja competitiva, en ahorro de costos (aunque tal vez no en el corto plazo), en pasivos reducidos y en la confianza del inversor. Es así que las empresas pueden aportar al conocimiento y a la internalización de la adaptación al cambio climático en sus propios procesos de toma de decisión, a través de una serie de acciones que realizarían como proveedores de oportunidades económicas y de crecimiento (creación de empleo, aumento de la productividad de las inversiones del sector privado), y de recursos financieros y técnicos que ayuden a reducir los riesgos locales (como innovaciones de tecnologías), con el potencial con el que cuentan las asociaciones público-privadas para fortalecer el impacto de los marcos normativos de adaptación en aquellas localidades que tienen menor riesgo de ser afectadas por el cambio climático (OECD, 2009).

En ese contexto, algunos grupos privados dedicados a agricultura, minería y ganadería han desarrollado algunas iniciativas aisladas de adaptación, aunque la preocupación por el tema de la adaptación al cambio climático todavía no constituye un punto importante en las agendas de todos los sectores económicos nacionales, salvo estas excepciones. 
Las iniciativas implementadas en dichos sectores han sido elaboradas principalmente a través de sus asociaciones gremiales. Tales son los casos de la Sociedad Nacional de Minería, Petróleo y Energía (SNMPE), la Central Piurana de Cafetaleros (CEPICAFÉ), la Convención Nacional del Agro Peruano (CONVEAGRO) y la Asociación de Ganaderos Lecheros del Perú (AGALEP); y, en el sector empresarial en general, a través de la Confederación Nacional de Instituciones Empresariales Privadas (CONFIEP).

\section{B. Propuestas de medidas para sectores seleccionados}

En este estudio se analizaron los impactos del cambio climático en ocho sectores (agricultura, ganadería altoandina, pesca, minería, hidroenergía, turismo, salud e infraestructura). A partir de la valoración de los principales impactos realizada en el capítulo $V$, fue posible identificar algunas medidas de adaptación relacionadas con las necesidades de investigación, el desarrollo de capacidades, las tecnologías adecuadas y los requerimientos organizacionales e institucionales.

Las medidas presentadas en los cuadros del VI.1 al VI.9 buscan contribuir y ser complementarias a las que han sido identificadas y priorizadas en las distintas políticas, programas y agendas del Gobierno del Perú para enfrentar los efectos del cambio climático. En estos cuadros se presenta un resumen de los principales impactos físicos y de las medidas de adaptación que se proponen para cada sector.

\section{CUADROVI.1}

\section{Medidas de adaptación para recursos naturales}

Principales impactos

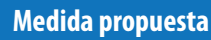

Cambios en la distribución del uso de suelo, ecosistemas y recursos hídricos.

- Generar y ampliar la información georreferenciada de ecosistemas y de cobertura vegetal para todas sus regiones (costa, sierra y selva).

- Ampliar estadísticas e información nacional que permitan modelar y analizar el comportamiento de los glaciares.

- Elaborar modelos específicos para distintos biomas, que permitan incorporar las capacidades de dispersión de especies, los efectos de facilitación y la dinámica de competencia, así como aspectos relacionados con la resiliencia de los ecosistemas.

- Implementar un sistema de monitoreo, predicción y alerta temprana de vulnerabilidades influenciadas por el cambio climático.

- Establecer técnicas agroecológicas para reducir las variaciones climáticas en la producción agrícola.
Desarrollo de capacidades
- Promover el análisis del territorio y el manejo de recursos utilizando herramientas de planificación integral (por ejemplo, herramientas para identificar, medir y regular el acceso al agua y los derechos de propiedad de la misma).

Tecnología

- Profundizar y apoyar el uso de tecnologías para la generación de información territorial (por ejemplo, bases de datos sistematizadas de proyectos ejecutados y por ejecutarse que modifiquen el territorio, así como mapas de la cobertura nacional a lo largo del tiempo). 


\section{Medidas de adaptación para el sector de agricultura}

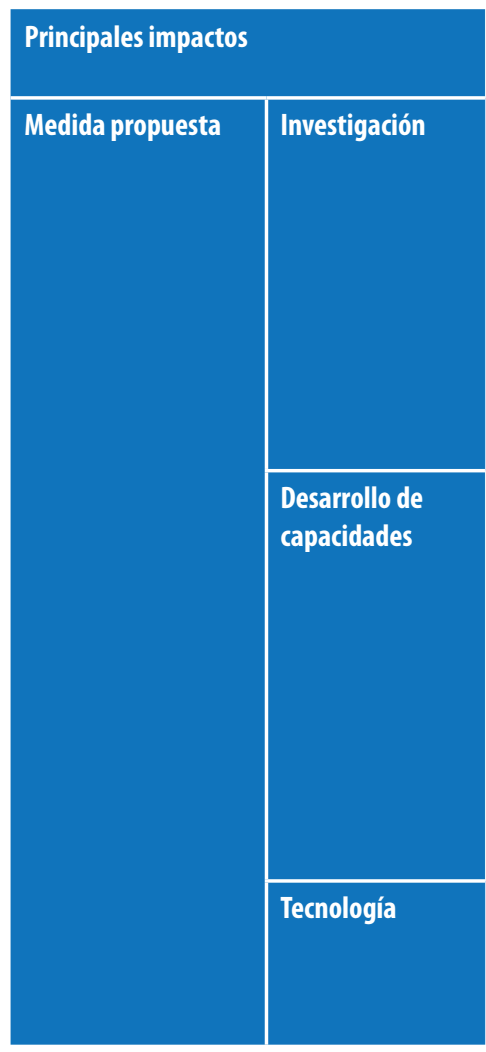

Fuente: Elaboración propia.
Cambios en la productividad de los cultivos debido a la variación en la disponibilidad del recurso hídrico y a la incidencia de plagas y enfermedades.

- Ampliar el estudio del rango de cultivos y de los efectos que el cambio climático pueda tener en su productividad.

- Analizar los cambios del uso de la tierra siguiendo la evolución en el tiempo de las zonas agrícolas.

- Generar información climática a menor escala para el análisis de impactos específicos en cada zona.

- Identificar las variedades de cultivos resistentes a estrés hídrico para la producción bajo un escenario con cambio climático.

- Capacitar a las empresas agroexportadoras y a medianos agricultores en gestión integrada de cuencas y en tecnologías de uso óptimo del agua.

- Capacitar a los productores en el uso de la diversidad de cultivos y de los sistemas productivos adaptados a su entorno natural.

- Fortalecer mecanismos de educación horizontal entre pobladores de las localidades, para que puedan aprender de experiencias de distintas comunidades.

- Establecer mecanismos de comunicación y transferencia de información entre pobladores del medio rural del país y centros de investigación internacionales y nacionales (La Torre et al., 2012).

- Promover la incorporación de tecnologías que permitan una optimización del uso del recurso hídrico y de suelos ; impulsar proyectos de irrigación que permitan un aprovechamiento eficiente tanto del recurso hídrico como del riego tecnificado, del mejoramiento de recursos genéticos y de otros sistemas.

CUADRO VI.3

Medidas de adaptación para el sector de ganadería altoandina

\section{Principales impactos}

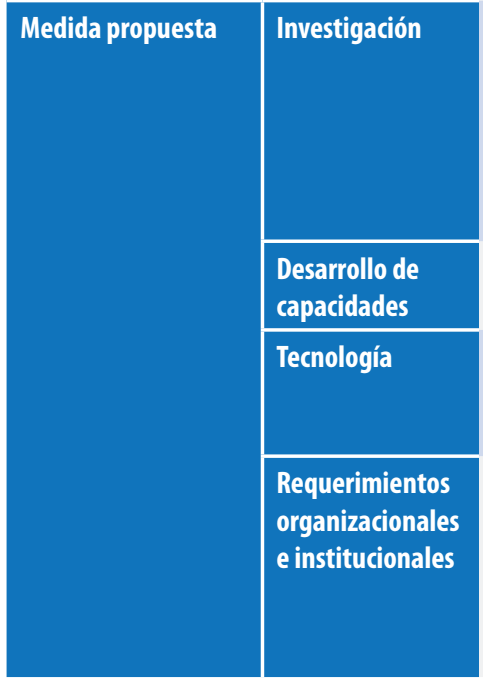

Fuente: Elaboración propia.
Cambios en la disponibilidad de forrajes debido a la variación en la composición de las especies vegetales, la productividad de los pastizales, y por la degradación de suelos.

- Ampliar la investigación en términos de composición de la vegetación.

- Desarrollar índices de vulnerabilidad de los ecosistemas para implementar estrategias más informadas de adaptación de los pastores de la puna al cambio climático.

- Establecer modelos de predicción de las respuestas de los ecosistemas ante los nuevos escenarios del cambio climático (Flores, 2011).

- Capacitar en el diseño y la aplicación de planes de manejo y de caracterización de sistemas de producción.

- Priorizar el uso de tecnologías que permitan la adaptación, especialmente en áreas como el manejo de pasturas, el control sanitario de plagas y enfermedades, los sistemas silvopastoriles integrados, las rotaciones y los forrajes hidropónicos (Tapia, 2013).

- Fortalecer la participación de los Gobiernos regionales en materias relacionadas con conservación.

- Generar una legislación especializada para uso, conservación y mejora de los pastizales (MINAGRI, 2012), y una regulación de cambios de uso del suelo (paso de pasturas a tierras agrícolas). 


\section{CUADRO VI.4}

\section{Medidas de adaptación para el sector pesquero}

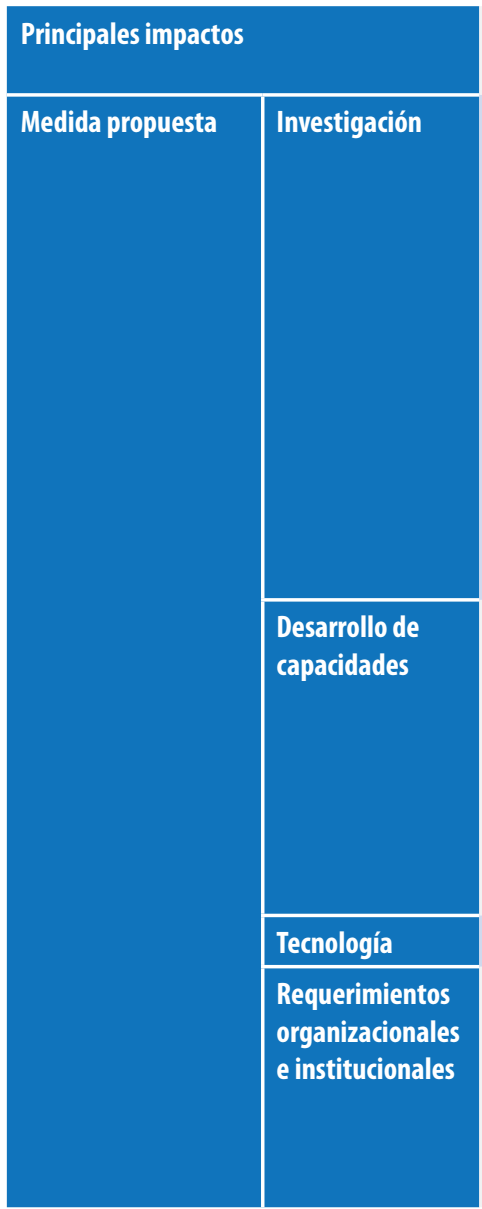

Fuente: Elaboración propia.
Variaciones en el nivel de la abundancia (stock) y en la distribución de las especies marinas, en particular de la anchoveta.

- Efectuar investigaciones de escenarios de cambio climático y de acidificación marina usando modelos atmosféricos, oceánicos, biogeoquímicos y bioclimáticos.

- Realizar investigaciones sobre la dinámica de los stocksy sobre las diferentes fases de la historia de vida de diversas especies, en particular de la anchoveta y de los recursos que dependen de ella.

- Ampliar la información para predecir los efectos del cambio climático en el contexto ecofisiológico de las especies explotadas en el ecosistema. Se sugiere que esta medida pueda ser materia de programas de investigación en institutos y universidades.

- Identificar y analizar la vulnerabilidad y el riesgo generado por los impactos al cambio climático en otras especies clave y en la trofodinámica de los ecosistemas de la costa peruana.

- Establecer centros de información y bases de datos que permitan normar las cuotas de captura.

- Implementar campañas de información que den a conocer la investigación científica relacionada con el cambio climático.

- Capacitar a los agentes involucrados en el sector en la adaptación basada en ecosistemas marinos y planes de contingencia.

- Desarrollar capacidades en el uso y el manejo de sistemas de monitoreo meteorológico, oceanográfico y de contaminación, incluyendo las materias relacionadas con calibración y sensores.

- Establecer sistemas de monitoreo meteorológico, oceanográfico y de contaminación.

- Promover el diálogo interinstitucional, para implementar la adaptación basada en ecosistemas y el enfoque ecosistémico aplicado a las pesquerías, incluyendo la participación de los diversos sectores productivos, de la academia y de los actores locales.

- Promover buenas prácticas de pesca para el consumo humano directo.

\section{CUADRO VI.5}

\section{Medidas de adaptación para el sector minero}

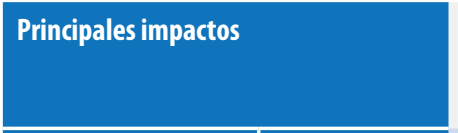

Medida propuesta

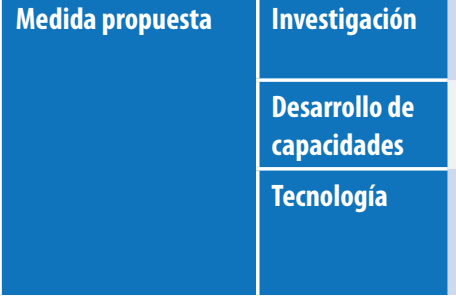

Fuente: Elaboración propia.
Cambios en la disponibilidad del recurso hídrico que pueden generar posibles eventos de escasez 0 inundaciones, deslizamientos o flujos de escombros, y que podrían elevar el riesgo o imposibilitar el desarrollo de la actividad minera.

- Realizar estudios en las cuencas mineras para establecer los volúmenes de agua necesarios para satisfacer el consumo de la población localizada aguas abajo.

- Capacitar en el uso y en el consumo eficiente del agua, para fines poblacionales y agrícolas, lo que contribuiría a reducir futuras disputas por el recurso hídrico.

- Promover la implementación de tecnologías (como reservorios de agua) para enfrentar las variaciones en la disponibilidad de agua y los posibles impactos en infraestructura derivados de eventos climáticos extremos. 
CUADRO VI.6

Medidas de adaptación para el sector de hidroenergía

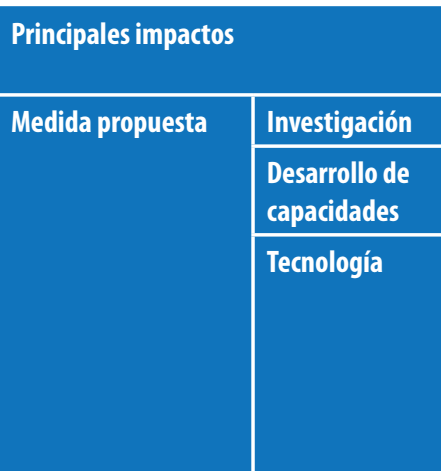

Fuente: Elaboración propia.
Variación de la distribución del recurso hídrico, que puede ocasionar inundaciones en las presas hidroeléctricas y/o disminución de la capacidad de generación.

- Aumentar los estudios de la variación en la disponibilidad hídrica en las zonas altoandinas.

- Incorporar el tema del cambio climático en el diseño y planificación de los proyectos hidroenergéticos y en el uso de otras energías renovables.

- Promover el uso de tecnologías para la optimización del manejo del agua (como las turbinas de baja velocidad, entre otras).

- Ampliar la matriz energética a partir de los posibles impactos sobre la disponibilidad del recurso hídrico ocasionados por el cambio climático.

\section{CUADRO VI.7}

\section{Medidas de adaptación para el sector de turismo}

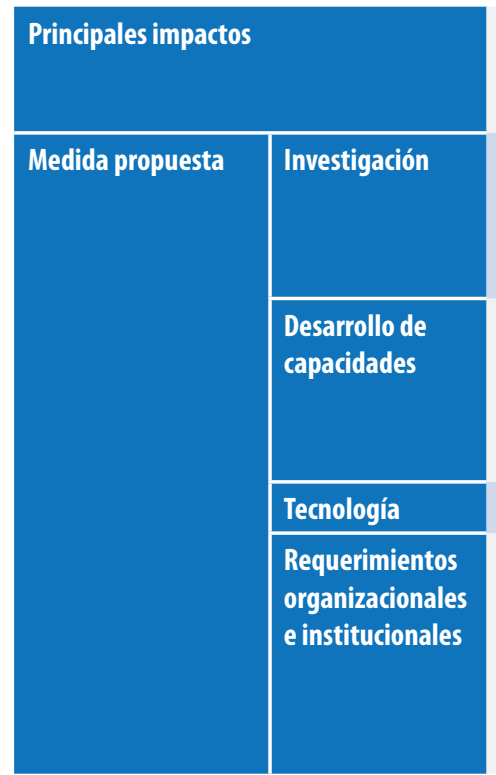

Fuente: Elaboración propia.
Variaciones en la competitividad de los destinos turísticos, ocasionadas por el deterioro del espacio geográfico y por alteraciones en la infraestructura de transportes y comunicaciones, producto de los posibles eventos climáticos extremos.

- Analizar circuitos alternativos de turismo.

- Identificar nuevas rutas de ingreso a los lugares turísticos existentes.

- Desarrollar mapas de zonas de vulnerabilidad y riesgo

- Capacitar a autoridades, operadores turísticos y población local en el desarrollo de turismo sostenible.

- Promover la gestión participativa del territorio para diseñar estrategias de adaptación vinculadas a la administración del turismo y del patrimonio histórico-cultural.

- Promover el uso de tecnologías que mejoren la accesibilidad.

- Incluir actividades relacionadas con el turismo sostenible dentro del marco del Plan Estratégico Nacional de Turismo (PENTUR).

- Establecer un espacio interinstitucional que permita un intercambio de conocimiento e información entre los investigadores científicos y los profesionales del turismo. 


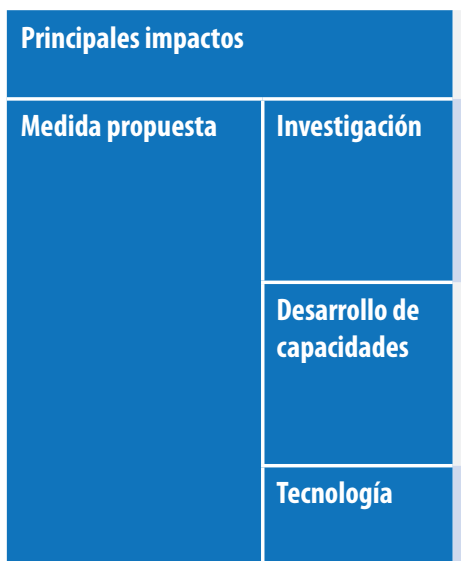

Fuente: Elaboración propia.
Afectación a la infraestructura vial, en particular en las carreteras asfaltadas, las calzadas y los puentes, producto de los posibles eventos climáticos extremos.

- Actualizar las bases de datos y los inventarios históricos de eventos y peligros naturales ocurridos en el Perú.

- Monitorear las tendencias del clima, para identificar el modelo que represente mejor los cambios en los patrones de precipitación y escorrentía de cuencas específicas.

- Incluir en las cátedras de hidrología el tema del cambio climático, el riesgo, la vulnerabilidad y los sistemas de monitoreo.

- Establecer programas de información avanzada sobre el cambio climático para los profesionales del Ministerio de Transportes y Comunicaciones (MTC).

- Promover tecnologías que permitan disminuir los efectos sobre la infraestructura vial (por ejemplo, los tipos de pavimentos o los drenantes utilizados).

\section{CUADRO VI.9}

\section{Medidas de adaptación para el sector de salud}

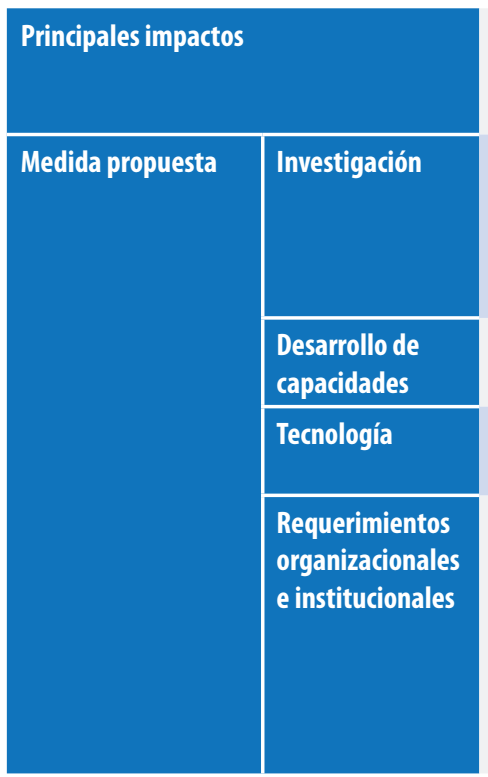

Fuente: Elaboración propia.
Presencia de malaria, especialmente en los departamentos endémicos. Migración de vectores de enfermedades. Variaciones en la biología y en la ecología de los vectores, y cambios de los hospederos intermediarios de enfermedades.

- Elaborar diagnósticos relacionados con la distribución espacial, la incidencia y la frecuencia de las enfermedades relacionadas con el cambio climático.

- Identificar y cuantificar el riesgo de otras amenazas a la salud pública como consecuencia del fenómeno climático.

- Desarrollar capacidades para la prevención, el diagnóstico y el tratamiento de enfermedades.

- Mejorar las tecnologías de los centros de salud regionales, especialmente en cuanto a equipos, insumos de control de vectores y fármacos.

- Desarrollar sistemas de información, de alerta temprana y de monitoreo de enfermedades.

- Establecer redes de prevención de salud que incluyan el acceso a fuentes de agua y alimentos seguros, aun en condiciones de variabilidad climática extrema. Esta organización debería incluir unidades de vigilancia epidemiológica, así como unidades para diagnóstico y tratamiento precoz que permitan minimizar el daño de las enfermedades que surjan. 



\section{Capítulo VII}

\section{Conclusiones y recomendaciones}

Estudiar la economía del cambio climático en el Perú tiene como objetivo principal identificar los potenciales impactos físicos y económicos que las variaciones climáticas pueden causar en distintos sectores del país. Tal como se señala en el Informe Stern (2007), los costos de no actuar a tiempo pueden superar los costos que se generen en materia de adaptación al fenómeno climático. Contar con información actualizada y oportuna es clave para diseñar e implementar políticas, planes, programas y acciones que ayuden a evitar $\mathrm{o}$ a reducir sus efectos.

La información producida y sistematizada en el presente estudio, incluyendo el enfoque metodológico utilizado, constituye un aporte al análisis de la economía del cambio climático, y a la elaboración y aplicación de políticas públicas. A través de una mejor descripción espacio-temporal del país y de la mayor comprensión de las dinámicas socioeconómicas y ambientales de los territorios, es posible reforzar el entendimiento de la capacidad productiva nacional y de los impactos que el cambio climático ocasionaría en su desarrollo.

Por contar con siete de las nueve características de vulnerabilidad reconocidas por la Convención Marco de las Naciones Unidas sobre el Cambio Climático, es decir, poseer zonas costeras bajas y zonas áridas y semiáridas, además de áreas susceptibles a deforestación o erosión, a desastres naturales, a sequía y a desertificación, y tener áreas urbanas altamente contaminadas y ecosistemas frágiles, el Perú es un país sumamente vulnerable al cambio climático. Lo anterior es respaldado por las proyecciones generadas por los modelos climáticos globales, que muestran que el aumento en la concentración de gases de efecto invernadero generaría variaciones en las precipitaciones y un aumento en las temperaturas promedio para todo el territorio nacional, en los tres escenarios modelados (B1, A1B y A2). Estas proyecciones presentan distintos grados de variabilidad cuando son analizadas de modo mensual y territorial. En algunas zonas del país se esperaría una disminución en las lluvias durante algunos meses, seguida por aumentos significativos. En contraste, en otras zonas se presentarían aumentos constantes de precipitaciones a lo largo de todo el año. En el caso de las temperaturas, si bien se observarían algunas diferencias, su proyección es más homogénea, estimándose aumentos en todo el territorio.

Las dinámicas de las variables climáticas permiten inferir variaciones en la dotación de recursos naturales, principalmente en lo que se refiere a la disponibilidad de agua, al uso del suelo y a la distribución de biomas. 
Al comparar escenarios futuros de cambio climático con la proyección del clima actual, se observaría una disminución en la disponibilidad de agua principalmente en las zonas bajas del país, ascensos en las bandas de vegetación de los Andes y mayor presencia de arbustales, entre otros aspectos. Lo anterior, sumado a las proyecciones de cambios de uso del suelo, que prevén una fuerte expansión de la agricultura, indicaría un cambio significativo en el paisaje del Perú y en sus recursos naturales.

La expansión agrícola a áreas como bofedales, bosques amazónicos u otras, puede afectar tanto los biomas como la disponibilidad de recursos hídricos, lo que a su vez impactaría sobre la productividad de los cultivos. Si bien en el presente estudio no se considera una valoración económica de los efectos directos sobre recursos naturales, sus resultados fueron incorporados en la valoración de impactos de algunos sectores productivos.

Las principales esferas económicas expuestas a los cambios de las dinámicas de las variables climáticas corresponden a agricultura, ganadería altoandina, pesca, minería, hidroenergía, turismo, infraestructura vial y salud. Las dos últimas no se valoran a través de alteraciones en la productividad, pero fueron incluidas en el análisis, ya que es esperable que el cambio climático las afecte directamente. Esto se traduciría en un mayor gasto público para enfrentar los efectos negativos traspasados a la población y a otros sectores productivos.

La valoración económica del impacto del cambio climático en dichos sectores se realizó a partir de un análisis de escenarios con y sin cambio climático. Para ello, se elaboraron modelos específicos para cada sector (véanse los capítulos III y IV) que vinculan las variables climáticas, las características físicas y el nivel de producción. La agregación se realizó sumando los impactos económicos esperados de cada sector seleccionado para el período 2010 a 2100, estimando su valor presente con distintas tasas de descuento (0,5\%, 2\% y 4\%).

En el caso del sector agrícola, los escenarios evaluados (A1B, A2 y B1) indican pérdidas equivalentes a entre 23,9\% y 33,1\% del PBI sectorial para el período 2010 a 2100, con respecto a la situación base a una tasa cercana a cero. Esto sería a causa de la disminución de la productividad de casi todos los cultivos seleccionados (papa, arroz, maíz amarillo duro, caña de azúcar, plátano y maíz amiláceo); mientras que el café mostraría leves aumentos de productividad al inicio del período, para luego disminuir. En los tres escenarios analizados, las caídas de la productividad de los cultivos se profundizan a lo largo del tiempo.

Con respecto a la ganadería altoandina, los resultados muestran que los impactos serían producto de la disminución de las tierras de pastoreo y de la expansión del sector agrícola. Las áreas de pastoreo, que en el año 2010 correspondían al 77,6\% de la puna, al final del siglo llegarían a un 50\%. Esto tendría un efecto en la cantidad de unidades ovinas equivalentes, las cuales disminuirían de manera sostenida, llegando a una merma de un $43 \%$ y un 34\% en el año 2100 con respecto al escenario base, en los escenarios A2 y B2, respectivamente. Lo anterior se traduce en una pérdida máxima acumulada equivalente al 90\% del PBI pecuario del año base en el escenario A2, a una tasa de 0,5\%.

Dados los niveles de información disponible, la evaluación del impacto del cambio climático en el sector pesquero peruano se concentra en la captura de la anchoveta. Para esto se modelaron las variaciones de la disponibilidad de oxígeno disuelto en el mar y de la temperatura, a través de escenarios globales y locales (RCP 4.5 y RCP 8.5, y el escenario local). Los resultados muestran que las proyecciones de captura de anchoveta en el escenario local serían muy similares a las del escenario base. Para los escenarios globales se observaría una tasa decreciente de captura, siendo mayor para el escenario RCP 8.5. La caída en la captura de este recurso marino tendría efectos importantes en la producción de harina de pescado, lo que implicaría un impacto significativo, hasta fines del siglo, con un rango de pérdidas de entre 326\% (escenario local) y $3.000 \%$ (escenario RCP 8.5), comparado con el PBI de pesca del año 2010, considerando una tasa de descuento de 0,5\%. 
El impacto del cambio climático en el sector minero fue evaluado sobre la base de los cambios proyectados en la disponibilidad de recursos hídricos en las zonas mineras. Los resultados muestran que solo en las áreas de explotación de cobre y de zinc se podrían observar efectos del cambio climático en la producción del mineral. Las zonas de extracción de oro y hierro no se verían perjudicadas por este fenómeno. La valoración económica del impacto se traduciría en una reducción acumulada para todo el período de 15\% en el escenario A2, 5\% en el escenario A1B y $11 \%$ en el escenario B1, en términos del PBI sectorial del año base, a una tasa de descuento de $0,5 \%$.

Al igual que en el caso minero, la evaluación del impacto climático en el sector hidroenergético fue realizada analizando la menor disponibilidad del recurso hídrico. Para este sector se consideraron los principales ríos del país, que cuentan con centrales hídricas en operación. El escenario sin cambio climático proyectado muestra que, debido a la expansión de la zona agrícola, se observarían disminuciones de disponibilidad de agua para la hidrogeneración. Al compararse con los escenarios con cambio climático, los efectos podrían ser menores que los esperados. En todo caso, los efectos agregados muestran que habría una menor producción de energía hidroeléctrica, lo que se traduciría en un impacto acumulado, que equivale a una disminución de ingresos de entre 3,3\% y 5,0\% del PBI sectorial del año base para los escenarios A1B y A2, respectivamente, a una tasa de 0,5\%.

El Perú cuenta con importantes atractivos turísticos en el ámbito internacional, entre los que destaca la zona de Machu Picchu. Debido a factores directos asociados al aumento en el número de eventos extremos que afectarían las vías de acceso a dicha zona, podría disminuir el número de turistas que visitan este atractivo. Por ello, se estimaron las pérdidas hasta 2100 en Machu Picchu, las cuales se encontrarían entre el 15\% y el 30\% del PBI del sector en el año base, descontadas a una tasa de 0,5\%. Es importante resaltar que el valor estimado no considera otros atractivos turísticos nacionales.

El impacto del cambio climático en el sector de infraestructura vial generaría un aumento en el gasto del sector público, ya que se esperarían costos adicionales dados por aumentos en reparaciones y mantenciones, producto de la mayor ocurrencia de inundaciones en las vías. Es así como se estima que este incremento de costos equivalga a un 2,8\% del PBI de transporte del año 2010, en comparación con la proyección sin cambio climático. En cuanto a salud, el sector público reforzaría los recursos destinados a cubrir el tratamiento de la malaria. Esto requeriría un aumento del gasto en un 0,02\% del PBI nacional de 2010. Dadas las limitaciones de información específica para las localidades y territorios, tanto para salud como para infraestructura, los montos estimados corresponden a una aproximación moderada de los costos adicionales.

En resumen, el análisis sectorial muestra que para agricultura, ganadería, pesca, turismo, minería, infraestructura y salud se presentan impactos consistentemente negativos en todos los escenarios. Por otro lado, en hidroenergía, los efectos serían positivos en el corto plazo para algunos escenarios, haciéndose negativos hacia el final del siglo. Por último, ningún sector muestra un impacto positivo consistente. Los sectores de pesca, agricultura y ganadería altoandina suman casi el 90\% de las pérdidas de los tres escenarios climáticos. Esta situación resulta esperable, considerando que estos sectores se encuentran directamente expuestos a las condiciones naturales del entorno.

Los impactos sectoriales identificados muestran distintos niveles de vulnerabilidad ante cambios en las variables climáticas. El análisis resalta la necesidad de analizar los resultados con cautela, dados los supuestos utilizados para las modelaciones y los niveles de incertidumbre asociados principalmente a las proyecciones de las variables climáticas. La valoración económica constituye principalmente una alerta sobre los posibles efectos que el cambio climático podría generar para la economía si no se consideran medidas de adaptación y/o de mitigación. 
Los resultados agregados hasta el año 2100 proyectan impactos que se traducirían en pérdidas en la economía nacional que oscilan en un rango de 11,4\% y 15,4\% del PBI de 2010, para una tasa de descuento del 0,5\%. El análisis de resultados muestra que los mayores impactos acumulados en todo el período se obtienen en el escenario A2, y, los menores, en el B1. Por otro lado, los impactos acumulados hasta el año 2040 serían mayores en el escenario B1. Los resultados varían al utilizarse distintas tasas de descuento, cuya elección refleja una posición de equidad intergeneracional. Por lo tanto, la elección de cada tasa asume una decisión ética sobre el reto y los costos que el cambio climático impone a las generaciones presentes y futuras.

En una economía basada en el uso intensivo de sus recursos naturales, en vías de desarrollo, con población en situación de pobreza y un territorio altamente vulnerable a cambios en las condiciones climáticas, el fenómeno global puede provocar situaciones aún más adversas para el desarrollo del país. Por esto, el diseño apropiado y a tiempo de estrategias, políticas, programas y proyectos en materia de adaptación es fundamental para contrarrestar los potenciales efectos negativos del cambio climático.

El Gobierno, desde hace más de una década, viene trabajando en adaptación. Resalta la publicación de la Estrategia Nacional de Cambio Climático, que contiene específicamente una línea de trabajo sobre esta materia. A través de iniciativas tales como la Agenda Nacional de Investigación Científica en Cambio Climático 2010-2021, el Plan de Acción de Adaptación y Mitigación frente al Cambio Climático (PNAAMCC), el Plan Nacional de Gestión del Riesgo y Adaptación a los Efectos Adversos del Cambio Climático en el Sector Agrario para el Período 2012-2021 y las Estrategias Regionales de Cambio Climático, se ha promovido la implementación de proyectos de adaptación para los distintos tipos de gobierno con la participación activa de múltiples actores de la sociedad.

Complementando este trabajo, y sobre la base del análisis de los diversos sectores involucrados, se han identificado medidas de adaptación específicas para cada uno de ellos. En todas ellas se resalta la necesidad de profundizar los estudios en los entornos locales y regionales, para lo cual se requiere de mejor información sectorial y climatológica, con mayor precisión. Contar con esta información permitirá diseñar pautas específicas para cada localidad y dar seguimiento tanto a las variables de análisis, como a los efectos que las medidas de adaptación causen en la población.

De un modo transversal, y para todos los sectores, es fundamental el desarrollo de capacidades, profundizar en el nivel de conocimiento del fenómeno climático y de sus impactos potenciales, y elaborar e implementar medidas de adaptación. Adicionalmente, se debe promover la investigación y la aplicación de tecnologías en las áreas donde se han identificado los mayores impactos económicos del cambio climático, como pesca, agricultura y ganadería.

Se reitera que los resultados presentados deben interpretarse a través de los órdenes de magnitud, dados los supuestos específicos y de agregación. El ejercicio analítico de proyección busca resaltar las implicancias del análisis integrado y constituye una alerta sobre las consideraciones que el cambio climático podría generar para la economía peruana si no se disponen medidas de adaptación. No obstante, los resultados de este análisis pueden ser asumidos como una base para estudios posteriores, pero deben profundizarse a medida que aumente la precisión estadística de los modelos y surja nueva información sectorial y climatológica.

Este estudio, por tanto, contribuye a la discusión nacional y a la investigación sobre el impacto económico del cambio climático en el Perú. Además de estimar los potenciales impactos económicos y de identificar los principales sectores que se verían afectados en un futuro, colabora en la agenda de desarrollo, aportando herramientas analíticas para la discusión de los caminos futuros. La difusión de la problemática asociada al cambio climático contribuirá, además, a contar con una población más sensibilizada y dispuesta a apoyar con la implementación de políticas públicas en pos de un desarrollo más sostenible. 


\section{Referencias bibliográficas}

Adger, N. et al. (2003), "Adaptation to Climate Change in the Developing World". En Progress in Development Studies, 3(3), pp. 179-195.

African Development Bank, Asian Development Bank, Department for International Development (United Kingdom), Directorate-General for Develoment (European Commission), Federal Ministry for Economic Cooperation and Development (Germany), Ministry of Foreign Affairs-Development Cooperation (Netherlands), Organization for Economic Cooperation and Development, United Nations Development Programme, United Nations Environment Programme, World Bank (2003), Poverty and Climate Change: Reducing the Vulnerability of the Poor through Adaptation.

Agueda Talaya, E.; López Palomeque, F. y Aguiló Pérez, E. (2005), "Impactos sobre el sector turístico". Moreno Rodríguez, J. M. (coordinador). Evaluación general de los impactos en España por efecto del cambio climático. Proyecto ECCE. Informe final. Madrid, Ministerio de Medio Ambiente-Universidad de Castilla-La Mancha, 65390.

Andrade, J. (1998), Turismo: fundamentos e dimensões. São Paulo, Ática, 213 pp.

Arnell, N. W. (1998), “Climate Change and Water Resources in Britain”, Climatic Change 39, pp. 83-110.

Ansohn A. y Pleskovic B. (eds.) (2011), Climate Governance and Development. Washington D.C., International Bank for Reconstruction and Development/World Bank.

Ávalos, G. (2005), "Validación del pronóstico de precipitación del modelo regional Eta/SENAMHI durante periodos secos y lluviosos". Tesis para optar al título de ingeniero meteorólogo. Lima, Universidad Nacional Agraria La Molina, 98 pp.

Banco Mundial (2012), "Peru. World Development Indicators". Disponible en data.worldbank.org/country/peru?display=default [fecha de consulta: 28 de noviembre de 2013].

Bates, B. C.; Kundzewicz, Z. W.; Wu, S. y Palutikof, J. (eds.) (2008), Climate Change and Water. Technical Paper of 
the Intergovernmental Panel on Climate Change. Ginebra, IPCC Secretariat, 210 pp.

BCRP, Banco Central de Reserva del Perú (2011), Memoria 2010. Lima, BCRP, 302 pp.

(2014), Memoria 2012. Anexos. Disponible en www.bcrp.gob.pe. [Fecha de actualización: 15 de marzo de 2014].

Bennett, A. et al. (2012), "Effects of the 1997-1998 El Niño Episode on Community Rates of Diarrhea". American Journal of Public Health. 102(7), e63-9.

Brown, J. y Macleod, N. (2011), "A Site-Based Approach to Delivering Rangeland Ecosystem Services". The Rangeland Journal. 33(2), pp. 99-108.

Buytaert, W. et al. (2010), "Uncertainties in Climate Change Projections and Regional Downscaling in the Tropical Andes: Implications for Water Resources Management". Hydrology and Earth System Science. 14(7). 1247-58.

Calvo, E. (2010), Guía metodológica para la adaptación a los impactos del cambio climático en las ciudades y opciones de mitigación de emisiones de gases de efecto invernadero. Lima, Foro Ciudades para la Vida.

CAPECO, Cámara Peruana de la Construcción (2012), Lineamientos para promover la inversión en infraestructura en el Perú durante el quinquenio 2012-2016.

CELADE, Centro Latinoamericano y Caribeño de Demografía, División de Población, CEPAL. Disponible en http://www.cepal.org/celade/

CEPAL, Comisión Económica para América Latina y el Caribe (2009a), Economía del cambio climático en Chile. Síntesis. CEPAL, colección Documentos de Proyectos. Santiago de Chile.

(2009b), La economía del cambio climático en América Latina y el Caribe. Síntesis 2009. Santiago, CEPAL, $73 \mathrm{pp}$.

(2010), La economía del cambio climático en Centroamérica. Santiago, CEPAL, 143 pp.

(2013), Dinámicas, tendencias y variabilidad climática. Estudio regional de los efectos del cambio climático en la costa de América Latina y el Caribe. Santiago, Naciones Unidas, 265 pp.

Cheung, W. W. L.; Dunne, J.; Sarmiento, J. y Pauly, D. (2011), "Integrating ecophysiology and plankton dynamics into projected changes in maximum fisheries catch potential under climate change in the Northeast AtlanticICES". Journal of Marine Science, doi:10.1093/icesjms/fsq012.

Chirichigno, N. y Vélez, J. (1998), Clave para identificar los peces marinos del Perú. Callao, Instituto del Mar del Perú, 496 pp.

Cochrane, K.; De Young, C.; Soto, D. y Bahri, T. (eds.) (2012), “Consecuencias del cambio climático para la pesca y la acuicultura: visión de conjunto del estado actual de los conocimientos científicos". FAO, Documento Técnico de Pesca y Acuicultura. N.o 530. Roma, FAO. 237.

COES-SINAC, Comité de Operación Económica del Sistema Interconectado Nacional (2011), Estadística de operaciones 2011. Lima, COES-SINAC, 191 pp.

CONAM, Consejo Nacional del Ambiente (2001), Comunicación Nacional del Perú a la Convención de Naciones Unidas sobre Cambio Climático. Primera comunicación. Lima, CONAM, 155 pp. 
Cubasch, U. et al. (2013), "Introduction". En Climate Change 2013: The Physical Science Basis. Contribution of Working Group I to the Fifth Assessment Report of the Intergovernmental Panel on Climate Change [Stocker T. F.; D. Qin, G. K. Plattner, M. Tignor, S. K. Allen, J. Boschung, A. Nauels, Y. Xia, V. Bex y P. M. Midgley (eds.)]. Cambridge, United Kingdom and New York, NY, USA, Cambridge University Press, pp. 119-158, doi:10.1017/ CBO9781107415324.007.

Dammert, A. y Molinelli, F. (2007), Panorama de la minería en el Perú. Lima, OSINERGMIN, 200 pp.

Dasgupta, P. (2008), “Discounting Climate Change”. Journal of Risk and Uncertainty. 37(2-3), 141-69.

Ecosecurities, Centro de Cambio Global (2009), Relación entre agua, energía y cambio climático. Estudio de alto nivel sobre el impacto del cambio climático en la industria minera de Argentina, Chile, Colombia y Perú. Dublín, EcoSecurities Consulting y Centro de Cambio Global, Universidad Católica de Chile, 88 pp.

Evans, S. y Workman, J. P. (1994), "Optimization of Range Improvements on Sagebrush and Pinyon-Juniper Sites". Journal of Range Management. 47(2). 159-64.

FAO, Organización de las Naciones Unidas para la Agricultura y la Alimentación (2012), El estado mundial de la pesca y la acuicultura. Roma, FAO, 233 pp.

Flores, E. M. (1996), "Reality, Limitations, and Research Needs of the Peruvian Livestock Sector". Latin America Livestock Regional Assessment Workshop. San José de Costa Rica. April 15-18, 1996. Costa Rica, Management Entity, Small Ruminant CRSP, University of California-Davis. 83-96.

(2012), Pastores de puna, cambio climático y seguridad alimentaria.

Flores, E. R.; Cruz, J. A. y López, M. (2007), "Management of Sheep Genetic Resources in the Central Andes of Peru". [Tempelman, K.; Cardellino, R. (eds.)]. People and Animals. Traditional Livestock Keepers: Guardians of Domestic Animal Diversity. Roma, Organización de las Naciones Unidas para la Agricultura y la Alimentación, pp. 47-58.

Flores, E. M. (2011), "Ecosistemas de puna y seguridad hídrica en el contexto del cambio climático global". Ponencia presentada en el seminario "Compartiendo avances y resultados en conservación e investigación: punas, agua y cambio climático". EPG-UNALM. Publicado por el Instituto de Montaña y la Fundación McKnight. Lima, Perú.

Fowler, H. J.; Blenkinsop, S. y Tebaldi, C. (2007), "Linking climate change modelling to impacts studies: recent advances in downscaling techniques for hydrological modeling". International Journal of Climatology. 27, pp. 1547-1578.

Galindo, L. M. y Caballero, K. (2011), "La economía del cambio climático en México: algunas reflexiones". Gaceta de Economía 16 (número especial), pp. 85-113.

Gallardo, C. (2006), "Análisis integral de los flujos comerciales entre el Perú y China con miras a la firma de un acuerdo de alcance parcial". Cuadernos de difusión. 11(20). 101-31.

Gellens, D. y Roulin, E. (1998), "Streamflow response of Belgian catchments to IPCC climate change scenarios". Journal of Hydrology. 210, pp. 242-258.

Gonzales, J. (2006), Crecimiento económico y desarrollo sustentable: el rol de los recursos naturales en la economía peruana: 1970-2005. 
Gutiérrez, D. et al. (2011), "Sensibilidad del sistema de afloramiento costero del Perú al cambio climático e implicancias ecológicas". Revista peruana Geo-Atmosférica (RPGA). 3, pp. 1-26.

Hamilton, J. M.; Maddison D. J. y Tol, R. S. J. (2005a), "Climate Change and International Tourism: A Simulation Study". Global Environmental Change. 15(3). 253-66.

(2005b), "The Effects of Climate Change on International Tourism”. Climate Research. 29. 245-254.

Harley, C. D. G. et al. (2006), "The impacts of climate change in coastal marine systems". Ecology Letters, 9, pp. 228-241.

Heltberg, R.; Siegel, P. B. y Jorgensen, S. L. (2009), “Addressing human vulnerability to climate change: Toward a 'no-regrets' approach". Global Environmental Change. 19, pp. 89-99.

ICEX, Instituto Español de Comercio Exterior (2010), "Informe sectorial. El sector de pesca y acuicultura en Perú". Madrid, Instituto Español de Comercio Exterior. 69 pp.

IIMP, Instituto de Ingenieros de Minas del Perú (2010), "Minería peruana: contribución al desarrollo económico y social. IIMP, enero 2010, Lima, IIMP.

IMARPE, Instituto del Mar del Perú (2011), "Estado poblacional del stock norte-centro de anchoveta y sus proyecciones de pesca para la temporada abril-setiembre 2011. Resultados del Crucero de Evaluación Hidroacústica de Recursos Pelágicos BIC Olaya 1102-04 y del Crucero de Evaluación de Estructuras de Cardúmenes de Anchoveta BIC SNP-2". Informe Ejecutivo. Callao, IMARPE, 7 pp.

INEI, Instituto Nacional de Estadística e Informática (2007), “Perú. Cuentas nacionales 2007: año base 2007”. Lima, INEI. Disponible en http://www.inei.gob.pe/media/MenuRecursivo/publicaciones_digitales/Est/Lib1138/Pdfs_ CAB2007/libro.pdf. [fecha de consulta: 26 de septiembre de 2014].

(2010), "Perú. Compendio estadístico 2010". Lima, INEI. Disponible en proyectos.inei.gob.pe/web/biblioineipub/bancopub/Est/Lib0982/compendio2010.html [fecha de consulta: 28 de noviembre de 2013].

(2011), "Perú. Compendio estadístico 2011". Lima, INEI. Disponible en proyectos.inei.gob.pe/web/biblioineipub/bancopub/Est/Lib1008/compendio2011.html [fecha de consulta: 28 de noviembre de 2013].

(2013), "Perú: evolución de los indicadores de empleo e ingresos por departamentos, periodo 20042011". Disponible en http://www.inei.gob.pe/biblioineipub/bancopub/Est/Lib1049/index.html [fecha de actualización: 7 de febrero de 2013].

(2014), "Estadísticas de Población y Vivienda". Disponible en http://www.inei.gob.pe/estadisticas/indice-tematico/poblacion-y-vivienda/

IPCC, Intergovernmental Panel on Climate Change (2001), Climate Change 2001: The Scientific Basis. Cambridge y Nueva York, Cambridge University Press, 881 pp.

(2007a), Climate Change 2007: Synthesis Report. Contribution of Working Groups I, II and III to the Fourth Assessment Report of the Intergovernmental Panel on Climate Change. Equipo editor principal: Pachauri, R. K.; Reisinger, A. (eds.). Ginebra, IPCC. 103 pp. + 1 CD-ROM.

(2007b), Climate Change. Impacts, Adaptation and Vulnerability. Contribution of Working Group II to the Fourth Assessment Report of the Intergovernmental Panel on Climate Change. Equipo editor principal: Parry, M. L.; Canziani, O. F.; Palutikof, J. P.; Van Der Linden, P. J.; Hanson, C. E. (eds.). Cambridge y Nueva York, Cambridge University Press, 976 pp. 
(2014), Climate Change 2013: The Physical Science Basis. Disponible en http://www.climatechange2013.org/

IPEA, Instituto Peruano de Economía (2014). Disponible en http://ipe.org.pe/pea

La Torre-Cuadros, M. A.; Arnillas, M. C. y Arellano, G. M. A. (2012), Fortalecimiento de capacidades para la gestión del Santuario Nacional Pampa Hermosa: construyendo las bases para un manejo adaptativo para el desarrollo local. Memoria del proyecto. Lima, Nueva York, World Agroforestry Centre (ICRAF), Center for Biodiversity and Conservation (CBC) at the American Museum of Natural History, 118 pp.

Lau, A. I. y Flores, E. R. (2011), "Ecosistemas de puna y seguridad hídrica”. En "Seminario Punas/agua/cambio climático: compartiendo avances en conservación e investigación". Lima, Universidad Nacional Agraria La Molina e Instituto de Montaña. Conferencia.

Lempert, R.; Nakicenovic, N.; Sarewitz, D. y Schlesinger, M. (2004), "Characterizing Climate-Change Uncertainties for Decision-Makers. An Editorial Essay". Climatic Change. 65(1-2), pp. 1-9.

Lieth, H. (1973), "Primary Production: Terrestrial Ecosystems”. Human Ecology 1(4). 303-32.

Lindsay, S. W.; Parson, L. y Thomas, C. J. (1998), "Mapping the Range and Relative Abundance of the Two Principal African Malaria Vectors, Anopheles Gambiae Sensu Stricto and An. Arabiensis, Using Climate Data. Proceedings of the Royal Society of London". Series B: Biological Sciences. 265(1399). 847-54.

Lipman G. (2007), UNWTO Overview: Tourism and climate change.

Maddison (2011), Maddison Project. Disponible en http://www.ggdc.net/maddison/index.htm

Manoukis, N. C. et al. (2011), Seasonal Climate Effects Anemotaxis in Newly Emerged Adult Anopheles Gambiae Giles in Mali. West Africa, PloS One. 6(11).

Maraun, D. et al. (2010), "Precipitation downscaling under climate change. Recent developments to bridge the gap between dynamical models and the end user". Reviews of Geophysics. En imprenta.

Marengo, J. A.; Jones, R.; Alves, L. M. y Valverde, M. C. (2009), "Future Change of Temperature and Precipitation Extremes in South America as Derived from the PRECIS Regional Climate Modeling System". International Journal of Climatology. 29(15). 2241-55.

Marengo, J. et al. (2011), "Climate Change: Evidence and Future Scenarios for the Anden Region". [Herzog, S.; Martínez, R.; Jorgensen, P., Tiessen, H. (eds.)]. Climate Change and Biodiversity in the Tropical Andes. Saõ José dos Campos y São Paulo, Inter-American Institute for Global Change Reseach y SCOPE. 110-27.

Mark, B. G.; McKenzie, J. M. y Gómez, J. (2005), “Hydrochemical Evaluation of Changing Glacier Meltwater Contribution to Stream Discharge: Callejon de Huaylas, Peru". Hydrological Sciences Journal. 50(6). 975-87.

Mark, B. G. y Seltzer, G. O. (2003), "Tropical Glacier Meltwater Contribution to Stream Discharge: A Case Study in the Cordillera Blanca, Peru”. Journal of Glaciology. 49(165). 271-81.

MEF, Ministerio de Economía y Finanzas (2013), "Marco Macroeconómico Multianual 2013-2015". Lima, MEF, 135 pp. Disponible en www.mef.gob.pe/contenidos/pol_econ/marco_macro/MMM2013_2015.pdf [fecha de consulta: 1 de febrero de 2014].

Middelkoop, H. et al. (2001), "Impact of climate change on hydrological regimes and water resources management in the Rhine Basin". Climatic Change 49, pp. 105-128. 
Millennium Ecosystem Assessment (2005), Ecosystems and Human Well-being: Synthesis. Washington D.C., Island Press, $137 \mathrm{pp}$.

MINAGRI, Ministerio de Agricultura y Riego (2011a), Seguro agrario catastrófico. Campaña 2010-2011. Lima, MINAGRI, 14 pp.

(2011b), Dinámica agropecuaria 1997-2009. Lima, MINAGRI, 63 pp.

(2011c), Dinámica agropecuaria 2002-2011. Lima, MINAGRI, 91 pp.

(2012), Sector pecuario en el Perú. Disponible en http://www.minag.gob.pe/portal/sector-agrario/pecuaria/situación-de-las-actividades-de-crianza-y-producción

MINAM, Ministerio del Ambiente (2010), "El Perú y el cambio climático". Segunda Comunicación Nacional del Perú a la Convención Marco de las Naciones Unidas sobre Cambio Climático. Lima, MINAM.

(2011), Mapa de vulnerabilidad física del Perú. Herramienta para la gestión del riesgo. Lima, MINAM, 51 pp.

(2012), Avances, retos, prioridades y orientaciones para la gestión del riesgo climático en el Perú. InterClima.

(2014), Borrador Estrategia Nacional ante el Cambio Climático. Disponible en http://www.minam.gob. pe/wp-content/uploads/2014/07/Estrategia-Nacional-ante-el-Cambio-Climatico_ENCC.pdf

MINCETUR, Ministerio de Comercio Exterior y Turismo (2008), „Plan Estratégico Nacional de Turismo 2008-2018. Síntesis para la puesta en operación", septiembre.

(2013a), Perú: Ilegada de turistas internacionales, según país de residencia permanente. Disponible en http://www.mincetur.gob.pe/newweb/Default.aspx?tabid=141

(2013b), "Plan Estratégico de Turismo (PENTUR) 2012-2021".

MINEM, Ministerio de Energía y Minas (2012), Anuario minero. Disponible en www.minem.gob.pe [fecha de actualización: junio de 2012].

(2013), Portal del Ministerio de Energía y Minas del Perú. Disponible en www.minem.gob.pe [fecha de consulta: 28 de noviembre de 2013].

(2014), Anuario ejecutivo de electricidad 2013. Lima, Dirección General de Electricidad. Disponible en http://www.minem.gob.pe/_publicacion.php?idSector=6\&idPublicacion=482

Moerlein, K. J. y Carothers C. (2012), "'Total environment of change: impacts of climate change and social transitions on subsistence fisheries in northwest Alaska". Ecology and Society. 17(1), p. 10. http://dx.doi.org/10.5751/ ES-04543-170110

Mora J.; Ordaz J.; Ramírez D. y Acosta A. (2010), Guatemala: efectos del cambio climático sobre la agricultura. México D. F., Comisión Económica para América Latina y el Caribe (CEPAL), sede subregional.

Morales, R. et al. (2011), Estudio de la economía del cambio climático en las regiones de Cusco y Apurímac. Cusco-Apurímac-Lima, Programa de Adaptación al Cambio Climático-Instituto de Estudios Peruanos-Libélula Comunicación, Ambiente y Desarrollo. 
MTC, Ministerio de Transportes y Comunicaciones (2013), Anuario estadístico.

OMT, OMM, PNUMA, Organización Mundial del Turismo, Organización Meteorológica Mundial, Programa de las Naciones Unidas para el Medio Ambiente (2007), Cambio climático y turismo. Responder a los retos mundiales. Resumen. Cartagena de Indias, OMT, OMM y PNUMA, 27 pp.

Ordaz J. et al. (2010), Honduras: efectos del cambio climático sobre la agricultura. México D. F., Comisión Económica para América Latina y el Caribe (CEPAL), sede subregional.

OSINERGMIN, Organismo Supervisor de la Inversión en Energía y Minería (2012), "Reporte semestral de monitoreo del mercado eléctrico. Primer semestre de 2012". Lima, OSINERGMIN.

Oudin, L.; Andreassian, V.; Lerat, J. y Michel, C. (2008), "Has Land Cover a Significant Impact on Mean Annual Streamflow? An International Assessment Using 1508 Catchments". Journal of Hydrology. 357(3-4). 303-16.

Park, J. W. (2011), "Changing Transmission Pattern of Plasmodium vivax Malaria in the Republic of Korea: Relationship with Climate Change". Environmental Health and Toxicology. 26.

Parry, M. L.; Canziani, O. F.; Palutikof, J. P.; Van Der Linden, P. J. y Hanson, C. E. (eds.) (2007), “Cross-chapter case study", pp. 843-868. In Climate change 2007: impacts, adaptation and vulnerability. Contribution of working group II to the Fourth Assessment Report of the Intergovernmental Panel on Climate Change. Cambridge, UK. Cambridge University Press.

Perry, A. (2000), Impacts of Climate Change on Tourism in the Mediterranean: Adaptive Responses. Milán, Fondazione Eni Enrico Mattei, 11 pp.

Pouyaud, B. et al. (2005), "Avenir des ressources en eau glaciaire de la Cordillère Blanche". Hydrological Sciences Journal. 50(5), pp. 999-1022.

PROMPERÚ, Comisión de Promoción del Perú para la Exportación y el Turismo (2010), Perfil del turista extranjero 2010. Lima, PROMPERÚ, 86 pp.

Proyecto Vigía, Ministerio de Salud del Perú, Usaid, Universidad Peruana Cayetano Heredia (2006), Relación costos-efectividad del uso de pruebas rápidas para el diagnóstico de la malaria en la Amazonía peruana. Lima, Ministerio de Salud del Perú, USAID y Universidad Peruana Cayetano Heredia.

Ramírez D.; Ordaz J. y Mora J. (2009), Istmo centroamericano: efectos del cambio climático sobre la agricultura. México D. F., Comisión Económica para América Latina y el Caribe (CEPAL), sede subregional.

Sánchez, A. y Dalle, M. (2005), Cambio climático. Efectos sobre el turismo. Madrid, Instituto Sindical de Trabajo, Ambiente y Salud, 47 pp.

Seas, C. et al. (2000), "New Insights on the Emergence of Cholera in Latin America During 1991: The Peruvian Experience". The American Journal of Tropical Medicine and Hygiene. 62(4). 513-7.

Seminario, B.; Cigarán, M. P. y Encinas C. (2002), Estudio de tendencias económicas y proyección de gases de efecto invernadero 1994-2025. Centro de Investigación de la Universidad del Pacífico. Consejo Nacional del Ambiente, mayo.

Seminario, B.; Rodríguez, M. y Zuloeta, J. (2008), Métodos alternativos para la estimación del PBI potencial 19502007, diciembre. 
SENAMHI, Servicio Nacional de Meteorología e Hidrología del Perú (2005), Mapa climático del Perú. Lima, SE$\mathrm{NAMHI}$.

(2007), Escenarios de cambio climático en la cuenca del río Mantaro para el año 2100. Lima, SENAMHI, MINAM, 124 pp.

(2008), Guía climática turística. Lima, SENAMHI, MINAM, 215 pp.

(2009a), "Escenarios climáticos en la cuenca del río Mayo para el año 2030". Segunda Comunicación Nacional de Cambio Climático. Lima, SENAMHI, MINAM, 133 pp.

(2009b), "Escenarios climáticos en la cuenca del río Santa para el año 2030". Segunda Comunicación Nacional de Cambio Climático. Lima, SENAMHI, MINAM, 139 pp.

(2011a), Atlas climático de precipitación y temperatura del aire. Cuenca del río Mantaro. Lima, SENAMHI, MINAM, 144 pp.

(2011b), Atlas climático de precipitación y temperatura del aire. Cuenca del río Urubamba. Lima, SENAMHI, MINAM, 138 pp.

(2011c), Caracterización climática de las regiones Cusco y Apurímac. Lima, SENAMHI, MINAM, 121 pp.

Silverio, W. (2004), Estudio de la evolución de la cobertura glaciar del Nevado Coropuna (6425) entre 1955 y 2003. Arequipa, Cooperación Peruana Alemana de Seguridad Alimentaria (COPASA), 289 pp.

Smith, L. y Stern, N. (2011), "Uncertainty in Science and Its Role in Climate Policy”. Philosophical Transactions of the Royal Society A: Mathematical, Physical \& Engineering Sciences. 369(1956). 4818-41.

Stern, N. (2007), The Economics of Climate Change: The Stern Review. Cambridge y Nueva York, Cambridge University Press.

Stern, D. I. et al. (2011), "Temperature and Malaria Trends In Highland East Africa”. PloS One. 6(9).

Tapia, M. (2013), Comunicación personal. Lima, 3 de enero de 2013.

Taylor, K. E. (2001), "Summarizing Multiple Aspects of Model Performance in a Single Diagram". Journal of Geophysical Research. 106(D7). 7183-92.

UNWTO, United Nations World Tourism Organization (2008), International Tourism. A Key Driver for the World Economy. Tourism Highlights. 2008 edition. Madrid, UNWTO. 1.

(2014), Tourism Highlights, 2014 edition. Disponible en http://mkt.unwto.org/publication/unwto-tourism-highlights-2014-edition

Vera, C.; Silvestri, G.; Liebmann, B. y González, P. (2006), "Climate Change Scenarios for Seasonal Precipitation in South America From IPCC-AR4 Models". Geophysical Research Letters. 33(13).

Vidal, C. y Muñoz, G. (2010), "Investigaciones del proyecto arqueológico en la temporada de campo 2010". Informes y trabajos. Excavaciones en el exterior. 2008. 3. 100-13.

Watkiss, P. (2012), State of the art for informing public policies on adaptation under uncertainty.

Weitzman, M. (1998), "Why the Far-Distance Future Should Be Discounted at its Lowest Possible Rate”. Journal of Environmental Economics and Management. 36(3). 201-8. 
WEF, World Economic Forum (2011), The Global Competitiveness Report 2011-2012. Disponible en http:// www.weforum.org/reports/global-competitiveness-report-2011-2012

(2013), The Peru Travel \& Tourism Competitiveness Report 2013.

WWF, World Wildlife Foundation (2001), Tourism and Climate Change. Surrey, WWF. 


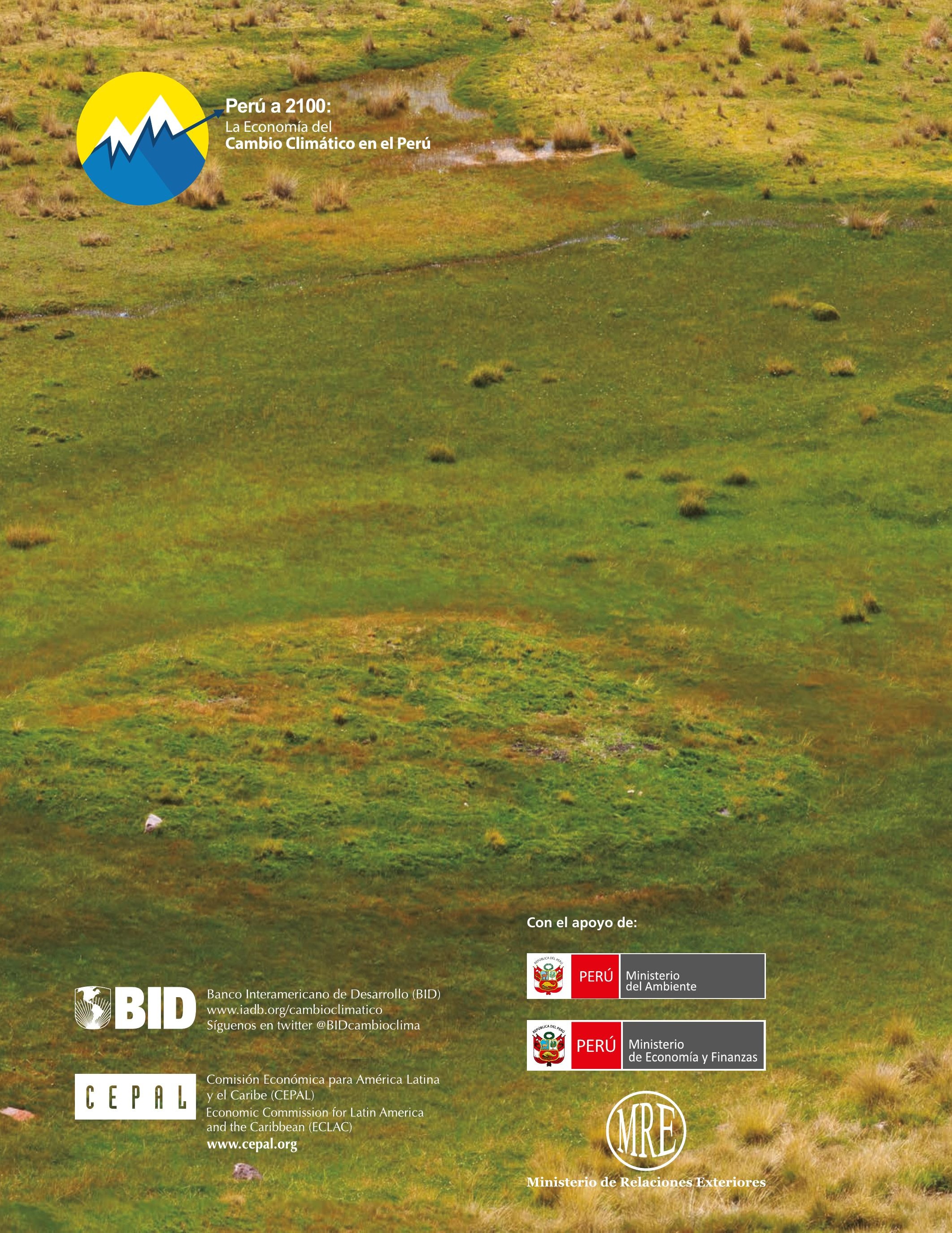

